Engineering Technology Division

\title{
HYDROSTATIC TESTING OF THICK \\ LAMINATED COMPOSITE CYLINDERS FOR PERFORMANCE MODEL VALIDATION
}

H. W. Blake

J. M. Starbuck

Date Published-March 1993

Prepared by the

Oak Ridge National Laboratory

Oak Ridge, Tennessee 37831-7294

managed by

MARTIN MARIETTA ENERGY SYSTEMS, INC.

for the

U.S. DEPARTMENT OF ENERGY

under contract DE-AC05-84OR21400 


\section{CONTENTS}

FIGURES $\ldots \ldots \ldots \ldots \ldots \ldots \ldots \ldots \ldots \ldots \ldots \ldots \ldots \ldots \ldots \ldots \ldots$

TABLES $\ldots \ldots \ldots \ldots \ldots \ldots \ldots \ldots \ldots \ldots \ldots \ldots \ldots \ldots \ldots \ldots \ldots \ldots \ldots$

ABSTRACT $\ldots \ldots \ldots \ldots \ldots \ldots \ldots \ldots \ldots \ldots \ldots \ldots \ldots \ldots \ldots \ldots \ldots \ldots$

INTRODUCTION $\ldots \ldots \ldots \ldots \ldots \ldots \ldots \ldots \ldots \ldots \ldots \ldots \ldots \ldots \ldots$

1. TEST ARTICLE DESIGN/ANALYSIS $\ldots \ldots \ldots \ldots \ldots \ldots \ldots \ldots \ldots \ldots \ldots$

1.1 PARAMETRIC STUDY $\ldots \ldots \ldots \ldots \ldots \ldots \ldots \ldots \ldots \ldots \ldots \ldots$

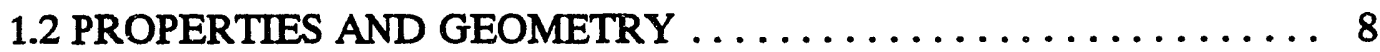

1.3 STRESS ANALYSIS RESULTS $\ldots \ldots \ldots \ldots \ldots \ldots \ldots \ldots \ldots \ldots \ldots \ldots$

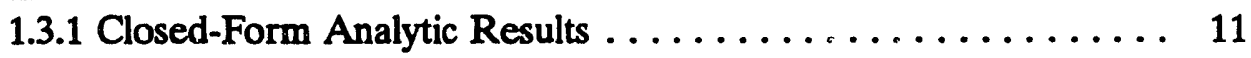

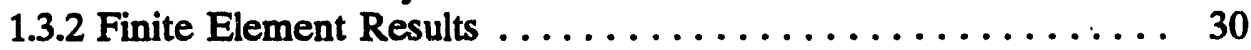

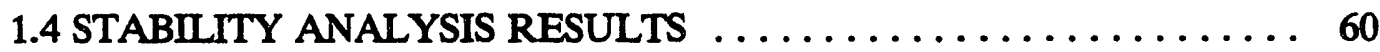

1.5 FAILURE ANALYSIS RESULTS ................ 65

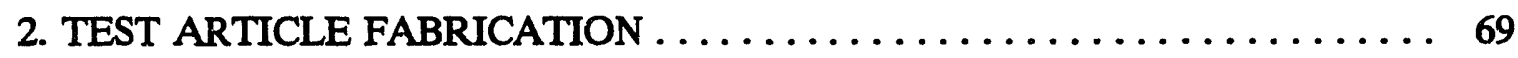

3. TEST ARTICLE TESTING $\ldots \ldots \ldots \ldots \ldots \ldots \ldots \ldots \ldots \ldots \ldots \ldots \ldots$

3.1 INSTRUMENTATION $\ldots \ldots \ldots \ldots \ldots \ldots \ldots \ldots \ldots \ldots \ldots \ldots \ldots$

3.2 TEST FACUITY $\ldots \ldots \ldots \ldots \ldots \ldots \ldots \ldots \ldots \ldots \ldots \ldots$

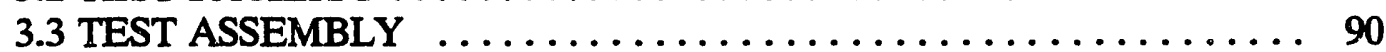

3.4 TEST RESULTS $\ldots \ldots \ldots \ldots \ldots \ldots \ldots \ldots \ldots \ldots \ldots \ldots \ldots \ldots \ldots \ldots$

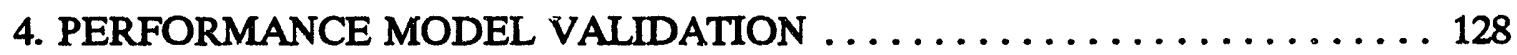

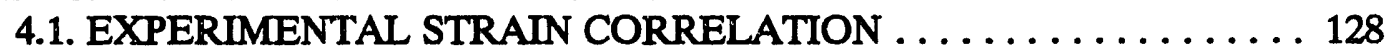

4.2. FAILURE PRESSURE CORRELATION ............. 132

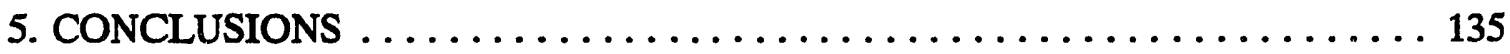

6. RECOMMENDATIONS ........................ 139

Appendix A: CYLINDER WEIGHT-TO-DISPLACEMENT RATIOS . . . . . . 140

Appendix B: HYDROSPACE ENGINEERING TEST REPORTS . . . . . . . . 142

REFERENCES $\ldots \ldots \ldots \ldots \ldots \ldots \ldots \ldots \ldots \ldots \ldots \ldots \ldots \ldots \ldots \ldots \ldots \ldots$

ACKNOWLEDGEMENTS . . . . . . . . . . . . . . . . . . . . . 219 


\section{FIGURES}

Fig. 1-1. Cylinder test assembly. $\ldots \ldots \ldots \ldots \ldots \ldots \ldots \ldots \ldots \ldots \ldots \ldots$

Fig. 1.1-1. Design pressures for IM6 cylinders with $Y_{c}=15 \mathrm{ksi} . \ldots \ldots \ldots \ldots 6$

Fig. 1.1-2. Design pressures for IM6 cylinders with $Y_{c}=30 \mathrm{ksi} . \ldots \ldots \ldots \ldots 6$

Fig. 1.1-3. Design pressures for S-GLASS cylinders with $Y_{c}=20 \mathrm{ksi} . \ldots \ldots \ldots 7$

Fig. 1.1-4. Design pressures for S-GLASS cylinders with $Y_{c}=45 \mathrm{ksi} . \ldots \ldots \ldots 7$

Fig. 1.3.1-1. Cylinder geometry for CCAP model. ............... 12 .

Fig. 1.3.1-2. Radial displacement for G6-1 at 13.8 ksi hydrostatic pressure. . . . . 18

Fig. 1.3.1-3. Radial displacement for G6-2 at 17.4 ksi hydrostatic pressure. ...... 18

Fig. 1.3.1-4. Radial displacement for G6-3 at 16 ksi hydrostatic pressure. . . . . . . 19

Fig. 1.3.1-5. Radial displacement for $\mathrm{G} 6-4$ at 19 ksi hydrostatic pressure. . . . . . 19

Fig. 1.3.1-6. Radial displacement for $\mathrm{C} 6-4$ at 9 ksi hydrostatic pressure. . . . . 20

Fig. 1.3.1-7. Normal strains for G6-1 at 13.8 ksi hydrostatic pressure. . . . . . . 20

Fig. 1.3.1-8. Normal strains for G6-2 at 17.4 ksi hydrostatic pressure. . . . . . . 21

Fig. 1.3.1-9. Normal strains for $\mathrm{G} 6-3$ at 16 ksi hydrostatic pressure. . . . . . . . 21

Fig. 1.3.1-10. Normal strains for $\mathrm{G} 6-4$ at $19 \mathrm{ksi}$ hydrostatic pressure. . . . . . . 22

Fig. 1.3.1-11. Normal strains for C6-4 at 9 ksi hydrostatic pressure. . . . . . . 22

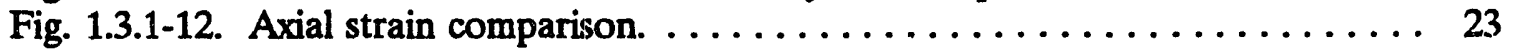

Fig. 1.3.1-13. Hoop strain comparison. $\ldots \ldots \ldots \ldots \ldots \ldots \ldots \ldots \ldots \ldots, 23$

Fig. 1.3.1-14. Radial strain comparison. ...................... 24

Fig. 1.3.1-15. Axial stress for $G 6-1$ at 13.8 ksi hydrostatic pressure . . . . . . . 24

Fig. 1.3.1-16. Hoop stress for G6-1 at 13.8 ksi hydrostatic pressure. . . . . . . . 25

Fig. 1.3.1-17. Axial stress for $\mathrm{G} 6-2$ at 17.4 ksi hydrostatic pressure. . . . . . . 25

Fig. 1.3.1-18. Hoop stress for G6-2 at 17.4 ksi hydrostatic pressure. . . . . . . . 26

Fig. 1.3.1-19. Axial stress for $\mathrm{G} 6-3$ at 16 ksi hydrostatic pressure. ......... 26

Fig. 1.3.1-20. Hoop stress for G6-3 at 16 ksi hydrostatic pressure. . . . . . . 27

Fig. 1.3.1-21. Axial stress for $G 6-4$ at 19 ksi hydrostatic pressure. $\ldots \ldots \ldots \ldots 27$

Fig. 1.3.1-22. Hoop stress for $\mathrm{G} 6-4$ at 19 ksi hydrostatic pressure. . . . . . . . 28

Fig. 1.3.1-23. Axial stress for $\mathrm{C} 6-4$ at 9 ksi hydrostatic pressure. . . . . . . . . 28

Fig. 1.3.1-24. Hoop stress for C6-4 at 9 ksi hydrostatic pressure. . . . . . . . 29

Fig. 1.3.2-1. Outline plot of axisymmetric model. $\ldots \ldots \ldots \ldots \ldots \ldots \ldots \ldots, 33$

Fig. 1.3.2-2. Finite element mesh. ...................... 34

Fig. 1.3.2-3. Contours of radial displacement for C6-1. . . . . . . . . . . 35

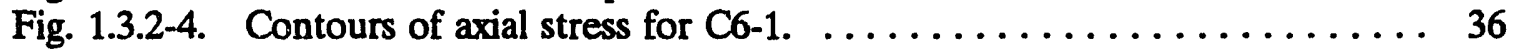

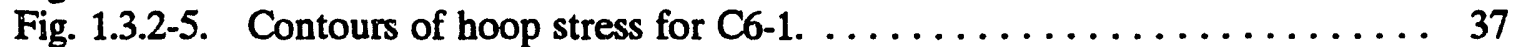

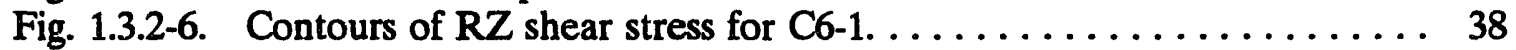

Fig. 1.3.2-7. Contours of radial displacement for $C 6-4 \ldots \ldots \ldots \ldots \ldots \ldots 39$

Fig. 1.3.2-8. Contours of axial stress for C6-4. $\ldots \ldots \ldots \ldots \ldots \ldots \ldots \ldots \ldots, 40$

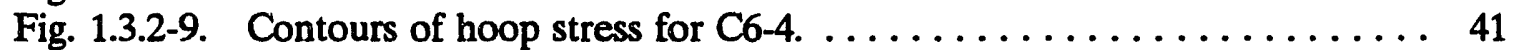

Fig. 1.3.2-10. Contours of $R Z$ shear stress for C6-4. $\ldots \ldots \ldots \ldots \ldots \ldots \ldots 42$

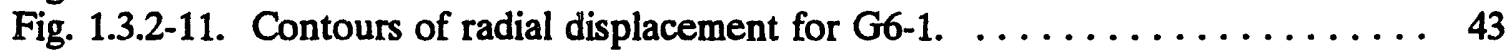

Fig. 1.3.2-12. Contours of axial stress for G6-1. . . . . . . . . . . . . . . . . 44

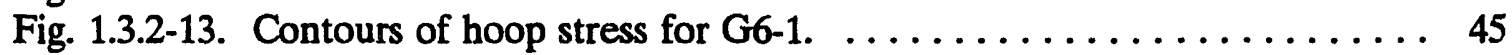

Fig. 1.3.2-14. Contours of $R Z$ shear stress for G6-1. ............. 46

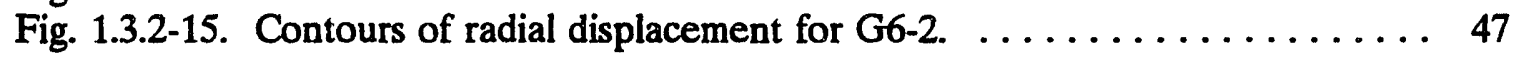

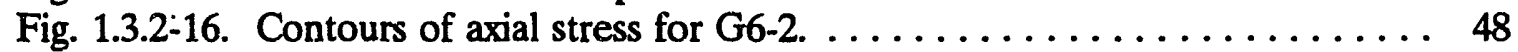

Fig. 1.3.2-17. Contours of hoop stress for G6-2. .............. 49 


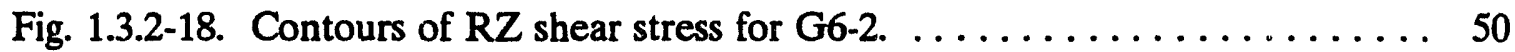

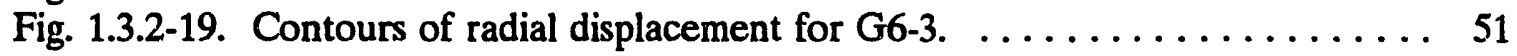

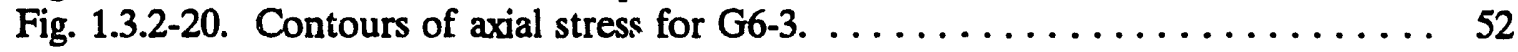

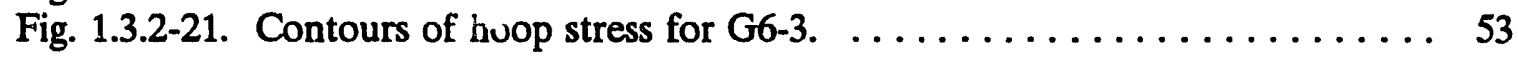

Fig. 1.3.2-22. Contours of $R Z$ shear stress for $G 6-3 . \ldots \ldots \ldots \ldots \ldots \ldots \ldots \ldots$

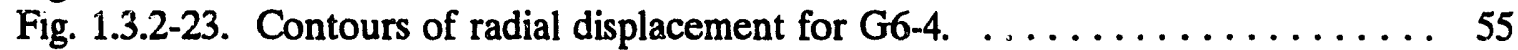

Fig. 1.3.2-24. Contours of axial stress for G6-4. . . . . . . . . . . . . . 56

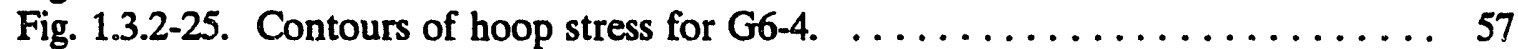

Fig. 1.3.2-26. Contours of $\mathrm{RZ}$ shear stress for $\mathrm{G} 6-4 . \ldots \ldots \ldots \ldots \ldots \ldots \ldots$

Fig. 1.4-1. Buckling pressure for $G 6-1$ as a function of $L / D$ ratio. . . . . . . . . 62

Fig. 1.4-2. Buckling pressure for $\mathrm{G} 6-2$ as a function of $\mathrm{L} / \mathrm{D}$ ratio. $\ldots \ldots \ldots \ldots 6$

Fig. 1.4-3. Buckling pressure for $G 6-3$ as a function of $L / D$ ratio. . . . . . . 63

Fig. 1.4-4. Buckling pressure for $\mathrm{G} \epsilon-4$ as a function of $\mathrm{L} / \mathrm{D}$ ratio. $\ldots \ldots \ldots \ldots$

Fig. 1.4-5. Buckling pressure for $\mathrm{C} 6-4$ as a function of $\mathrm{L} / \mathrm{D}$ ratio. . . . . . . . 64

Fig. 1.5-1. Predicted first-ply failure pressures for different values of $Y_{c} \ldots \ldots 68$

Fig. 3.1-1. Location of strain gages for $\mathrm{G} 6-1 . \ldots \ldots \ldots \ldots \ldots \ldots \ldots$

Fig. 3.1-2. Location of strain gages for $\mathrm{G} 6-2, \mathrm{G} 6-3, \mathrm{G} 6-4$, and $\mathrm{C} 6-4 . \ldots . \ldots . .87$

Fig. 3.2-1. Stachiw Associates test facility pressure vessel (20,000-psi capacity). . . 88

Fig. 3.2-2. Test facility instrumentation. ................... 89

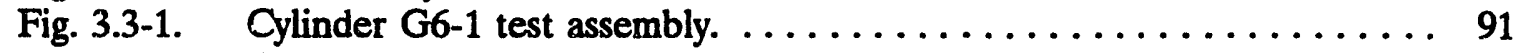

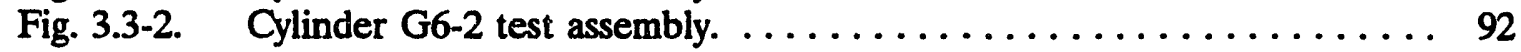

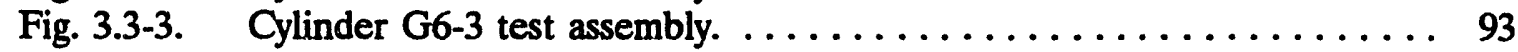

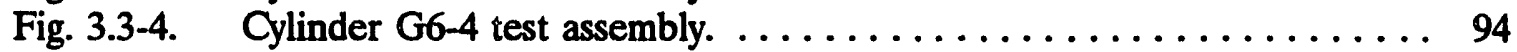

Fig. 3.4-1. Midbay interior hoop strains versus pressure for $G 6-1 . \ldots \ldots$. . . . 98

Fig. 3.4-2. Midbay exterior hoop strains versus pressure for G6-1. . . . . . . 98

Fig. 3.4-3. Midbay interior axial strains versus pressure for $\mathrm{G} 6-1 \ldots \ldots \ldots \ldots$

Fig. 3.4-4. Midbay exterior axial strains versus pressure for $G 6-1 \ldots \ldots \ldots \ldots$. . . . 99

Fig. 3.4-5. Interior hoop strains at 4.5 in. from end versus pressure for $(66-1 . \ldots 100$

Fig. 3.4-6. Exterior hoop strains at 4.5 in. from end versus pressure for G6-1. . . 100

Fig. 3.4-7. Interior axial strains at 4.5 in. from end versus pressure for G6-1. . . . 101

Fig. 3.4-8. Exierior axial strains at 4.5 in. from end versus pressure for G6-1. . . . 101

Fig. 3.4-9. Exterior hoop strains at 0.5 in. from end versus pressure for G6-1. . . 102

Fig. 3.4-10. Midbay interior hoop strains versus pressure for $G 6-2 \ldots \ldots \ldots \ldots 102$

Fig. 3.4-11. Midbay exterior hoop strains versus pressure for G6-2. . . . . . . . 103

Fig. 3.4-12. Midbay interior axial strains versus pressure for G6-2. . . . . . . 103

Fig. 3.4-13. Midbay exterior axial strains versus pressure for G6-2. . . . . . 104

Fig. 3.4-14. Interior hoop strains at 4.5 in. from end versus pressure for G6-2. . . 104

Fig. 3.4-15. Exterior hoop strains at 4.5 in. from end versus pressure for G6-2. . . 105

Fig. 3.4-16. Interior axial strains at 4.5 in. from end versus pressure for G6-2. . . 105

Fig. 3.4-17. Exterior axial strains at 4.5 in. from enc versus pressure for G6-2. . . 106

Fig. 3.4-18. Exterior hoop strains at 0.5 in. from end versus pressure for G6-2. . . 106

Fig. 3.4-19. Midbay interior hoop strains versus pressure for G6-3. . . . . . 107

Fig. 3.4-20. Midbay exterior hoop strains versus pressure for G6-3 . . . . . . . 107

Fig. 3.4-21. Midbay interior axial strains versus pressure for $G 6-3 . \ldots \ldots \ldots \ldots . \ldots 108$

Fig. 3.4-22. Midbay exterior axial strains versus pressure for G6-3. . . . . . 108

Fig. 3.4-23. Interior hoop strains at 4.5 in. from end versus pressure for G6-3. . . 109

Fig. 3.4-24. Exterior hoop strains at 4.5 in. from end versus pressure for G6-3. . . 109

Fig. 3.4-25. Interior axial strains at 4.5 in. from end versus pressure for G6-3. . . . 110 
Fig. 3.4-26. Exterior axial strains at 4.5 in. from end versus pressure for G6-3. . . 110

Fig. 3.4-27. Exterior hoop strains at 0.5 in. from end versus pressure for G6-3. . . 111

Fig. 3.4-28. Midbay interior hoop strains versus pressure for C6-4. . . . . . . 111

Fig. 3.4-29. Midbay exterior hoop strains versus pressure for C6-4. . . . . . . 112

Fig. 3.4-30. Midbay interior axial strains versus pressure for C6-4. . . . . . . 112

Fig. 3.4-31. Midbay exterior axial strains versus pressure for C6-4. . . . . . . 113

Fig. 3.4-32. Interior hoop strains at 4.5 in. from end versus pressure for C6-4. . . . 113

Fig. 3.4-33. Exterior hoop strains at 4.5 in. from end versus pressure for C6-4. . . 114

Fig. 3.4-34. Interior axial strains at 4.5 in. from end versus pressure for C6-4. . . . 114

Fig. 3.4-35. Exterior axial strains at 4.5 in. from end versus pressure for C6-4. . . . 115

Fig. 3.4-36. Exterior hoop strains at 0.5 in. from end versus pressure for C6-4. . . 115

Fig. 3.4-37. Midbay interior hoop strains versus pressure for G6-4 . . . . . 116

Fig. 3.4-38. Midbay exterior hoop strains versus pressure for G6-4. . . . . . . . 116

Fig. 3.4-39. Midbay interior axial strains versus pressure for G6-4. . . . . . . . . 117

Fig. 3.4-40. Midbay exterior axial strains versus pressure for G6-4. . . . . . . 117

Fig. 3.4-41. Interior hoop strains at 4.5 in. from end versus pressure for G6-4. . . 118

Fig. 3.4-42. Exterior hoop strains at 4.5 in. from end versus pressure for G6-4. . . 118

Fig. 3.4-43. Interior axial strains at 4.5 in. from end versus pressure for G6-4. . . . 119

Fig. 3.4-44. Exterior axial strains at 4.5 in. from end versus pressure for G6-4. . . 119

Fig. 3.4-45. Exterior hoop strains at 0.5 in. from end versus pressure for G6-4. . . 120

Fig. 3.4-46. Exterior axial strains at 0.5 in. from end versus pressure for G6-4. . . 120

Fig. 3.4-47. Average midbay interior hoop strains versus pressure. . . . . . . . 121

Fig. 3.4-48. Average midbay exterior hoop strains versus pressure. . . . . . . 121

Fig. 3.4-49. Average midbay interior axial strains versus pressure. . . . . . . . . 122

Fig. 3.4-50. Average midbay exterior axial strains versus pressure. . . . . . . . 122

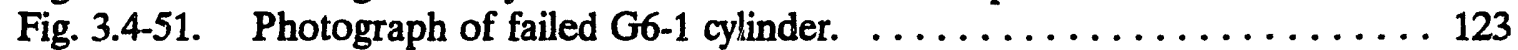

Fig. 3.4-52. Photograph of failed G6-2 cylinder. . . . . . . . . . . . . . . . 124

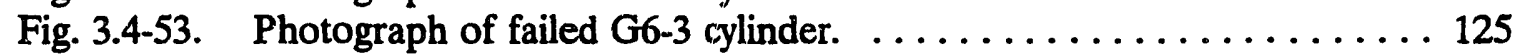

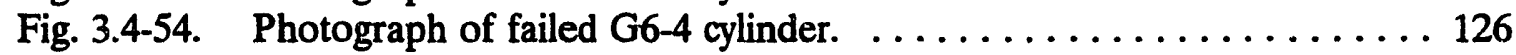

Fig. 3.4-55. Photograph of failed C6-4 cylinder. . . . . . . . . . . . . 127

Fig. 4-1. Performance model flow chart. . . . . . . . . . . . . . . 129 


\section{TABLES}

Table 1.1-1. Layer strengths $\ldots \ldots \ldots \ldots \ldots \ldots \ldots \ldots \ldots \ldots \ldots \ldots \ldots$

Table 1.2-1. Test article stacking sequences $\ldots \ldots \ldots \ldots \ldots \ldots \ldots \ldots \ldots, \ldots$

Table 1.2-2. Test article geometric properties ................... 9

Table 1.2-3. CLASS computed layer properties $\ldots \ldots \ldots \ldots \ldots \ldots \ldots \ldots \ldots, 10$

Table 1.2-4. NDPROP computed laminate properties $\ldots \ldots \ldots \ldots \ldots \ldots \ldots, 10$

Table 1.3.1-1. Radial displacement results at maximum test pressure ......... 13

Table 1.3.1-2. CCAP results for normal strains at maximum test pressure $\ldots \ldots \ldots 15$

Table 1.3.1-3. LST results for normal strains at maximum test pressure $\ldots \ldots \ldots \ldots 15$

Table 1.3.1-4. Maximum axial stresses (ksi) for maximum test pressure . . . . . . . 17

Table 1.3.1-5. Maximum hoop stresses (ksi) for maximum test pressure $\ldots \ldots \ldots \ldots 17$

Table 1.3.2-1. Maximum bending and shear stresses. . . . . . . . . . . . 59

Table 1.4-1. Stability analysis results for critical hydrostatic pressure ......... 64

Table 1.5-1. Failure analysis results for assumed preliminary strengths $\ldots \ldots \ldots 67$

Table 1.5-2. Failure analysis results for experimental strengths $\ldots \ldots \ldots \ldots \ldots 68$

Table 2-1. Band advance calculations for cylinder G6-2 $\ldots \ldots \ldots \ldots \ldots \ldots 70$

Table 2-2. Band advance calculations for cylinder G6-3 $\ldots \ldots \ldots \ldots \ldots \ldots 71$

Table 2-3. Band advance calculations for cylinder G6-4 $\ldots \ldots \ldots \ldots \ldots \ldots 72$

Table 2-4. Composition data for cylinder $G 6-1 \ldots \ldots \ldots \ldots \ldots \ldots \ldots \ldots \ldots$

Table 2-5. Composition data for cylinder $\mathrm{G} 6-2 \ldots \ldots \ldots \ldots \ldots \ldots \ldots \ldots \ldots$

Table 2-6. Composition data for cylinder $66-3 \ldots \ldots \ldots \ldots \ldots \ldots \ldots \ldots 73$

Table 2-7. Composition data for cylinder $G 6-4 \ldots \ldots \ldots \ldots \ldots \ldots \ldots \ldots 73$

Table 2-8. Composition data for cylinder $\mathrm{C} 6-4 \ldots \ldots \ldots \ldots \ldots \ldots \ldots .74$

Table 2-9. Dimensional inspection rcsults for G6-1 inner and outer diameters ... 76

Table 2-10. Dimensional inspection results for G6-1 wall thickness ......... 76

Table 2-11. Dimensional inspection results for G6-2 inner and outer diameters ... 77

Table 2-12. Dimensional inspection results for G6-2 wall thickness ........ 78

Table 2-13. Dimensional inspection results for G6-3 inner and outer diameters ... 79

Table 2-14. Dimensional inspection results for G6-3 wall thickness ........ 80

Table 2-15. Dimensional inspection results for G6-4 inner and outer diameters ... 81

Table 2-16. Dimensional inspection results for G6-4 wall thickness ........ 82

Table 2-17. Dimensional inspection results for C6-4 inner and outer diameters . . 83

Table 2-18. Dimensional inspection results for $\mathrm{C} 6-4$ wall thickness $\ldots \ldots \ldots \ldots 84$

Table 2-19. Dimensional inspection results for TIR $\ldots \ldots \ldots \ldots \ldots \ldots \ldots .84$

Table 4.1-1. Experimental and theoretical hoop strain comparison . . . . . . . 131

Table 4.1-2. Experimental and theoretical axial strain comparison $\ldots \ldots \ldots \ldots 131$

Table 4.2-1. Predicted failure pressures from the performance model . . . . . . 134

Table 4.2-2. Performance model validation $\ldots \ldots \ldots \ldots \ldots \ldots \ldots \ldots \ldots \ldots . \ldots \ldots$

Table A-1. Weight-to-displacement ratios $\ldots \ldots \ldots \ldots \ldots \ldots \ldots \ldots \ldots \ldots 14$ 


\begin{abstract}
This report details the design, fabrication, and testing of four S-GLASS cylinders and an all circ-wound graphite cylinder. The results of an extensive parametric design study are presented which formed the foundation for the test article constructions. Included are the details of the cylinder constructions, the design calculations for stress and buckling, and the cylinder failure predictions. Analytical results are presented for both closed-form elasticity solutions and finite element methods. The test data and observations from the five hydrotests are summarized and correlated with the analytical results. Also provided are the details of a performance model for thick composites in compression, validated by the results of the experimental/analytical correlation. The predicted first-ply failure pressures from the performance model were within $10 \%$ of the experimentally measured pressures with the exception of the 2:1 hoop:axial ply ratio S-GLASS cylinder. The performance of this cylinder was underpredicted by $25 \%$. This work is sponsored by the Director as a three-year project funded from the Oak Ridge National Laboratory, Laboratory Directed Research and Development Fund.
\end{abstract}




\section{INTRODUCTION}

In work, to date, by a variety of organizations in the United States, ${ }^{1-4}$ the measured performance of thick-section composite cylindrical pressure vessels has fallen far short of analytical predictions. Also, the reported stress values in test cylinders have not achieved the compressive strengths measured in flat coupon tests. The variety of test methods currently being used for determining the compression performance of thick-section composite cylinders has greatly contributed to the variability of reported results. The overall difficulty of predicting performance in laminated composites and the nonexistence of standardized test methods for cylinders in part explains the current lack of success. Success in this area will require careful experimentation and the parallel development of supporting failure theories.

In a combined experimental/analytical approach for predicting performance of laminated composite cylinders, analytical tools are needed for the determination of ply-level stress states and elastic stability and the application of various failure criteria. The validity of a certain failure criterion can be established by carefully designing and testing a series of test articles to measure the performance and to identify the possible failure modes. In developing a valid performance model for predicting failure, it is important that representative test articles are used for determining the material strengths input into the model. However, standardized test methods will be required before consistent data can be obtained for both material strengths and test article performance.

This report summarizes the design, analysis, fabrication, and testing of four glass-reinforced cylinders and one graphite-reinforced cylinder for performance model validation and test method standardization. The four glass-reinforced epoxy test articles consist of an all circ-wound cylinder, a 6:1 hoop:axial ply ratio cylinder, a 4:1 hoop:axial ply ratio cylinder, and a 2:1 hoop:axial ply ratio cylinder. The graphite-reinforced epoxy test article is an all circ-wound construction. The details of an earlier graphite-reinforced epoxy test article that had a 2:1 hoop:axial ply ratio are described in a previous report. All of the cylinders listed above were subjected to monotonic hydrostatic pressure up to failure. Each of the cylinders has a nominal diameter of $6.0 \mathrm{in}$. and a nominal design wall thickness of to 0.5 in.. The layers or plies of the cylinder wall are constructed from either S-GLASS or IM6 graphite fibers and an ERL2258 epoxy resin. 


\section{TEST ARTICLE DESIGN/ANALYSIS}

The design of composite cylinder test articles is facilitated by having state-of-the art closed-form analytical solutions for calculating internal (ply-level) stress states and structural stability. In this investigation the closed-form expressions for the ply-level stresses were derived from the mathematical theory of anisotropic elasticity. The derivation was based on the simplifying assumptions of axisymmetry and a state of generalized plane deformation. The generalized plane deformation assumption models the test article as an infinitely long cylinder, and the stress state is independent of the axial coordinate. The structural stability of the cylinders was calculated using an orthotropic laminated shell theory which included the effects of radial strain and transverse shear deformations. The ends of the cylinder are restrained by using simply-supported boundary conditions.

The numerical method of finite elements is used for validation of the analytic solutions and for determining stresses associated with more realistic and complex boundary conditions, e.g., stresses associated with the transfer of load from the test assembly end closures to the ends of the cylinder. The closed-form analytic solutions can be evaluated computationally much faster than the numerical technique of finite elements, which facilitates the design iteration process, but they can not accurately predict the cylinder response at the supported ends. Finite element models were constructed for the test cylinder assembly and analyzed to determine local stress values within the volume and on the surfaces of the cylinder and the metal end closures. The drawing of a typical test assembly is shown in Fig. 1-1.

The design of a test cylinder includes the specification of the materials and the laminate stacking sequence. The design is based on parametric studies conducted with the analytic tools described above and on a clearly defined test objective. Results from the stress and buckling analyses are the basis for the selection of material type, specification of material layup, and specification of test article dimensions. The test article is specified in drawing form to the required level of detail to accomplish the fabrication, cutoff and final machining.

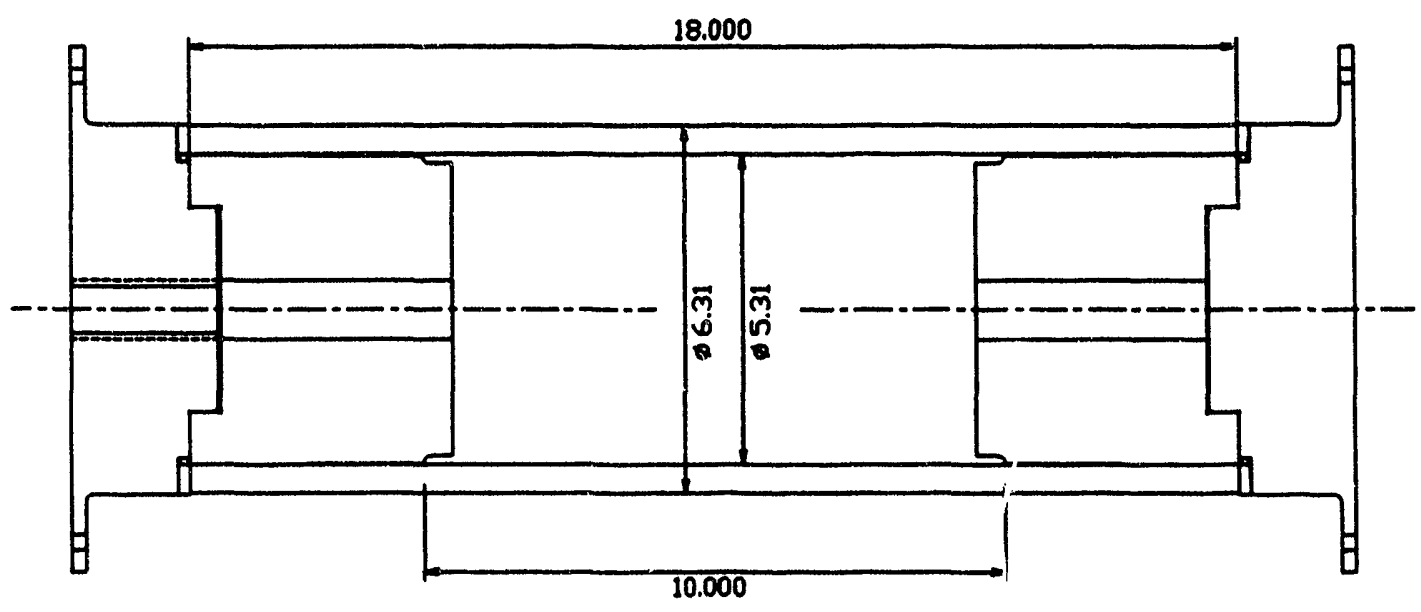

Fig. 1-1. Cylinder test assembly. 


\subsection{PARAMETRIC STUDY}

A parametric design study was performed for composite cylinders subjected to hydrostatic pressure loading to determine optimum constructions for testing. The methodology of the parametric study consisted of calculating design pressures based on a first-ply failure analysis using allowable material strengths for the layers and on a structural stability analysis. For the failure analysis, Hashin's ${ }^{5}$ criteria was used and failure pressures were calculated for the compressive fiber mode and the compressive matrix mode. The critical buckling pressures in the stability analysis were calculated based on an orthotropic shell theory which included transverse shear deformations. The buckling analysis and Hashin's failure criteria are described in greater detail in Sect. 1.4 and 1.5.

The cylinder model for the parametric study had a laminate stacking sequence which was restricted to having only circumferential (hoop) and axial layers with the design parameter being the ratio of the hoop to axial plies. The exact stacking sequences used had the following forms:

$$
\left[90 /\left(90_{k} / 0_{2} / 90_{k}\right)_{n} / 90\right]
$$

and

$$
\left[90 /\left(0 \mathrm{k} / 90_{2} / 0_{k}\right)_{\mathrm{p}} / 90\right]
$$

where $k$ and $n$ were integers which varied according to the hoop:axial ply ratio. The nominal dimensions for the cylinder model were an inner diameter of 5.32 in., a wall thickness of 0.50 in., and a layer thickness of 0.0067 in.. For these cylinder dimensions, the combined values of $k$ and $n$ were chosen such that the total number of layers in the stacking sequence equaled 74. Ply ratios that ranged from 35:1 to 1:35 hoop:axial were considered. In holding the wall thickness and total number of layers constant, one extra hoop ply was required at the inner and outer radius of the cylinder when ply ratios of 5:1, 7:1, 1:7, and 1:5 were used. The two material systems investigated were IM6/ERL2258 graphite/epoxy and S-GLASS/ERL2258 glass/epoxy, with an assumed fiber volume fraction for each system. A fiber volume fraction of 0.67 was used for the graphite/epoxy system and 0.80 was used for the glass/epoxy system. The buckling predictions were based on an unsupported length of 10 in. for the IM6/ERL2258 cylinders and 9 in. for the S-GLASS/ERL2258 cylinders.

For an IM6/ERL2258 layer and an S-GLASS/ERL2258 layer, the three-dimensionai strength allowables used for the failure analyses are given in Table 1.1-1. The allowables are specified for the principal material directions, where $X$ corresponds to strengths in the fiber direction, $Y$ corresponds to strengths transverse to the fiber direction, and $S$ corresponds to the shear strengths. The transverse compressive strength was initially assumed to be 15,000 psi for the graphite/epoxy material and 20,000 psi for the glass/epoxy material. These quantities were subsequently determined from the all-circ-wound cylinder tests to be 30,000 psi and 45,000 psi for the graphite/epoxy and glass/epoxy material systems, respectively. The analytical stress predictions and the experimental results for the all-circ-wound cylinders are described in Sect. 1.3 and 3.4, respectively. 
Table 1.1-1. Layer strengths

\begin{tabular}{lcc}
\hline & \multicolumn{2}{c}{ Material } \\
\cline { 2 - 3 } Strength (psi) & S-GLASS/ERL2258 & IM6/ERL2258 \\
\hline Axial tensile $-X_{\mathrm{t}}$ & 300,000 & 500,000 \\
Axial compressive $-X_{\mathrm{c}}$ & 250,000 & 250,000 \\
Transverse tensile $-Y_{\mathrm{t}}$ & 15,000 & 5,000 \\
Transverse compressive $-Y_{\mathrm{c}}$ & 20,000 & 15,000 \\
Axial shear $-S_{\mathrm{a}}$ & 10,000 & 10,000 \\
Transverse shear $-S_{\mathrm{t}}$ & 10,000 & 5,000 \\
\hline
\end{tabular}

In Fig. 1.1-1 the results from the parametric design study for the IM6/ERI2258 graphite/epoxy cylinders are presented. The results in this figure are based on using a value of $15 \mathrm{ksi}$ for the transverse compressive strength. For the entire range of ply ratios considered, the cylinders have a strength critical design corresponding to first-ply failure in a compressive matrix failure mode. For this mode of failure, the location of the first ply to fail is in the innermost hoop ply for ply ratios ranging from 35:1 to $2: 1$ and changes to the innermost axial ply for ratios ranging from 1:1 to 1:35. For the compressive fiber mode of failure, the outermost axial ply is the first ply to fail for ply ratios of $35: 1$ to $3: 1$, whereas the innermost hoop ply fails first in ply ratios ranging from 2:1 to 1:35. A very distinct peak is seen in the two plots for the failure pressures predicted from Hashin's criteria. Based on this criteria, the 2:1 hoop:axial ply ratio is clearly an optimum design. However, for a 2:1 ply ratio and an unsupported length of 10 in., the cylinder may be buckling critical as evident by the plotted results for the allowable buckling pressures. The results for the allowable buckling pressures also show the buckling pressure is nearly independent of the hoop:axial ply ratio for ratios between 35:1 and 3:1. For ply ratios starting at 2:1, the allowable buckling pressure decreases to a minimum value at the 1:35 hoop:axial ply ratio.

If the assumption is made that ultimate failure or last-ply failure corresponds to a fiber mode of failure, then the difference between the matrix mode results and the fiber mode results is an indication of the amount of damage the cylinder can withstand prior to total loss of load carrying capability. For ply ratios ranging from $1: 1$ to $1: 35$, the failure pressures for matrix mode and fiber mode are almost the same, which based on the above stated assumption means these cylinder designs would have very little damage accumulation and experience a catastrophic failure. The same is true when the cylinder design approaches an all hoop-wound construction. The largest difference between the failure pressures for matrix mode and fiber mode occurs for the optimum design case of a 2:1 hoop:axial ply ratio.

A dramatic change in the results, as depicted in Fig. 1.1-2, occurs when an allowable transverse compressive strength of $30 \mathrm{ksi}$ is used for the IM6/ERL2258 graphite/epoxy cylinders. The results for the compressive fiber mode of failure using Hashin's criteria and the buckling allowables are the same as presented in Fig. 1.1-1. However, as a result of an increase in the transverse compressive strength, the matrix mode of failure plot is shifted up and first-ply failure is now a fiber mode for the entire range of hoop:axial ply ratios. The 
2:1 ratio is still an optimum design based on Hashin's criteria but is now definitely buckling critical for a 10-in. unsupported length. If a 10-in. unsupported length is used, the 3:1 hoop:axial ply ratio may be a more optimum design because of the slight increase in the allowable buckling pressure for this stacking sequence.

The parametric study results for the S-GLASS/ERL2258 cylinders are given in Figs. 1.1-3 and 1.1-4 for transverse compressive strengths of $20 \mathrm{ksi}$ and $45 \mathrm{ksi}$, respectively. In Fig. 1.1-3 the critical design pressure is governed by the compressive matrix mode of failure. The first ply to fail is the innermost hoop ply for ply ratios between 35:1 and 11:1. When the ply ratio ranges from 8:1 to 1:35 the first-ply failure occurs in the innermost axial ply. The shift in location of the first ply to fail from innermost hoop to innermost axial is at a much higher hoop:axial ply ratio in the S-GLASS/ERL2258 material system when compared with the IM6/ERL2258 material system. For the compressive fiber mode of failure, the innermost hoop ply is always the critical ply independent of the ply ratio, and an axial layer is never predicted to fail in a compressive fiber mode. The results for the critical buckling pressure are seen to be independent of the hoop:axial ply ratio over a wide spectrum of ratios.

In contrast to the behavior of the Hashin failure criteria plots for the IM6/ERL2258 system, there is not a real distinct peak nor a clear optimum design for the S-GLASS/ERL2258 system. The results in Fig. 1.1-3 ïdicate there is a wide range of ply ratios where the first ply failure pressure does not differ by more than 1000 rsi. The difference between the matrix mode results and the fiber mode results is also in contrast to the graphite/epoxy results. For the glass/epoxy system, this difference is seen to be very large, with the maximum difference occurring for the 35:1 ratio. The difference between the matrix mode results and the fiber mode results is seen to decrease sharply between the 3:1 and the 1:3 hoop:axial ply ratios. These results indicate that for a large range of hoop:axial ply ratios the S-GLASS/ERL2258 cylinders will have a significant amount of damage accumulation prior to their total collapse.

The change in the results between Fig. 1.1-3 to Fig. 1.1-4, where the larger transverse compressive strength of $45 \mathrm{ksi}$ was used, is not as dramatic as was described previously for the graphite/epoxy results. The critical design pressure still corresponds to the compressive matrix mode for first-ply failure but with an increase in the maximum pressure associated with an increase in the allowable transverse compressive strength. Also, a wide range of ply ratios still exist where the first-ply failure pressure is relatively constant and consequently, there is not a clear optimum design.

In addition to fabricating all circ-wound cylinders using the IM6/ERL2258 and S-GLASS/ERL2258 material systems to measure the transverse compressive strength, the results of the parametric design study led to the selection of a 6:1 and a 4:1 hoop:axial ply ratio cylinder design for the glass/epoxy system. Also, the results from this study indicated that the 2:1 hoop:axial ply ratio cylinder design for the C6-1 test article was a near optimum design for the IM6/ERL2258 material system. The design, fabrication, and testing of this cylinder was described in detail by Blake and Starbuck. ${ }^{6}$ In addition, a 2:1 hoop:axial ply ratio S-GLASS/ERL2258 cylinder was fabricated and tested. The experimental failure pressures for these test articles are included in Figs. 1.1-2 and 1.1-4. A discussion of the experimental results is provided in Sect. 3. 


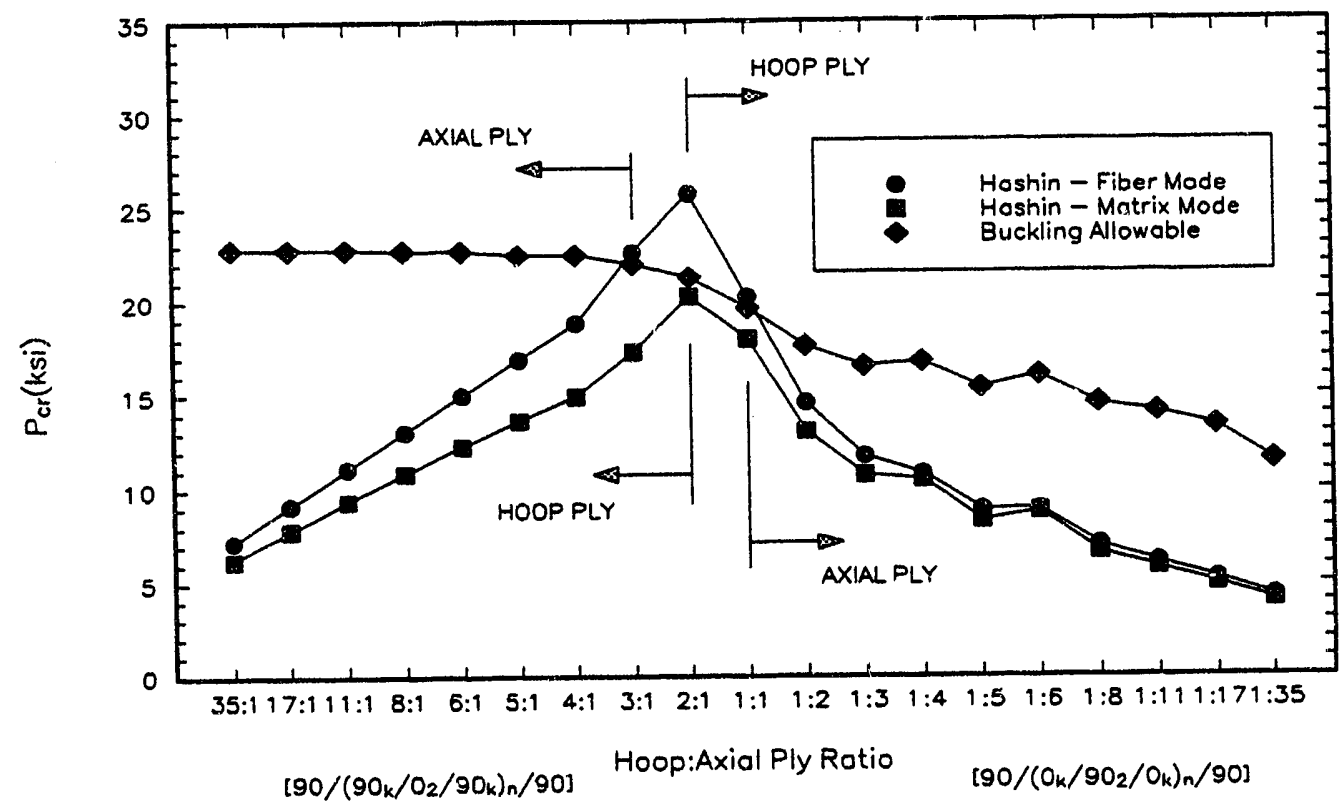

Fig. 1.1-1. Design pressures for IM6 cylinders with $Y_{c}=15$ ksi.

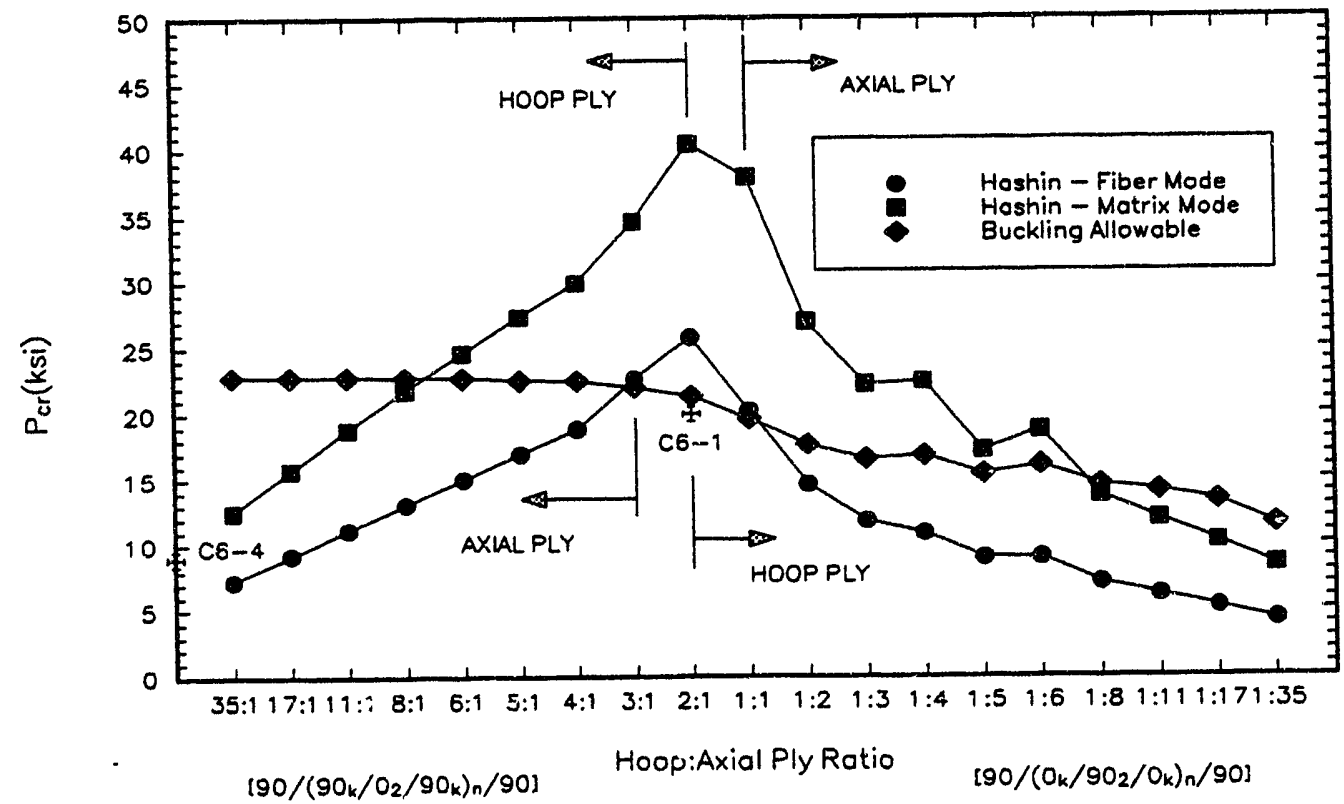

Fig. 1.1-2. Design pressures for $\mathrm{IM} 6$ cyiinders with $Y_{c}=30$ ksi. 


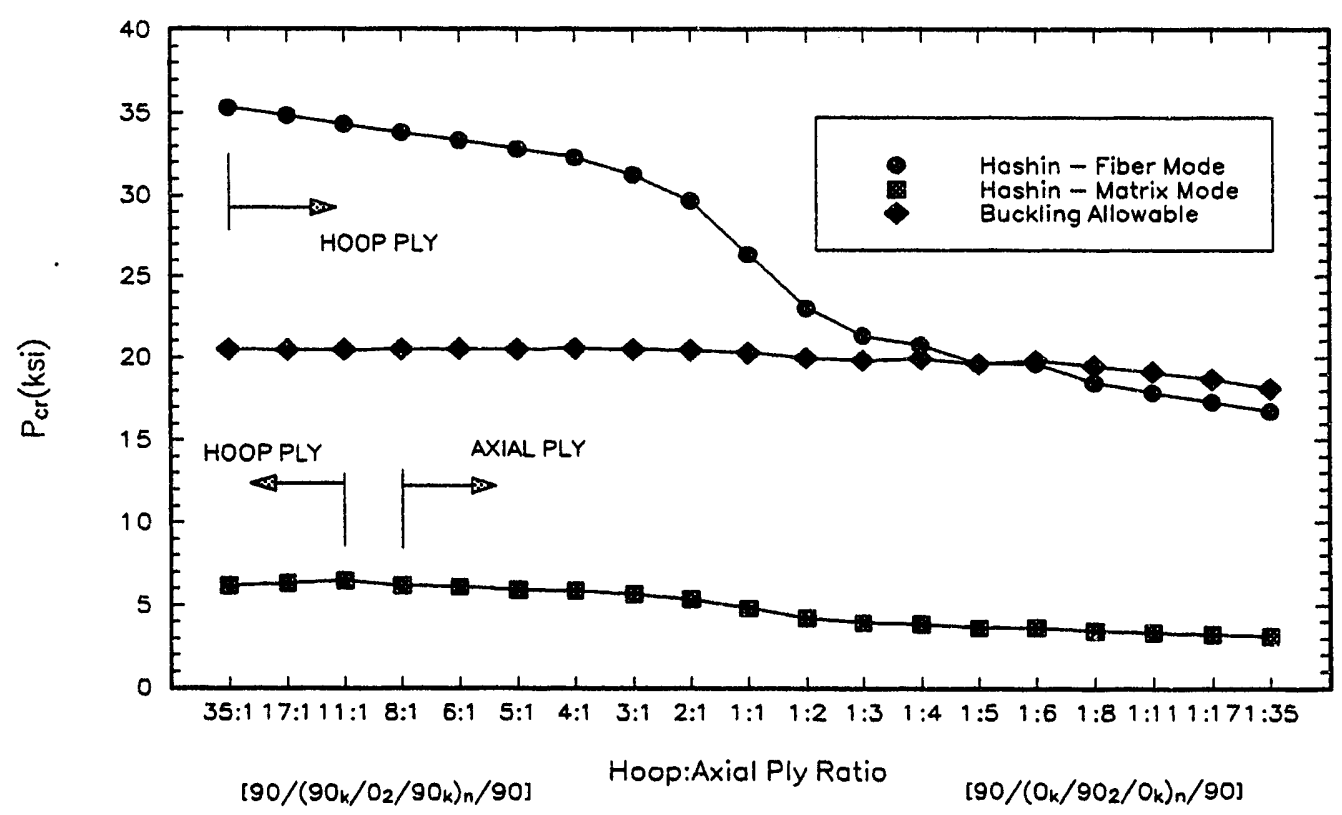

Fig. 1.1-3. Design pressures for S-GLASS cylinders with $Y_{\mathfrak{c}}=20 \mathrm{ksi}$.

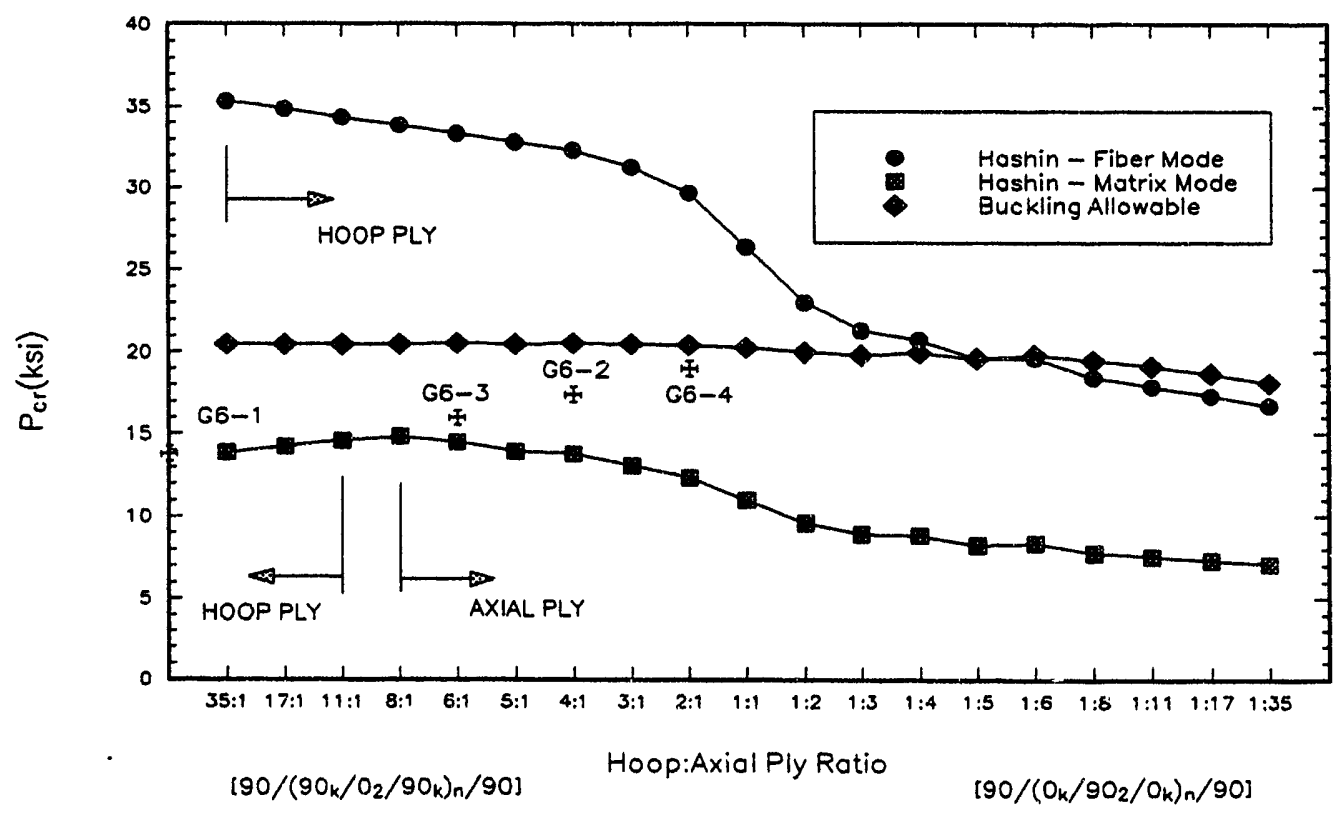

Fig. 1.1-4. Design pressures for S-GLASS cylinders with $Y_{c}=45 \mathrm{ksi}$. 


\subsection{PROPERTIES AND G.EOMETRY}

The glass-reinforced epoxy test articles fabricated for demonstration testing are identified as follows: cylinder G6-1 was designed to have an ail circ-wound construction, cylinder G6-2 had a nominal 4:1 hoop to axial ply ratio with one extra hoop ply placed at both the inner and outer radii, cylinder $\mathrm{G} 6-3$ had a nominal 6:1 hoop to axial ply ratio with one extra hoop ply placed at both the inner and outer radii, and cylinder G6-4 had a nominal 2:1 hoop to axial ply ratio with one extra hoop ply placed at both the inner and outer radii. The graphite-reinforced epoxy test article is identified as C6-4 and had an all circ-wound construction. A more detailed description for the fabrication of these cylinders is presented in Sect. 2. After fabrication, the material properties and geometry were determined.

The nomenclature for the laminate stacking sequence in each cylinder is given in Table 1.2-1. The total number of layers, $N$, in the all circ-wound cylinders, G6-1 and C6-4, was determined by the target wall thickness of 0.5 in.. For the 6:1, 4:1, and 2:1 hoop:axial ply ratio constructions, the number of repeating sublaminate patterns was determined by the target wall thickness of $0.5 \mathrm{in}$.. In the case of the 2:1 ply ratio, 11 repeating patterns were required. For the 4:1 and 6:1 ply ratios, 7 and 5 repeating patterns, respectively, were required. Dimensional inspection of the test articles after fabrication (see Sect. 2) resulted in geometric properties for the analytical cylinder models as shown in Table 1.2-2. The machined lengths and the unsupported lengths were determined on the basis of stability considerations discussed in Sect. 1.4.

The fiber volume fractions for each of the fabricated cylinders were determined from composition samples. The layer properties were then computed using the S-GLASS or IM6 fiber properties and the ERL 2258 epoxy matrix properties with the corresponding fiber volume fraction. Table 1.2-3 shows the CLASS computed layer properties in the principal material directions. ${ }^{7}$ The layers were assumed to be transversely-isotropic, with the properties in the 2-3 plane being equal in all directions, i.e., the 2-3 plane is a plane of material property symmetry and the 2 and 3 subscripts are interchangeable. To model the laminated composite cylinders as homogeneous single-layered anisotropic cylinders, equivalent sets of three-dimensional effective elastic constants or smeared laminate properties were computed. A program called NDPROP, which yields volume averaged composite elastic properties from input layer properties and laminate stacking sequence, was used for this purpose. ${ }^{\beta}$ The calculated properties are in the global reference frame and are given in Table 1.2-4. For the all-circ-wound cylinders, G6-1 and C6-4, the NDPROP computed laminate properties are for a single layer and serve as a check on the CLASS computed layer properties. 
Table 1.2-1. Test article stacking sequences

\begin{tabular}{cc}
\hline Cylinder identification & Stacking sequence \\
\hline G6-1 & {$\left[90_{\mathrm{N}}\right]_{\mathrm{T}}$} \\
G6-2 & {$\left[90 /\left(90_{4} / 0_{2} / 90_{4}\right)_{7} / 90\right]_{\mathrm{T}}$} \\
G6-3 & {$\left[90 /\left(90_{6} / 0_{2} / 90_{6}\right)_{5} / 90\right]_{\mathrm{T}}$} \\
G6-4 & {$\left[90 /\left(90_{2} / 0_{2} / 90_{2}\right)_{11} / 90\right]_{\mathrm{T}}$} \\
C6-4 & {$\left[90_{\mathrm{N}}\right]_{\mathrm{T}}$} \\
\hline
\end{tabular}

Table 1.2-2. Test article geometric properties

\begin{tabular}{lccccc}
\hline & \multicolumn{5}{c}{ Cylinder identification } \\
\hline Dimensions (in.) & G6-1 & G6-2 & G6-3 & G6-4 & C6-4 \\
\hline Inner diameter $\left(D_{\mathrm{i}}\right)$ & 5.3102 & 5.3105 & 5.3090 & 5.3118 & 5.3181 \\
Outer diameter $\left(D_{\mathrm{o}}\right)$ & 6.3215 & 6.3379 & 6.2596 & 6.3056 & 6.3203 \\
Inner radius $\left(R_{\mathrm{i}}\right)$ & 2.6551 & 2.6552 & 2.6545 & 2.6559 & 2.6590 \\
Outer radius $\left(R_{\mathrm{o}}\right)$ & 3.1607 & 3.1689 & 3.1298 & 3.1529 & 3.1601 \\
Mean radius $\left(R_{\mathrm{m}}\right)$ & 2.9079 & 2.9121 & 2.8921 & 2.9044 & 2.9096 \\
Wall thickness $(H)$ & 0.5057 & 0.5137 & 0.4753 & 0.4969 & 0.5011 \\
$R_{\mathrm{m}} / H$ & 5.7508 & 5.6687 & 6.0849 & 5.8449 & 5.8062 \\
Unsupported length $(L)$ & 9.0 & 9.0 & 7.0 & 7.0 & 10.0 \\
Machined length & 17.0 & 17.0 & 15.0 & 15.0 & 18.0 \\
Layer thickness $(t)$ & N/A & 0.00714 & 0.00660 & 0.00731 & N/A \\
\hline
\end{tabular}


Table 1.2-3. CLASS computed layer properties

\begin{tabular}{lccccc}
\hline & \multicolumn{5}{c}{ Cylinder identification } \\
\cline { 2 - 6 } Property & $\mathrm{G} 6-1$ & $\mathrm{G} 6-2$ & $\mathrm{G} 6-3$ & $\mathrm{G} 6-4$ & $\mathrm{C} 6-4$ \\
\hline $\mathrm{V}_{\mathrm{f}}(\%)$ & 80.0 & 72.0 & 78.0 & 70.7 & 69.3 \\
$\mathrm{E}_{1}(\mathrm{MSI})$ & 9.9571 & 9.0200 & 9.7230 & 8.8670 & 23.400 \\
$\mathrm{E}_{2}(\mathrm{MSI})$ & 4.2225 & 3.2650 & 3.9450 & 3.1410 & 1.5840 \\
$\mathrm{E}_{3}(\mathrm{MSI})$ & 4.2225 & 3.2650 & 3.9450 & 3.1410 & 1.5840 \\
$\mathrm{G}_{12}$ (MSI) & 1.3775 & 1.0290 & 1.2730 & 0.9869 & 0.9002 \\
$\mathrm{G}_{13}$ (MSI) & 1.3775 & 1.0290 & 1.2730 & 0.9869 & 0.9002 \\
$\mathrm{G}_{23}$ (MSI) & 1.6186 & 1.2343 & 1.5072 & 1.1845 & 0.5638 \\
$\nu_{12}$ & 0.2287 & 0.2408 & 0.2317 & 0.2428 & 0.3197 \\
$\nu_{13}$ & 0.2287 & 0.2408 & 0.2317 & 0.2428 & 0.3197 \\
$\nu_{23}$ & 0.3045 & 0.3226 & 0.3087 & 0.3259 & 0.4047 \\
\hline
\end{tabular}

Table 1.2-4. NDPROP computed laminate properties

\begin{tabular}{lccccc}
\hline & \multicolumn{5}{c}{ Cylinder identification } \\
\cline { 2 - 6 } Property & $\mathrm{G} 6-1$ & $\mathrm{G} 6-2$ & $\mathrm{G} 6-3$ & $\mathrm{G} 6-4$ & $\mathrm{C} 6-4$ \\
\hline $\mathrm{E}_{\mathrm{x}}(\mathrm{MSI})$ & 4.2225 & 4.3986 & 4.7575 & 5.0163 & 1.5840 \\
$\mathrm{E}_{\theta}(\mathrm{MSI})$ & 9.9571 & 7.9266 & 8.9392 & 7.0461 & 23.400 \\
$\mathrm{E}_{\mathrm{r}}(\mathrm{MSI})$ & 4.2225 & 3.3477 & 4.0062 & 3.2519 & 1.5840 \\
$\mathrm{G}_{\mathrm{x} \theta}(\mathrm{MSI})$ & 1.3775 & 1.0296 & 1.2730 & 0.9870 & 0.9002 \\
$\mathrm{G}_{\mathrm{xx}}(\mathrm{MSI})$ & 1.6185 & 1.1945 & 1.4696 & 1.1207 & 0.5638 \\
$\mathrm{G}_{\theta \mathrm{r}}(\mathrm{MSI})$ & 1.3775 & 1.0694 & 1.3011 & 1.0509 & 0.9220 \\
$\nu_{\mathrm{x} \theta}$ & 0.0970 & 0.0995 & 0.1025 & 0.1087 & 0.0216 \\
$\nu_{\mathrm{xx}}$ & 0.3045 & 0.3132 & 0.3018 & 0.3094 & 0.4047 \\
$\nu_{\theta \mathrm{r}}$ & 0.2288 & 0.2684 & 0.2496 & 0.2843 & 0.3197 \\
$\nu_{\theta \mathrm{x}}$ & 0.2288 & 0.1793 & 0.1926 & 0.1527 & 0.3197 \\
$\nu_{\mathrm{rx}}$ & 0.3045 & 0.2384 & 0.2541 & 0.2006 & 0.4047 \\
$\nu_{\mathrm{r} \theta}$ & 0.0970 & 0.1134 & 0.1119 & 0.1312 & 0.0216 \\
\hline
\end{tabular}




\subsection{STRESS ANALYSIS RESULTS}

The cylinder characteristics described by the geometry, properties, and strengths in Sect. 1.2 were used in modeling the different test articles for their as-fabricated construction. A program called CCAP was developed for performing the closed-form, analytic, ply-level stress computations based on the mathematical theory of anisotropic elasticity. The results obtained from the elasticity solution in CCAP were compared with laminated shell theory (LST) results when layered analyses were performed and with finite element (FE) results when equivalent smeared properties were used. The LST results were generated from a program called CYLAN ${ }^{9}$ and the FE results were generated from NIKE2D. ${ }^{10}$

The solution procedure in the CCAP program is based on an anisotropic elasticity formulation by Hyer, ${ }^{11}$ with modifications to include the exact solution for isotropic and transversely isotropic layers, i.e., the solution to the governing differential equation for the case of repeated roots equal to 1.0. In addition to axisymmetric thermal and mechanical loading, the program can determine the hygroscopic response of a laminated cylinder. The mechanical loadings available in CCAP are uniform internal and external lateral pressure, axial force, torque, and hydrostatic pressure. The number of stress calculation points in each layer is a specified variable, and hybrid cylinders can be analyzed. A more detailed description of CCAP and other analytical tools used in the design and analysis of test articles is presented by Blake et al. ${ }^{12}$

The closed-form analytic solution in CCAP is limited to generalized plane deformation assumptions which apprcximately model the cylinder midplane where axial bending and shear stresses are negligible. For generalized plane deformation, all of the stress components are independent of the axial coordinate. The FE model was used to provide detailed stress results in the regions adjacent to the end closures where high axial bending and shear stresses occur. In addition to the detailed model of the entire test assembly which includes the cylinder and end closures, a model of the cylinder (without the end closures) was also constructed. This "cylinder only" model provided displacements, strains, and composite stress values for comparison with the elasticity solution in CCAP. Stress values from these initial FE analyses which model the cylinder as a single layer having smeared elastic properties are composite stresses rather than the layer stresses.

The cylinder model used in the CCAP program is a three-dimensional, arisymmetric model. For axisymmetry all stress, strain, and displacement components are independent of the circumferential coordinate. The laminated shell theory solution in the CYLAN program is a two-dimensional plane stress model and is not capable of predicting radial displacements, radial strains, and radial stresses. In the CYLAN program the in-plane stress and strain calculations are based on a Vlasov-Ambartsumyan type of laminated shell theory with modifications by Whitney to include through-the-thickness strain effects. ${ }^{13,14,15}$ The two-dimensional plane stress results from the CYLAN program are compared with the three-dimensional elasticity solution used in CCAP.

\subsubsection{Closed-Form Analytic Results}

The geometry of the laminated cylinder model in CCAP is shown in Fig. 1.3.1-1, where the cylindrical coordinate system, $x, \theta$, and $r$, represents the axial, circumferential, and radial directions, respectively. For an applied hydrostatic pressure loading, the cylinder is 
subjected to a uniform external lateral pressure, $p_{0}$, and an axial compressive force, $F_{x}$ due to the component of hydrostatic pressure acting on the end plugs. The results from the closed-form analytic solutions in CCAP and CYLAN are summarized in this section.

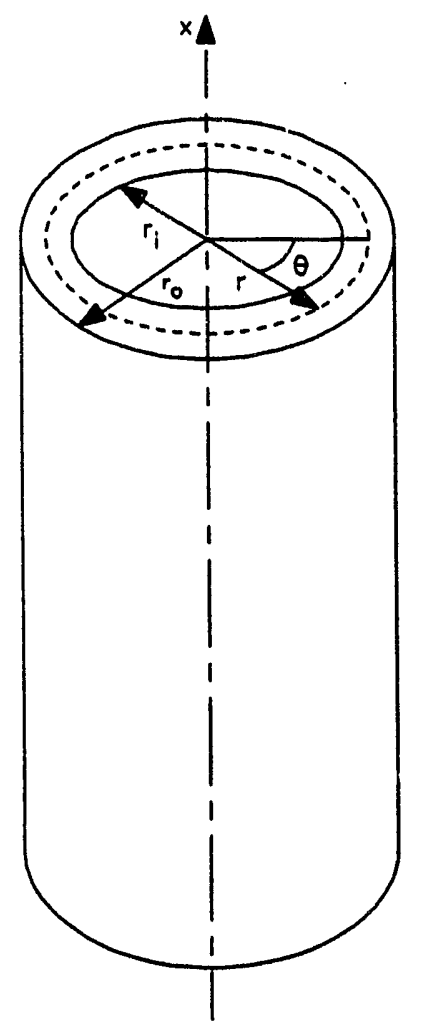

Fig. 1.3.1-1. Cylinder geometry for CCAP model.

The cylinders are modeled by their as-fabricated construction (e.g., dimensions and composition data in Tables 1.2-2, 1.2-3, and 1.2-4), where adjacent plies in the repeating pattern having the same fiber orientation are modeled as a single layer. The all-circ-wound cylinders, G6-1 and C6-4, are modeled by a single layer having a 90 degree fiber orientation. An applied hydrostatic pressure equal to the maximum achieved test pressure was specified, and results for the radial distribution of strains, stresses, and radial displacement were generated. The results for the out-of-plane stress components $\left(\sigma_{r}, \tau_{r e}\right.$, and $\left.\tau_{x x}\right)$, the in-plane strain components $\left(\epsilon_{x}, \epsilon_{\theta}\right.$, and $\gamma_{x \theta}$ ), and the radial displacement $(w)$ are continuous at the interfaces between two adjacent layers. However, the in-plane stress components $\left(\sigma_{x}, \sigma_{\theta}\right.$, and $\left.\tau_{x p}\right)$ and the out-of-plane strain components $\left(\epsilon_{r}, \gamma_{r e}\right.$, and $\left.\gamma_{x r}\right)$ are discontinuous across an interface between different materials and/or different ply orientations.

The distribution of the radial displacement, $w$, through the thickness for cylinder G6-1 is plotted in Fig. 1.3.1-2. The plotted results for radial displacement in cylinders G6-2, G6-3, G6-4, and C6-4 are shown in Figs. 1.3.1-3, 1.3.1-4, 1.3.1-5, and 1.3.1-6, respectively. For cylinders G6-2, G6-3, and G6-4, results are presented from the CCAP program using both layered and smeared properties. The smeared property analyses are shown to predict almost the same results as does the layered analysis, with a nearly identical distribution across the cylinder wall. This will be the case only when the deformations are assumed to be continuous in the radial direction, a large number of layers exists across the cylinder wall, and the layers have an interspersed stacking sequence. The magnitudes of $w$ at the inner 
and outer radii of the cylinder wall for the five cylinders are given in Table 1.3.1-1. For comparison purposes, the results for cylinder C6-1, a 2:1 hoop:axial IM6/ERL2258 cylinder, are included in this table (see Blake and Starbuck ${ }^{6,12}$ ).

Table 1.3.1-1. Radial displacement results at maximum test pressure

\begin{tabular}{lcc}
\hline & \multicolumn{2}{c}{$w$ (mils) } \\
\cline { 2 - 3 } Cylinder identification & Inner radius & Outer radius \\
\hline i6-1 & -22.515 & -20.707 \\
G6-2 & -36.013 & -33.470 \\
G6-3 & -30.967 & -28.880 \\
G6-4 & -45.896 & -43.055 \\
C6-1 & -22.298 & -22.315 \\
C6-4 & -7.1567 & -4.4480 \\
\hline
\end{tabular}

In all cases, except for cylinder C6-1, the cylinders experience a larger radial contraction at the inner radius when compared with the radial contraction at the outer radius. A larger displacement at the inner radius than at the outer radius can, in part, be a Poisson ratio effect when hydrostatic pressure is applied. The axial force associated with hydrostatic loading produces a tensile radial strain at the inner radius which adds to the radial contraction resulting from the applied external pressure. At the outer radius, the Poisson ratio effect is diminished by a larger compressive radial stress at this surface which produces a smaller tensile radial strain and thus reduces the amount of radial growth associated with the compressive axial force. The larger percentage of axial reinforcement in the 2:1 hoop:axial construction of $66-1$ results in a smaller axial strain compared with the other cylinder constructions which, due to the Poisson ratio effect, results in a smaller tensile radial strain. However, the IM6/ERI2258 graphite/epoxy has a very low transverse stiffness which has a significant effect on the amount of radial growth. For C6-1, the combination of a low transverse stiffness and a 2:1 hoop:axial construction with the Poisson ratio effec $i$ and biaxial loading results in a larger radial contraction at the outer radius than at the inner radius.

For cylinder constructions where only axial and circumferential plies are used, the analytical formulation in CCAP predicts vanishing shear strains. The CCAP predictions for the normal components of strain (axial, hoop, and radial) have a distribution across the G6-1 cylinder wall as shown in Fig. 1.3.1-7. The LST results are also presented in this figure for the axial and hoop components of strain. The plotted results correspond to an applied load equal to the maximum hydrostatic pressure achieved during testing. Similar plots are given in Figs. 1.3.1-8, 1.3.1-9, 1.3.1-10, and 1.3.1-11 for cylinders G6-2, G6-3, G6-4, and C6-4, respectively. These five figures show that the in-plane normal strains are uniform through the thickness, i.e., continuous across the layer interfaces. The distribution of the axial strain is constant across the wall thickness, whereas the radial and hoop strains have gradients. The radial component of strain has an almost linear distribution with discontinuous steps at interfaces between 0 degree and 90 degree plies. The radial strain is tensile across the entire wall thickness for cylinders G6-1, G6-2, G6-3, G6-4, and C6-4. This was not the case for the 2:1 hoop:axial IM6/ERL2258 cylinder, C6-1, discussed in Refs. 6 and 12 where the radial strain varied from being tensile at the inner radius to compressive at the outer radius. 
The analytical results for the strains using the two-dimensional plane stress solution in LST predict compressive axial strains which are larger than the three-dimensional elasticity solution results. An opposite trend was observed for the hoop strains, where the LST predicts smaller compressive hoop strains than the elasticity solution. The difference between the LST results and the elasticity results for the hoop strains is greater at the inner radius of the cylinder wall than at the outer radius. In fact, the hoop strains at the outer radius based on LST are nearly equal to the elasticity solution. The gradient of the hoop strain across the wall thickness is not as steep when the cylinders are analyzed using LST, which produced larger differences between the two theories at the inner radius.

The axial strain distributions for all of the cylinders are compared in Fig. 1.3.1-12 for their respective maximum test pressures. In addition to the five cylinders described in this report, the results for the C6-1 cylinder are presented. For the 2:1 hoop:axial ply ratio glass-reinforced cylinder, G6-4; the 4:1 hoop:axial ply ratio glass-reinforced cylinder, G6-2; the 6:1 hoop:axial ply ratio glass-reinforced cylinder, G6-3; and the 2:1 hoop:axial ply ratio graphite-reinforced cylinder, C6-1, results are presented from both a layered analysis and an equivalent single-layer smeared property analysis. Similar plots are given in Figs. 1.3.1-13 and 1.3.1-14 for the hoop and radial strains, respectively.

As shown in Fig. 1.3.1-12, the maximum axial strain is in the all circ-wound graphite-reinforced cylinder, C6-4, and the lowest axial strain is in the 2:1 hoop:axial graphite-reinforced cylinder, C6-1. In between these two cases are the results for the four glass-reinforced cylinders. In contrast to the graphite-reinforced cylinders, where the all circ-wound construction has a larger axial strain than the 2:1 construction, the largest axial strain in the glass-reinforced cylinders occurs in the cylinder having the $4: 1$ ply ratio. These results may be somewhat misleading as a result of the different fiber volume fractions achieved during fabrication of the different cylinder constructions.

The hoop strain results plotted in Fig. 1.3.1-13 indicate that cylinder G6-4 has the largest hoop strain at its respective maximum test pressure when compared with the other cylinder results. The smallest hoop strain is in the all circ-wound graphite-reinforced cylinder, C6-4. Also, the results show the all circ-wound glass-reinforced cylinder, G6-1, to have almost the same distribution and magnitude of hoop strain across the wall thickness as does the C6-1 graphite-reinforced cylinder.

The radial strain gradients across the cylinder wall thickness, as shown in Fig. 1.3.1-14, further illustrate what was described above for the radial displacement results. To reiterate, the radial strains for all of the cylinders tested are tensile at the inner radius and are tensile across the entire wall thickness, except for the C6-1 cylinder which has a compressive strain over the outer half of the wall thickness. The tensile strain occurring at the inner radius is most probably a result of a through-the-thickness Poisson effect produced by the axial compressive force. Also, the radial strain gradient is shown to be much steeper for the C6-1 cylinder when compared with the other cylinder constructions.

The magnitudes of the normal strain components at the inner and outer radii are given in Table 1.3.1-2 for the elasticity solution results from CCAP using layered properties. Recall that G6-1 and C6-4 are modeled by a single layer having transversely-isotropic properties. The results shown in Figs. 1.3.1-12 through 1.3.1-14 using smeared properties, although not presented in this table, indicate accurate strains can be predicted by modeling 
the cylinders as single layers having equivalent smeared orthotropic properties. As was discussed above for the radial displacement, the in-plane normal components of strain are continuous quantities and the results using smeared properties are nearly identical to the layered analysis results. The three-dimensional elasticity results in Table 1.3.1-2 can be compared with the two-dimensional LST results presented in Table 1.3.1-3.

Table 1.3.1-2. CCAP results for normal strains at maximum test pressure

\begin{tabular}{|c|c|c|c|c|c|c|}
\hline \multirow{2}{*}{ Cylinder ID } & \multicolumn{2}{|c|}{ Axial strain (\%) } & \multicolumn{2}{|c|}{ Hoop strain (\%) } & \multicolumn{2}{|c|}{ Radial strain (\%) } \\
\hline & $\begin{array}{l}\text { Inner } \\
\text { radius }\end{array}$ & $\begin{array}{l}\text { Outer } \\
\text { radius }\end{array}$ & $\begin{array}{l}\text { Inner } \\
\text { radius }\end{array}$ & $\begin{array}{l}\text { Outer } \\
\text { radius }\end{array}$ & $\begin{array}{l}\text { Inner } \\
\text { radius }\end{array}$ & $\begin{array}{l}\text { Outer } \\
\text { radius }\end{array}$ \\
\hline G6-1 & -0.8563 & -0.8563 & -0.8480 & -0.6551 & 0.5448 & 0.2021 \\
\hline G6-2 & -1.0155 & -1.0155 & -1.3564 & -1.0561 & 0.7977 & 0.2424 \\
\hline G6-3 & -0.9159 & -0.9159 & -1.1666 & -0.9228 & 0.6710 & 0.2440 \\
\hline G6-4 & -0.9785 & -0.9785 & -1.7280 & -1.3655 & 0.9147 & 0.2776 \\
\hline C6-1 & -0.7287 & -0.7287 & -0.8386 & -0.7075 & 0.6445 & -0.5469 \\
\hline C6.4 & -1.7373 & -1.7373 & -0.2691 & -0.1408 & 0.8418 & 0.3165 \\
\hline
\end{tabular}

Table 1.3.1-3. LST results for normal strains at maximum test pressure

\begin{tabular}{lcccc}
\hline & \multicolumn{2}{c}{ Axial strain (\%) } & \multicolumn{2}{c}{ Hoop strain (\%) } \\
\cline { 2 - 5 } & Inner radius & Outer radius & Inner radius & Outer radius \\
\hline G6-1 & -0.929 & -0.929 & -0.740 & -0.633 \\
G6-2 & -1.110 & -1.110 & -1.190 & -1.030 \\
G6-3 & -0.989 & -0.989 & -1.030 & -0.905 \\
G6-4 & -1.060 & -1.060 & -1.530 & -1.340 \\
C6-1 & -0.784 & -0.784 & -0.772 & -0.660 \\
C6-4 & -1.880 & -1.880 & -0.220 & -0.130 \\
\hline
\end{tabular}

In contrast to the in-plane strains and the out-of-plane radial stress, which are continuous functions across the cylinder wall for a layered analysis, the in-plane hoop and axial stresses are discontinuous. The assumed state of stress and axisymmetry considered in the CCAP analysis resulted in the in-plane component of shear stress, $\tau_{x \neq}$, being the only nonzero shear stress, but for the case of having only axial and hoop plies in the cylinder constructions, $\tau_{x \neq}$ is also zero. The distribution of the hoop and axial components of stress across the wall thickness was determined using the elasticity formulation in CCAP and the LST in CYLAN.

In Fig. 1.3.1-15 the axial stress distribution is plotted, and in Fig. 1.3.1-16 the hoop stress distribution is shown for cylinder G6-1. The results in Fig. 1.3.1-15 show that the axial 
stress is a maximum at the outer radius for the CCAP results, whereas it is a maximum at the inner radius for the CYLAN results. Figure 1.3.1-16, shows that the hoop stress has a maximum compressive value at the inner radius and that the two-dimensional CYLAN analysis predicts a maximum hoop stress which is much less than the prediction from the three-dimensional analysis of CCAP.

The axial and hoop stress distributions for G6-2 are shown in Figs. 1.3.1-17 and 1.3.1-18, respectively. Similar plots are given in Figs. 1.3.1-19 and 1.3.1-20 for G6-3 and in Figs. 1.3.1-21 and 1.3.1-22 for G6-4. From Figs. 1.3.1-17, 1.3.1-19, and 1.3.1-21, the IST results are shown to predict slightly larger axial compressive stresses in the axial layers than the elasticity solution. Whereas, in Figs. 1.3.1-18, 1.3.1-20, and 1.3.1-22, the compressive hoop stresses are less when LST is compared with the three-dimensional elasticity approach. In other words, for these two cross-ply cylinder constructions, the LST overpredicts the maximum axial compressive stress and underpredicts the maximum hoop compressive stress.

Similar observations, as described previously for the circ-wound glass-reinforced cylinder, G6-1, can be made from Figs. 1.3.1-23 and 1.3.1-24 for the circ-wound graphite-reinforced cylinder, C6-4. In both cases, LST underpredicts the maximum hoop stress. The C6-4 cylinder does exhibit a larger hoop stress gradient across the wall thickness than G6-1. Clearly, as seen from these two figures and the G6-1 results, the twodimensional analysis of LST cannot be used to accurately predict the stress state in the two circ-wound cylinders.

For an applied pressure equal to the maximum test pressure, the magnitudes of the maximum axial stress are reported in Table 1.3.1-4 and the magnitudes of the maximum hoop stresses are reported in Table 1.3.1-5. The location of the maximum axial stress is in the outermost axial ply, whereas the maximum hoop stress is located in the innermost hoop ply. The reported maximum axial stresses in the all circ-wound cylinder constructions (G6-1 for the S-GLASS/ERL2258 system and C6-4 for the IM6/ERL2258 system) are used as the experimentally determined values for the allowable transverse compressive strengths. A slightly conservative approximation was made, and it was assumed that the S-GLASS/ERL2258 material had a transverse compressive strength of $45 \mathrm{ksi}$ and the IM6/ERL2258 material had a transverse compressive strength of $30 \mathrm{ksi}$.

It was discussed previously that accurate predictions for the in-plane strains were possible by modeling the laminated cylinder as a single homogeneous layer having equivalent smeared properties. However, this is not the case for predicting in-plane stresses, as seen by the smeared property CCAP results in Table 1.3.1-4 and Table 1.3.1-5. The single-layered composite cylinder analyses using smeared properties severely underpredict the maximum hoop and axial stresses. 
Table 1.3.1-4. Maximum axial stresses (ksi) for maximum test pressure

\begin{tabular}{|c|c|c|c|}
\hline \multirow[b]{2}{*}{ Cylinder ID } & \multicolumn{3}{|c|}{ Type of analysis } \\
\hline & CCAP (Layered) & CCAP (Smeared) & LST \\
\hline G6-1 & -48.064 & -48.064 & -47.42 \\
\hline G6-2 & -107.480 & $-59.990^{b}$ & -111.00 \\
\hline G6-3 & -104.370 & $-58.419^{b}$ & -108.00 \\
\hline G6-4 & -105.310 & $-67.115^{b}$ & -108.00 \\
\hline C6-1 & -177.496 & $-72.548^{b}$ & -181.60 \\
\hline C6-4 & -32.160 & $-32.160^{a}$ & -31.05 \\
\hline
\end{tabular}

Table 1.3.1-5. Maximum hoop stresses (ksi) for maximum test pressure

\begin{tabular}{|c|c|c|c|}
\hline \multirow[b]{2}{*}{ Cylinder ID } & \multicolumn{3}{|c|}{ Type of analysis } \\
\hline & CCAP (Layered) & CCAP (Smeared) & LST \\
\hline G6-1 & -94.813 & $-94.813^{a}$ & -83.75 \\
\hline G6-2 & -133.130 & $-117.640^{6}$ & -119.00 \\
\hline G6-3 & -124.510 & $-114.950^{b}$ & -111.00 \\
\hline$G 6-4$ & -164.110 & $-131.440^{b}$ & -147.00 \\
\hline C6-1 & -194.402 & $-136.620^{b}$ & -179.20 \\
\hline C6-4 & -72.270 & $-72.270^{a}$ & -62.92 \\
\hline
\end{tabular}

a Smeared results are from a single-layer analysis using layer properties.

b Smeared results are from a single-layer analysis using equivalent smeared orthotropic properties. 


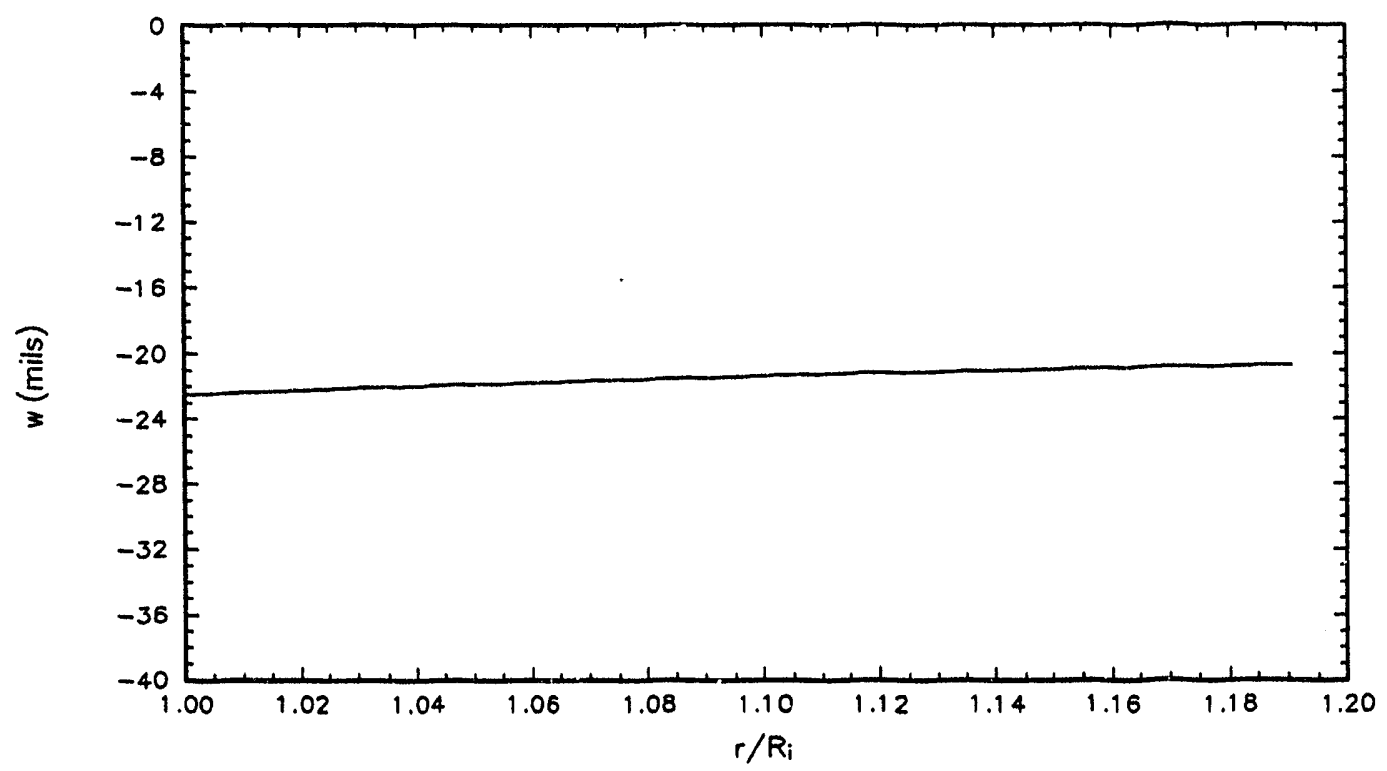

Fig. 1.3.1-2. Radial displacement for G6-1 at $13.8 \mathrm{ksi}$ hydrostatic pressure.

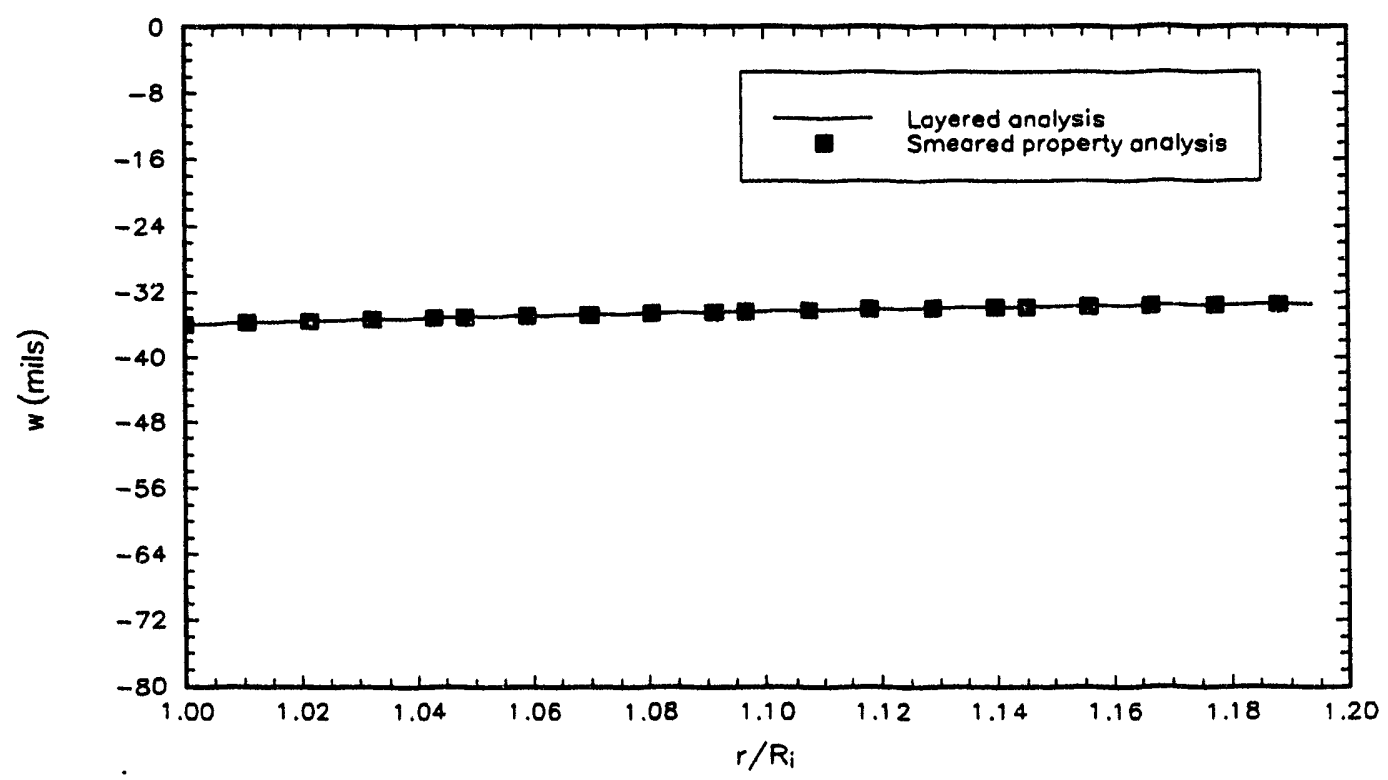

Fig. 1.3.1-3. Radial displacement for G6-2 at 17.4 ksi hydrostatic pressure. 


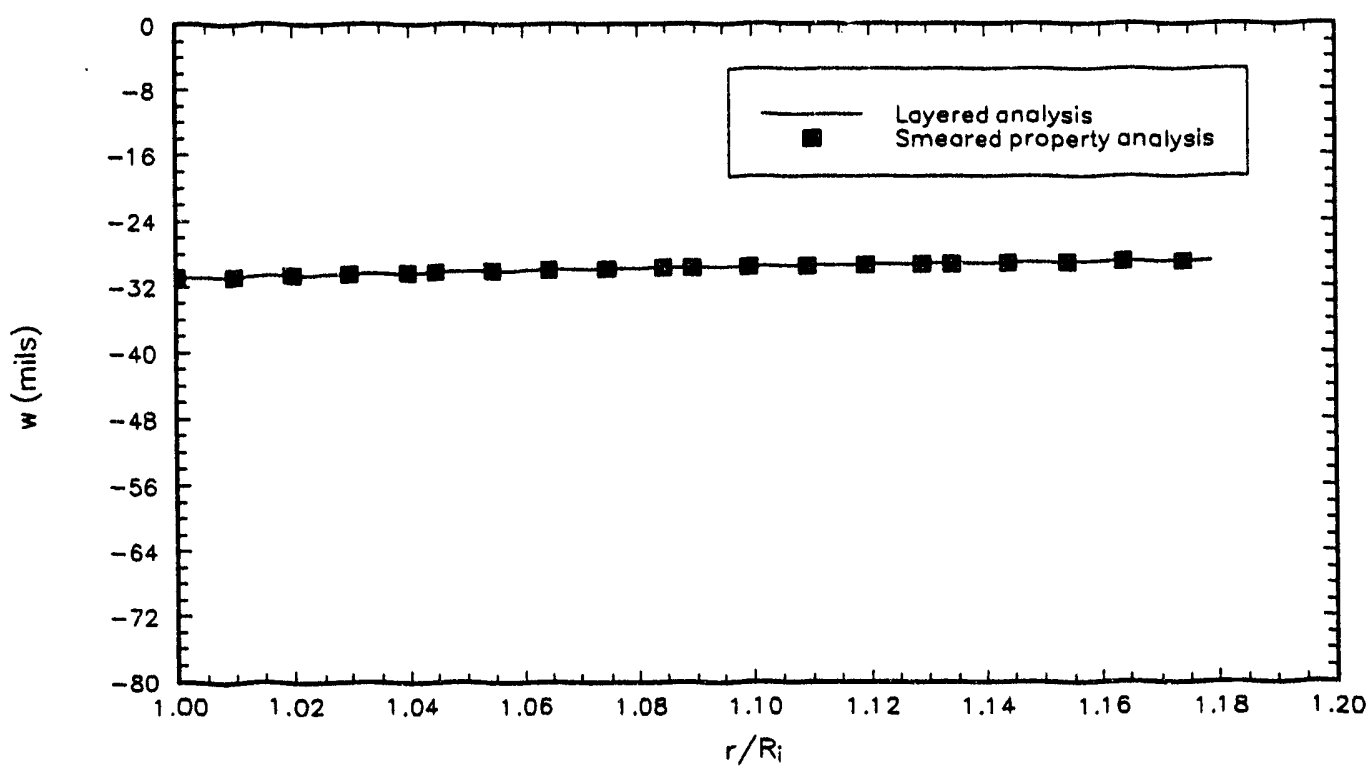

Fig. 1.3.1-4. Radial displacement for G6-3 at 16 ksi hydrostatic pressure.

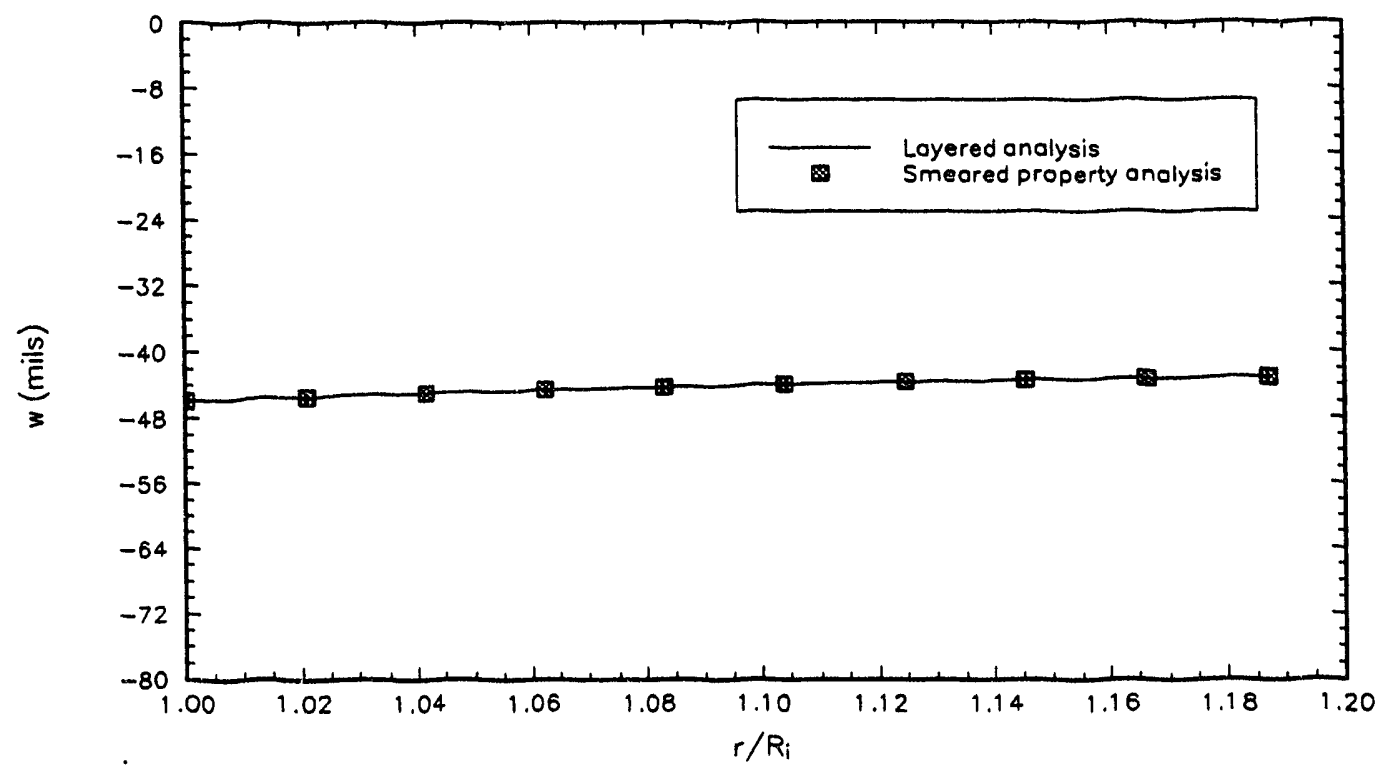

Fig. 1.3.1-5. Radial displacement for G6-4 at 19 ksi hydrostatic pressure. 


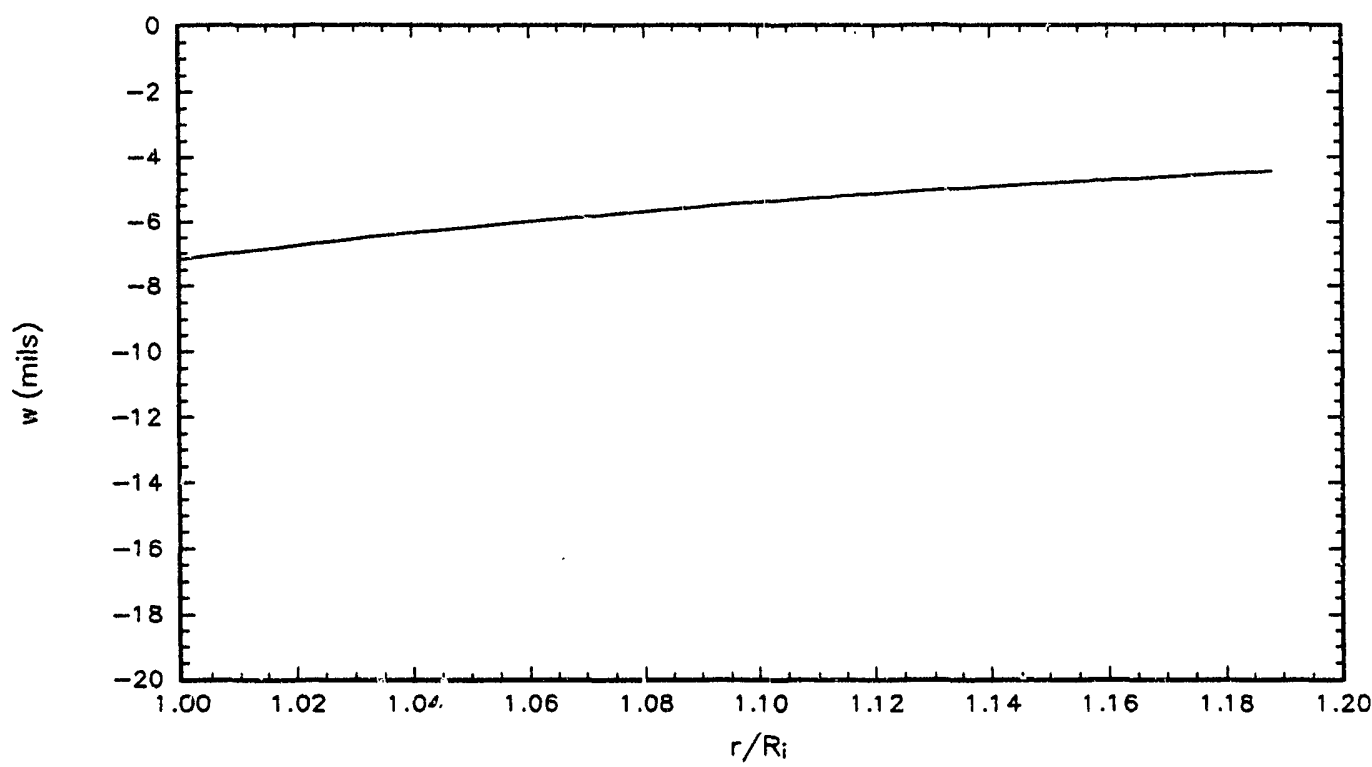

Fig. 1.3.1-6. Radial displacement for C6-4 ai 9 ksi hydrostatic presiure.

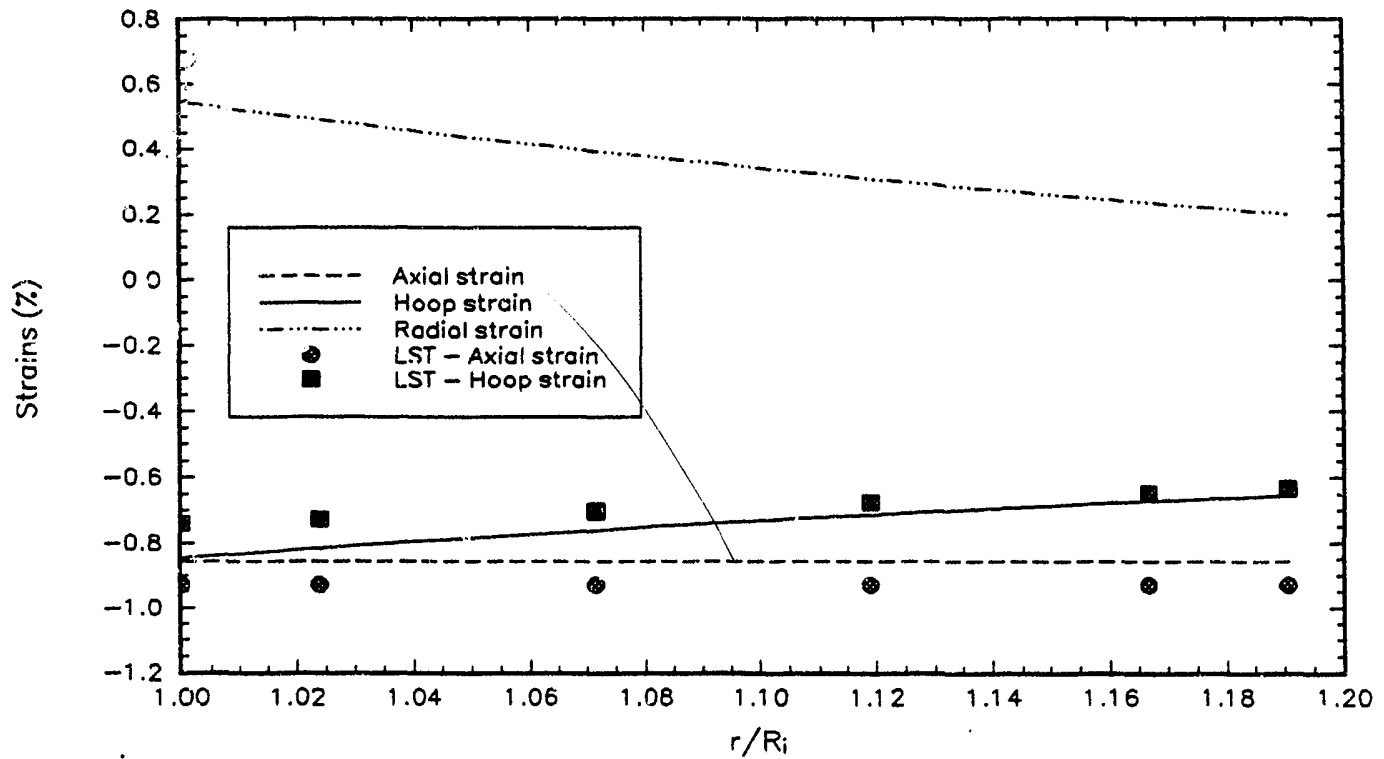

Fig. 1.3.1-7. Normal strains for G6-1 at 13.8 ksi hydrostatic pressure. 


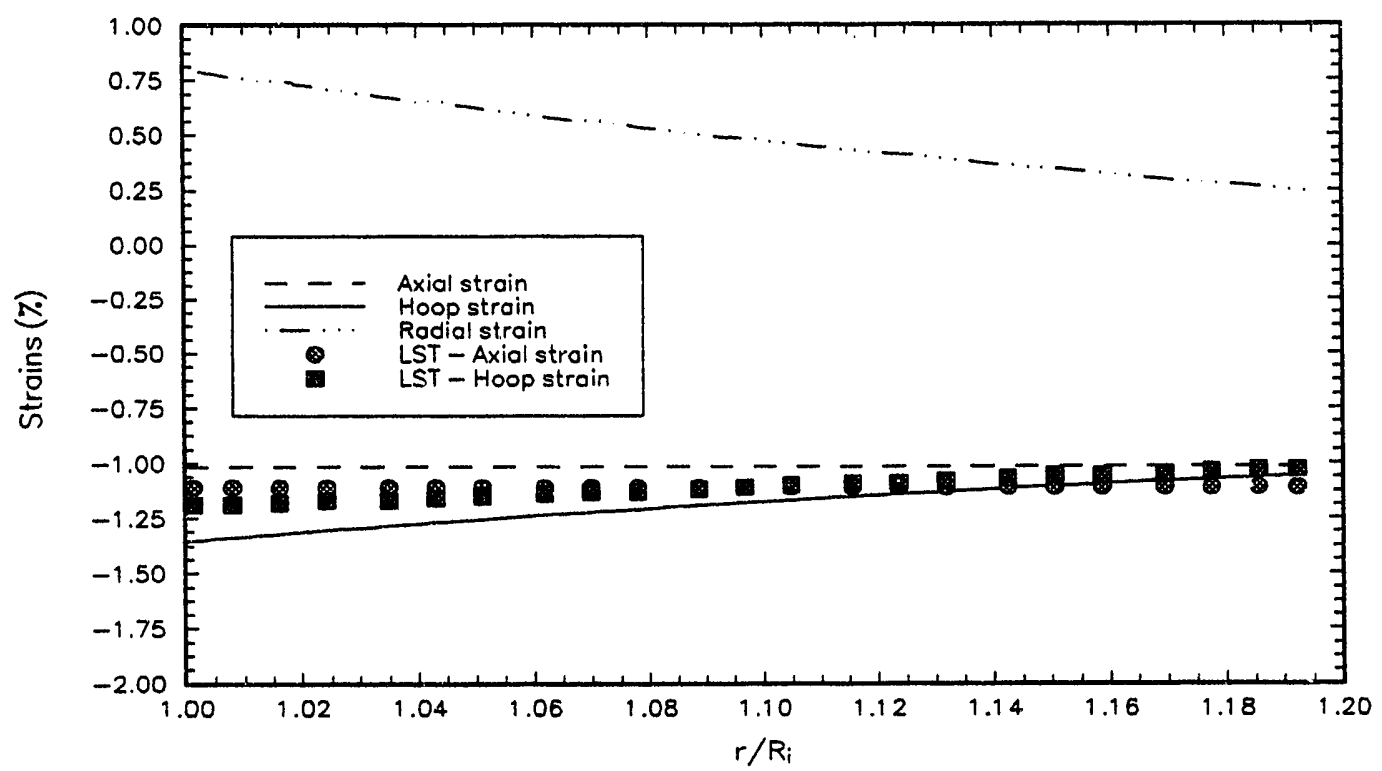

Fig. 1.3.1-8. Normal strains for G6-2 at 17.4 ksi hydrostatic pressure.

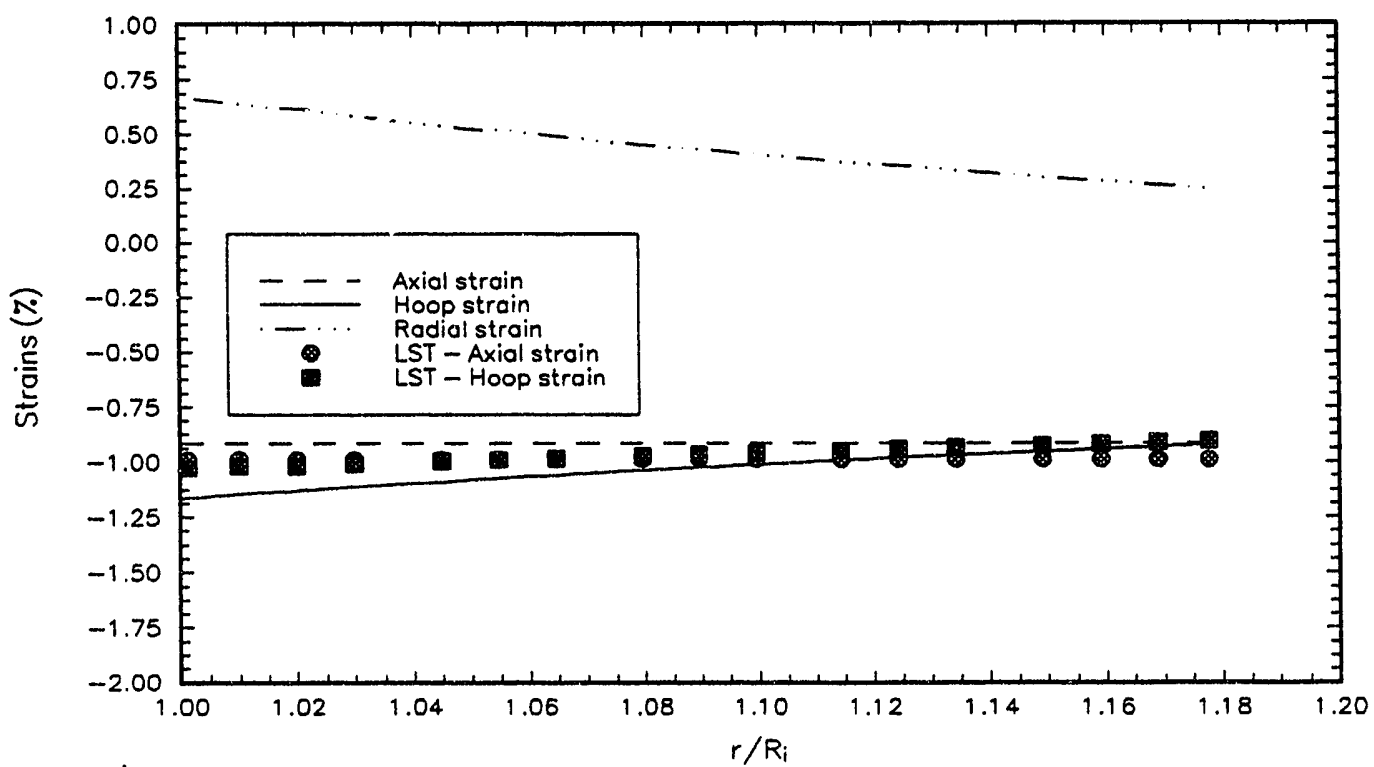

Fig. 1.3.1-9. Normal strains for G6-3 at 16 ksi hydrostatic pressure. 


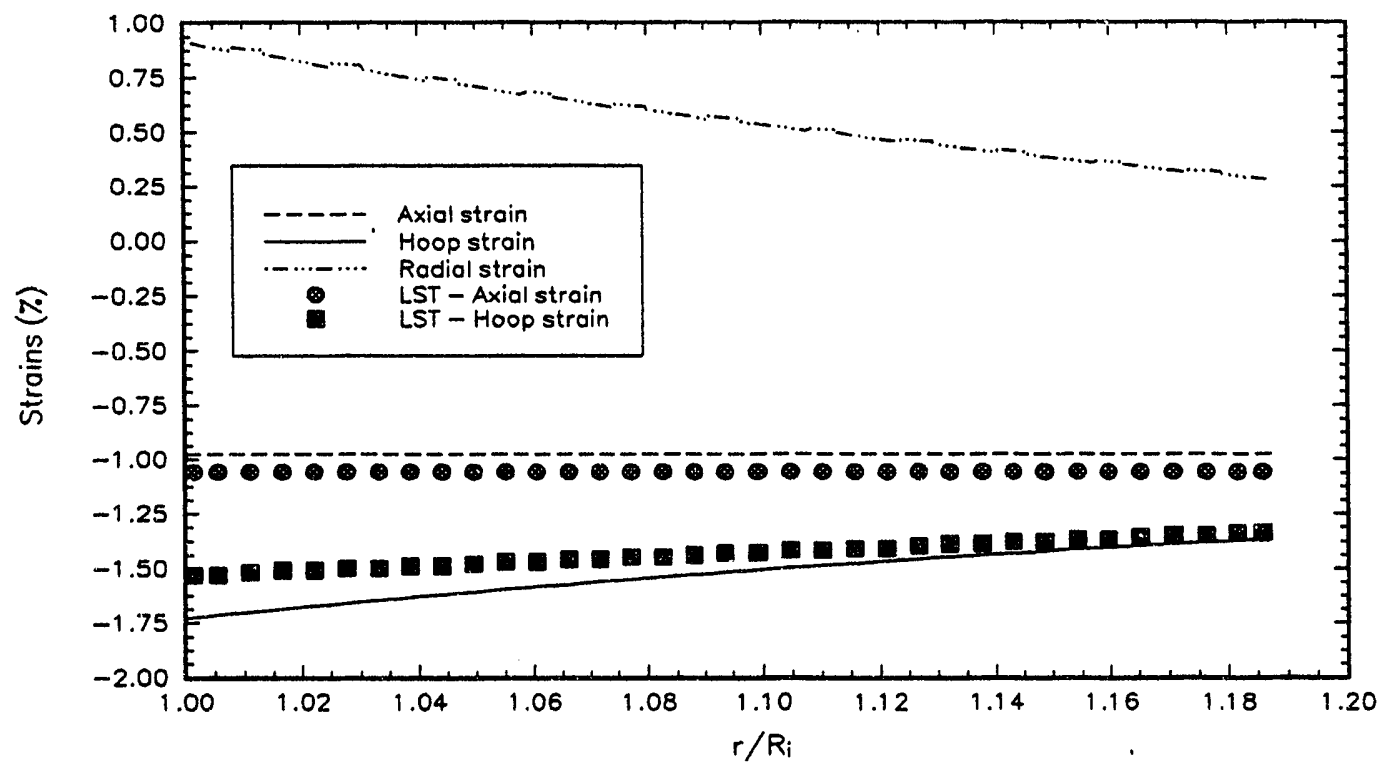

Fig. 1.3.1-10. Normal strains for G6-4 at $19 \mathrm{ksi}$ hydrostatic pressure.

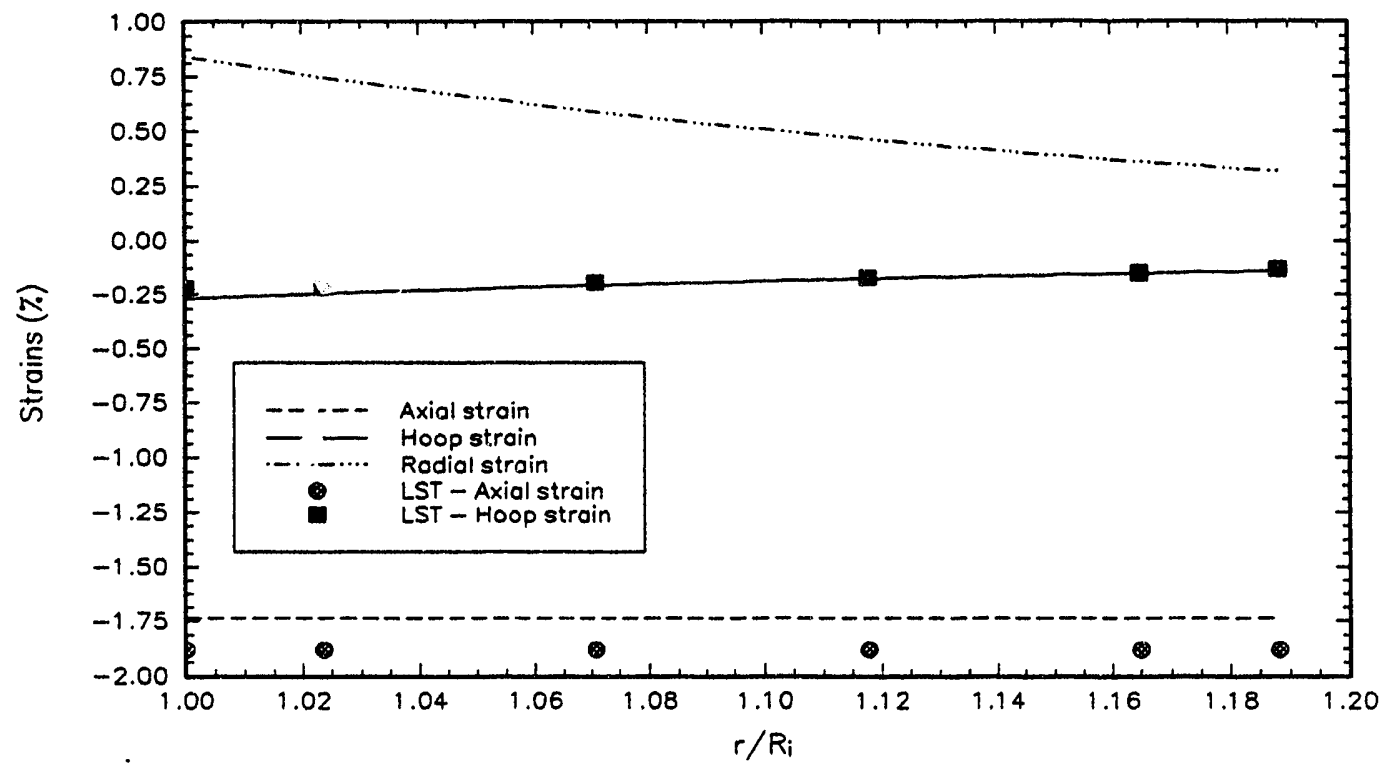

Fig. 1.3.1-11. Normal strains for C6-4 at 9 ksi hydrostatic pressure. 


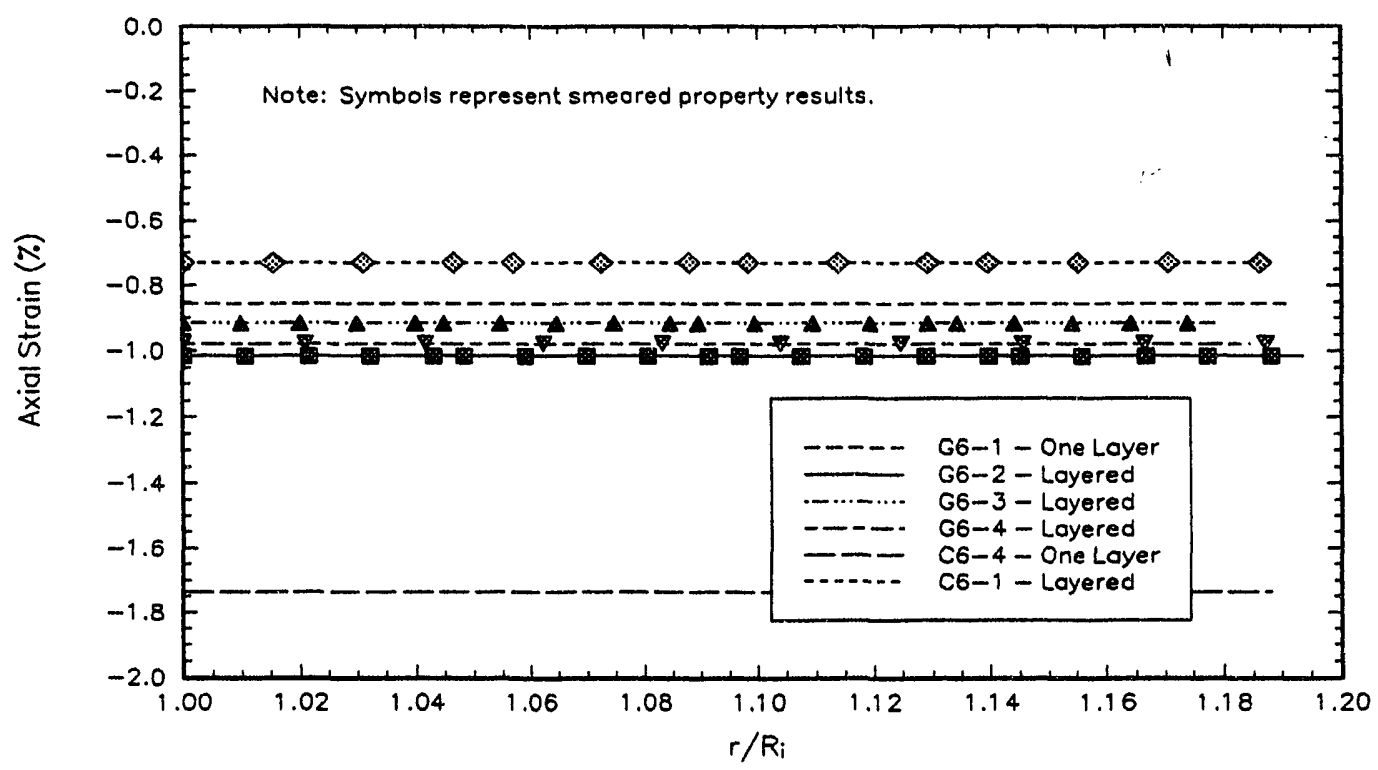

Fig. 1.3.1-12. Axial strain comparison.

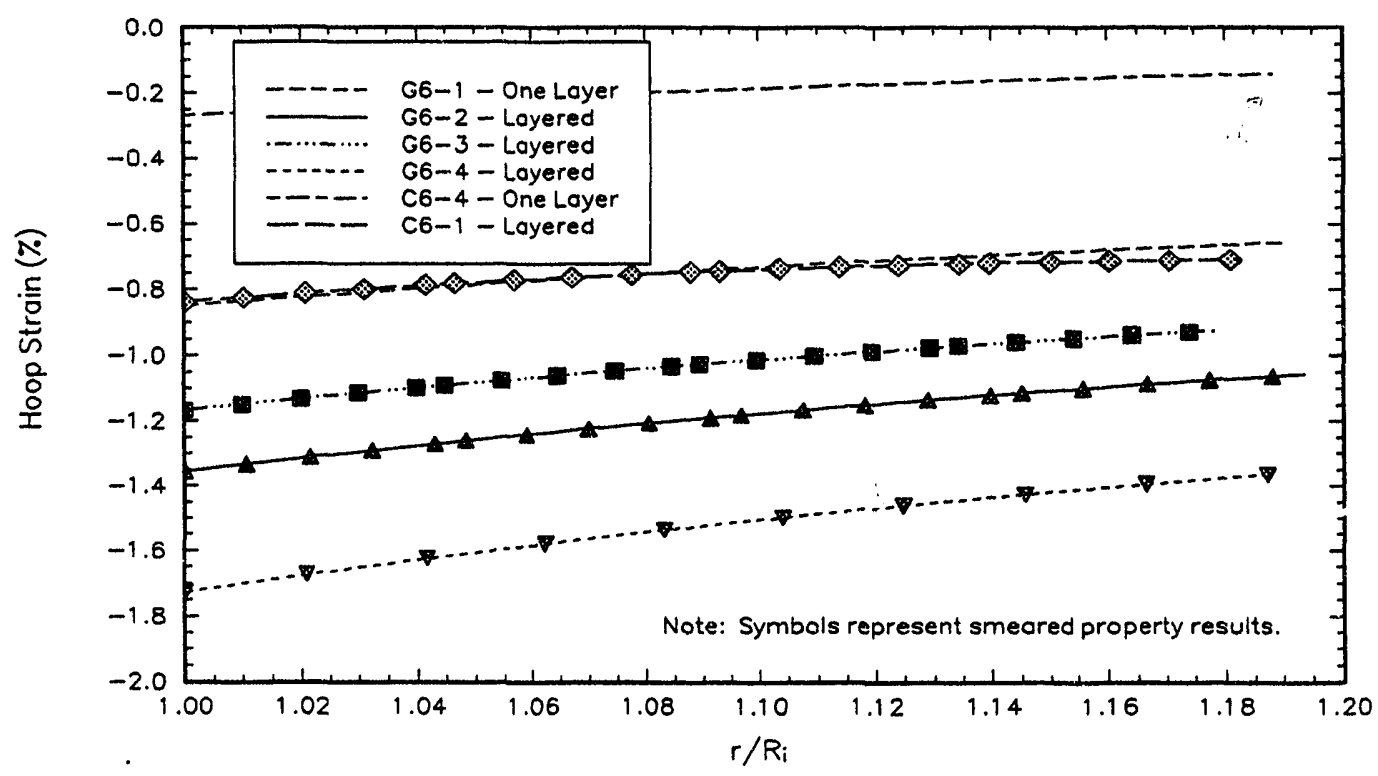

Fig. 1.3.1-13. Hoop strain comparison. 


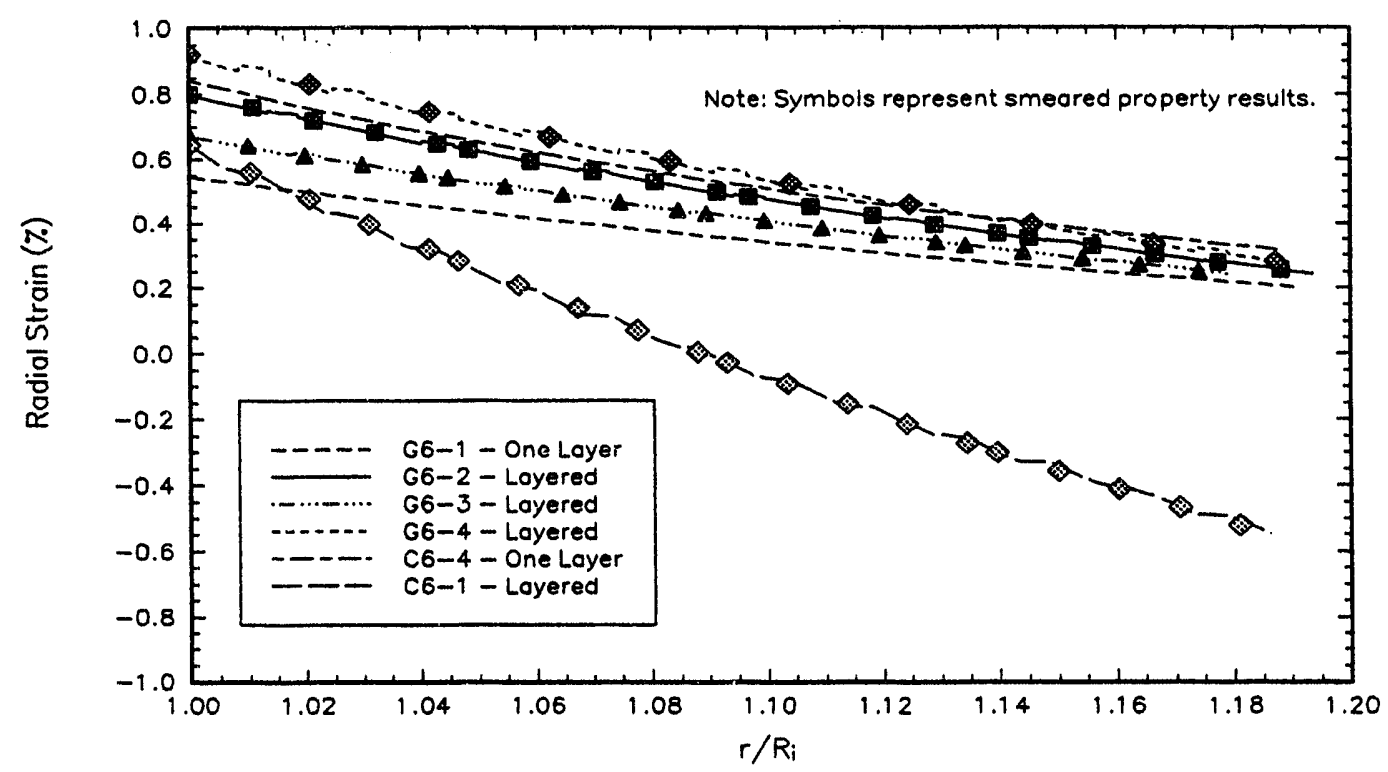

Fig. 1.3.1-14. Radial strain comparison.

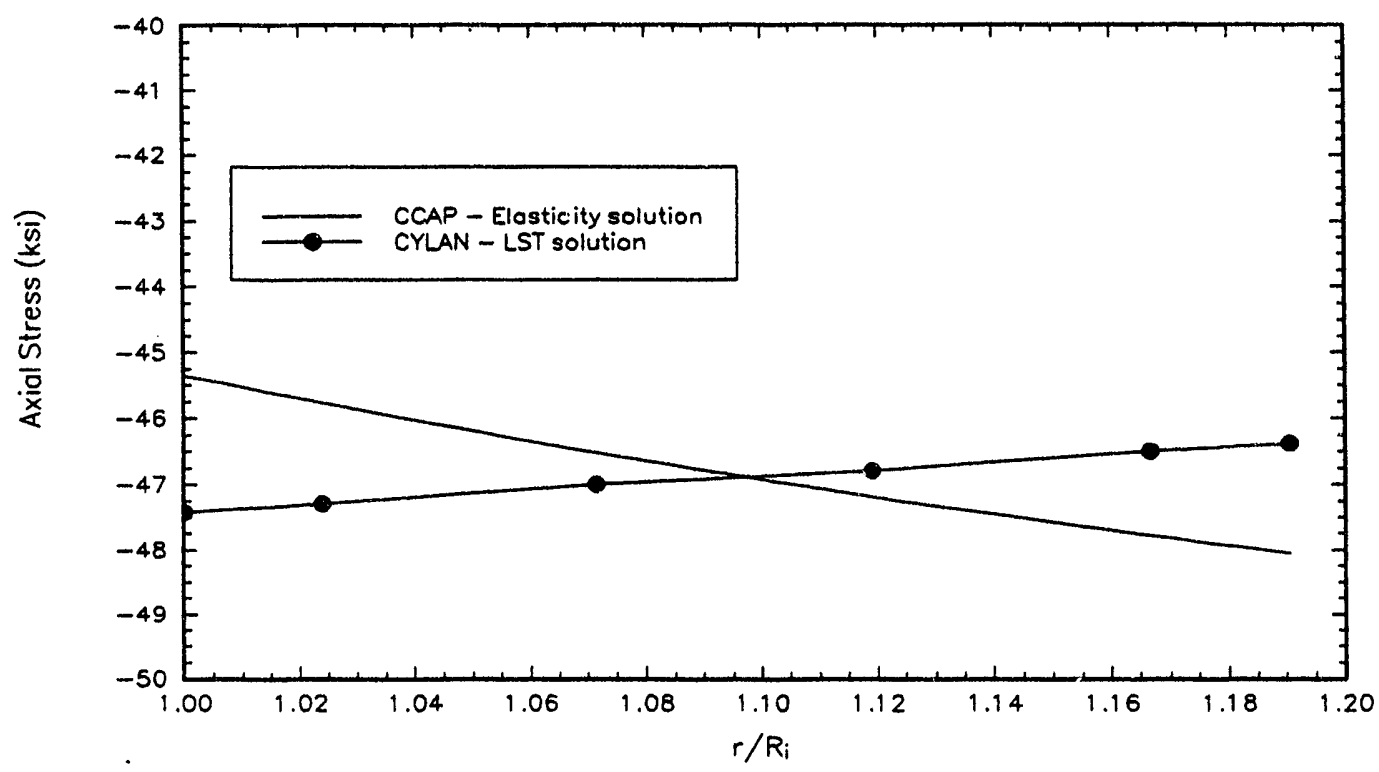

Fig. 1.3.1-15. Axial stress for G6-1 at $13.8 \mathrm{ksi}$ hydrostatic pressure. 


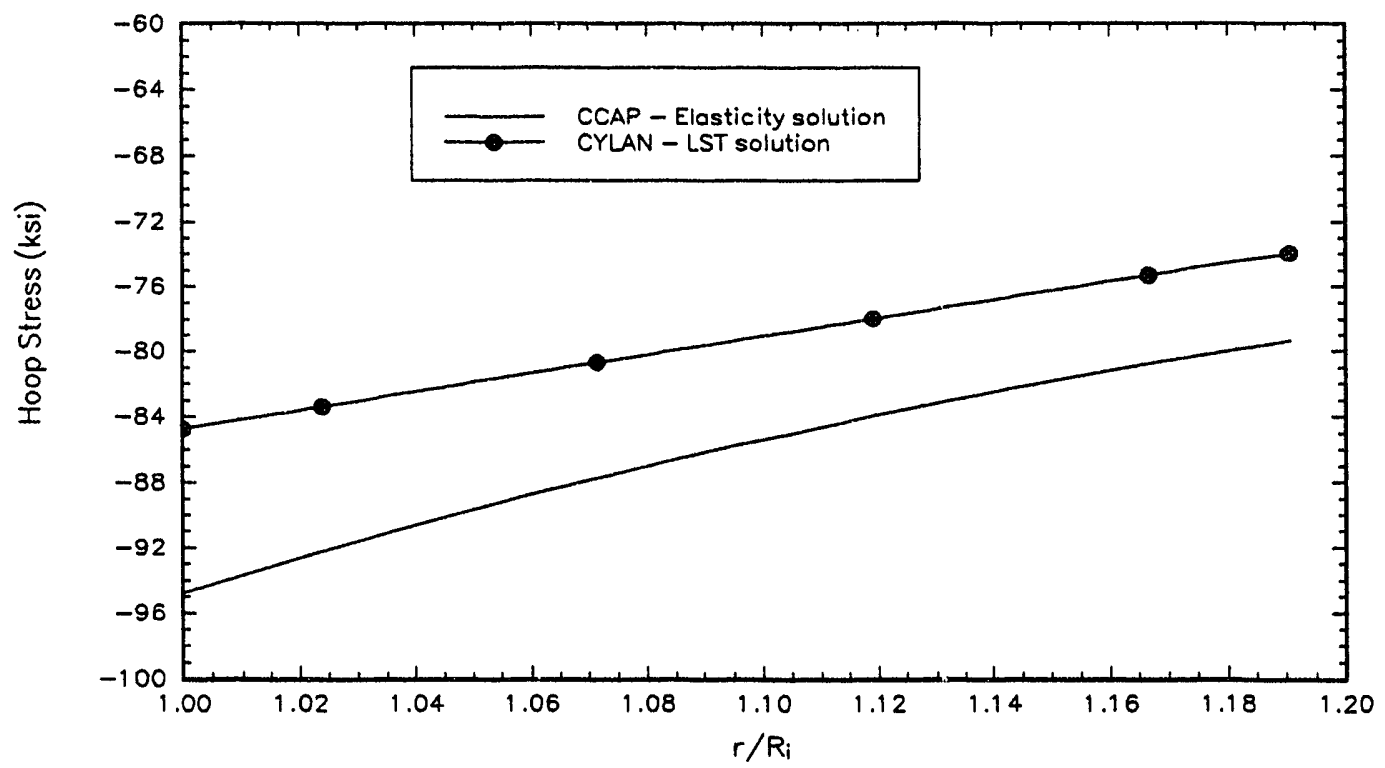

Fig. 1.3.1-16. Hoop stress for G6-1 at 13.8 ksi hydrostatic pressure.

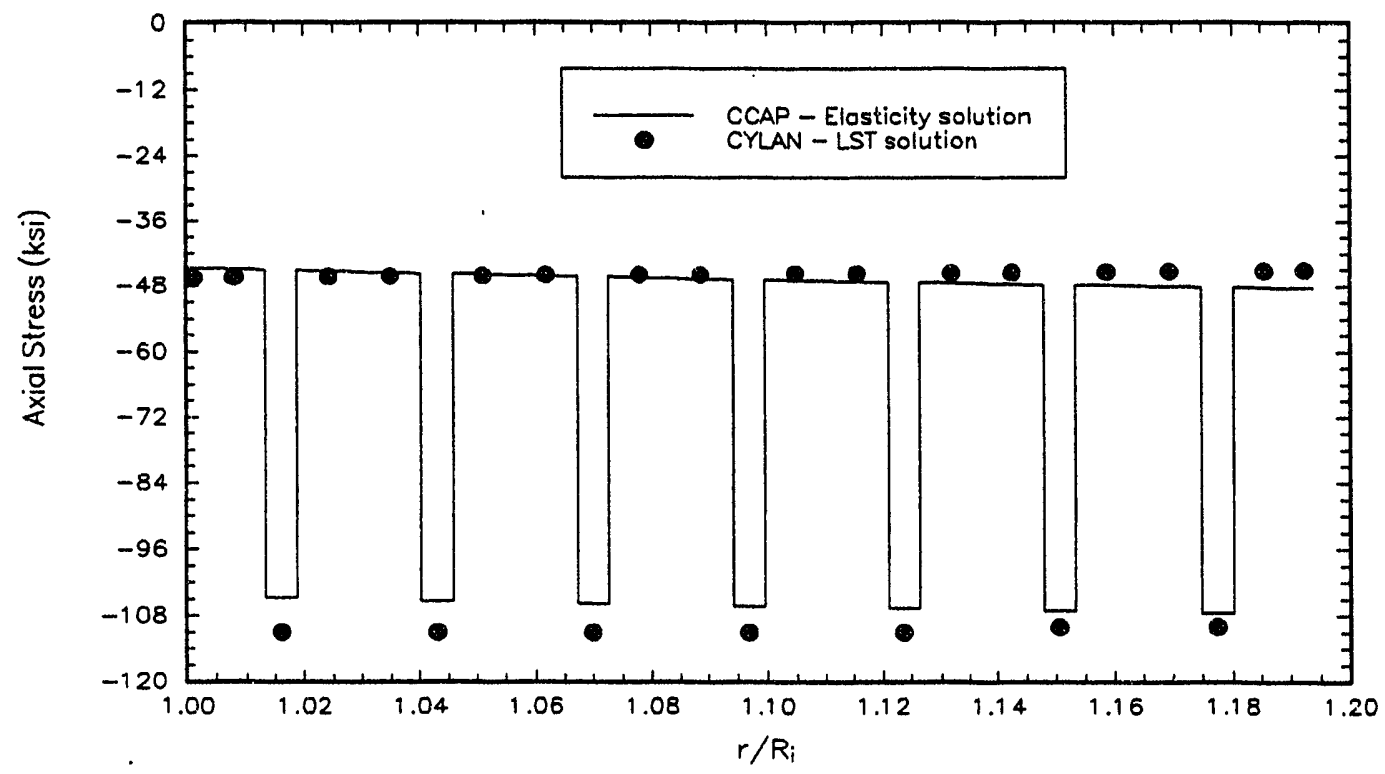

Fig. 1.3.1-17. Axial stress for G6-2 at 17.4 ksi hydrostatic pressure. 


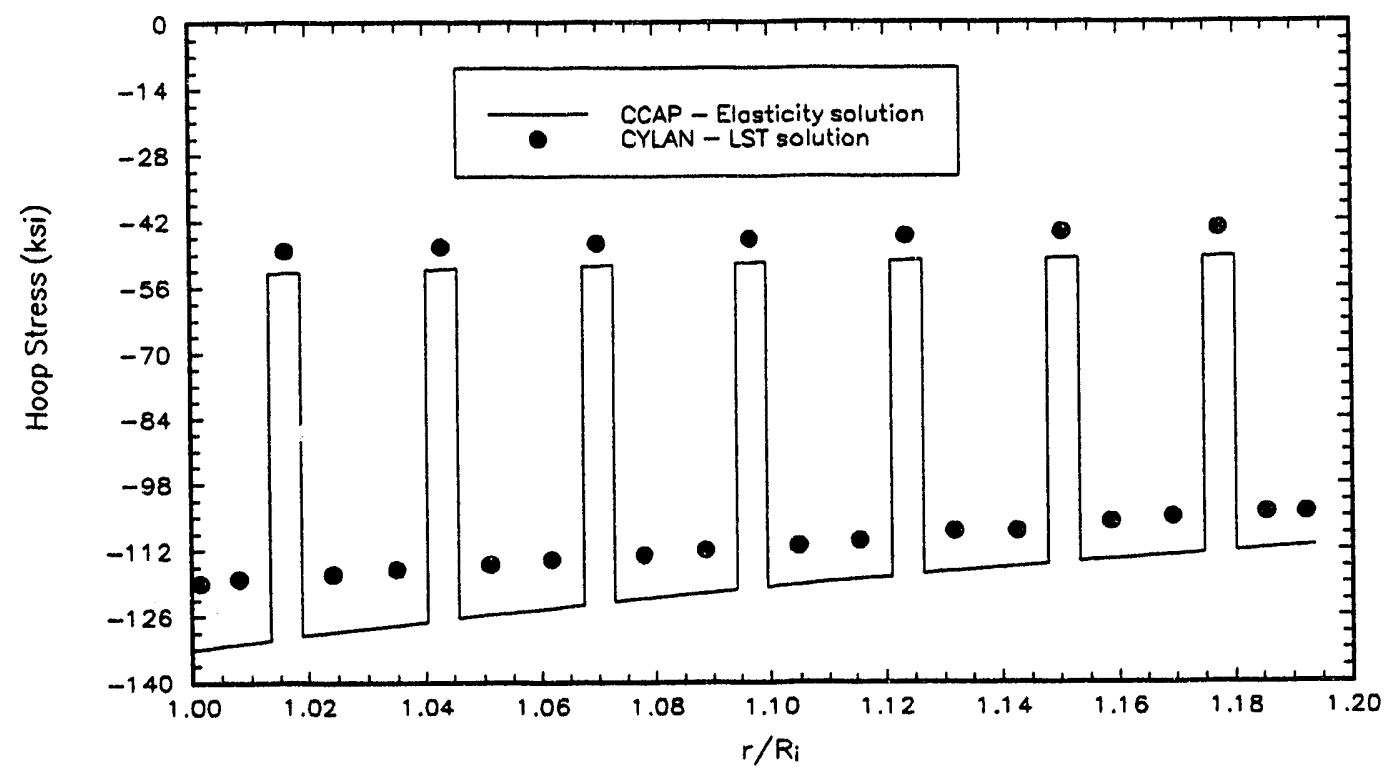

Fig. 1.3.1-18. Hoop stress for G6-2 at 17.4 ksi hydrostatic pressure.

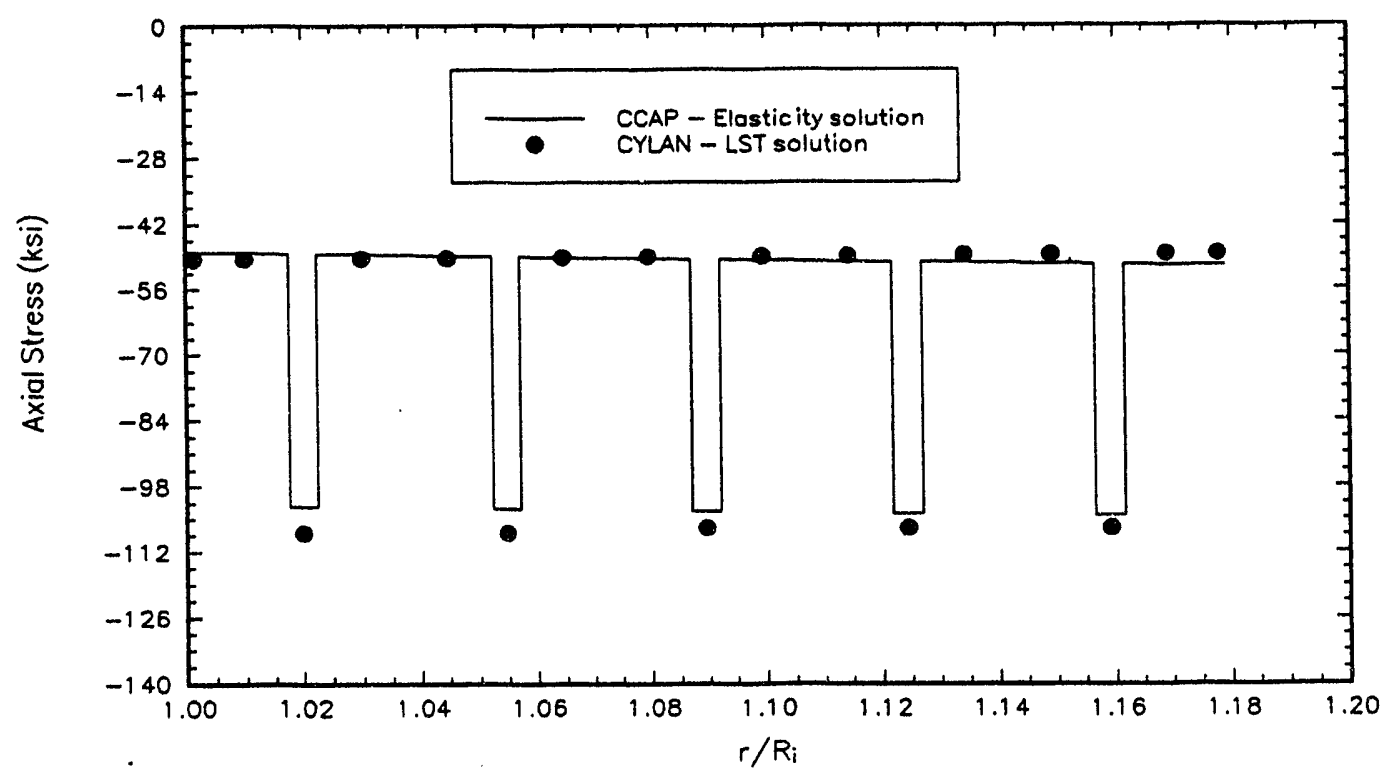

Fig. 1.3.1-19. Axial stress for G6-3 at 16 ksi hydrostatic pressure. 


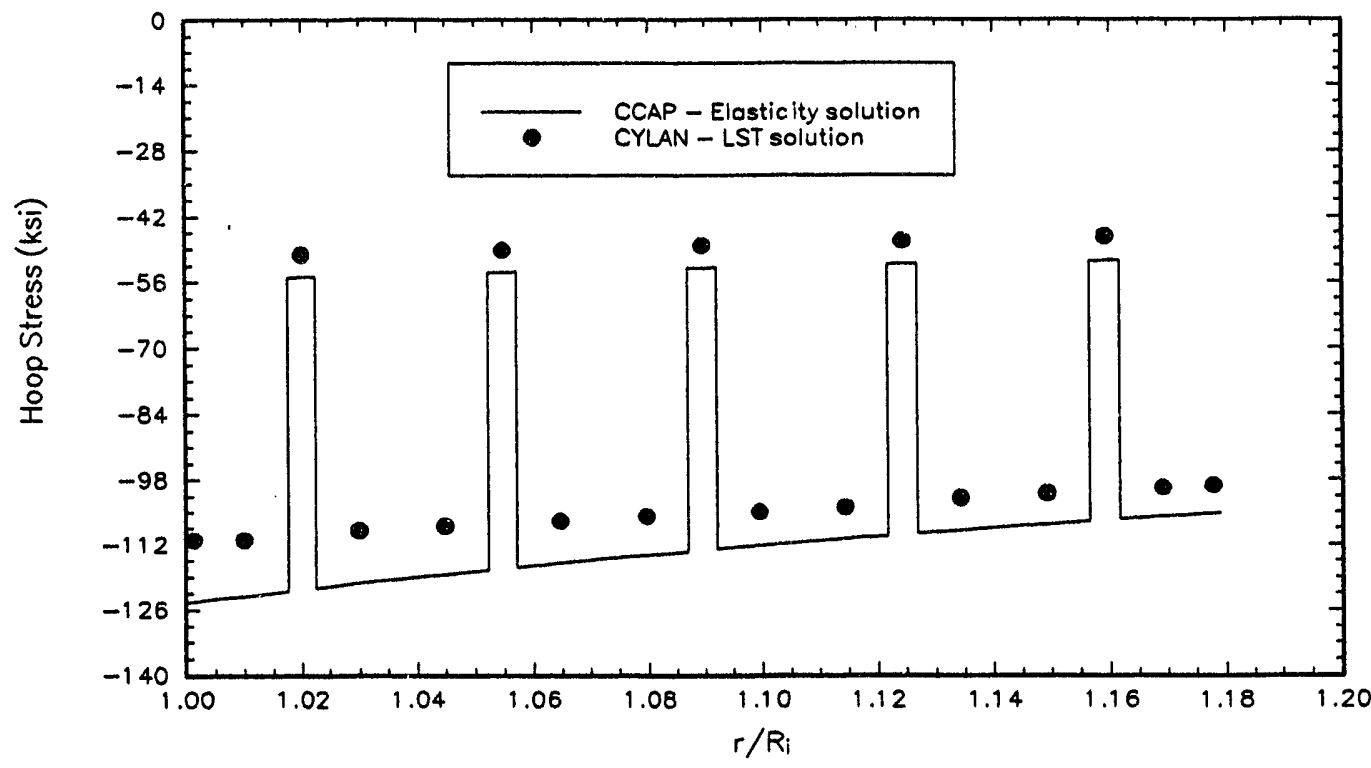

Fig. 1.3.1-20. Hoop stress for G6-3 at 16 ksi hydrostatic pressure.

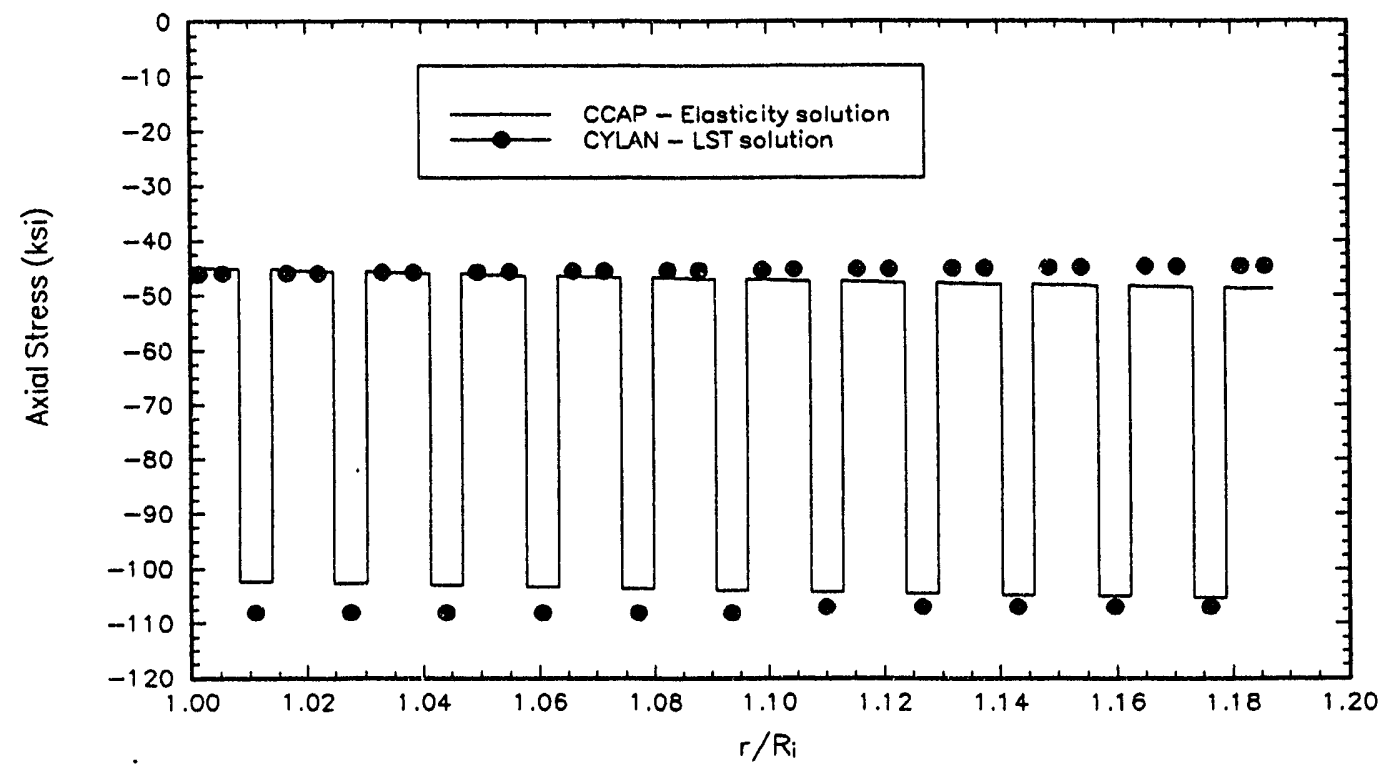

Fig. 1.3.1-21. Axial stress for G6-4 at 19 ksi hydrostatic pressure. 


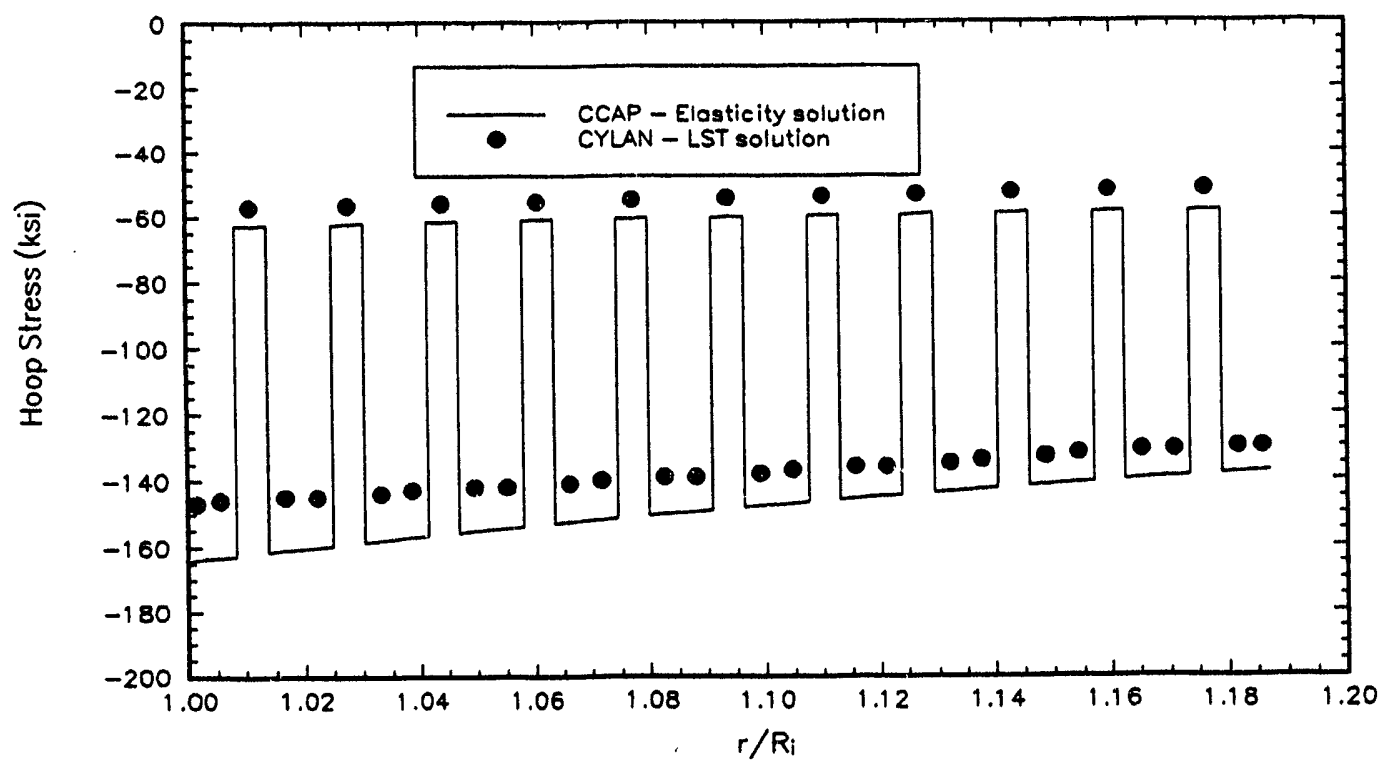

Fig. 1.3.1-22. Hoop stress for G6-4 at 19 ksi hydrostatic pressure.

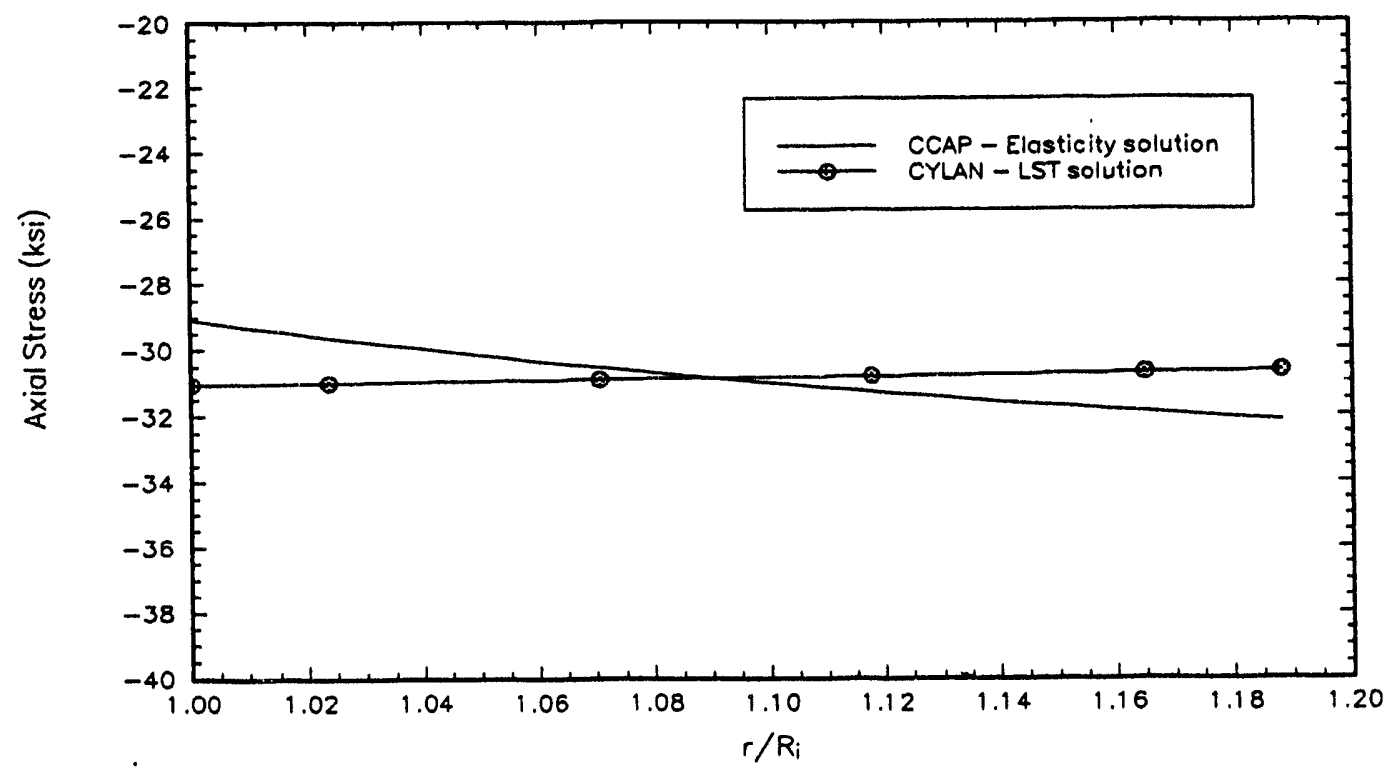

Fig. 1.3.1-23. Axial stress for C6-4 at 9 ksi hydrostatic pressure. 


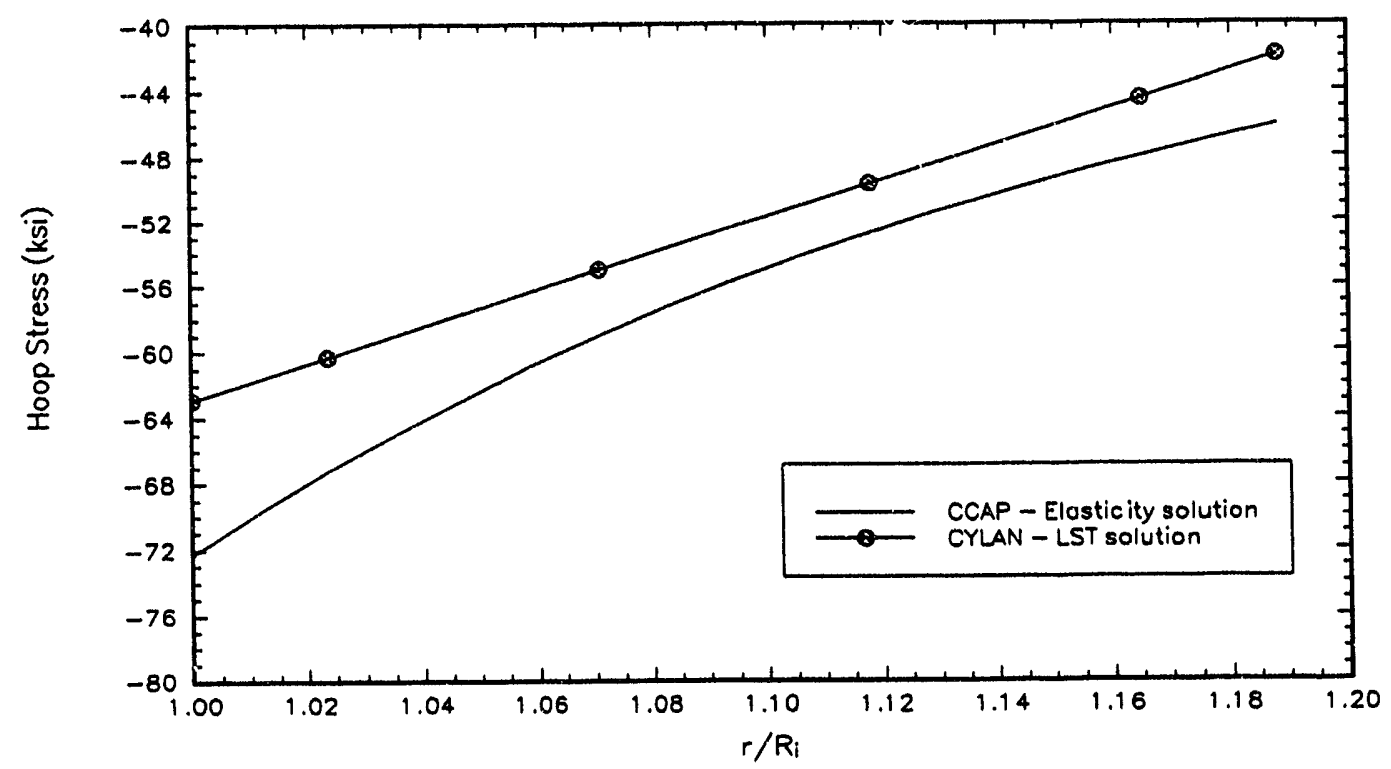

Fig. 1.3.1-24. Hoop stress for C6-4 at 9 ksi hydrostatic pressure. 


\subsubsection{Finite Element Results}

Stress analysis results from the FE model of the test assembly are summarized in this section. All of the test cylinder assemblies utilized the end closures designed by Blake.,12 A separate design was done for each cylinder. An axisymmetric FE model of the cylinder test assembly was constructed for analysis with the FE program NIKE2D written by Lawrence Livermore National Laboratory (LLNL). ${ }^{10}$ The model was generated using the LLNL mesh generation program MAZE. ${ }^{16}$ Postprocessing of the analysis results from NIKE2D was done using the LLNL program ORION. ${ }^{17}$ A typical model outline is shown in Fig. 1.3.2-1. The model included only one quadrant of the test assembly cross section, as shown in Fig. 1.3.2-1. This "one-quarter" model was sufficient because of the axisymmetric geometry and symmetry of the stress distributions at the cylinder midplane. The model is described in detail in Refs. 6 and 12.

The finite element mesh is shown in Fig. 1.3.2-2. The elements in this model were 2-D, four-noded, axisymmetric, quadrilateral, isoparametric, solid elements. The NIKE2D code has only the four-noded quadrilateral element in its element library. These elements are essentially linear and use a low order of interpolation and numerical integration. This type of element requires a relatively fine mesh to reduce discretization errors and to provide the required accuracy. The model in Fig. 1.3.2-2 contained 1868 elements and 2083 nodes. The model had a total of 4160 unconstrained degrees of freedom.

An incremental nonlinear solution method was applied with the pressure increasing incrementally in accordance with a linear increase from 0 psig to the maximum test pressure. The load was applied in equal load increments. Equilibrium iterations and stiffness matrix reformations were permitted at each load step. The solution converged over the entire range of pressures within the tolerances prescribed.

The analysis results were postprocessed with the ORION code. In general, several types of plots were generated at selected load states. These included contour plots of the displacements, stresses and strains; displaced outline plots; and interface plots. Line plots of selected variables were also produced for selected boundary lines on the cylinder. The line plots give the variation of the selected variable along the chosen boundary. Line plots are selected for free edges or planes of symmetry. Interface plots are produced for contacting surfaces.

The displaced outline plots are particularly useful for visualizing the deformations and the relative displacement of mating parts during the load application. In this case, the displaced outline plots show the closing of the clearance between the cylinder and end plug as pressure was increased. This was used to verify the end plug design calculations.

Contour plots were generated for displacements, stresses, and strains for several different pressure values. The stress contours are the smeared composite stresses rather than layer stresses. Layer stress values can be estimated from the composite stress values given the ply ratio of the layup. The strain values apply to either the layered or smeared materials because of strain compatibility in the laminate formulation. 
Contour plots are presented for the radial displacement, axial stress, hoop stress, and $\mathrm{RZ}$ shear stress in each of the six cylinders tested. The axial stress and shear stress plots are used to determine the peak bending and shear stress in the cylinder near the end of the plug. Typically, several plots are done using selected values for the contour range limits to precisely determine the pec: values for each stress component. The cylinders consist of the five cylinders described herein and the C6-1 cylinder. Results are given for the maximum pressure attained in the test of each cylinder.

The FE results for the 2:1 hoop:axial graphite/epoxy cylinder, C6-1, are presented in Figs. 1.3.2-3 through 1.3.2-6 for the radial displacement, axial stress, hoop stress, and RZ shear stress, respectively. In Fig. 1.3.2-3, the maximum radial displacement contour is -22.0 mils which is in excellent agreement with the elasticity solution result in Table 1.3.1-1. The radial displacement contours also illustrate a uniform radial displacement across the cylinder wall at the midbay. In addition, This figure shows that at the maximum test pressure the clearance between the end closure and the cylinder wall is completely consumed.

In Figs. 1.3.2-7 through 1.3.2-10, the FE results are shown for C6-4 (the circ-wound graphite-reinforced cylinder). The maximum radial displacement contour in Fig. 1.3.2-7 corresponds to -6.7 mils. The contour closest to the outer radius of the cylinder wall shows a radial displacement of -4.5 mils. Both of these results are in good agreement with the results from the elasticity solution in Table 1.3.1-1. The FE results for the axial stress, hoop stress, and RZ shear stress are plotted in Figs. 1.3.2-8, 1.3.2-9, and 1.3.2-10, respectively.

The contours of radial displacement for the circ-wound glass-reinforced cylinder, G6-1, are shown in Fig. 1.3.2-11. Again, the magnitudes of the radial displacement from the FE results are in good agreement with the elasticity solution results (see Table 1.3.1-1). From Fig. 1.3.2-11, a clearance is shown to still exist between the end closure and the cylinder wall at the maximum test pressure. In Figs. 1.3.2-12, 1.3.2-13, and 1.3.2-14, the FE results for the axial stress, hoop stress, and RZ shear stress, respectively, are shown.

The contours of radial displacement, axial stress, hoop stress, and RZ shear stress for the 4:1 hoop:axial glass/epoxy cylinder, G6-2, are shown in Figs. 1.3.2-15, 1.3.2-16, 1.3.2-17, and 1.3.2-18, respectively. The same set of plots for the 6:1 hoop:axial glass/epoxy cylinder, G6-3, are presented in Figs. 1.3.2-19 through 1.3.2-22. In both cylinders, the agreement between the $\mathrm{FE}$ analysis and the elasticity solution results for radial displacement is very good (see Fig. 1.3.2-15, Fig. 1.3.2-19, and Trijle 1.3.1-1).

The FE results for the 2:1 hoop:axial glass/epoxy cylinder, G6-4, are plotted in Figs. 1.3.2-23 through 1.3.2-26 for the radial displacement, axial stress, hoop stress, and RZ shear stress, respectively. As previously described for the other cylinders, the FE results for the radial displacement are in excellent agreement with the elasticity solution results. Also, as described for C6-1, the clearance between the end closure and the G6-4 cylinder wall is completely consumed at the maximum test pressure.

Based on the FE results given in Table 1.3.2-1, the axial bending stress is typically less than 5000 psi and the maximum shear stress is less than 1000 psi for all the cylinders. For the purpose of comparison, the laminated shell solution results for the maximum bending stress and maximum shear stress are provided in Table 1.3.2-1. The shell solution results 
typically tend to overpredict the maximum bending and shear stress when compared with the $\mathrm{FE}$ results. The procedure used in calculating the peak bending and shear stress is described in Appendix A of Refs. 6 and 12. The details of the laminated shell solution are given by Blake and Starbuck ${ }^{18}$. 


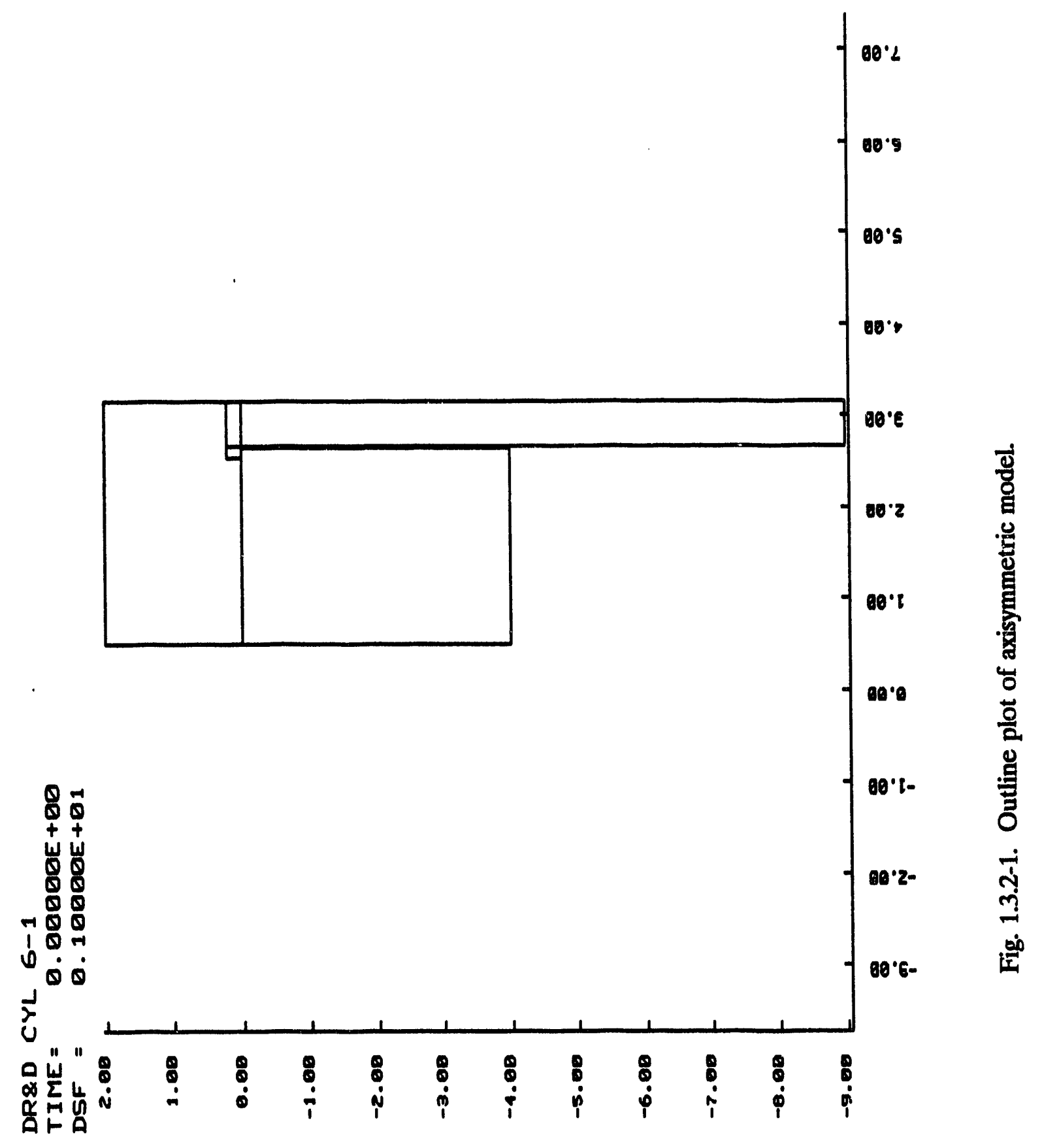




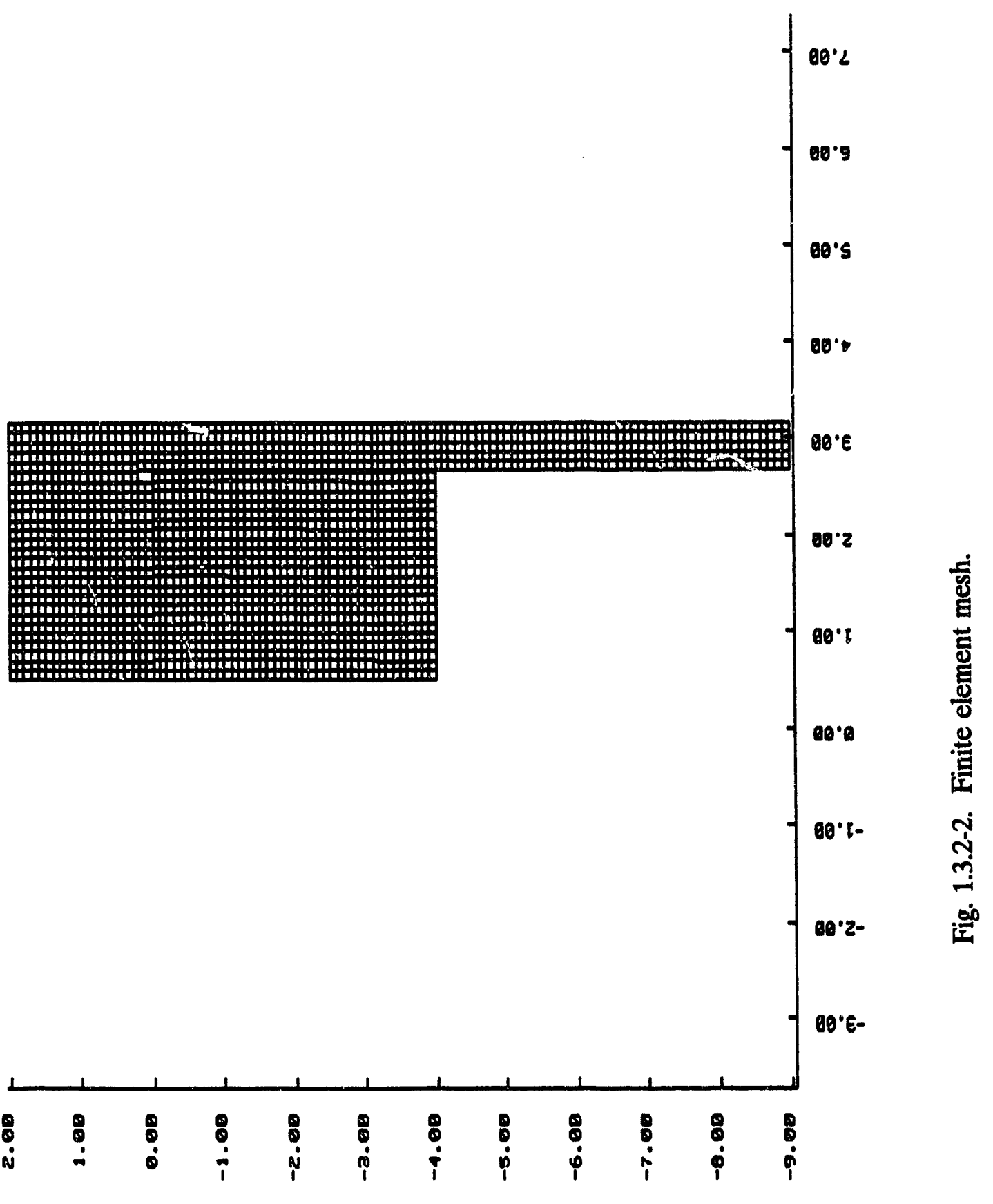




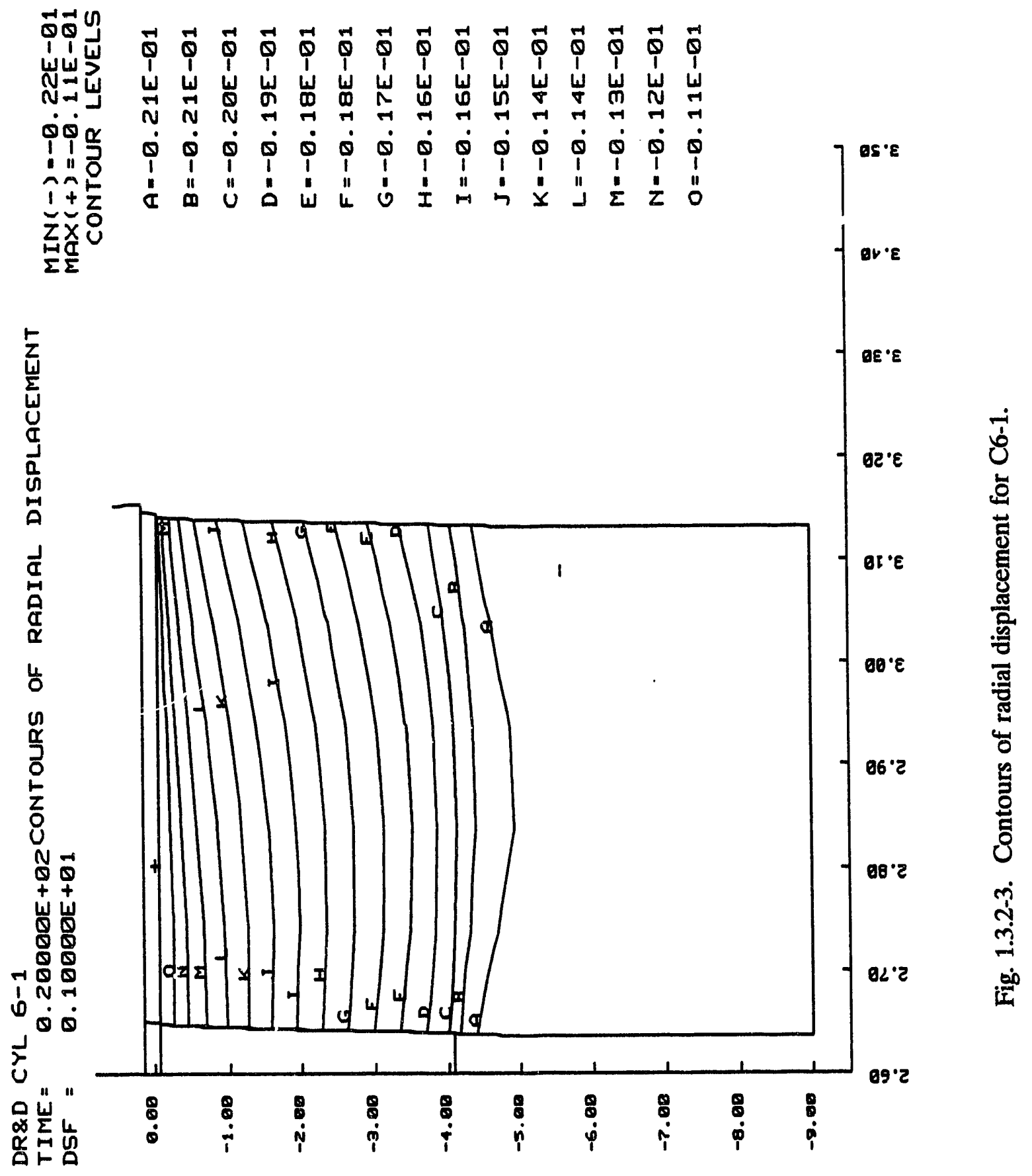




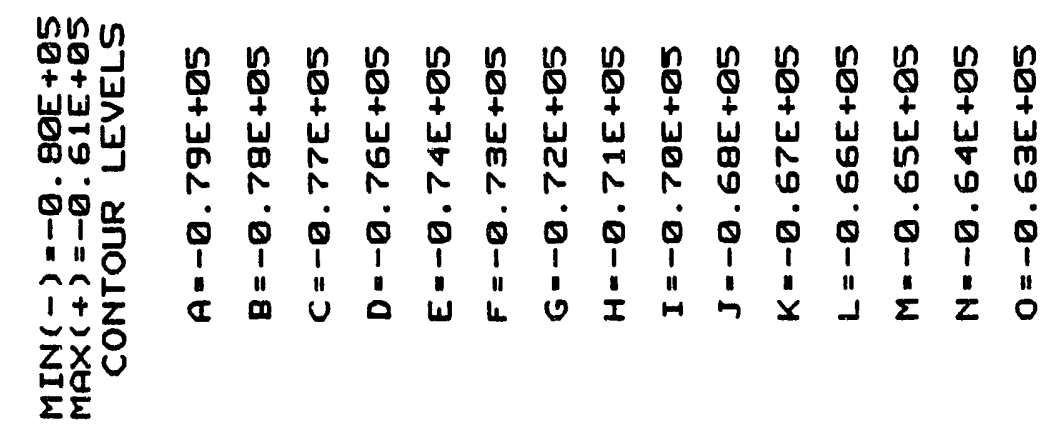

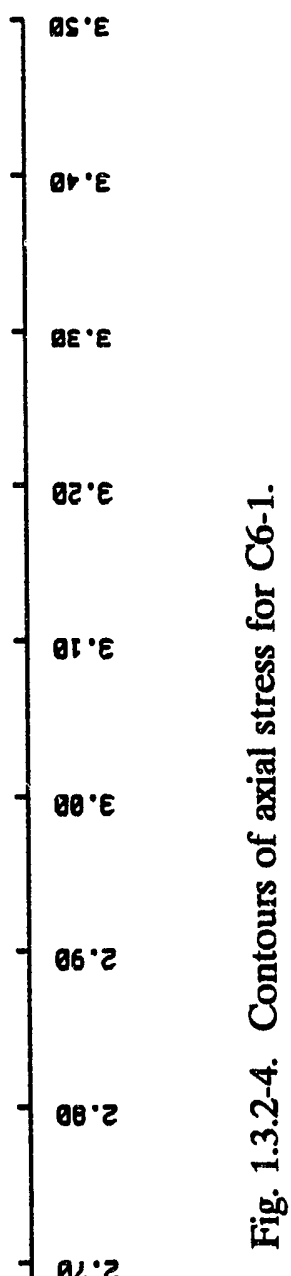

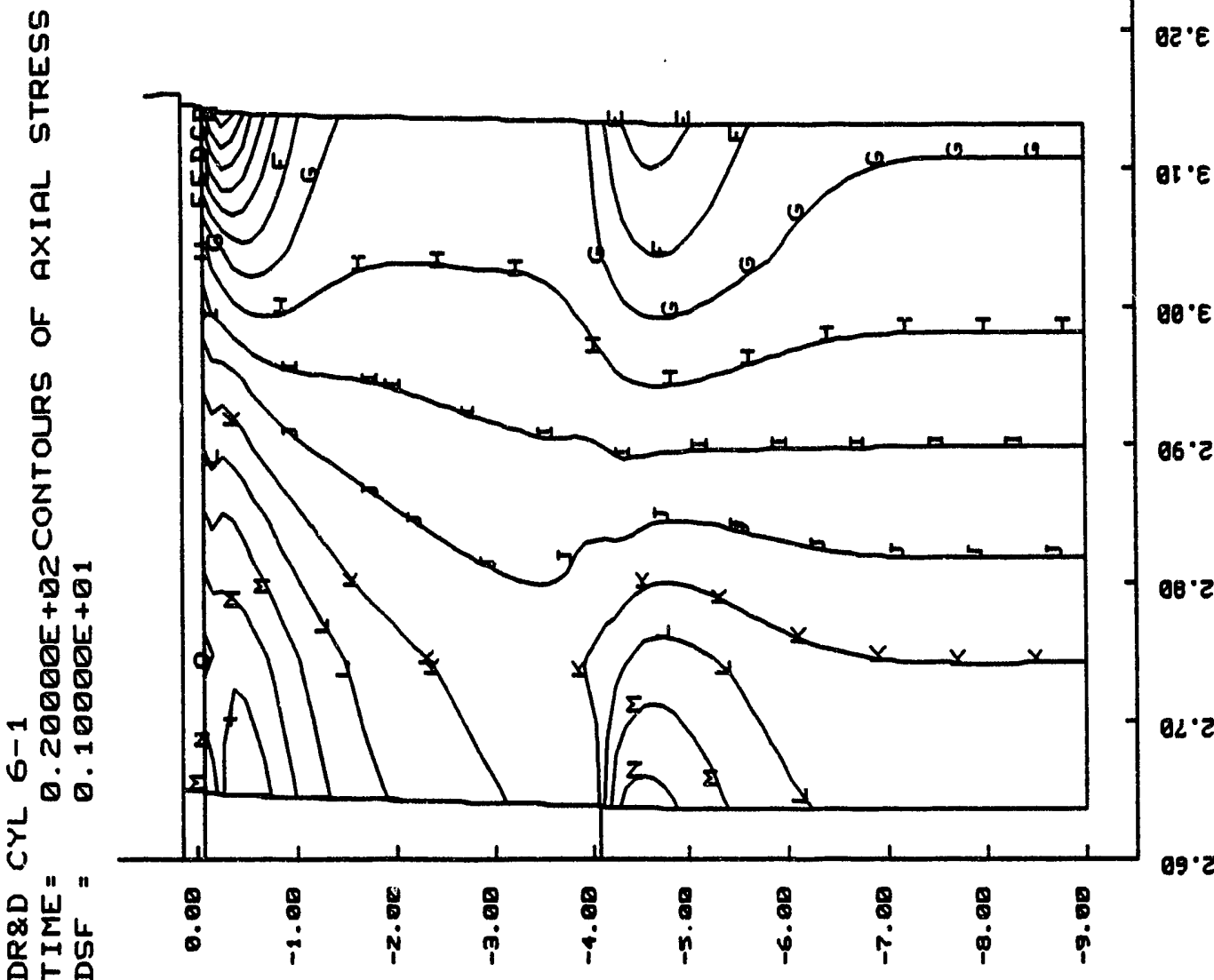




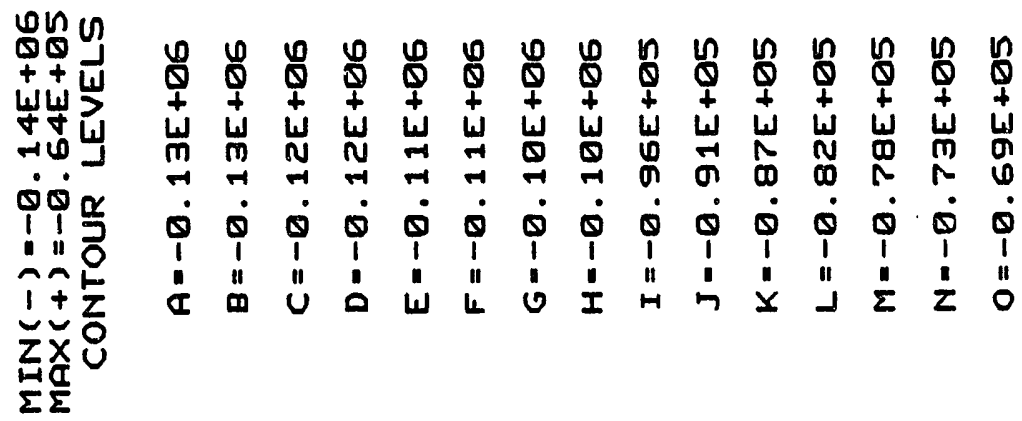

G

0
0
0
0
0
0

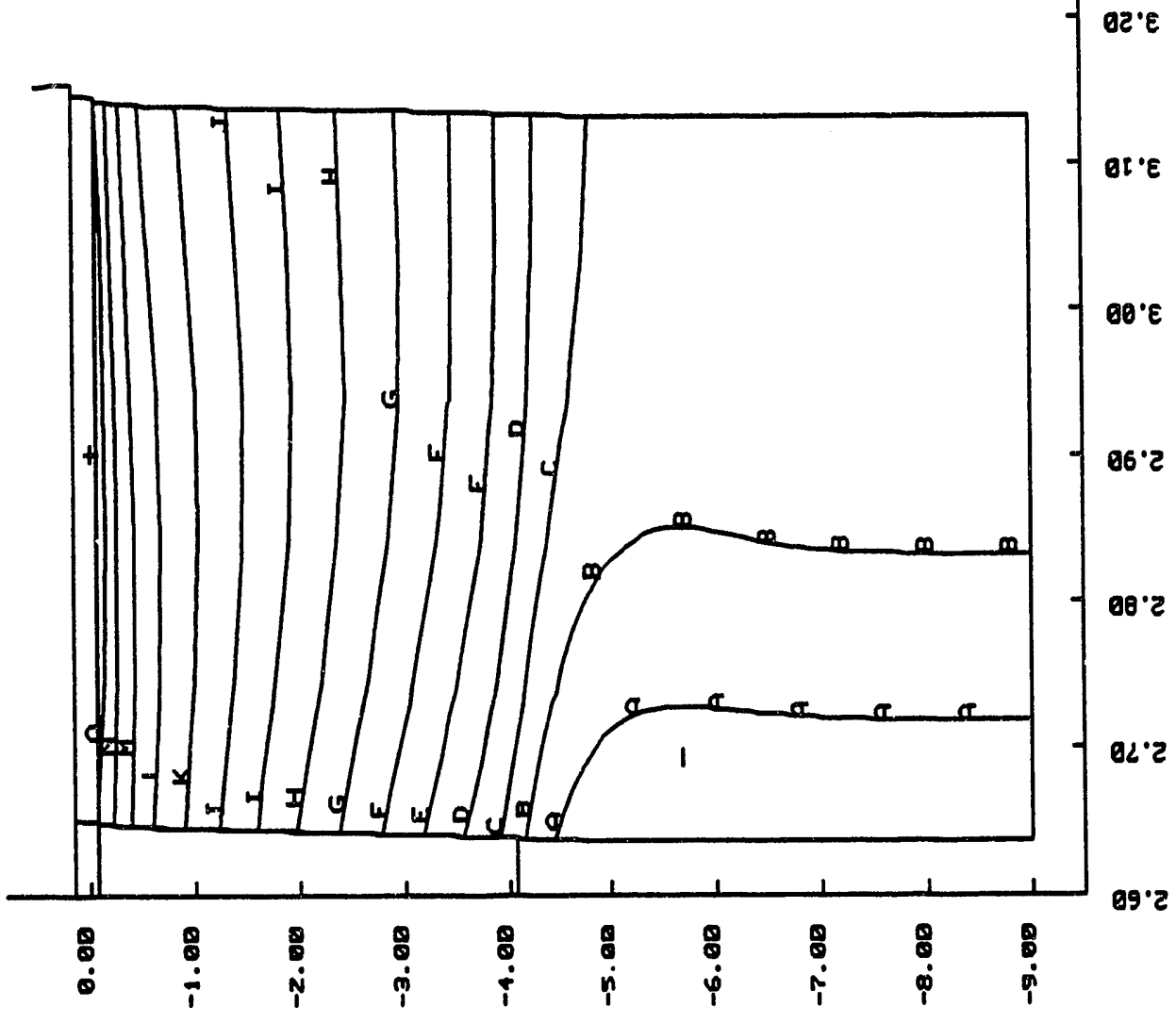

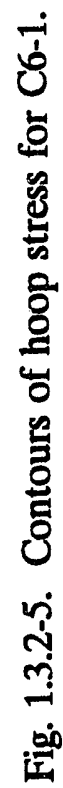

Hष

1 $\mathrm{N}$

0

\%

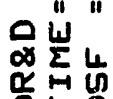

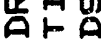




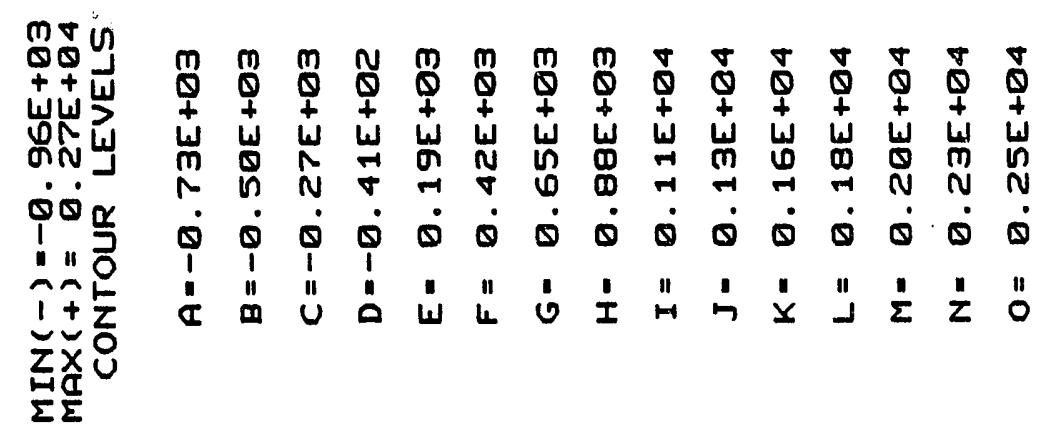

$\left\{\begin{array}{l}\text { OS'E } \\ \text { ar' } \varepsilon \\ \text { aE' } \varepsilon\end{array}\right.$

$u$
$u$
$u$
$\alpha$
0
0

足

แ。

品

2

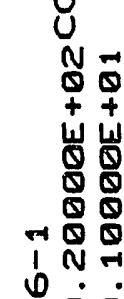

0ن

$\frac{1}{0}$

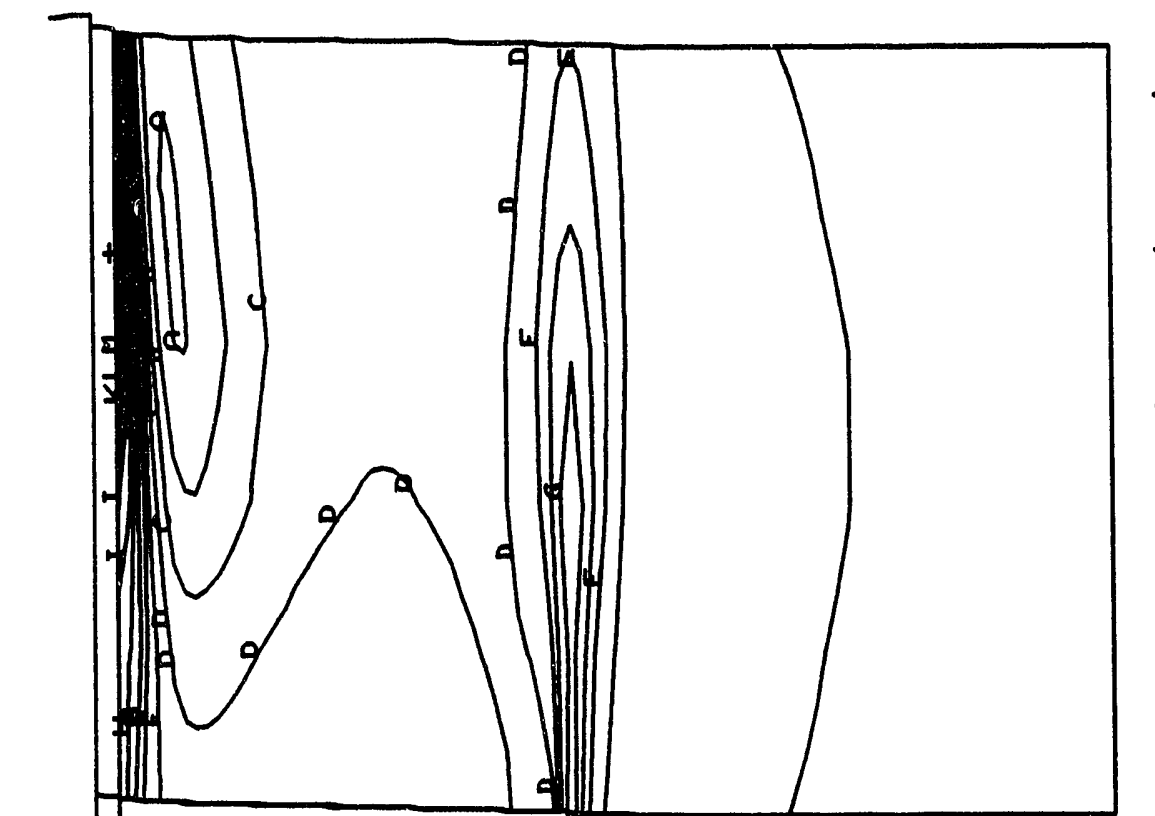

อ2'E

हैं

品崖

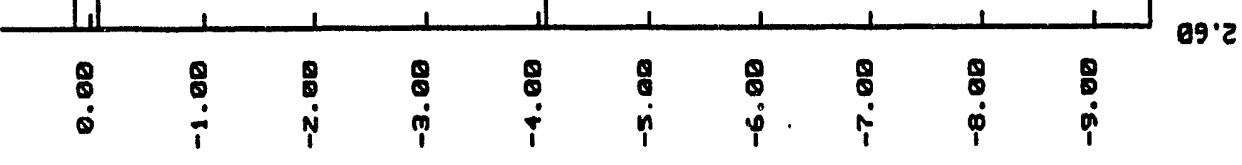

08.2

능

at' $\varepsilon$

岁

$02.2 \quad$ in 


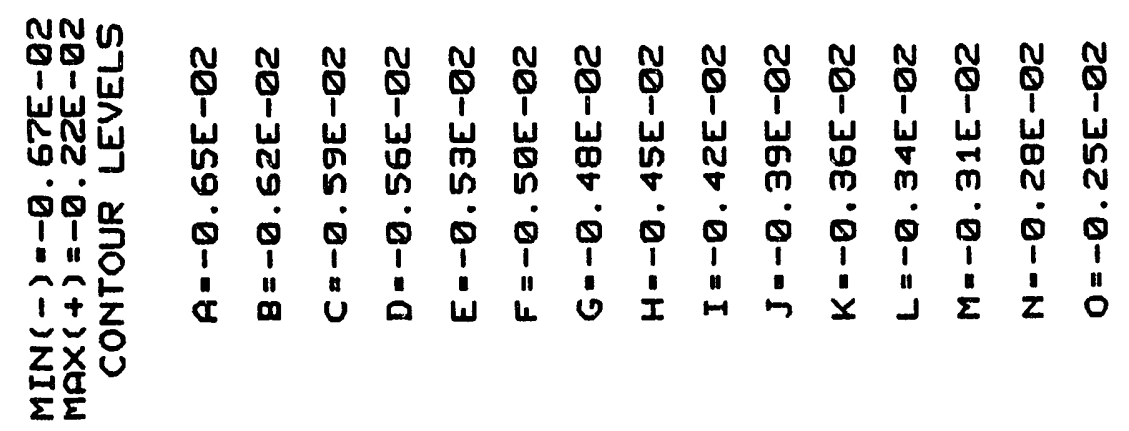

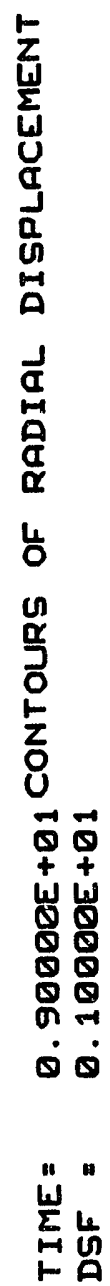

ช̛ 


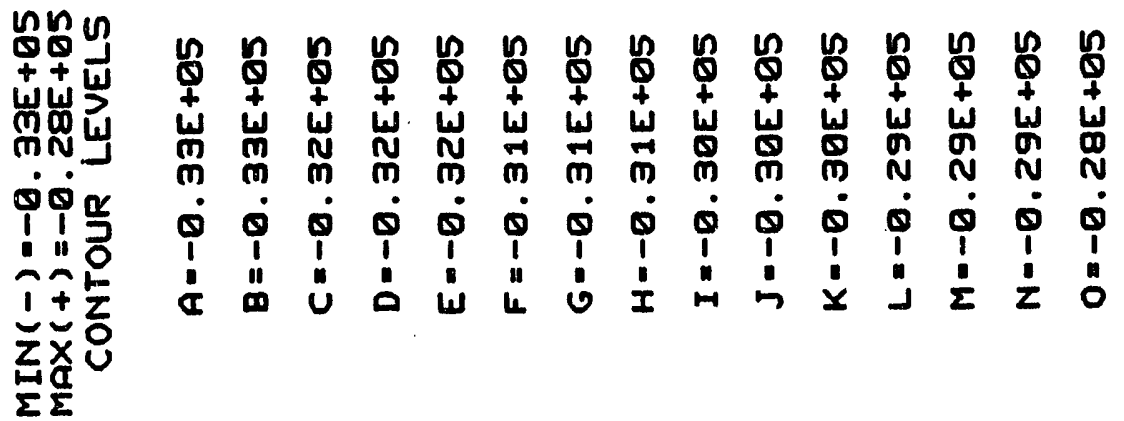

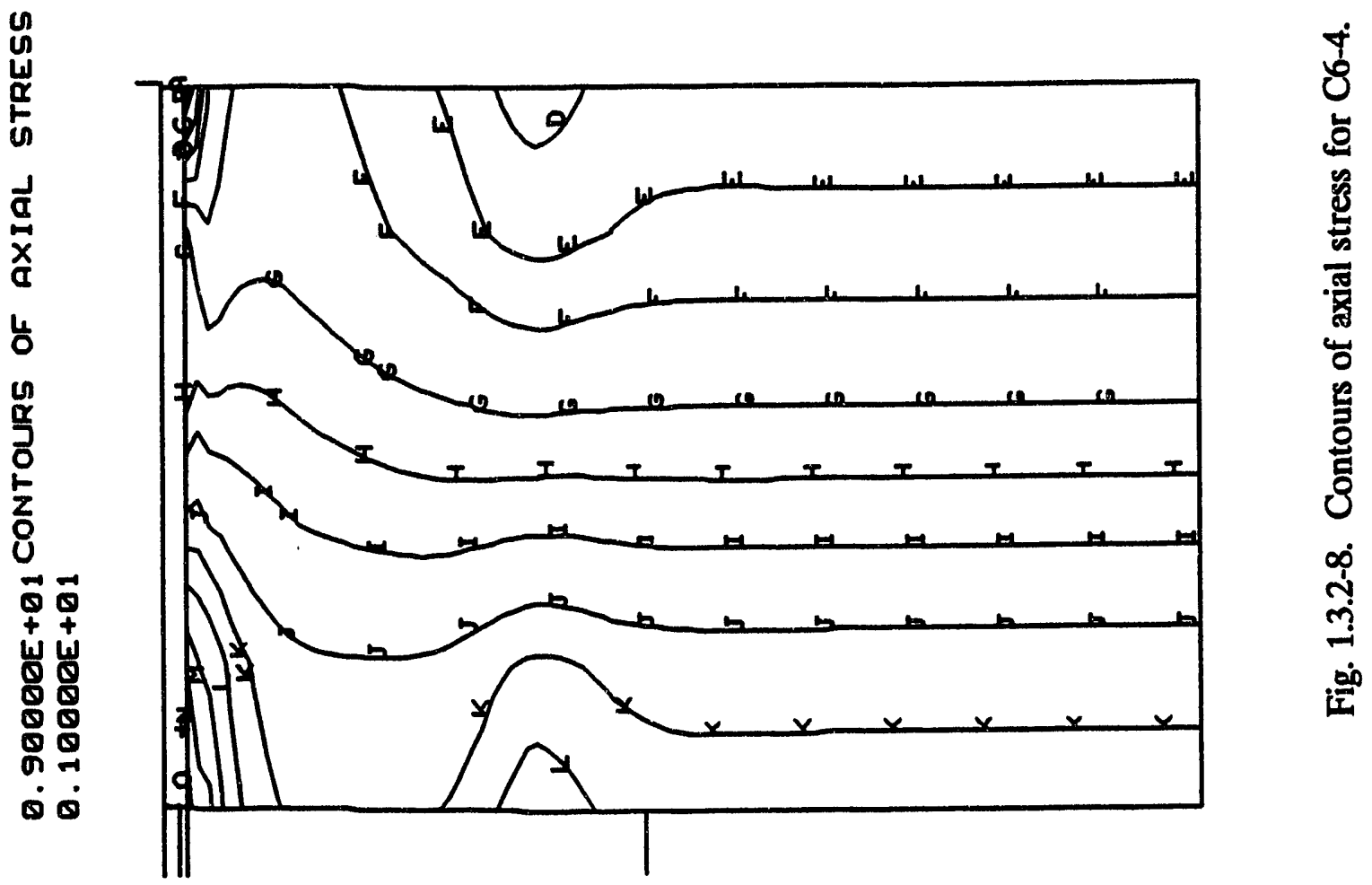

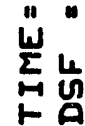




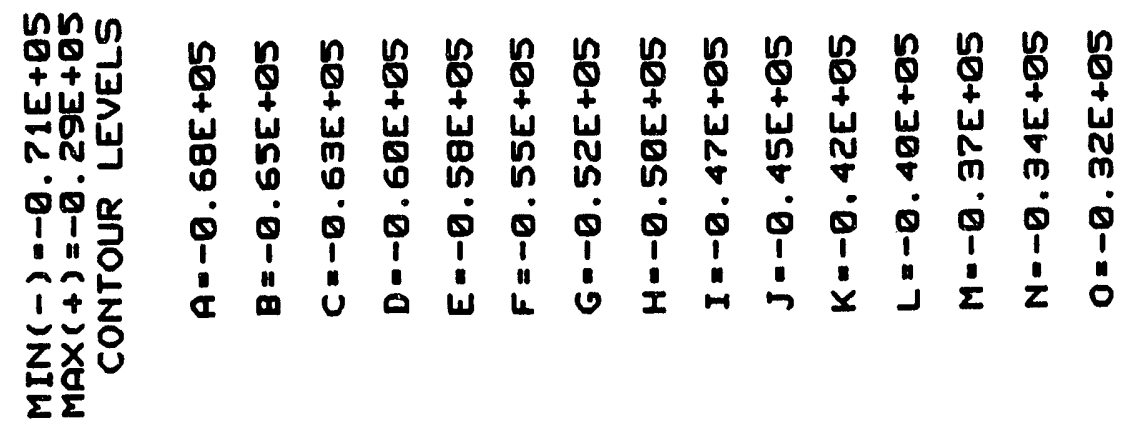

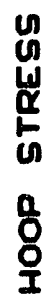

4

品

$\frac{5}{8}$

10

$+4$

岾剀

80

88

in

$\dot{0}$

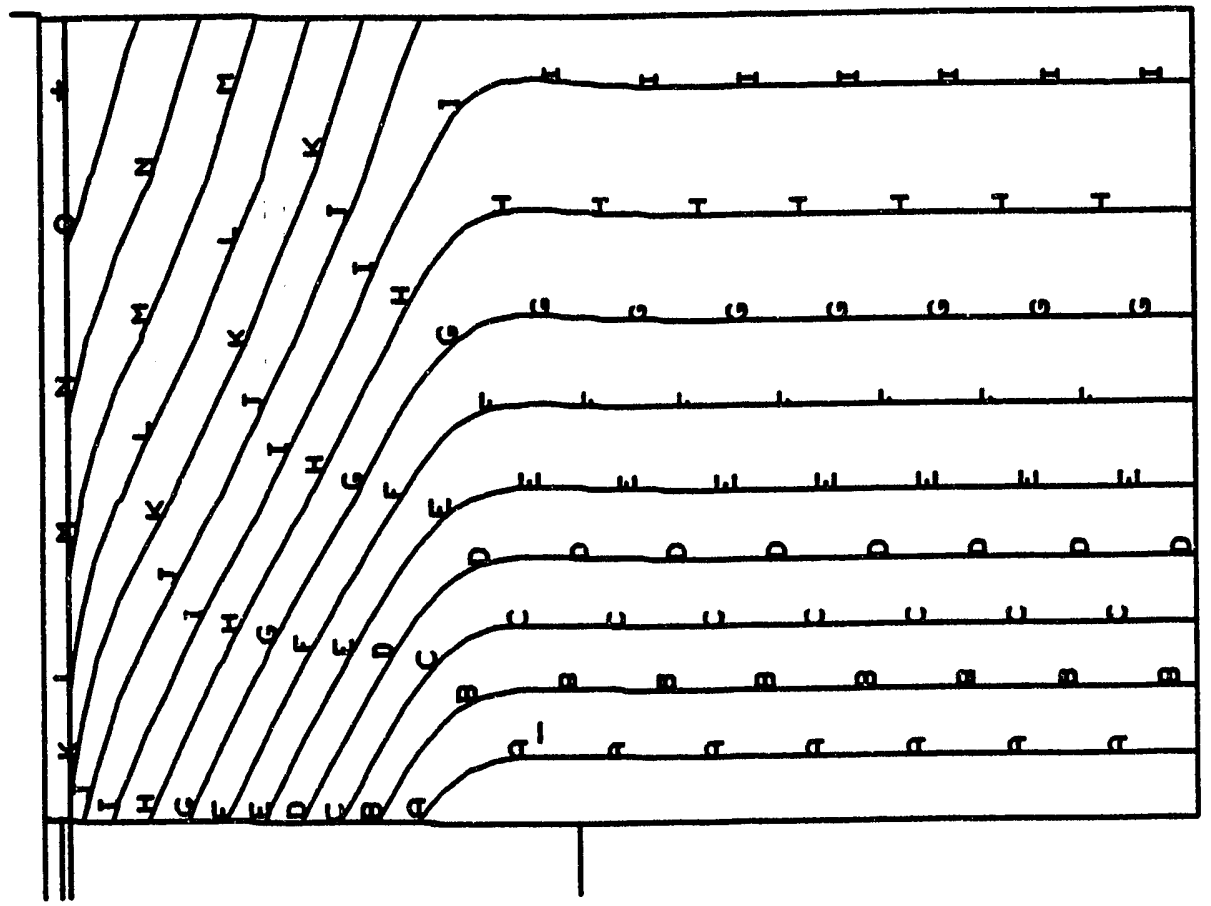

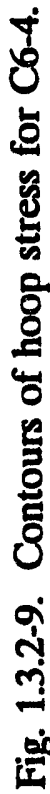

$\sum_{-\infty}^{n} \frac{1}{6}$ 

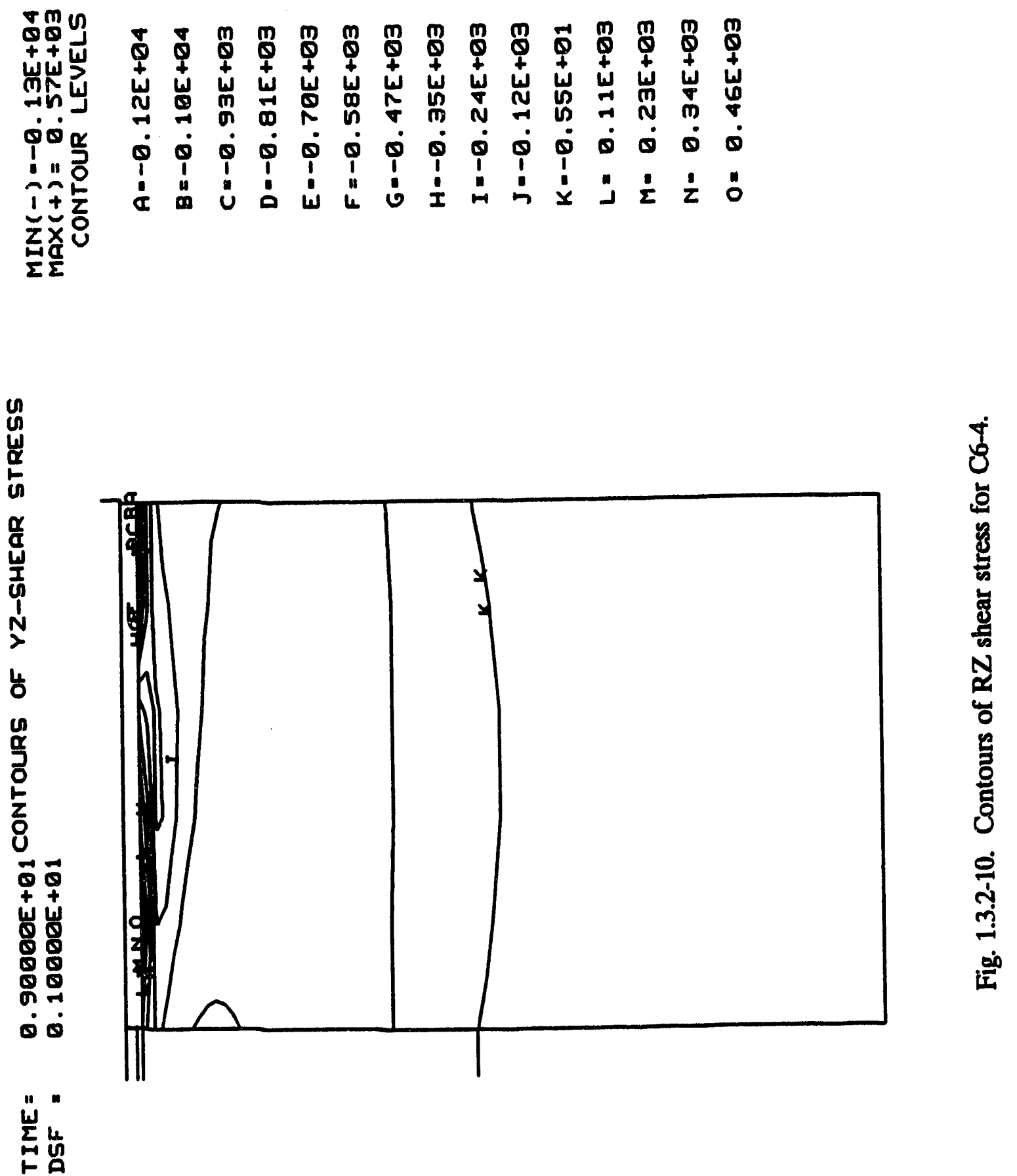


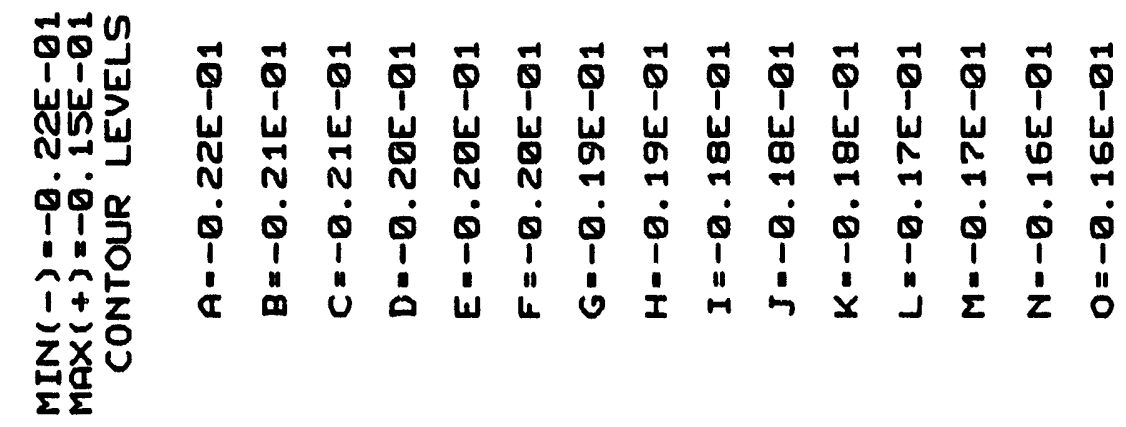

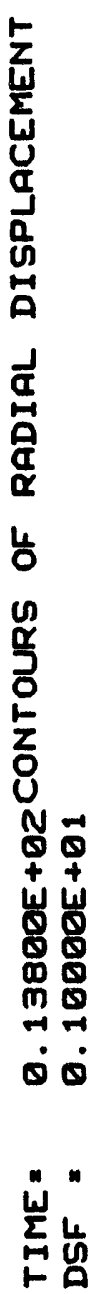

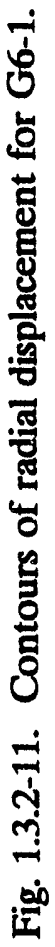



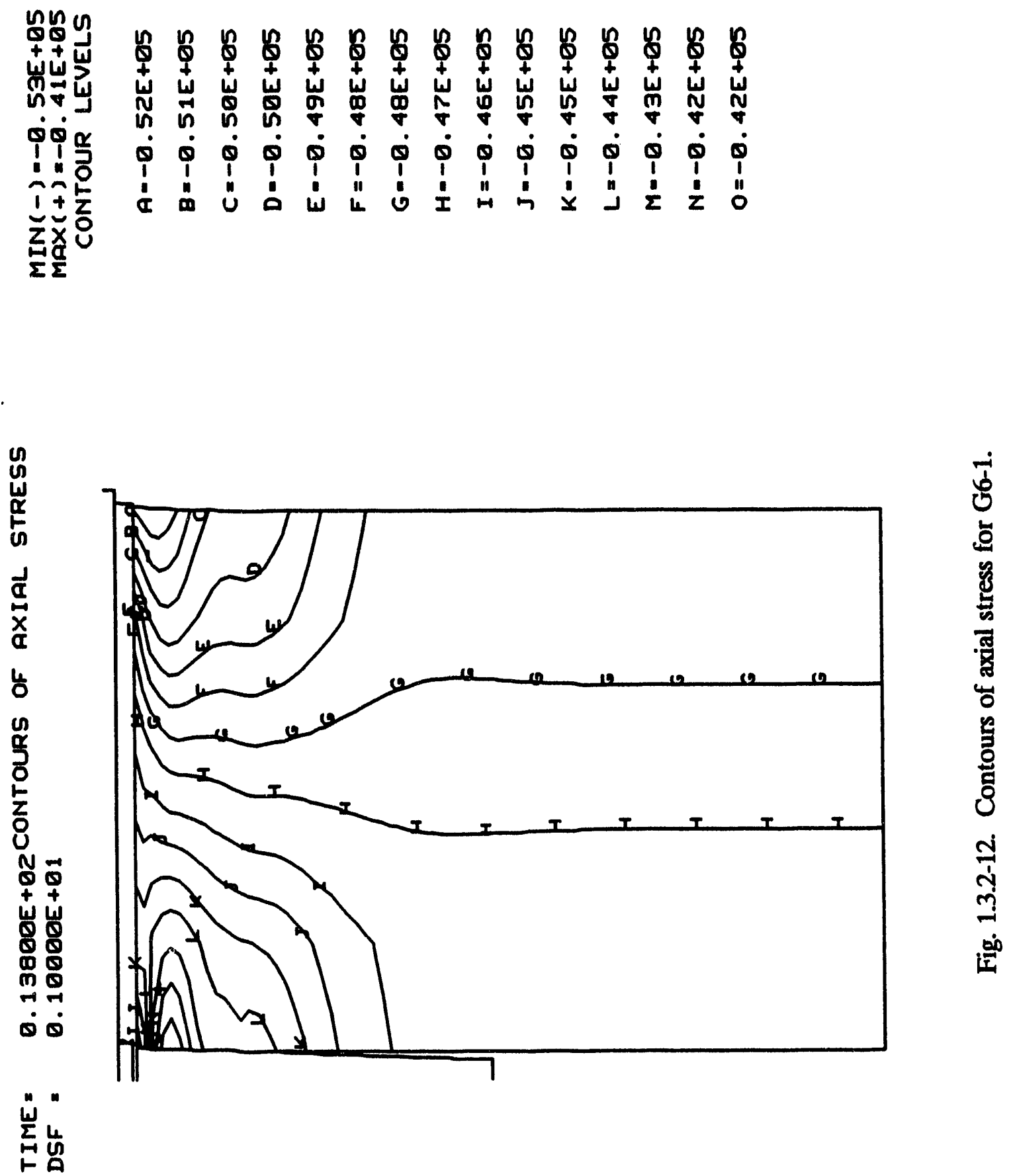


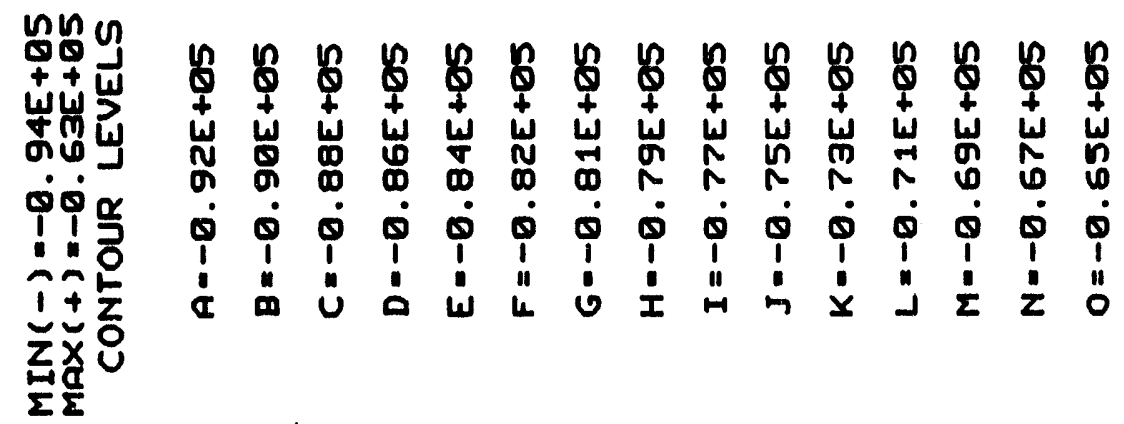

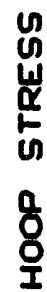

4

品

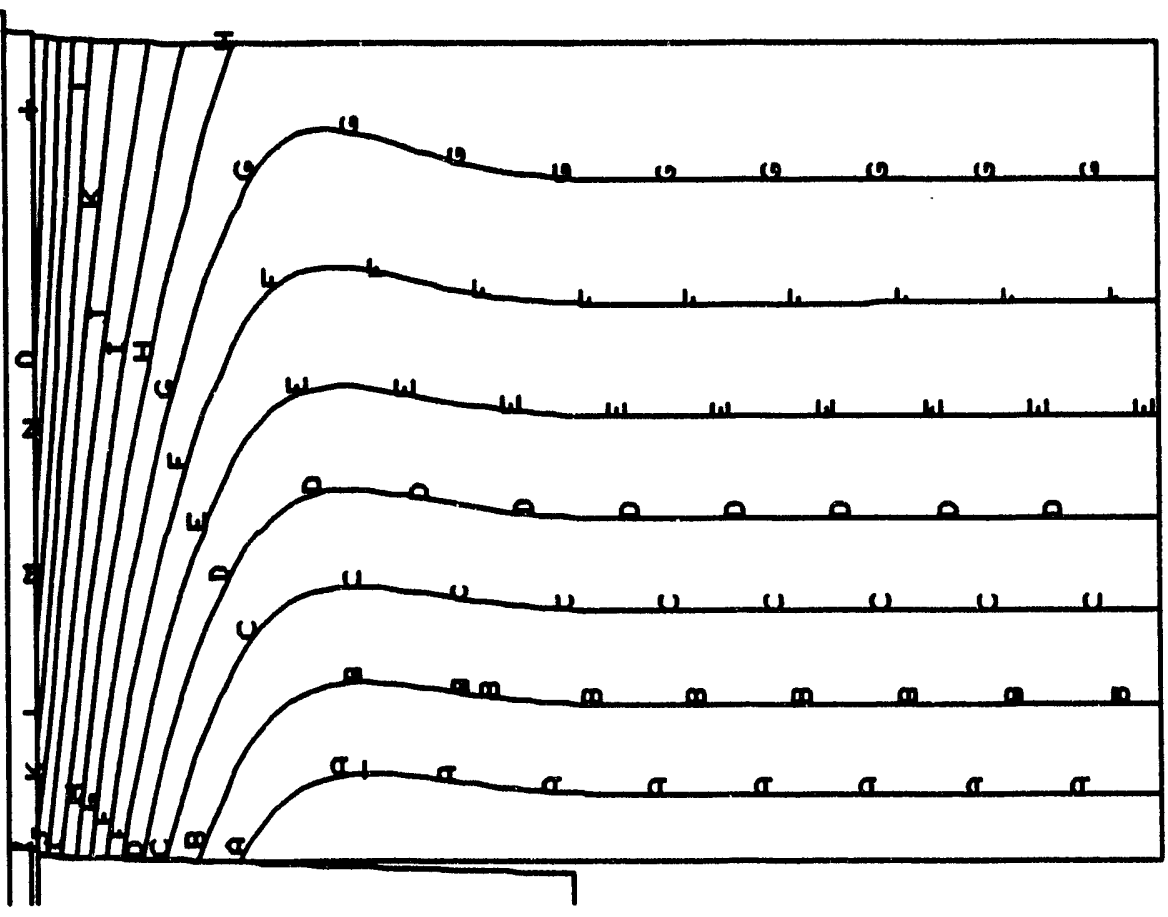

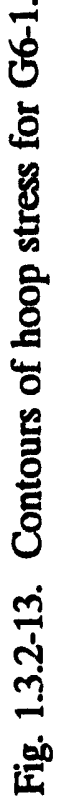

$\sum_{n}^{\omega} \frac{\omega}{\omega}$ 


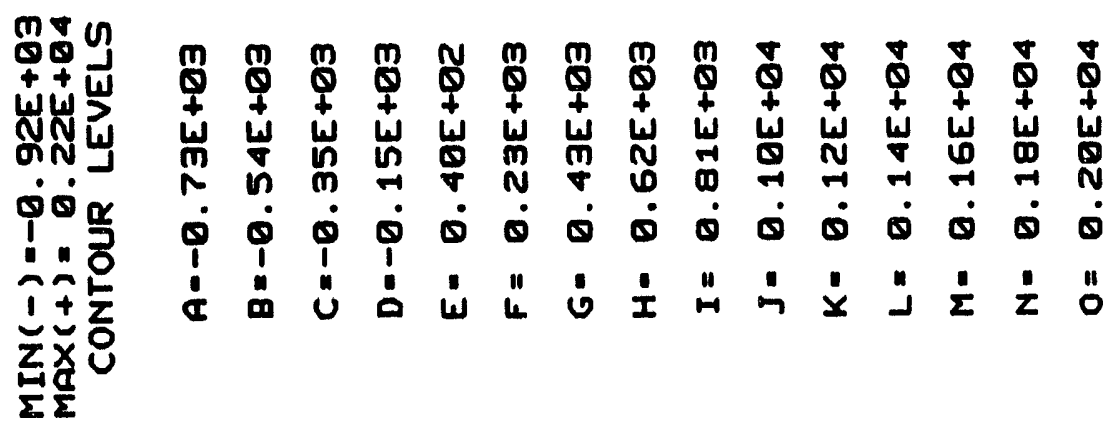

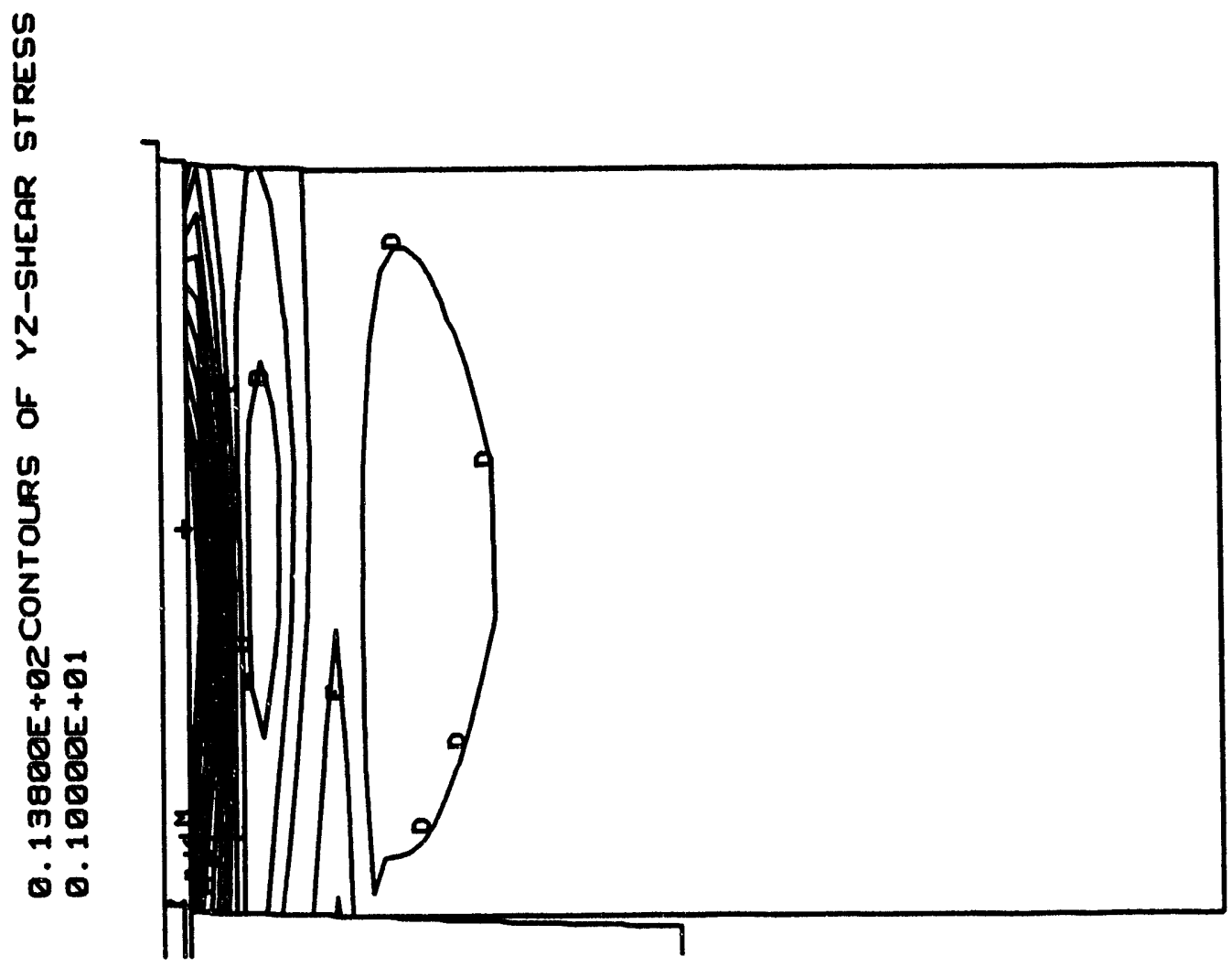

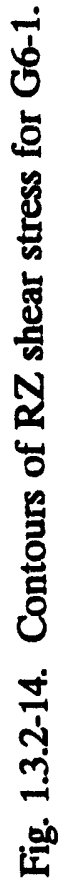

峘”品 


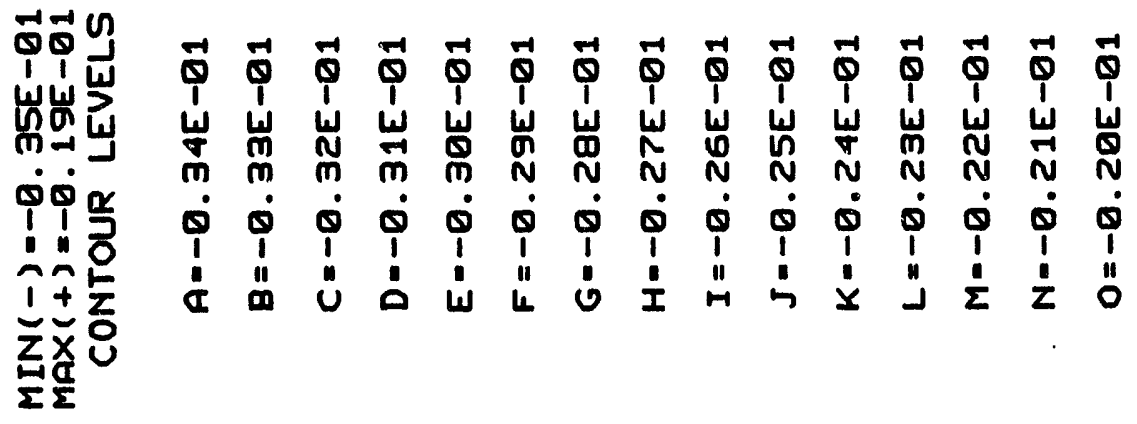

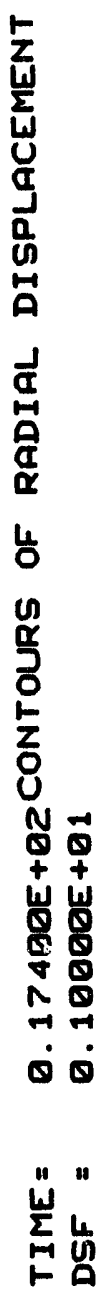

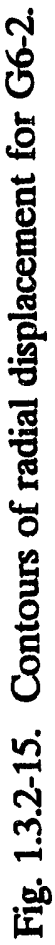




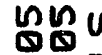

$+\infty+$

II)

काष

年

i⿻

$\prod_{1}=$

$1+2$
$2 \times 2$

żx

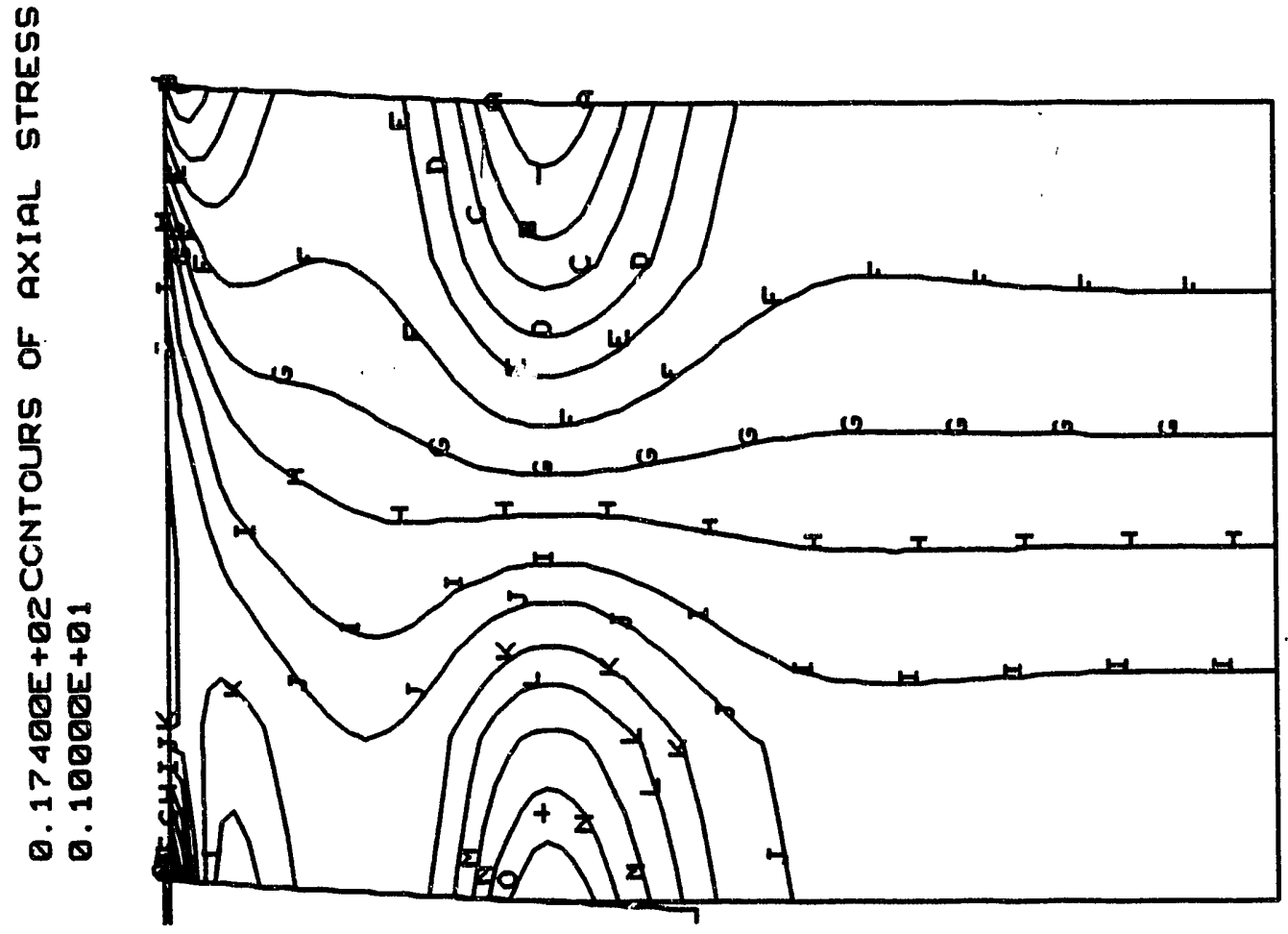

$\sum_{1}^{\prime \prime}$ 
禺的

$++1$

亗耑

N要

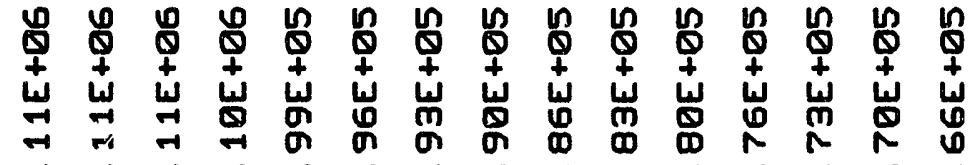

Q

1!

동

$1 \pm z$

Z氐

ம

$\sum \Sigma$

un

号

t。

몸

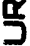

z

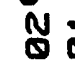

$+4$

岕

四

N 8

-1 -1

$\dot{0} \dot{0}$

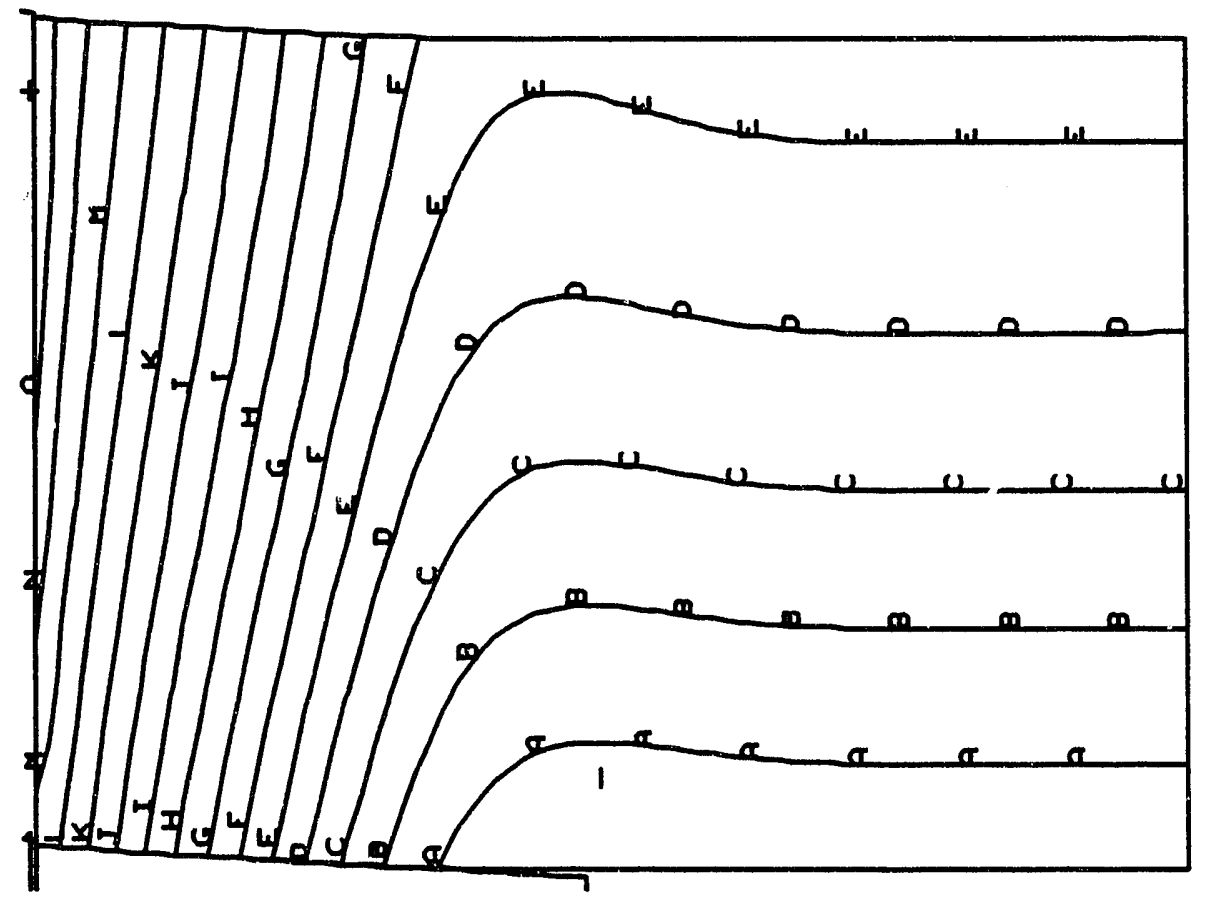

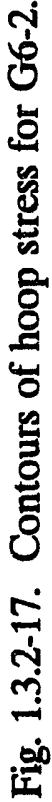

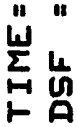




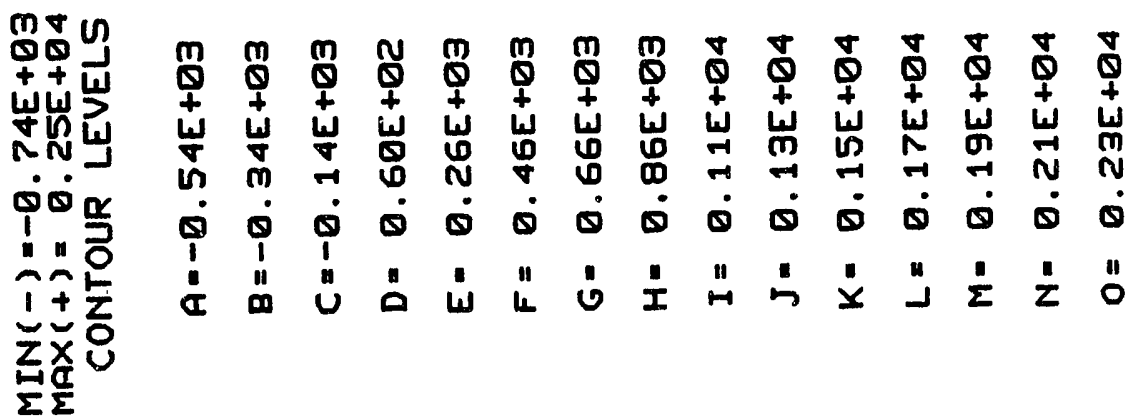

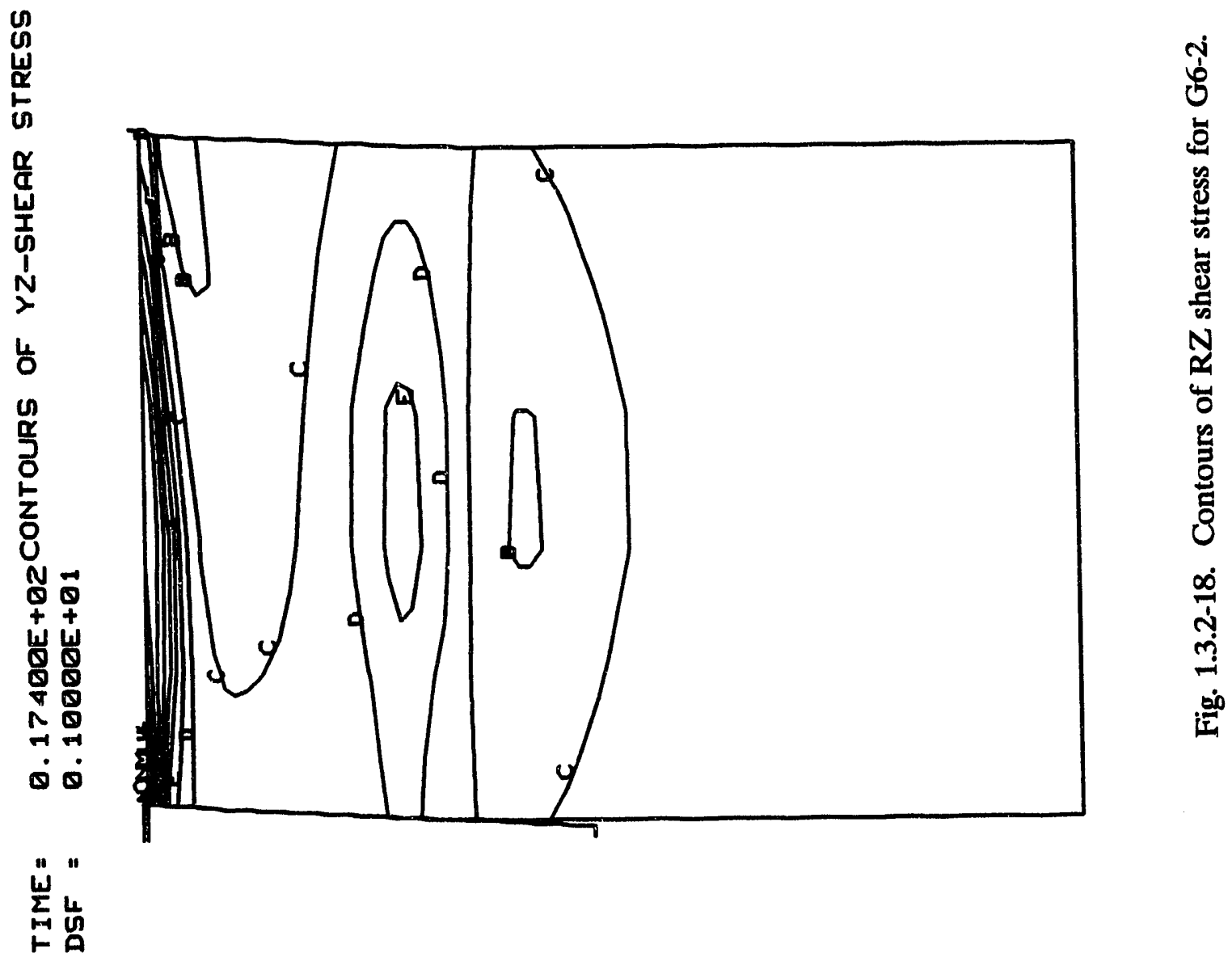



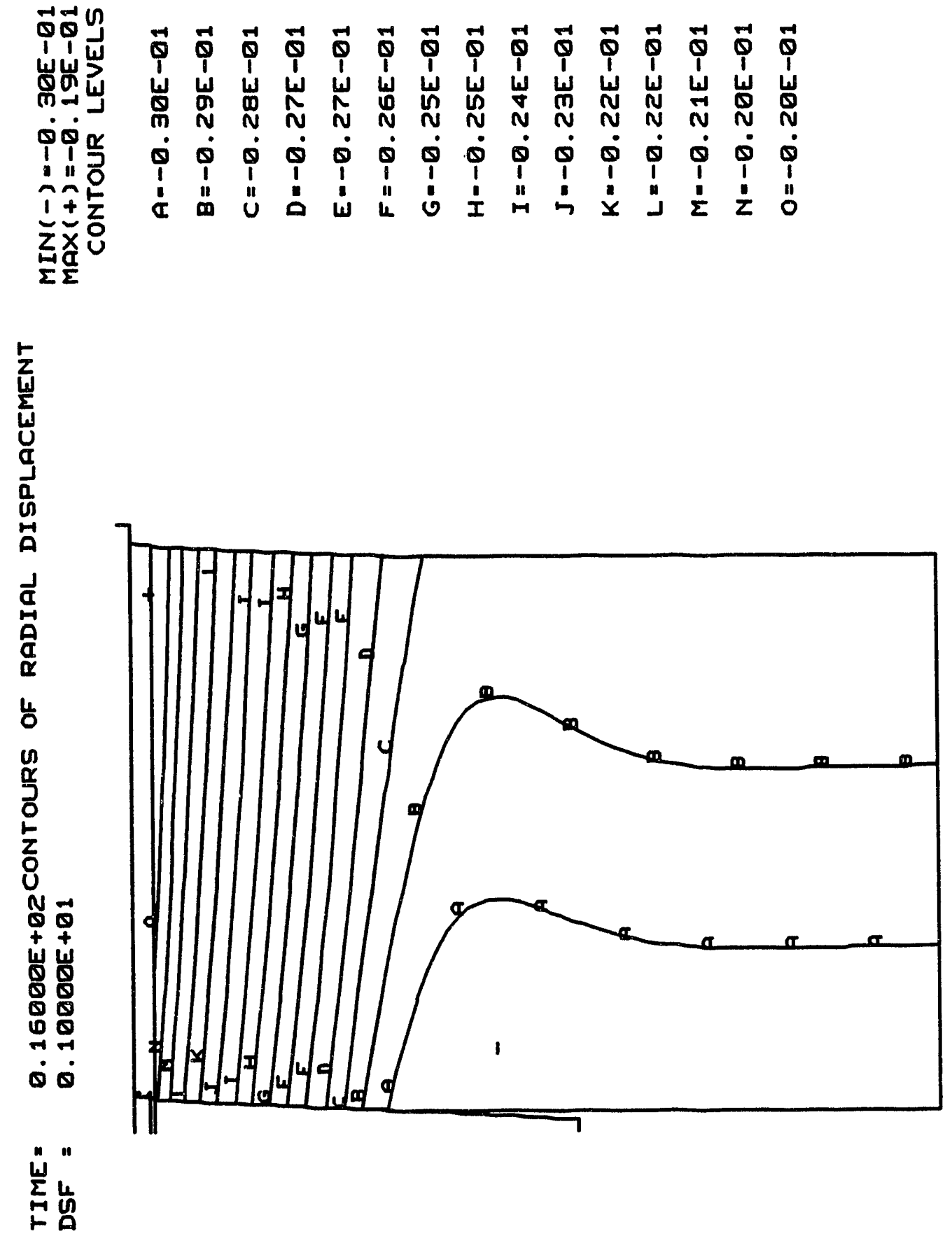

ปे 


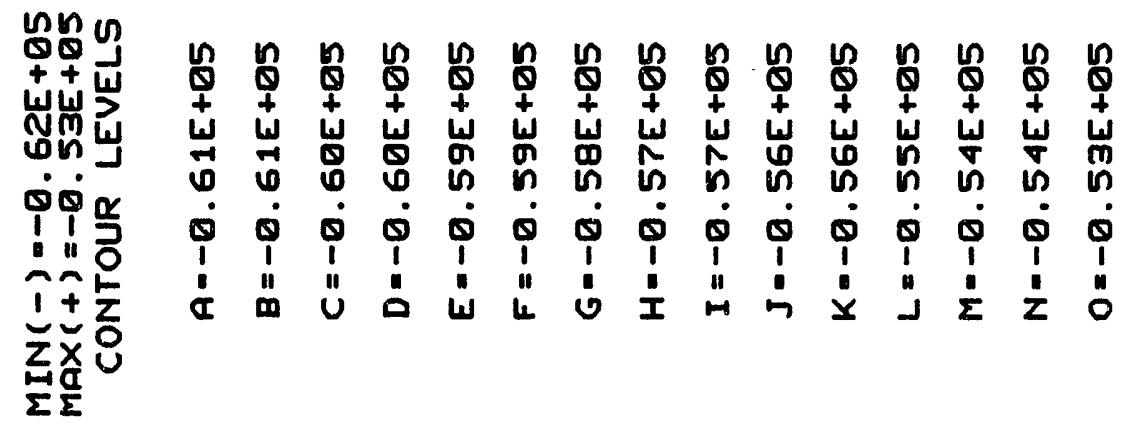

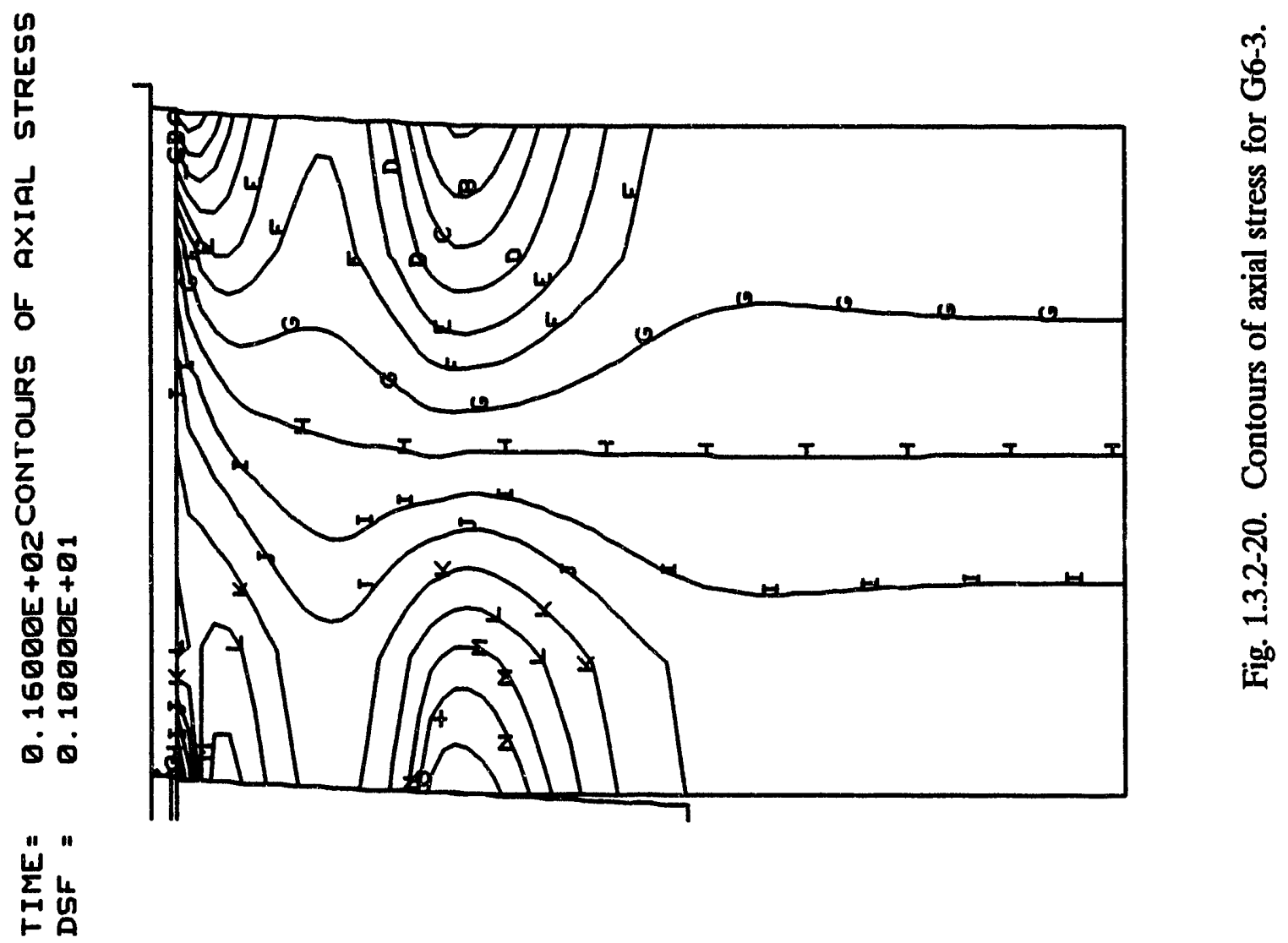




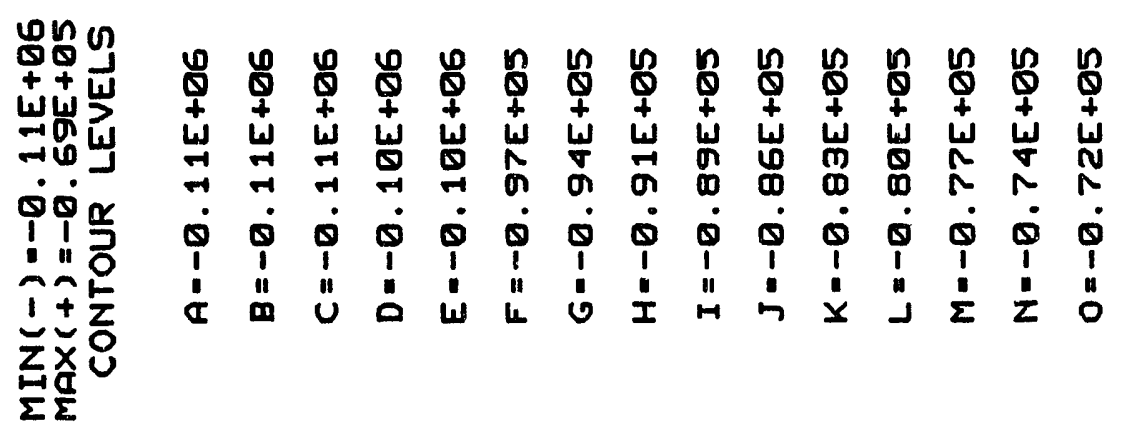

Un
$\boldsymbol{U}$
$\mathbf{W}$
$\mathbf{U}$

8

b

n

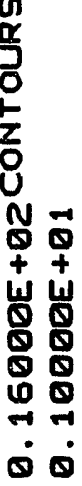

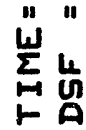

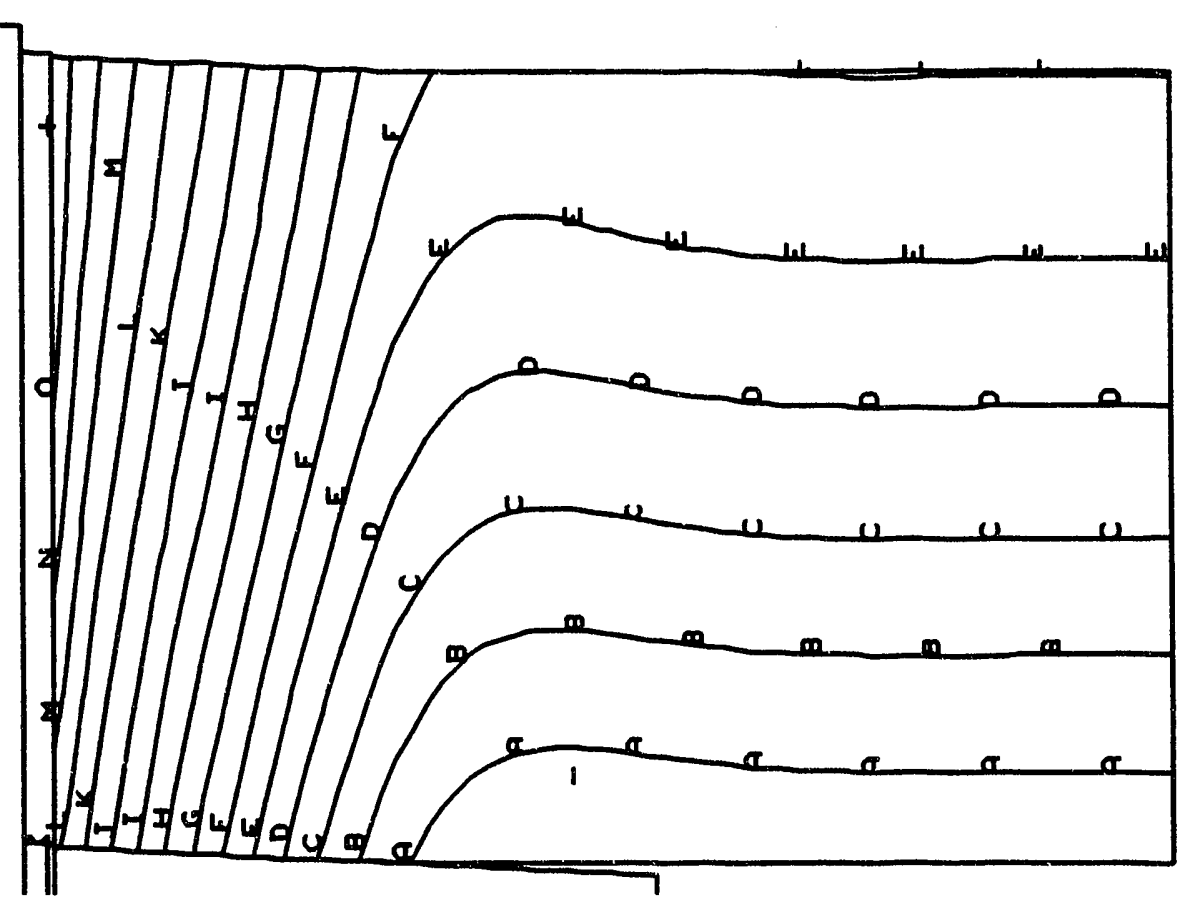

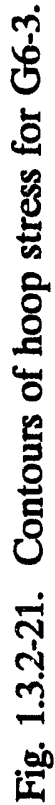




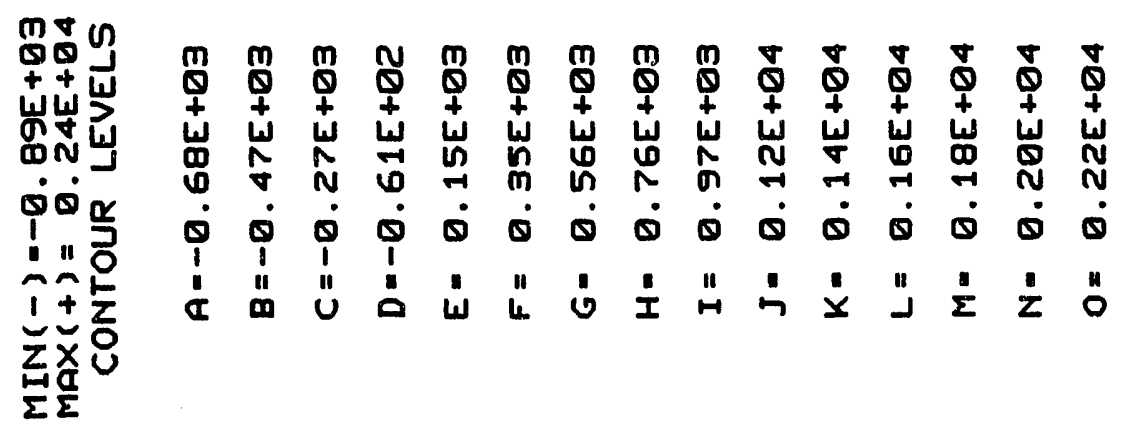

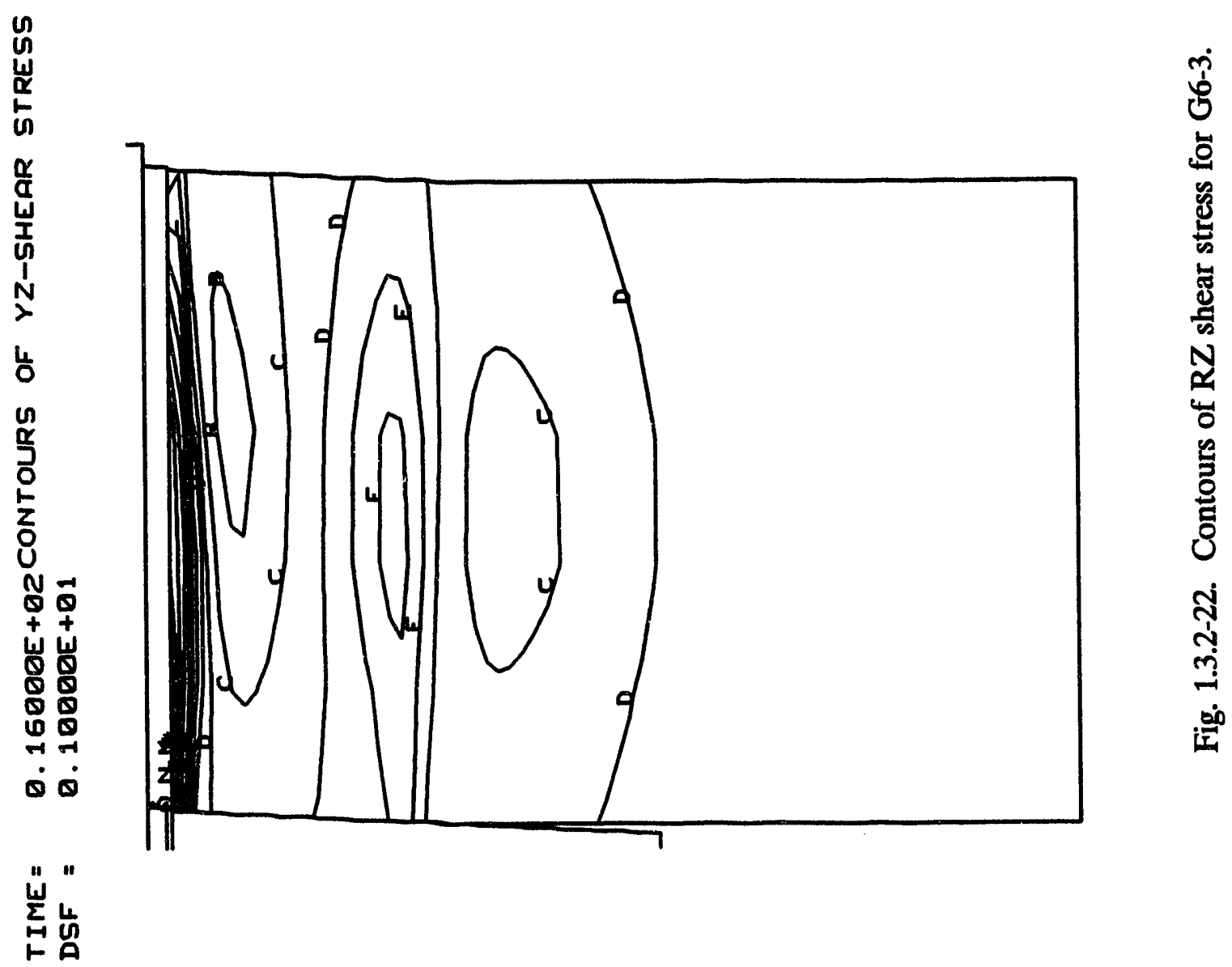




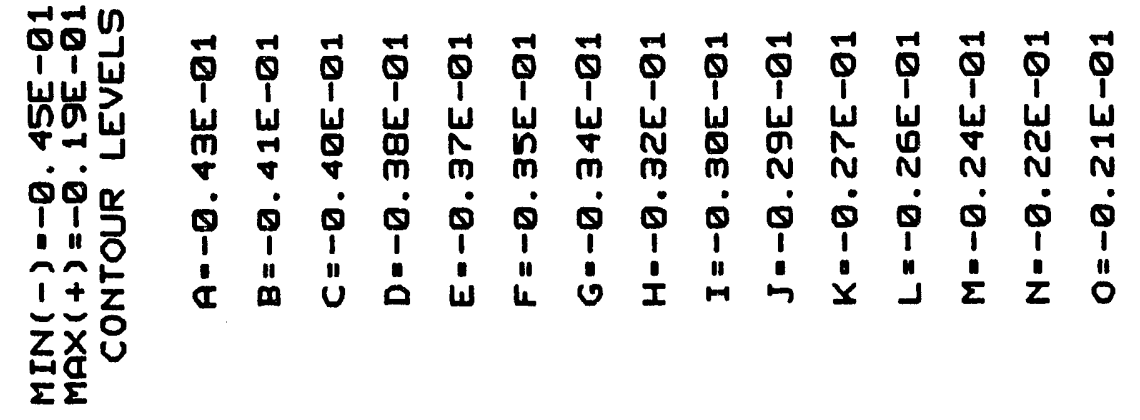

帒

嘼

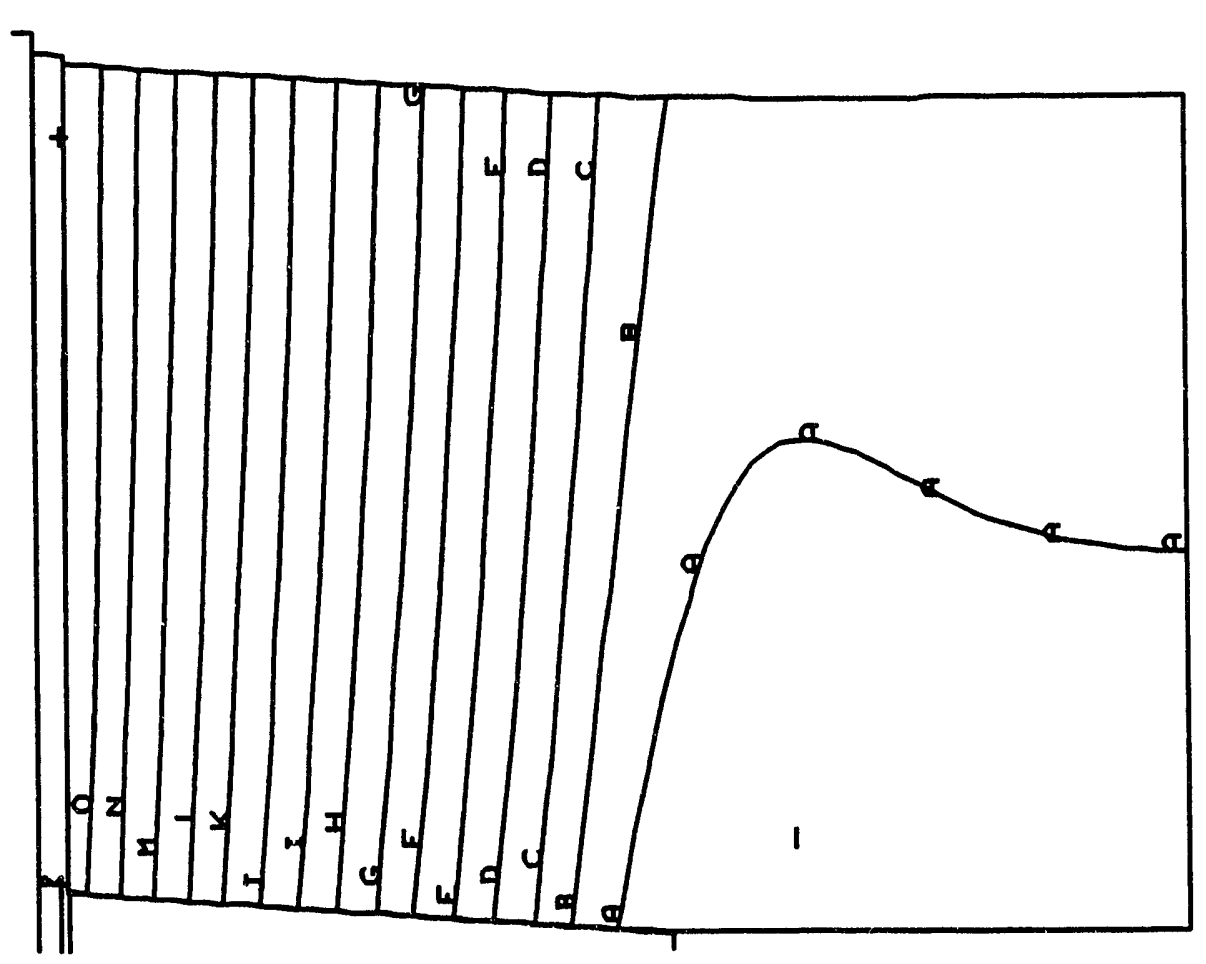

ป̛ं

a

I

4

足

-

岃

愚

ब

ज。

$\dot{\theta} \dot{0}$

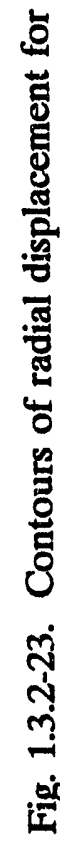

峘 


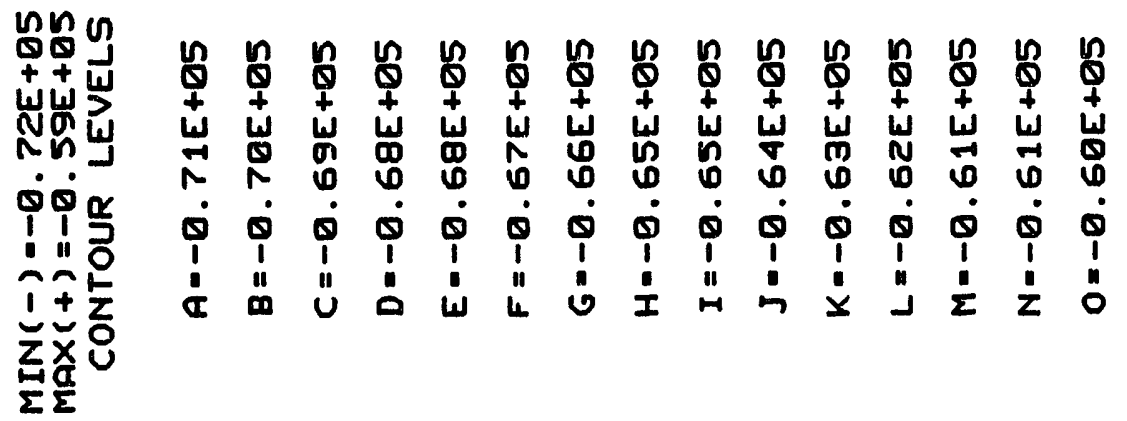

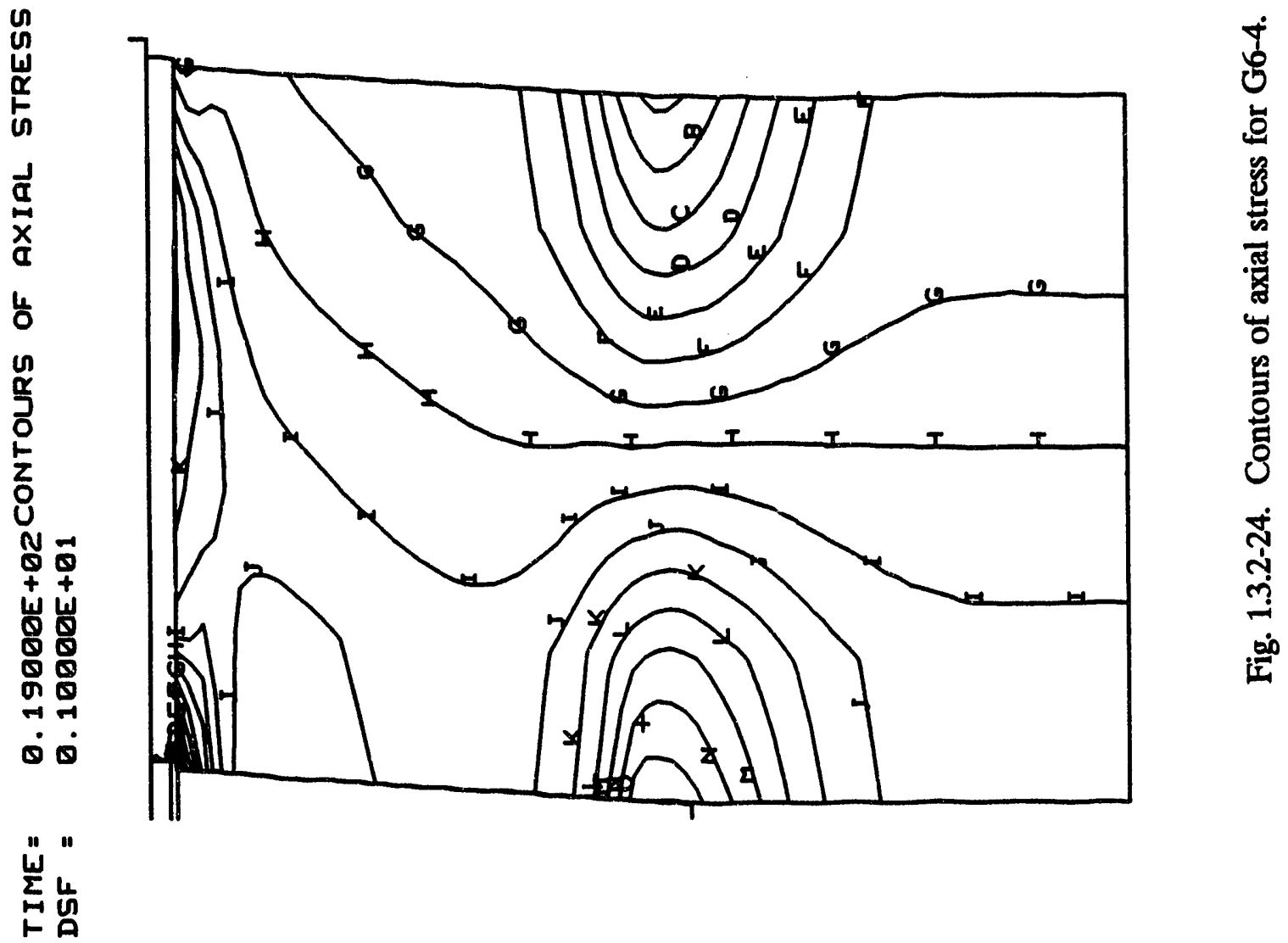




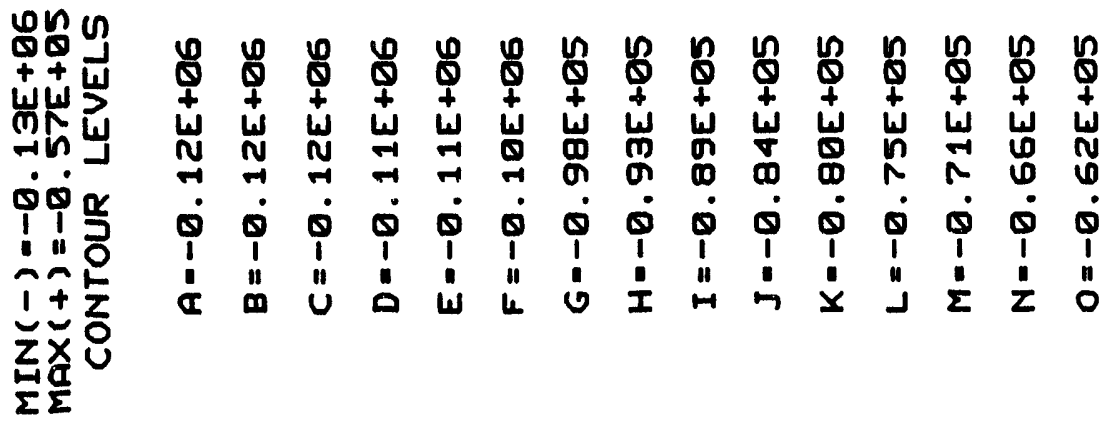

$u$
$u$
$u$
0
0
$u$
0
0
0

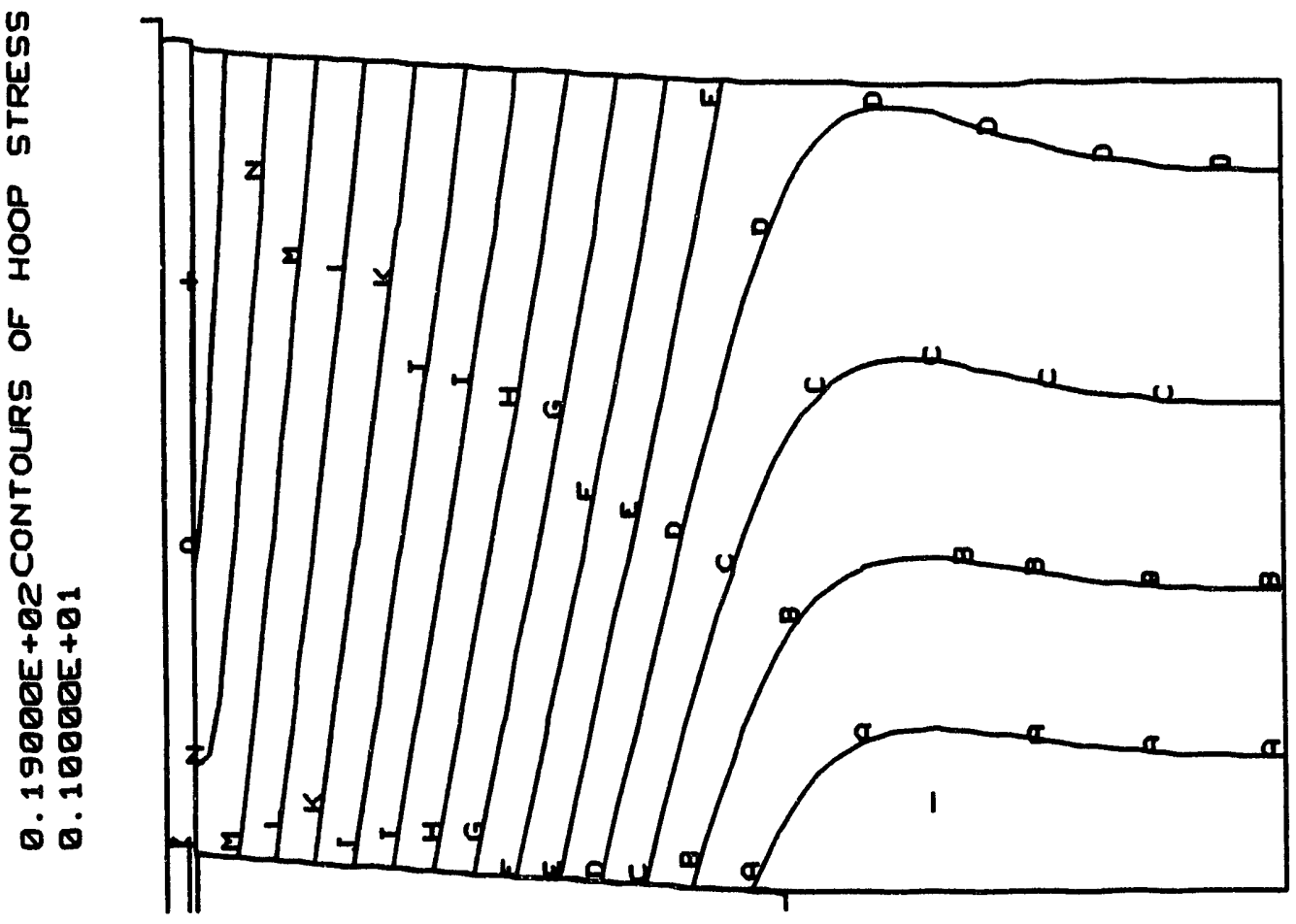

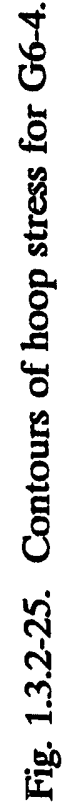

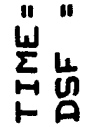




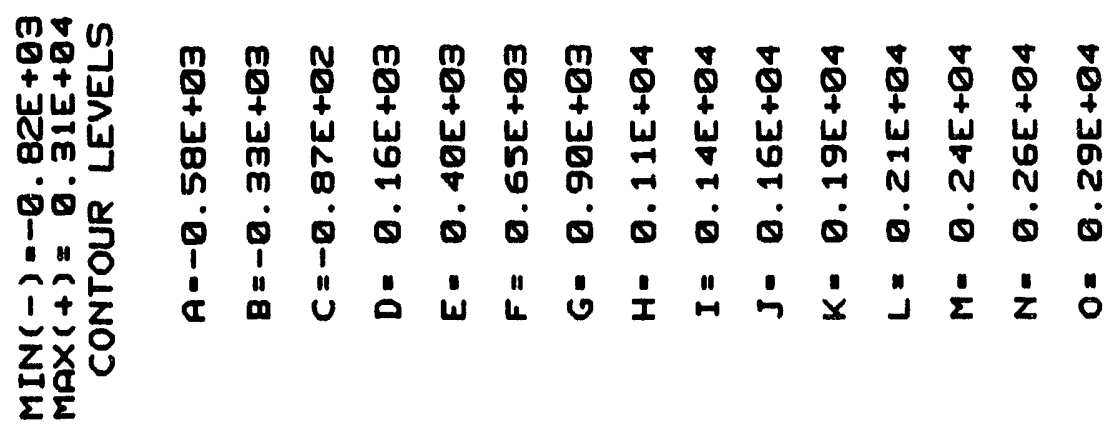

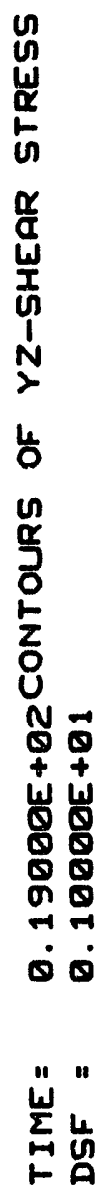

ปे 
Table 1.3.2-1. Maximum bending and shear stresses.

\begin{tabular}{ccccc}
\hline \multirow{2}{*}{ Cylinder } & \multicolumn{2}{c}{ Maximum bending stress (psi) } & \multicolumn{2}{c}{ Maximum shear stress (psi) } \\
\cline { 2 - 5 } & Shell solution & FE solution & Shell solution & FE solution \\
\hline C6-1 & 2624 & 2626 & 483 & 780 \\
C6-4 & 443 & 354 & 160 & 79 \\
G6-1 & 2362 & N.D. ${ }^{a}$ & 708 & 210 \\
G6-2 & 3711 & 2772 & 996 & 330 \\
G6-3 & 3501 & 2969 & 959 & 430 \\
G6-4 & 5068 & 3884 & 1247 & 490 \\
\hline
\end{tabular}

a Not determined. 


\subsection{STABILITY ANALYSIS RESULTS}

Existing clssed-form analytic solutions for buckling of laminated composite cylindrical sheiis arc must commonly formulated by using an orthotropic stiffness layer approach or a laminated shell theory approach. Typically, both of these formulations are based on small-deflection, thin-shell theory, i.e., Donnell type equilibrium equations, ${ }^{19}$ and no transverse shear deformations. The kinematic relations for the strains in laminated shell theory are expressed in terms of the midplane strains and the midplane curvatures. These equations are derived by integrating the strain-displacement relations and assuming vanishing transverse shear strains. In modifying the expressions for the curvatures in terms of the displacements to include transverse shear deformations, the effects of nonvanishing transverse shear strains can be determined (see Christoforou and Swanson ${ }^{20}$ ). In most cases, the assumed form of the displacements satisfy ideal simply-supported boundary conditions at the cylinder ends. Results are presented in this section for the stability of each test article based on a shear-deformable orthotropic shell theory.

A previously developed computer program called CYBUCK was used to calculate the critical buckling pressures for simply-supported boundary conditions and hydrostatic pressure loading. The buckling pressures are calculated from four different solutions, where all of the solutions are derived from Flugge's ${ }^{21}$ governing equations. The first solution uses the curvature expressions given by Ambartsumyan ${ }^{12}$ 14. The second solution modifies the Ambartsumyan curvatures to include the effect of transverse normal strains (see Whitney ${ }^{12,15}$ ). The formulation in the third solution is based on the Donnell approximation for the curvatures, i.e., curvatures that retain only terms involving the radial displacement and its derivatives. The fourth solution is based on a modification to the Ambartsumyan curvatures to include the effects of transverse shear deformations. A more detailed description of these various stability theories and the CYBUCK program are described by Blake et al. (see Refs. 6 and 12).

Comparisons are made between the different stability theories by plotting the critical pressure as a function of the length to diameter ratio, L/D. The predicted critical hydrostatic pressures for cylinders G6-1, G6-2, G6-3, G6-4, and C6-4, respectively, are shown in Figs. 1.4-1 through 1.4-5. For all $L / D$ ratios considered these figures show for the cylinders being studied, i.e., cylinders having only hoop and axial plies, the transverse normal strains have a negligible effect on the buckling pressures independent of the L/D ratio. The effect of including transverse shear strains in the stability formulation is demonstrated by a reduction in the critical buckling pressures. This reduction is larger in the graphite-reinforced epoxy cylinder, $\mathrm{C6}-4$, than in the four glass-reinforced epoxy cylinders. This result is attributable to the IM6/ERL2258 graphite/epoxy material system having a much lower transverse shear modulus than the S-GLASS/ERL2258 glass/epoxy system (see Table 1.2-3). For the four S-GLASS cylinders the effects of including transverse shear deformations are more apparent at the smallest $L / D$ ratios.

In Figs. 1.4-1 through 1.4-5, the results show that as L/D becomes large, the solutions based on the Donnell approximation approach a magnitude of $4 D_{\mathrm{y}} / R_{\mathrm{m}}{ }^{3}$. The same expression, where $R_{\mathrm{m}}$ is the mean radius, was obtained analytically by letting the length of the cylinder, $L$, approach infinity in the limit. For an orthotropic cylinder the value of $D_{\mathrm{yy}}$ is given by Eq. 1.4-1, where $I=h^{3} / 12$ and $h$ is the cylinder thickness. When derivatives of the axial and hoop displacement components are retained in the curvature expressions (e.g., 


$$
D_{y y}=\frac{E_{y y} I}{1-v_{x y} v_{y x}} .
$$

Whitney and Ambartsumyan) lower critical hydrostatic pressures are predicted. As L/D becomes large the critical pressures approaches $3 D_{\mathrm{yy}} / R_{\mathrm{m}}{ }^{3}$. This agrees with the well-known result by Timoshenko for an isotropic tube. Again, it was analytically shown that by letting $L$ go to infinity in the solution, the expression for the critical hydrostatic pressure reduces to $3 D_{y y} / R_{\mathrm{m}}{ }^{3}$. These figures also illustrate that the critical pressure approaches the infinite length solution very rapidly. An approximate solution for an infinite length cylinder, which includes transverse shear, is given by

$$
P_{c r}^{\infty}=\frac{3 D_{y y}}{R_{m}^{3}}\left[\frac{1}{1+0.4\left(\frac{h}{R_{m}}\right)^{2} \frac{D_{y y}}{G_{y r} I}}\right],
$$

where $G_{y t}$ is the circumferential transverse shear modulus and $D_{y y}$ is given in Eq. (1.4-1). For a material which has an infinite transverse shear stiffness, i.e., $G_{y r}$ is very large, Eq. (1.42) reduces to an infinite length solution that agrees with Timoshenkos isotropic tube solution.

The length of the mandrel used in fabricating the test cylinders was such that, after machining the scrap material from the ends, the overall lengths of the cylinders were approximately 26 in.. The final machined lengths of each cylinder were determined in the following manner from the buckling results described previously. A design consideration was that the test article not be buckling critical which meant the allowable buckling pressure had to be greater than allowable strength. Also, it was desirable to have the unsupported cylinder length as long as possible to minimize any end closure effects on the gage section stress state but short enough to preclude buckling failure. The five test articles were to be tested in a pressure vessel rated for use up to 20,000 psi hydraulic fo:ssure (see Sect. 3.2). The design assumption was to have the allowable buckling pressure greater than the pressure vessel capability of 20,000 psi, with a margin of safety. The results plotted in Figs. 1.4-1 through 1.4-5 indicate different unsupported lengths were required for the different cylinder designs.

The critical hydrostatic pressure results and corresponding test lengths are presented in Table 1.4-1 for the four different stability theories. In all cases, the theory based on Ambartsumyan's curvature expressions, modified to include transverse shear, gives the lowest result for the buckling pressure. This theory was used to select the unsupported length for each cylinder. The end closures utilized in the testing were $4.0 \mathrm{in}$. long, which resulted in machined lengths $8 \mathrm{in}$. longer than the unsupported lengths given in Table 1.4-1. The unsupported lengths in Table 1.4-1 and in Figs. 1.4-1 through 1.4-5 are minimum values for full contact with the end closure. The actual unsupported lengths are greater and depend on the contact length versus pressure characteristics of each test assembly. In Fig. 1.4-2, the unsupported length of 9 in. for G6-2 was based on a design that used a target fiber volume fraction rather than the actual value from the composition data. The actual fiber volume fraction was lower than the design value which reduced the allowable buckling pressure. 


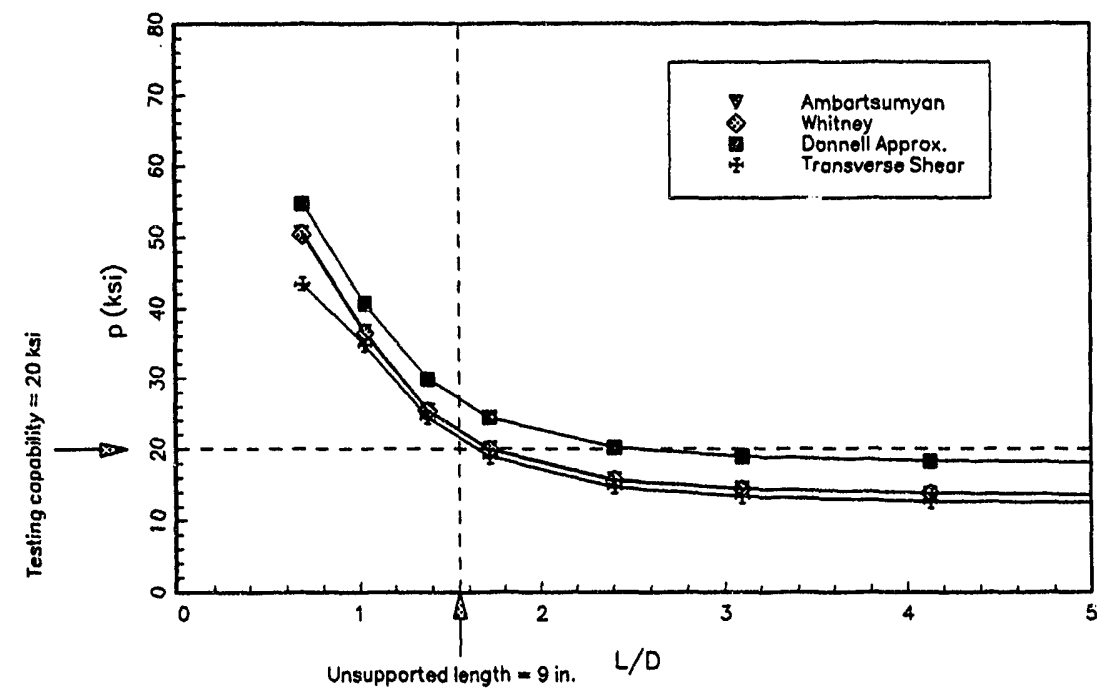

Fig. 1.4-1. Buckling pressure for G6-1 as a function of $L / D$ ratio.

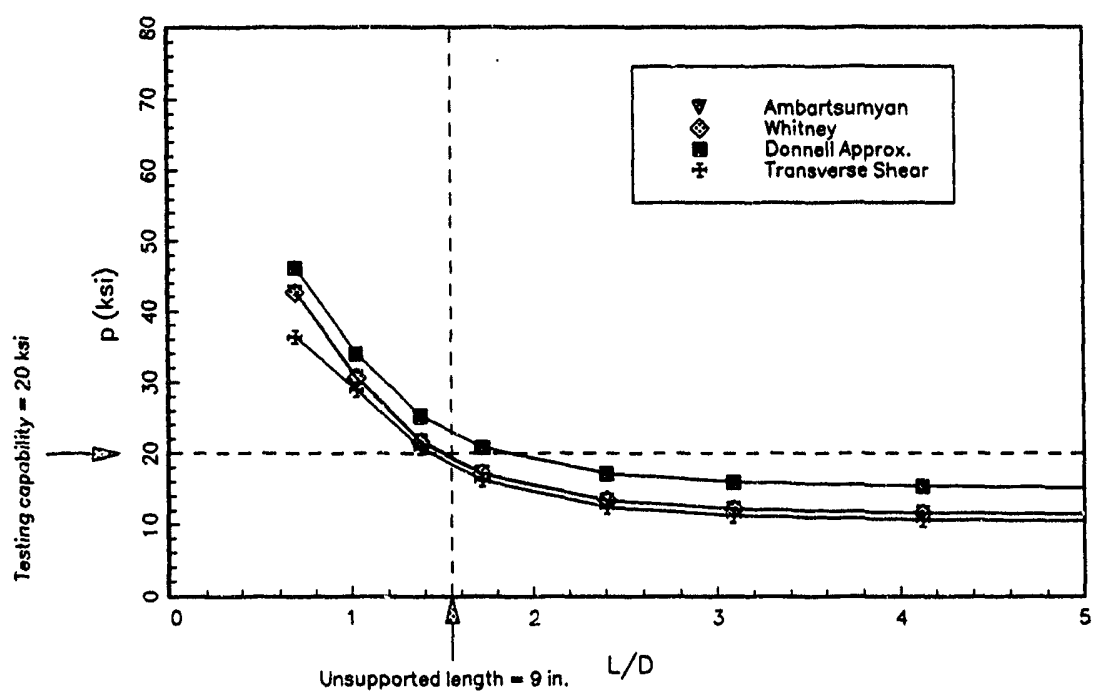

Fig. 1.4-2. Buckling pressure for G6-2 as a function of $L / D$ ratio. 


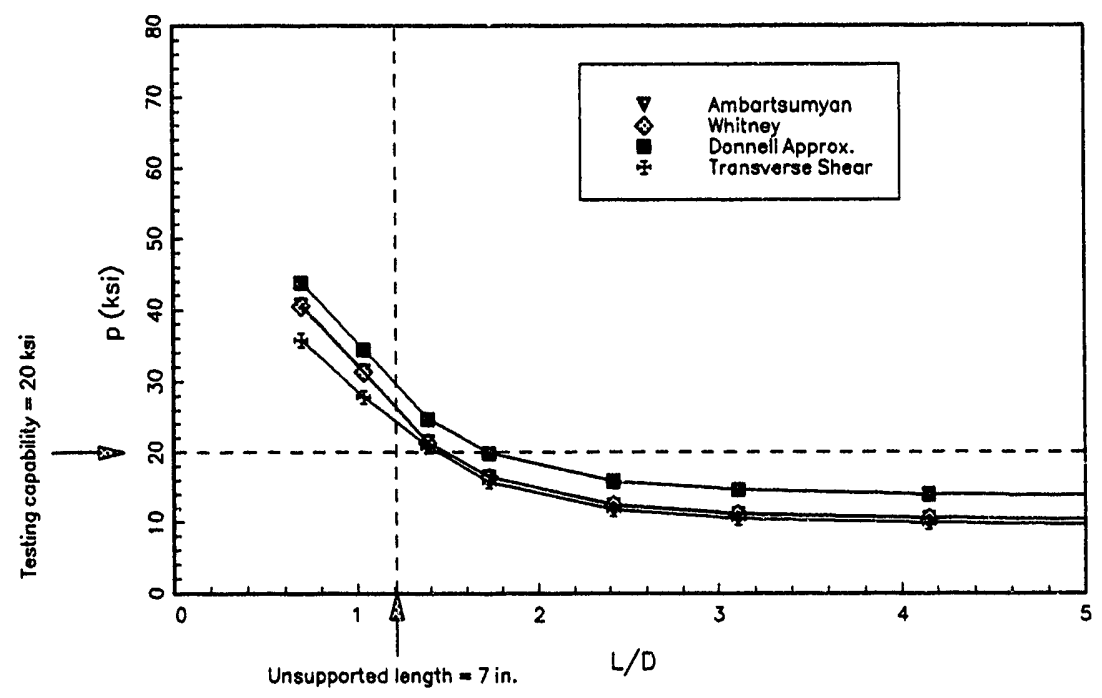

Fig. 1.4-3. Buckling pressure for $G 6-3$ as a function of $L / D$ ratio.

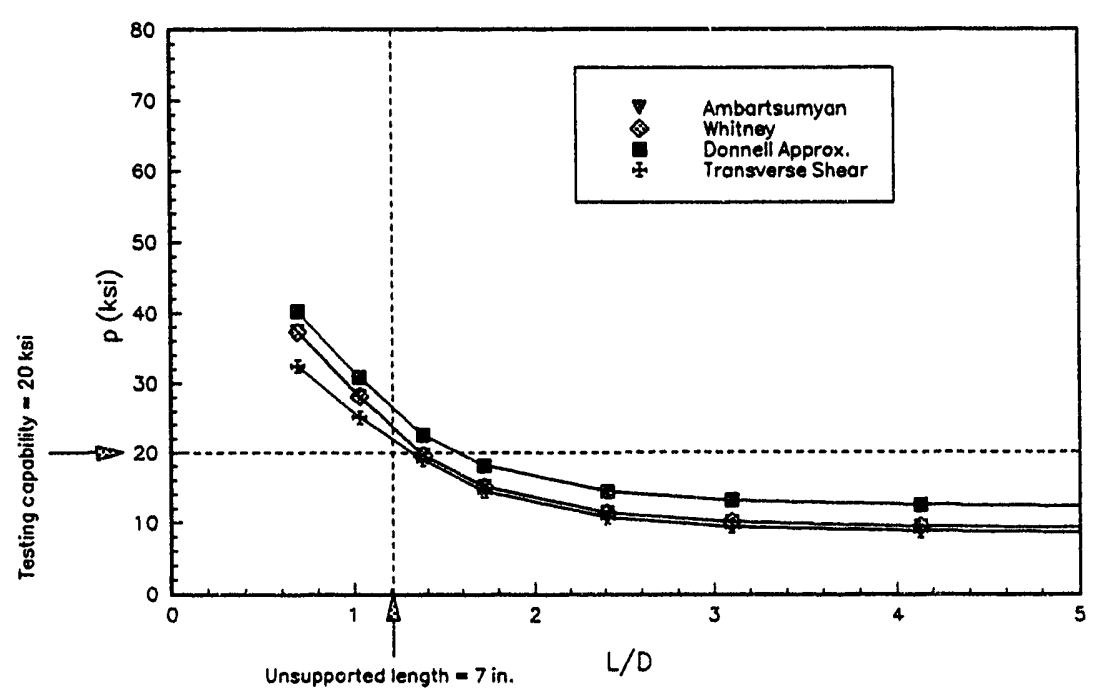

Fig. 1.4-4. Buckling pressure for $G 6-4$ as a function of $L / D$ ratio. 


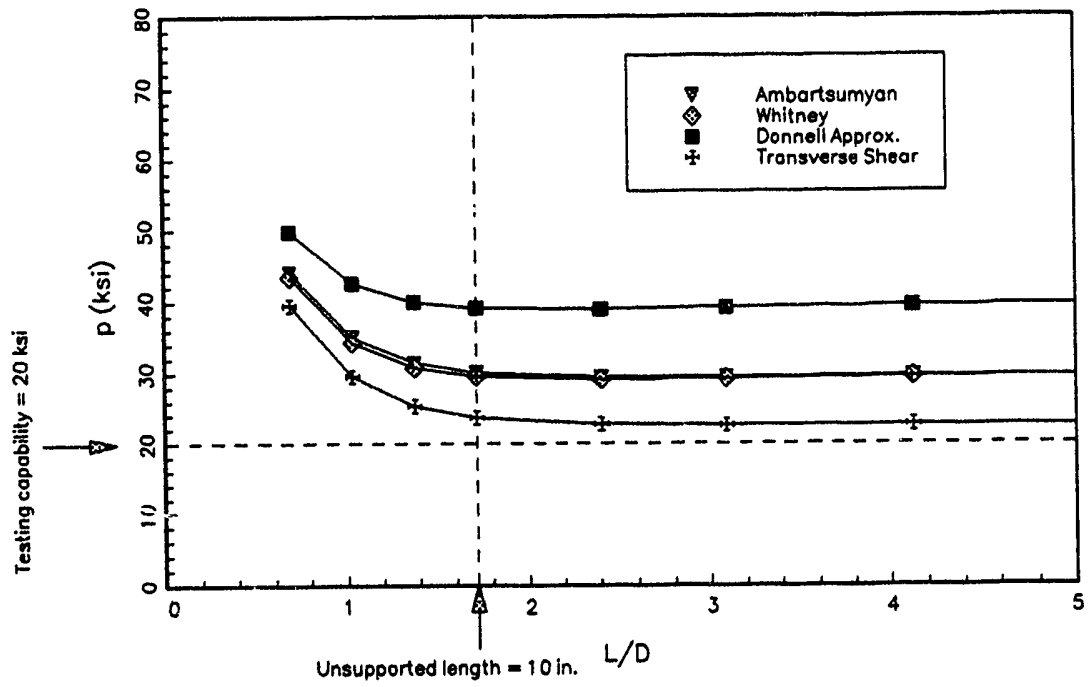

Fig. 1.4-5. Buckling pressure for $\mathrm{C} 6-4$ as a function of $L / D$ ratio.

Table 1.4-1. Stability analysis results for critical hydrostatic pressure

\begin{tabular}{lccccc}
\hline Cylinder ID & G6-1 & G6-2 & G6-3 & G6-4 & C6-4 \\
\hline \multicolumn{1}{c}{ Length (in.) } & 9.0 & 9.0 & 7.0 & 7.0 & 10.0 \\
\hline \multicolumn{1}{c}{ Theory } & \multicolumn{5}{c}{ Critical pressure (ksi) } \\
\hline Ambartsumyan & 22.294 & 19.086 & 25.611 & 23.187 & 30.119 \\
Whitney & 22.122 & 18.960 & 25.469 & 23.077 & 29.616 \\
Donnell approximation & 26.648 & 22.663 & 28.786 & 25.978 & 39.147 \\
Transverse shear & 21.224 & 18.120 & 24.888 & 22.447 & 23.687 \\
\hline
\end{tabular}




\subsection{FAILURE ANALYSIS RESULTS}

A first-ply failure analysis for laminated composites requires that principal material direction stresses be calculated for each ply in the laminate construction. These stress components are then input into the selected failure criteria along with the ply material strengths. In this investigation, the closed-form analytic solutions described in Sect. 1.3 are used to calculate the ply-level stress distributions in the global cylindrical coordinate system, and then a coordinate transformation is used to determine the stresses in the principal material directions. In calculating the ply-level stresses, the cylinders are modeled by their as-fabricated dimensions and composition data. In the program CCAP, a 1-ksi hydrostatic pressure is applied and first-ply failure is predicted based on Hashin's ${ }^{5}$ criteria, the $\mathrm{Tsai}-\mathrm{Wu}^{22}$ criterion, maximum stress theory, and maximum strain theory. The first-ply failure results from these analyses are presented in this section.

Hashin's three-dimensional failure criteria for unidirectional fiber composites determine not only the critical pressure for first-ply failure but also the failure mode. The four distinct failure modes considered are: tensile fiber mode, tensile matrix mode, compressive fiber mode, and compressive matrix mode. Each mode is modeled separately and the criteria are formulated in terms of quadratic stress polynomials which results in a piecewise smooth failure surface. First-ply failure is determined by the minimum value of a stress ratio, $R$, defined to be

$$
\{\sigma\}_{\text {MAX }}=R\left\{_{\text {APPLEDD }}\right. \text {, }
$$

where $\{\sigma\}_{\text {MAX }}$ is the maximum allowable stress permitted. For an applied unit pressure, the magnitude of $\mathbf{R}$ in each layer determines the critical pressure for that layer, and the location of the minimum value defines the first-ply to fail.

For the cross-ply laminated cylinders C6-1, G6-2, G6-3, and G6-4, stress values were determined within each layer as defined by the laminate stacking sequences given in Table 1.2-1. Stresses were computed at three solution points within each layer, one point at each layer interface and the third point at the layer midplane. The stress ratio $R$ was then determined at each solution point. The minimum value of $R$ was found by searching through the $R$ values for each layer and for each solution point. In the case of the circ-wound cylinders, C6-4 and G6-1, where the individual layers were not distinguishable, the analysis was done using four layers. Again, three solution points per layer were computed.

The specified layer strengths used in the failure criteria are the same as used in the parametric study (see Table 1.1-4). Prior to conducting the tests on the all circ-wound cylinders, the allowable transverse compressive strengths were assumed to be $15 \mathrm{ksi}$ for the IM6/ERL2258 material and $20 \mathrm{ksi}$ for the S-GLASS/ERL2258 material. The results based on the preliminary design strengths are presented in Table 1.5-1. After the all circ-wound cylinder tests were conducted, it was determined that the IM6/ERL2258 material had a transverse compressive strength of $30 \mathrm{ksi}$ and the S-GLASS/ERL2258 material had a transverse compressive strength of $45 \mathrm{ksi}$. These results are from the C6-4 and G6-1 tests, respectively. The revised failure predictions based on the experimentally determined strengths are presented in Table 1.5-2. 
The results in Tables 1.5-1 and 1.5-2 show that all criteria used in the failure analysis predict an increase in the allowable pressure for first-ply failure when the transverse compressive strength is increased. As stated above, the application of Hashin's criteria identifies one of four different failure modes associated with the pressure at first-ply failure. For an allowable transverse compressive strength of $15 \mathrm{ksi}$, the results for the C6-1 cylinder indicate a compressive matrix mode of failure in the innermost hoop ply. An increase in the allowable transverse compressive strength to $30 \mathrm{ksi}$ changes the failure mode to a compressive fiber mode in the same ply. The mode of failure for the all circ-wound graphitereinforced cylinder, C6-4, and the four S-GLASS cylinders is a compressive matrix mode and does not change when their respective transverse compressive strengths are increased. Therefore, the 2:1 hoop:axial graphite-reinforced cylinder, C6-1, is the only cylinder construction tested for which Hashin's criteria predicts a fiber-dominated mode of failure.

From Table 1.5-2, the location of the first-ply failure for C6-1 is the innermost hoop ply and the maximum pressure is directly related to the allowable ply axial compressive strength, $\mathrm{X}_{c}$, and the calculated hoop stress at the inner radius of the cylinder wall. In this case, the results for Hashin's criteria predict a failure pressure which is equal to the maximum stress prediction. Different results are obtained from Hashin's criteria and the maximum stress criteria when an allowable compressive strength of $15 \mathrm{ksi}$ is applied (see Table 1.5-1). In this case, the maximum stress criterion predicts transverse matrix failure of the outermost hoop layer and the Hashin criteria predicts the innermost ply will fail first. This difference is caused by the influence of the radial stress component in the Hashin prediction. The radial stress value approximately equals the applied hydrostatic pressure at the outermost ply, whereas the stress value is nearly zero for the innermost ply. The compressive radial stress increases the $\mathbf{R}$ value in the Hashin compressive matrix mode criterion.

Results for the maximum stress criterion in Table 1.5-1 indicate that the ply transverse stress (global axial stress) in the outer hoop layer is the critical stress component when a transverse compressive strength of $15 \mathrm{ksi}$ is used in the one-dimensional maximum stress criterion. When a transverse compressive strength of $30 \mathrm{ksi}$ is used, the hoop stress in the inner hoop layer becomes the critical component. Therefore, based on a maximum stress criterion the failure mode for $\mathrm{C} 6-1$ switches from a transverse or matrix compressive mode to an axial or fiber compressive mode when the material has an allowable transverse compressive strength of $30 \mathrm{ksi}$.

In using Hashin's criteria, the first ply to fail in a compressive matrix mode for the all-circ-wound cylinders, G6-1 and C6-4, is the innermost hoop ply located at the inner radius of the cylinder wall. This result is true for both the preliminary design strengths and the experimentally determined strengths. The one-dimensional maximum stress criterion predicts first ply failure to occur not in the innermost hoop layer but in the outermost hoop layer. For the 6:1, 4:1, and 2:1 hoop:axial glass-reinforced cylinder designs, G6-3, G6-2, and G6-4, respectively, Hashin's criteria and the maximum stress criterion predict first ply failure in the innermost axial layer instead of the innermost or outermost hoop layer.

Two examples of the mode transition from compressive matrix to compressive fiber are illustrated in Fig. 1.5-1 where the predicted failure pressure from Hashin's criteria is plotted as a function of the transverse compressive strength, $Y_{c^{*}}$. Results are plotted for the 2:1 hoop:axial graphite-reinforced cylinder, C6-1, and the 2:1 hoop:axial glass-reinforced cylinder, G6-4. The results based on the Tsai-Wu criterion are also presented. This figure 
illustrates that drastically different results are obtained when analyzing a glass-reinforced epoxy material system for first-ply failure as compared with a graphite-reinforced epoxy material system. Much higher transverse compressive strengths are needed in the S-GLASS/ERL2258 glass/epoxy system to achieve the same maximum pressure for first-ply failure versus the IM6/ERL2258 graphite/epoxy system. Also, the mode transition from compressive matrix to compressive fiber, demonstrated by the zero slope portion of the plotted Hashin results, occurs at a much higher transverse compressive strength in the glass/epoxy cylinder than in the graphite/epoxy cylinder. Realistically, obtainable strengths for the glass/epoxy system fall well below the mode transition point, and first-ply failure in a glass/epoxy cylinder design will always be a compressive matrix mode of failure.

Large differences are also seen in Fig. 1.5-1 when comparing Hashin's criteria with the Tsai-Wu criterion for first-ply failure in the two different material systems. The Tsai-Wu criterion, which does not distinguish between different failure modes, predicts a first-ply failure pressure which is an increasing function of the allowable transverse compressive strength. As the transverse compressive strength is increased, the predicted pressure based on the Tsai-Wu criterion begins to diverge from the Hashin criteria results, with very large discrepancies occurring when Hashin's criteria predict a change in failure mode. For the transverse compressive strengths measured in this investigation, there is good agreement between the Tsai-Wu and Hashin predictions for the S-GLASS/ERL2258 glass/epoxy system. However, for the IM6/ERL2258 graphite/epoxy system, the Tsai-Wu criterion predicts a much larger first-ply failure pressure than Hashin's criteria.

Table 1.5-1. Failure analysis results for assumed preliminary strengths

\begin{tabular}{lcccccccc}
\hline & \multicolumn{2}{c}{ Tsai-Wu } & \multicolumn{2}{c}{ Hashin } & \multicolumn{2}{c}{ Max. stress } & \multicolumn{2}{c}{ Max. strain } \\
\cline { 2 - 8 } Cylinder & $\mathrm{p}_{\sigma}(\mathrm{ksi})$ & Layer & $\mathrm{p}_{\sigma}(\mathrm{ksi})$ & Layer & $\mathrm{p}_{\alpha}(\mathrm{ksi})$ & Layer & $\mathrm{p}_{\alpha}(\mathrm{ksi})$ & Layer \\
\hline $\mathrm{C} 6-1$ & 21.830 & 1 & $20.219^{a}$ & 1 & 13.659 & 38 & 24.338 & 3 \\
$\mathrm{C} 6-4$ & 4.7601 & 1 & $4.6418^{a}$ & 1 & 4.1978 & 4 & 4.9056 & 4 \\
$\mathrm{G} 6-1$ & 6.4430 & 1 & $6.0847^{a}$ & 1 & 5.7423 & 4 & 7.6322 & 4 \\
G6-2 & 7.1262 & 3 & $6.7819^{a}$ & 3 & 6.5579 & 3 & 8.0248 & 3 \\
G6-3 & 6.3226 & 3 & $6.0422^{a}$ & 3 & 5.8109 & 3 & 7.1428 & 3 \\
G6-4 & 6.4447 & 3 & $6.1785^{a}$ & 3 & 6.0470 & 3 & 7.0892 & 3 \\
\hline
\end{tabular}

a Compressive matrix mode 
Table 1.5-2. Failure analysis results for experimental strengths

\begin{tabular}{lcccccccc}
\hline \multirow{2}{*}{ Cylinder } & \multicolumn{2}{c}{ Tsai-Wu } & \multicolumn{2}{c}{ Hashin } & \multicolumn{2}{c}{ Max. stress } & \multicolumn{2}{c}{ Max. strain } \\
\cline { 2 - 8 } & $\mathrm{P}_{\sigma}$ (ksi) & Layer & $\mathrm{P}_{\sigma}(\mathrm{kss})$ & Layer & $\mathrm{P}_{\sigma}$ (ksi) & Layer & $\mathrm{P}_{\sigma}$ (ksi) & Layer \\
\hline C6-1 & 45.691 & 1 & $25.720^{\circ}$ & 1 & 25.720 & 1 & 26.347 & 1 \\
C6-4 & 9.7462 & 1 & $9.2836^{b}$ & 1 & 8.3956 & 4 & 9.8112 & 4 \\
G6-1 & 15.351 & 1 & $13.691^{b}$ & 1 & 12.920 & 4 & 17.172 & 4 \\
G6-2 & 17.356 & 3 & $15.963^{b}$ & 3 & 14.755 & 3 & 18.056 & 3 \\
G6-3 & 15.413 & 3 & $14.326^{b}$ & 3 & 13.075 & 3 & 16.071 & 3 \\
G6-4 & 15.429 & 3 & $14.309^{b}$ & 3 & 13.606 & 3 & 15.951 & 3 \\
\hline
\end{tabular}

a Compressive fiber mode

${ }^{b}$ Compressive matrix mode

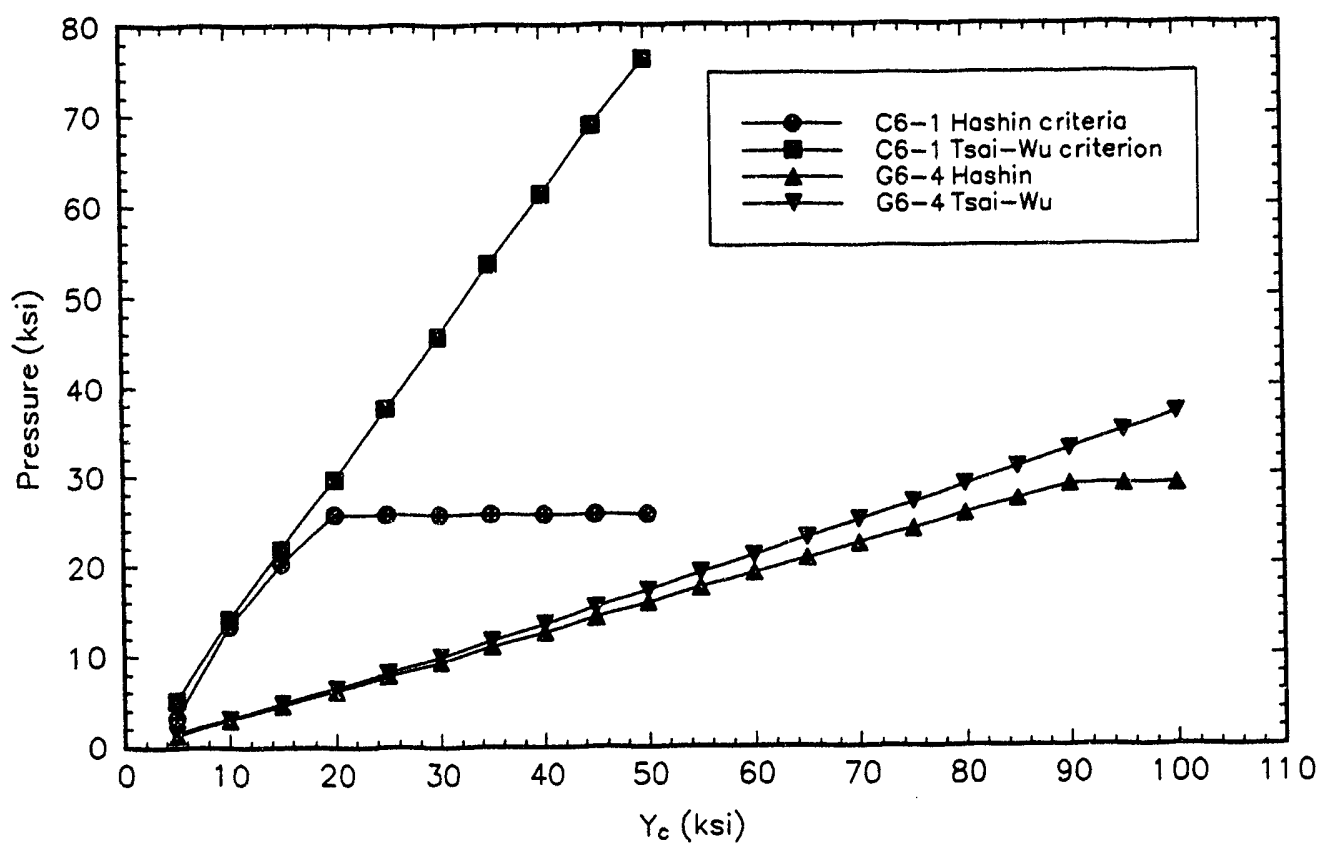

Fig. 1.5-1. Predicted first-ply failure pressures for different values of $\mathbf{Y}_{c}$. 


\section{TEST ARTICLE FABRICATION}

All test articles were wet wound on an aluminum mandrel using a four-axis, computer-controlled winding machine. The aluminum mandrel had a nominal 5.31-in. diameter and was 30 in. long. A combination comb and roller feedeye was used to maintain fiber placement during axial and hoop fabrication. Sprocket-shaped "pin-rings" were attached to each end of the mandrel to maintain placement of the axial strands for cylinders G6-2, G6-3, and G6-4. A modified pin-ring for improved tensioning of the axial layers was used for $\mathrm{G} 6-4$. Winding pattern band advance for the axial layers was chosen to maximize coverage for the increasing part diameter. The band advance was calculated on the basis of an assumed wall thickness buildup and an assumed bandwidth. Axial layer band advance calculations for cylinders G6-2, G6-3, and G6-4 are listed in Tables 2-1, 2-2, and 2-3, respectively.

The materials of construction for the hoop layers in G6-1 and for both the axial and hoop layers in cylinders G6-2, G6-3, and G6-4 were Owens-Corning S-Glass fiber and Union Carbide ERL2258, a 50/50 blend of diglycidyl ether of bisphenol A and bis (2,3 epoxycyclopentyl) ether. For the C6-4 graphite-reinforced cylinder, a Hercules IM6-G graphite fiber was used with the Union Carbide ERL2258 resin. Both systems were cured with $25 \mathrm{pphr}$ m-phenylenediamine.

The nominal processing conditions utilized for the cylinder designs are described below. The 30-in. long aluminum mandrel was preheated to $130^{\circ} \mathrm{F}$ prior to initiating fabrication. The resin temperature was maintained between $125^{\circ} \mathrm{F}$ and $135^{\circ} \mathrm{F}$ during impregnation, and heat was applied to the mandrel during the winding operation to promote resin bleed-out. The glass fiber tows were tensioned at the 8- to 9-1b range during hoop winding and the 4- to 5-lb range during axial winding. The modified pin rings used for G6-4 featured a groove for wrapping additional hoop material over the axial layers for added tensioning. The tensioning used for hoop winding the graphite tows was 11 to $12 \mathrm{lb}$.

The glass fiber cylinders were fabricated in two stages with a full cure between stages. The incremental full cure was performed at a thickness of approximately 0.25 in.. The C6-4 graphite-reinforced cylinder was also fabricated in two stages but with a B-staged cure, approximately $130^{\circ} \mathrm{F}$, for a minimum of 16 hours between stages. The incremental B-staged cure was performed at a thickness of approximately 0.25 in.. After completion of the winding, the parts were staged at $130^{\circ} \mathrm{F}$ for $16 \mathrm{hr}$. and then cured in a forced air oven. The parts were ramped to $185^{\circ} \mathrm{F}$, held for two $\mathrm{hr}$., ramped to $305^{\circ} \mathrm{F}$, held for four $\mathrm{hr}$., and allowed to cool to ambient overnight. The cylinders were removed from the mandrel by chilling the part and mandrel with liquid nitrogen. The cylinders were sampled for composition and dimensionally inspected.

The as-fabricated composition of the test articles was determined by sampling the material at each end of the cylinders. Three samples were taken from the head stock and the tail stock and then averaged. The results for the density, percent volume fraction of fibers $\left(V_{t}\right)$, percent volume fraction of resin $\left(V_{t}\right)$, and percent volume fraction of voids $\left(V_{v}\right)$ are presented in Tables 2-4, 2-5, 2-6, 2-7, and 2-8 for cylinders G6-1, G6-2, G6-3, G6-4, and C6-4, respectively. Composition data were determined for G6-3 by sampling only the material at the head stock. A very low percentage of voids was achieved in the test articles, with the exception of the circ-wound graphite-reinforced cylinder, C6-4, which had a $2.54 \%$ void content. 
Table 2-1. Band advance calculations for cylinder G6-2

\begin{tabular}{|c|c|c|c|c|c|c|}
\hline & Layer & $\begin{array}{l}\text { Added } \\
\text { thickness } \\
\text { (in.) }\end{array}$ & $\begin{array}{l}\text { Added } \\
\text { diameter } \\
\text { (in.) }\end{array}$ & $\begin{array}{c}\text { Part } \\
\text { diameter } \\
\text { (in.) }\end{array}$ & $\begin{array}{c}\text { Circum. } \\
\text { (in.) }\end{array}$ & $\begin{array}{c}\text { Band } \\
\text { advance } \\
\text { (degrees) }\end{array}$ \\
\hline \multirow[t]{2}{*}{0} & Mandrel & & & 5.310 & 16.682 & \\
\hline & 5 hoops & 0.035 & 0.070 & 5.380 & 16.902 & 6.816 \\
\hline \multirow[t]{2}{*}{1} & 2 axials & 0.014 & 0.028 & 5.408 & 16.990 & \\
\hline & 8 hoops & 0.056 & 0.112 & 5.520 & 17.342 & 6.643 \\
\hline \multirow[t]{2}{*}{2} & 2 axials & 0.014 & 0.028 & 5.548 & 17.430 & \\
\hline & 8 hoops & 0.056 & 0.112 & 5.660 & 17.781 & 6.479 \\
\hline \multirow[t]{2}{*}{3} & 2 axials & 0.014 & 0.028 & 5.688 & 17.869 & \\
\hline & 8 hoops & 0.056 & 0.112 & 5.800 & 18.221 & 6.322 \\
\hline \multirow[t]{2}{*}{4} & 2 axials & 0.014 & 0.028 & 5.828 & 18.309 & \\
\hline & 8 hoops & 0.056 & 0.112 & 5.940 & 18.661 & 6.173 \\
\hline \multirow[t]{2}{*}{5} & 2 axials & 0.014 & 0.028 & 5.968 & 18.749 & \\
\hline & 8 hoops & 0.056 & 0.112 & 6.080 & 19.101 & 6.031 \\
\hline \multirow[t]{2}{*}{6} & 2 axials & 0.014 & 0.028 & 6.108 & 19.189 & \\
\hline & 8 hoops & 0.056 & 0.112 & 6.220 & 19.541 & 5.895 \\
\hline \multirow[t]{2}{*}{7} & 2 axials & 0.014 & 0.028 & 6.248 & 19.629 & \\
\hline & 5 hoops & 0.035 & 0.070 & 6.318 & 19.849 & \\
\hline
\end{tabular}


Table 2-2. Band advance calculations for cylinder G6-3

\begin{tabular}{|c|c|c|c|c|c|c|}
\hline & Layer & $\begin{array}{l}\text { Added } \\
\text { thickness } \\
\text { (in.) }\end{array}$ & $\begin{array}{l}\text { Added } \\
\text { diameter } \\
\text { (in: }\end{array}$ & $\begin{array}{c}\text { Part } \\
\text { diameter } \\
\text { (in.) }\end{array}$ & $\begin{array}{c}\text { Circum. } \\
\text { (in.) }\end{array}$ & $\begin{array}{c}\text { Band } \\
\text { advance } \\
\text { (degrees) }\end{array}$ \\
\hline \multirow[t]{2}{*}{0} & Mandrel & & & 5.310 & 16.682 & \\
\hline & 7 hoops & 0.049 & 0.098 & 5.408 & 16.990 & 6.781 \\
\hline \multirow[t]{2}{*}{1} & 2 axials & 0.014 & 0.028 & 5.436 & 17.078 & \\
\hline & 12 hoops & 0.084 & 0.168 & 5.604 & 17.605 & 6.543 \\
\hline \multirow[t]{2}{*}{2} & 2 axials & 0.014 & 0.028 & 5.632 & 17.693 & \\
\hline & 12 hoops & 0.084 & 0.168 & 5.800 & 18.221 & 6.322 \\
\hline \multirow[t]{2}{*}{3} & 2 axials & 0.014 & 0.028 & 5.828 & 18.309 & \\
\hline & 12 hoops & 0.084 & 0.168 & 5.996 & 18.837 & 6.116 \\
\hline \multirow[t]{2}{*}{4} & 2 axials & 0.014 & 0.028 & 6.024 & 18.925 & \\
\hline & 12 hoops & 0.084 & 0.168 & 6.192 & 19.453 & 5.922 \\
\hline \multirow[t]{2}{*}{5} & 2 axials & 0.014 & 0.028 & 6.220 & 19.541 & \\
\hline & 7 hoops & 0.049 & 0.098 & 6.318 & 19.849 & \\
\hline
\end{tabular}


Table 2-3. Band advance calculations for cylinder G6-4

\begin{tabular}{|c|c|c|c|c|c|c|}
\hline & Layer & $\begin{array}{l}\text { Added } \\
\text { thickness } \\
\text { (in.) }\end{array}$ & $\begin{array}{l}\text { Added } \\
\text { diameter } \\
\text { (in.) }\end{array}$ & $\begin{array}{c}\text { Part } \\
\text { diameter } \\
\text { (in.) }\end{array}$ & $\begin{array}{l}\text { Circum. } \\
\text { (in.) }\end{array}$ & $\begin{array}{c}\text { Band } \\
\text { advance } \\
\text { (degrees) }\end{array}$ \\
\hline \multirow[t]{2}{*}{0} & Mandrel & & & 5.3100 & 16.6819 & \\
\hline & 3 hoops & 0.0219 & 0.0438 & 5.3538 & 16.8195 & 6.7925 \\
\hline \multirow[t]{2}{*}{1} & 2 axiaks & 0.0146 & 0.0292 & 5.3830 & 16.9112 & \\
\hline & 4 hoops & 0.0292 & 0.0584 & 5.4414 & 17.0947 & 6.6667 \\
\hline \multirow[t]{2}{*}{2} & 2 axials & 0.0146 & 0.0292 & 5.4706 & 17.1864 & \\
\hline & 4 hoops & 0.0292 & 0.0584 & 5.5290 & 17.3699 & 6.6055 \\
\hline \multirow[t]{2}{*}{3} & 2 axials & 0.0146 & 0.0292 & 5.5582 & 17.4616 & \\
\hline & 4 boops & 0.0292 & 0.0584 & 5.6166 & 17.6451 & 6.4865 \\
\hline \multirow[t]{2}{*}{4} & 2 axials & 0.0146 & 0.0292 & 5.6458 & 17.7368 & \\
\hline & 4 hoops & 0.0292 & 0.0584 & 5.7042 & 17.9203 & 6.3717 \\
\hline \multirow[t]{2}{*}{5} & 2 axials & 0.0146 & 0.0292 & 5.7334 & 18.0120 & \\
\hline & 4 hoops & 0.0292 & 0.0584 & 5.7918 & 18.1955 & 6.3158 \\
\hline \multirow[t]{2}{*}{6} & 2 axials & 0.0146 & 0.0292 & 5.8210 & 18.2872 & \\
\hline & 4 hoops & 0.0292 & 0.0584 & 5.8794 & 18.4707 & 6.2069 \\
\hline \multirow[t]{2}{*}{7} & 2 axials & 0.0146 & 0.0292 & 5.9086 & 18.5624 & \\
\hline & 4 boops & 0.0292 & 0.0584 & 5.9670 & 18.7459 & 6.1017 \\
\hline \multirow[t]{2}{*}{8} & 2 axials & 0.0146 & 0.0292 & 5.9962 & 18.8376 & \\
\hline & 4 hoops & 0.0292 & 0.0584 & 6.0546 & 19.0211 & 6.0000 \\
\hline \multirow[t]{2}{*}{9} & 2 axials & 0.0146 & 0.0292 & 6.0838 & 19.1128 & \\
\hline & 4 hoops & 0.0292 & 0.0584 & 6.1422 & 19.2963 & 5.9504 \\
\hline \multirow[t]{2}{*}{10} & 2 axials & 0.0146 & 0.0292 & 6.1714 & 19.3880 & \\
\hline & 4 boops & 0.0292 & 0.0584 & 6.2298 & 19.5715 & 5.8537 \\
\hline \multirow[t]{2}{*}{11} & 2 axials & 0.0146 & 0.0292 & 6.2590 & 19.6632 & \\
\hline & 3 hoops & 0.0219 & 0.0438 & 6.3028 & 19.8008 & \\
\hline
\end{tabular}


Table 2-4. Composition data for cylinder G6-1

\begin{tabular}{ccccccccc}
\hline & \multicolumn{3}{c}{ Head stock } & \multicolumn{5}{c}{ Tail stock } \\
\cline { 2 - 9 } & Sample 1 & Sample 2 & Sample 3 & Avg. & Sample 1 & Sample 2 & Sample 3 & Avg. \\
\hline $\begin{array}{c}\text { Density } \\
(\mathrm{g} / \mathrm{cc})\end{array}$ & 2.2210 & 2.2206 & - & 2.2208 & 2.2238 & 2.2236 & - & 2.2237 \\
\hline$V_{f}(\%)$ & 79.78 & 80.03 & 79.89 & 79.90 & 79.88 & 80.13 & 79.99 & 80.00 \\
$V_{r}(\%)$ & 19.22 & 18.72 & 19.00 & 18.98 & 19.25 & 18.74 & 19.02 & 19.00 \\
$V_{v}(\%)$ & 1.00 & 1.25 & 1.11 & 1.12 & 0.87 & 1.13 & 0.99 & 1.00 \\
\hline
\end{tabular}

Table 2-5. Composition data for cylinder G6-2

\begin{tabular}{ccccccccc}
\hline & \multicolumn{3}{c}{ Head stock } & \multicolumn{5}{c}{ Tail stock } \\
\cline { 2 - 9 } & Sample 1 & Sample 2 & Sample 3 & Avg. & Sample 1 & Sample 2 & Sample 3 & Avg. \\
\hline $\begin{array}{c}\text { Density } \\
(g / c c)\end{array}$ & 2.1188 & 2.1183 & - & 2.1186 & 2.1297 & 2.1280 & - & 2.1289 \\
\hline$V_{f}(\%)$ & 72.04 & 72.08 & 72.36 & 72.16 & 72.71 & 72.70 & 72.70 & 72.70 \\
$V_{r}(\%)$ & 26.47 & 26.40 & 25.83 & 26.23 & 25.98 & 26.00 & 26.01 & 26.00 \\
$V_{v}(\%)$ & 1.49 & 1.52 & 1.81 & 1.61 & 1.31 & 1.30 & 1.29 & 1.30 \\
\hline
\end{tabular}

Table 2-6. Composition data for cylinder G6-3

\begin{tabular}{ccccccccc}
\hline & \multicolumn{3}{c}{ Head stock } & \multicolumn{5}{c}{ Tail stock } \\
\cline { 2 - 9 } & Sample 1 & Sample 2 & Sample 3 & Avg. & Sample 1 & Sample 2 & Sample 3 & Avg. \\
\hline $\begin{array}{c}\text { Density } \\
(\mathrm{g} / \mathrm{cc})\end{array}$ & 2.1946 & 2.1946 & - & 2.1946 & - & - & - & - \\
\hline $\mathrm{V}_{\mathrm{f}}(\%)$ & 77.68 & 77.69 & 77.78 & 77.72 & - & - & - & - \\
$\mathrm{V}_{\mathrm{r}}(\%)$ & 21.31 & 21.30 & 21.11 & 21.24 & - & - & - & - \\
$\mathrm{V}_{\mathrm{v}}(\%)$ & 1.01 & 1.01 & 1.11 & 1.04 & - & - & - & - \\
\hline
\end{tabular}

Table 2-7. Composition data for cylinder G6-4

\begin{tabular}{ccccccccc}
\hline & \multicolumn{4}{c}{ Head stock } & \multicolumn{5}{c}{ Tail stock } \\
\cline { 2 - 9 } & Sample 1 & Sample 2 & Sample 3 & Avg. & Sample 1 & Sample 2 & Sample 3 & Avg. \\
\hline $\begin{array}{c}\text { Density } \\
(\mathrm{g} / \mathrm{cc})\end{array}$ & 2.1085 & 2.1085 & 2.1085 & 2.1085 & 2.1030 & 2.1030 & 2.1030 & 2.1030 \\
\hline $\mathrm{V}_{\mathrm{f}}(\%)$ & 71.02 & 71.04 & 70.87 & 70.98 & 70.37 & 70.35 & 70.47 & 70.40 \\
$\mathrm{~V}_{\mathrm{r}}(\%)$ & 27.70 & 27.67 & 28.01 & 27.79 & 28.58 & 28.61 & 28.37 & 28.52 \\
$\mathrm{~V}_{\mathrm{v}}(\%)$ & 1.27 & 1.29 & 1.12 & 1.23 & 1.05 & 1.04 & 1.16 & 1.08 \\
\hline
\end{tabular}


Table 2-8. Composition data for cylinder $\mathrm{C} 6-4$

\begin{tabular}{ccccccccc}
\hline & \multicolumn{3}{c}{ Head stock } & \multicolumn{5}{c}{ Tail stock } \\
\cline { 2 - 9 } & Sample 1 & Sample 2 & Sample 3 & Avg. & Sample 1 & Sample 2 & Sample 3 & Avg. \\
\hline $\begin{array}{c}\text { Density } \\
(g / c c)\end{array}$ & 1.5668 & 1.5673 & - & 1.5671 & 1.5661 & 1.5657 & - & 1.5659 \\
\hline$V_{f}(\%)$ & 69.52 & 69.41 & 69.33 & 69.42 & 69.28 & 69.28 & 69.08 & 69.21 \\
$V_{r}(\%)$ & 27.82 & 27.97 & 28.09 & 27.96 & 28.16 & 28.16 & 28.44 & 28.25 \\
$V_{v}(\%)$ & 2.66 & 2.62 & 2.58 & 2.62 & 2.56 & 2.56 & 2.48 & 2.54 \\
\hline
\end{tabular}

The target tube dimensions were approximately 5.31-in. inside diameter (ID) and nominally 0.5 -in. thickness. The measured diameters and thickness of the G6-1 cylinder are shown in Tables 2-9 and 2-10, respectively. The inner and outer diameters of the cylinder were dimensionally inspected at 45-degree intervals around the circumference and at three places along its uncut length, e.g., head stock, center, and tail stock. The wall thickness was measured every $\mathbf{4 5}$ degrees around the circumference at the head stock, center, and tail stock. The dimensional inspection results indicated the G6-1 test article had a very uniform geometry with minimal variation in wall thickness around the circumference and from one end to the other. All of the target fabrication dimensions were within the specified tolerance.

The cylinder was machined to its test length of 17 in., then dimensionally inspected for radial run-out at 10-degree intervals. The total indicator reading (TIR) given in Table 2-19 is calculated as the algebraic difference between the maximum positive radial run-out and the maximum negative radial run-out as the test article is rotated through 360 degrees. The TIR for the ID is very small because the part conforms to the mandrel during cure and the mandrel is precision machined with very close tolerances. The TIR measurement taken for the OD is one of the key parameters in ascertaining the quality of the fabrication effort. For G6-1, the largest TIR was measured in the head stock region and was equal to 0.0017 in.. This magnitude of TIR is considered to be reflective of a very high quality test article in terms of geometric imperfections.

The dimensional inspection results for G6-2 are presented in Tables 2-11 and 2-12, where the inner and outer diameter measurements are shown in Table 2-11 and the wall thicknesses are shown in Table 2-12. The diameter and wall thickness were measured every 22.5 degrees around the circumference. The diameter was measured at the head stock, tail stock, and center, whereas the wall thickness was measured only at the two ends. The fabrication of the G6-2 test article utilized the technique of compaction rollers for increasing the fiber volume fraction. However, the use of this technique produced flat spots on the OD of the test article. Correspondingly, according to Table 2-12 there were variations in the wall thickness. Also, the TIR, as shown in Table 2-19, was as large as 0.007 in..

Based on the composition data for the four glass-reinforced test articles, the use of compaction rollers does not appear to have as strong an affect on the fiber volume fraction as the laminate stacking sequence used in the cylinder construction. The composition data results indicate the fiber volume fraction decreased as the fraction of axial layers in the 
stacking sequence increased. It is believed the axial layers have a lower fiber volume fraction than the hoop layers. Consequently, the more axial layers used in the fabrication, i.e., the lower the hoop:axial ply ratio is, the lower the fiber volume fraction will be for the composite.

In Tables 2-13 and 2-14, the G6-3 diameter and wall thickness measurements are shown. The inspection procedure was the same as described for G6-2 with the addition of taking thickness measurements at the center section. As a result of the flat spots produced in G6-2, compaction rollers were not used for the fabrication of G6-3. The G6-3 test article had a greater dimensional variation between the head stock results and the tail stock results than was seen in previous fabrications, and the wall thickness fell short of the target dimension. Therefore, a shorter test length of 15 in. was required due to buckling considerations. Also, the 15 -in. test section was machined from the 26 -in. overall length by cutting the cylinder length from the head stock end instead of cutting an equal amount of excess material off both the head stock and tail stock ends.

The diameter and wall thickness measurements for G6-4 are given in Tables 2-15 and $2-16$, respectively. These results are indicative of a cylinder that is uniform from head stock to tail stock and around the circumference. The TIR given if Table 2-19 is higher than expected based on the diameter and thickness readings and may be attributed to the surface finish achieved during fabrication of this test article.

The dimensional inspections results for the circ-wound graphite-reinforced cylinder, C6-4, are given in Tables 2-17 and 2-18 for the diameters and wall thicknesses, respectively. The wall thickness measurements were only taken at the ends of the cylinder. These results are within the specified tolerances and in conjunction with the TIR results in Table 2-19 indicate a high quality part with very little geometric imperfections. The TIR results for cylinder C6-1 (2:1 hoop:axial graphite/epoxy) are included for reference. 
Table 2-9. Dimensional inspection results for G6-1 inner and outer diameters

\begin{tabular}{lcccc}
\hline & Location & Head stock & Center & Tail stock \\
\hline Inner diameter (in.) & 0.0 & 5.3101 & 5.3106 & 5.3098 \\
& 45.0 & 5.3098 & 5.3105 & 5.3097 \\
& 90.0 & 5.3099 & 5.3106 & 5.3100 \\
& 135.0 & 5.3100 & 5.3107 & 5.3101 \\
& & & & \\
& AVG. & 5.3100 & 5.3106 & 5.3099 \\
\hline Outer diameter $($ in.) & & & & \\
& 0.0 & 6.3220 & 6.3199 & 6.3210 \\
& 45.0 & 6.3223 & 6.3210 & 6.3209 \\
& 90.0 & 6.3219 & 6.3213 & 6.3212 \\
& 135.0 & 6.3227 & 6.3220 & 6.3213 \\
& & & & \\
& AVG. & 6.3222 & 6.3211 & 6.3211 \\
\hline
\end{tabular}

Table 2-10. Dimensional inspection results for G6-1 wall thickness

\begin{tabular}{cccc}
\hline Location & Head stock & Center & Tail stock \\
\hline 0.0 & 0.5043 & 0.5050 & 0.5051 \\
45.0 & 0.5044 & 0.5055 & 0.5049 \\
90.0 & 0.5049 & 0.5052 & 0.5040 \\
135.0 & 0.5049 & 0.5051 & 0.5048 \\
180.0 & 0.5051 & 0.5057 & 0.5058 \\
225.0 & 0.5052 & 0.5050 & 0.5057 \\
270.0 & 0.5059 & 0.5055 & 0.5051 \\
315.0 & 0.5058 & 0.5056 & 0.5053 \\
& & & 0.5051 \\
\hline
\end{tabular}


Table 2-11. Dimensional inspection results for G6-2 inner and outer diameters

\begin{tabular}{|c|c|c|c|c|}
\hline & Location & Head stock & Center & Tail stock \\
\hline \multirow[t]{9}{*}{ Inner diameter (in.) } & 0.0 & 5.3106 & 5.3106 & 5.3104 \\
\hline & 22.5 & 5.3105 & 5.3106 & 5.3104 \\
\hline & 45.0 & 5.3105 & 5.3105 & 5.3103 \\
\hline & 67.5 & 5.3105 & 5.3106 & 5.3103 \\
\hline & 90.0 & 5.3100 & 5.3105 & 5.3105 \\
\hline & 112.5 & 5.3101 & 5.3106 & 5.3106 \\
\hline & 135.0 & 5.3102 & 5.3105 & 5.3106 \\
\hline & 157.5 & 5.3103 & 5.3105 & 5.3106 \\
\hline & AVG. & 5.3103 & 5.3106 & 5.3105 \\
\hline \multirow[t]{9}{*}{ Outer diameter (in.) } & 0.0 & 6.3405 & 6.3350 & 6.3410 \\
\hline & 22.5 & 6.3410 & 6.3337 & 6.3355 \\
\hline & 45.0 & 6.3410 & 6.3349 & 6.3410 \\
\hline & 67.5 & 6.3380 & 6.3347 & 6.3388 \\
\hline & 90.0 & 6.3398 & 6.3319 & 6.3375 \\
\hline & 112.5 & 6.3390 & 6.3360 & 6.3385 \\
\hline & 135.0 & 6.3420 & 6.3345 & 6.3390 \\
\hline & 157.5 & 6.3390 & 6.3359 & 6.3409 \\
\hline & AVG. & 6.3400 & 6.3346 & 6.3390 \\
\hline
\end{tabular}


Table 2-12. Dimensional inspection results for G6-2 wall thickness

\begin{tabular}{cccc}
\hline Location & Head stock & Center & Tail stock \\
\hline 0.0 & 0.5141 & - & 0.5135 \\
22.5 & 0.5140 & - & 0.5105 \\
45.0 & 0.5142 & - & 0.5126 \\
67.5 & 0.5150 & - & 0.5131 \\
90.0 & 0.5133 & - & 0.5152 \\
112.5 & 0.5131 & - & 0.5140 \\
135.0 & 0.5164 & - & 0.5151 \\
157.5 & 0.5130 & - & 0.5140 \\
180.0 & 0.5155 & - & 0.5150 \\
202.5 & 0.5131 & - & 0.5132 \\
225.0 & 0.5160 & - & 0.5095 \\
247.5 & 0.5133 & - & 0.5120 \\
270.0 & 0.5134 & - & 0.5110 \\
292.5 & 0.5150 & - & 0.5140 \\
315.0 & 0.5145 & - & 0.5110 \\
337.5 & 0.5140 & - & 0.5150 \\
& & - & 0.5130 \\
AVG. & 0.5142 & &
\end{tabular}


Table 2-13. Dimensional inspection results for G6-3 inner and outer diameters

\begin{tabular}{|c|c|c|c|c|}
\hline & Location & Head stock & Center & Tail stock \\
\hline \multirow[t]{9}{*}{ Inner diameter (in.) } & 0.0 & 5.3088 & 5.3090 & 5.3091 \\
\hline & 22.5 & 5.3084 & 5.3091 & 5.3091 \\
\hline & 45.0 & 5.3087 & 5.3089 & 5.3093 \\
\hline & 67.5 & 5.3089 & 5.3091 & 5.3093 \\
\hline & 90.0 & 5.3088 & 5.3089 & 5.3093 \\
\hline & 112.5 & 5.3088 & 5.3090 & 5.3091 \\
\hline & 135.0 & 5.3091 & 5.3089 & 5.3089 \\
\hline & 157.5 & 5.3090 & 5.3092 & 5.3090 \\
\hline & AVG. & 5.3088 & 5.3090 & 5.3091 \\
\hline \multirow[t]{9}{*}{ Outer diameter (in.) } & 0.0 & 6.2410 & 6.2500 & 6.2490 \\
\hline & 22.5 & 6.2610 & 6.2600 & 6.2630 \\
\hline & 45.0 & 6.2590 & 6.2700 & 6.2620 \\
\hline & 67.5 & 6.2590 & 6.2590 & 6.2630 \\
\hline & 90.0 & 6.2620 & 6.2500 & 6.2570 \\
\hline & 112.5 & 6.2660 & 6.2790 & 6.2550 \\
\hline & 135.0 & 6.2470 & 6.2620 & 6.2520 \\
\hline & 157.5 & 6.2710 & 6.2740 & 6.2590 \\
\hline & AVG. & 6.2583 & 6.2630 & 6.2575 \\
\hline
\end{tabular}


Table 2-14. Dimensional inspection results for G6-3 wall thickness

\begin{tabular}{cccc}
\hline Location & Head stock & Center & Tail stock \\
\hline 0.0 & 0.4720 & 0.4740 & 0.4670 \\
22.5 & 0.4750 & 0.4760 & 0.4810 \\
45.0 & 0.4840 & 0.4830 & 0.4780 \\
67.5 & 0.4710 & 0.4790 & 0.4790 \\
90.0 & 0.4810 & 0.4790 & 0.4790 \\
112.5 & 0.4730 & 0.4790 & 0.4720 \\
135.0 & 0.4700 & 0.4750 & 0.4780 \\
157.5 & 0.4840 & 0.4850 & 0.4720 \\
180.0 & 0.4630 & 0.4750 & 0.4770 \\
202.5 & 0.4810 & 0.4790 & 0.4750 \\
225.0 & 0.4670 & 0.4810 & 0.4750 \\
247.5 & 0.4750 & 0.4770 & 0.4780 \\
270.0 & 0.4700 & 0.4680 & 0.4700 \\
292.5 & 0.4840 & 0.4920 & 0.4910 \\
315.0 & 0.4620 & 0.4740 & 0.4690 \\
337.5 & 0.4810 & 0.4830 & 0.4800 \\
& & & 0.4763 \\
AVG. & 0.4746 & 0.4787 &
\end{tabular}


Table 2-15. Dimensional inspection results for G6-4 inner and outer diameters

\begin{tabular}{|c|c|c|c|c|}
\hline & Location & Head stock & Center & Tail stock \\
\hline \multirow[t]{9}{*}{ Inner diameter (in.) } & 0.0 & 5.3121 & 5.3121 & 5.3111 \\
\hline & 22.5 & 5.3121 & 5.3121 & 5.3111 \\
\hline & 45.0 & 5.3123 & 5.3120 & 5.3112 \\
\hline & 67.5 & 5.3124 & 5.3121 & 5.3113 \\
\hline & 90.0 & 5.3123 & 5.3122 & 5.3112 \\
\hline & 112.5 & 5.3122 & 5.3121 & 5.3112 \\
\hline & 135.0 & 5.3123 & 5.3121 & 5.3113 \\
\hline & 157.5 & 5.3121 & 5.3119 & 5.3112 \\
\hline & AVG. & 5.3122 & 5.3121 & 5.3112 \\
\hline \multirow[t]{9}{*}{ Outer diameter (in.) } & 0.0 & 6.3090 & 6.3030 & 6.3060 \\
\hline & 22.5 & 6.3080 & 6.3020 & 6.3050 \\
\hline & 45.0 & 6.3050 & 6.3040 & 6.3050 \\
\hline & 67.5 & 6.3060 & 6.3040 & 6.3060 \\
\hline & 90.0 & 6.3080 & 6.3040 & 6.3040 \\
\hline & 112.5 & 6.3100 & 6.3060 & 6.3050 \\
\hline & 135.0 & 6.3080 & 6.3050 & 6.3050 \\
\hline & 157.5 & 6.3070 & 6.3050 & 6.3050 \\
\hline & AVG. & 6.3076 & 6.3041 & 6.3051 \\
\hline
\end{tabular}


82

Table 2-16. Dimensional inspection results for G6-4 wall thickness

\begin{tabular}{cccc}
\hline Location & Head stock & Center & Tail stock \\
\hline 0.0 & 0.4970 & 0.4950 & 0.4980 \\
22.5 & 0.4970 & 0.4950 & 0.4990 \\
45.0 & 0.4970 & 0.4980 & 0.4980 \\
67.5 & 0.4980 & 0.4950 & 0.4980 \\
90.0 & 0.4980 & 0.4960 & 0.4980 \\
112.5 & 0.4980 & 0.4960 & 0.4990 \\
135.0 & 0.4970 & 0.4970 & 0.4970 \\
157.5 & 0.4960 & 0.4960 & 0.4970 \\
& & & 0.4980 \\
\hline
\end{tabular}


Table 2-17. Dimensional inspection results for C6-4 inner and outer diameters

\begin{tabular}{|c|c|c|c|c|}
\hline & Location & Head stock & Center & Tail stock \\
\hline \multirow[t]{9}{*}{ Inner diameter (in.) } & 0.0 & 5.3178 & 5.3189 & 5.3177 \\
\hline & 22.5 & 5.3178 & 5.3187 & 5.3176 \\
\hline & 45.0 & 5.3177 & 5.3188 & 5.3177 \\
\hline & 67.5 & 5.3177 & 5.3188 & 5.3177 \\
\hline & 90.0 & 5.3178 & 5.3185 & 5.3177 \\
\hline & 112.5 & 5.3177 & 5.3186 & 5.3176 \\
\hline & 135.0 & 5.3177 & 5.3187 & 5.3177 \\
\hline & 157.5 & 5.3178 & 5.3188 & 5.3177 \\
\hline & AVG. & 5.3178 & 5.3187 & 5.3177 \\
\hline \multirow[t]{9}{*}{ Outer diameter (in.) } & 0.0 & 6.3195 & 6.3170 & 6.3230 \\
\hline & 22.5 & 6.3215 & 6.3180 & 6.3240 \\
\hline & 45.0 & 6.3190 & 6.3195 & 6.3235 \\
\hline & 67.5 & 6.3200 & 6.3190 & 6.3210 \\
\hline & 90.0 & 6.3190 & 6.3210 & 6.3210 \\
\hline & 112.5 & 6.3190 & 6.3210 & 6.3215 \\
\hline & 135.0 & 6.3180 & 6.3185 & 6.3215 \\
\hline & 157.5 & 6.3200 & 6.3190 & 6.3225 \\
\hline & AVG. & 6.3195 & 6.3191 & 6.3223 \\
\hline
\end{tabular}


Table 2-18. Dimensional inspection results for C6-4 wall thickness

\begin{tabular}{cccc}
\hline Location & Head stock & Center & Tail stock \\
\hline 0.0 & 0.5020 & - & 0.5025 \\
22.5 & 0.5020 & - & 0.5025 \\
45.0 & 0.5030 & - & 0.5020 \\
67.5 & 0.5030 & - & 0.5020 \\
90.0 & 0.5020 & - & 0.5030 \\
112.5 & 0.5025 & - & 0.5020 \\
135.0 & 0.5010 & - & 0.5020 \\
157.5 & 0.5015 & - & 0.5025 \\
180.0 & 0.5020 & - & 0.5025 \\
202.5 & 0.5020 & - & 0.5020 \\
225.0 & 0.5020 & - & 0.5030 \\
247.5 & 0.5020 & - & 0.5030 \\
270. l $^{\prime}$ & 0.5035 & - & 0.5035 \\
292.5 & 0.5020 & - & 0.5020 \\
315.0 & 0.5025 & - & 0.5025 \\
337.5 & 0.5030 & - & 0.5025 \\
& 0.5023 & & 0.5025 \\
AVG. & & - & \\
\hline & & - & - \\
\hline
\end{tabular}

Table 2-19. Dimensional inspection results for TIR

\begin{tabular}{ccccccc}
\hline & \multicolumn{2}{c}{ Head stock } & \multicolumn{2}{c}{ Center } & \multicolumn{2}{c}{ Tail stock } \\
\hline Cylinder & ID & OD & ID & OD & ID & OD \\
\hline G6-1 & 0.0003 & 0.0017 & 0.0004 & 0.0012 & 0.0003 & 0.0012 \\
G6-2 & 0.0005 & 0.0068 & 0.0004 & 0.0070 & 0.0006 & 0.0064 \\
G6-3 & 0.0006 & 0.0270 & 0.0006 & 0.0290 & 0.0004 & 0.0290 \\
G6-4 & 0.0003 & 0.0070 & 0.0005 & 0.0070 & 0.0004 & 0.0050 \\
C6-4 & 0.0004 & 0.0052 & 0.0002 & 0.0030 & 0.0007 & 0.0024 \\
C6-1 & 0.0006 & 0.0107 & 0.0006 & 0.0083 & 0.0005 & 0.0115 \\
\hline
\end{tabular}




\section{TEST ARTICLE TESTING}

Existing ASTM procedures and conventional test approaches are not adequate for characterizing composite materials under hydrostatic pressure. Efforts were directed at developing improved test methodologies and/or standard test methods for composite cylinders. In testing the cylinders described in this report, prototype test devices were designed, analyzed, and evaluated experimentally. The selection of prototype test devices for these cylinders was not based solely on the criteria of wide acceptance or universality but rather on the ability to control parameters which govern a particular mode of failure. It is recognized that different tests will likely be required to completely characterize the different modes of failure in compression.

The activities related to the test fixturing includes the development and design of improved end closures for hydrostatic testing of cylinders. This effort is aimed at reducing the discontinuity stresses at the cylinder ends that result from the use of rigid end closures. The end closure assembly developed for these tests is based on the concept of the contoured end plug which was originally proposed by Miller. ${ }^{23}$ The design is an improved concept end closure which incorporates an end plug with a tapered contour that achieves very low discontinuity stresses. For each of the cylinder constructions, the test assembly is analyzed to determine operational stress levels to insure end plug design adequacy (see Sect. 1.3.2). The details of this design and the supporting theory were reported on by Blake and Starbuck. ${ }^{6,12,18}$ Additional stress analysis capabilities are being developed with emphasis given to closed-form analytic solutions which permit the efficient design of end closures without having to resort to detailed finite element stress analysis.

The test articles were monitored using diagnostic methods for detecting failure initiation to facilitate identifying modes of failure. The test article instrumentation included electrical resistance strain gages and acoustic emission pickups. The cylinders were subjected to a posttest visual examination to characterize any damage which may have resulted from the pressurization of the test article. The observations made and the data generated from the test will be useful for evaluation and validation of design codes.

\subsection{INSTRUMENTATION}

A total of 32 strain gages were affixed by Hydrospace Engineering Services of Richardson, Texas, to the interior and exterior walls of cylinder G6-1. The location and orientation of these gages is shown in Fig. 3.1-1. The axial locations for these gages were at midbay, at $4.5 \mathrm{in}$. from either end, and at $0.5 \mathrm{in}$. from either end. The three midbay gages were located on both the interior and exterior walls and consisted of three biaxial gages located at 120-degree intervals for recording hoop and axial strains. The two gages at 4.5 in. from each end were located on both the interior and exterior walls and were biaxial gages located at 0 and 90 degrees for recording hoop and axial strains. The two gages at 0.5 in. from each end were located only on the exterior wall and were uniaxial gages located at 0 and 90 degrees for recording hoop strain only.

An additional 4 gages, for a total of 36 strain gages, were used in the testing of cylinders G6-2, G6-3, and C6-4. The location and orientation of these gages are shown in Fig. 3.1-2. The axial locations for these gages were the same as shown in Fig. 3.1-1. The additional gages consisted of using four biaxial gages instead of three biaxial gages at the 
cylinder midbay. The four biaxial gages were located at 90-degree intervals. Cylinder G6-4 was tested using 40 strain gages. The gage layout was the same as shown in Fig. 3.1-2 with the addition of 4 exterior axial gages at 0.5 in. from the cylinder end.

Acoustic emission monitoring was provided by attaching an acoustic emission pickup on the outside of the pressure vessel at mid-height. The accumulative number of events was recorded from a digital indicator as a function of pressure. Also, the event amplitude and count rate were plotted as a function of time and pressure on a strip-chart recorder.

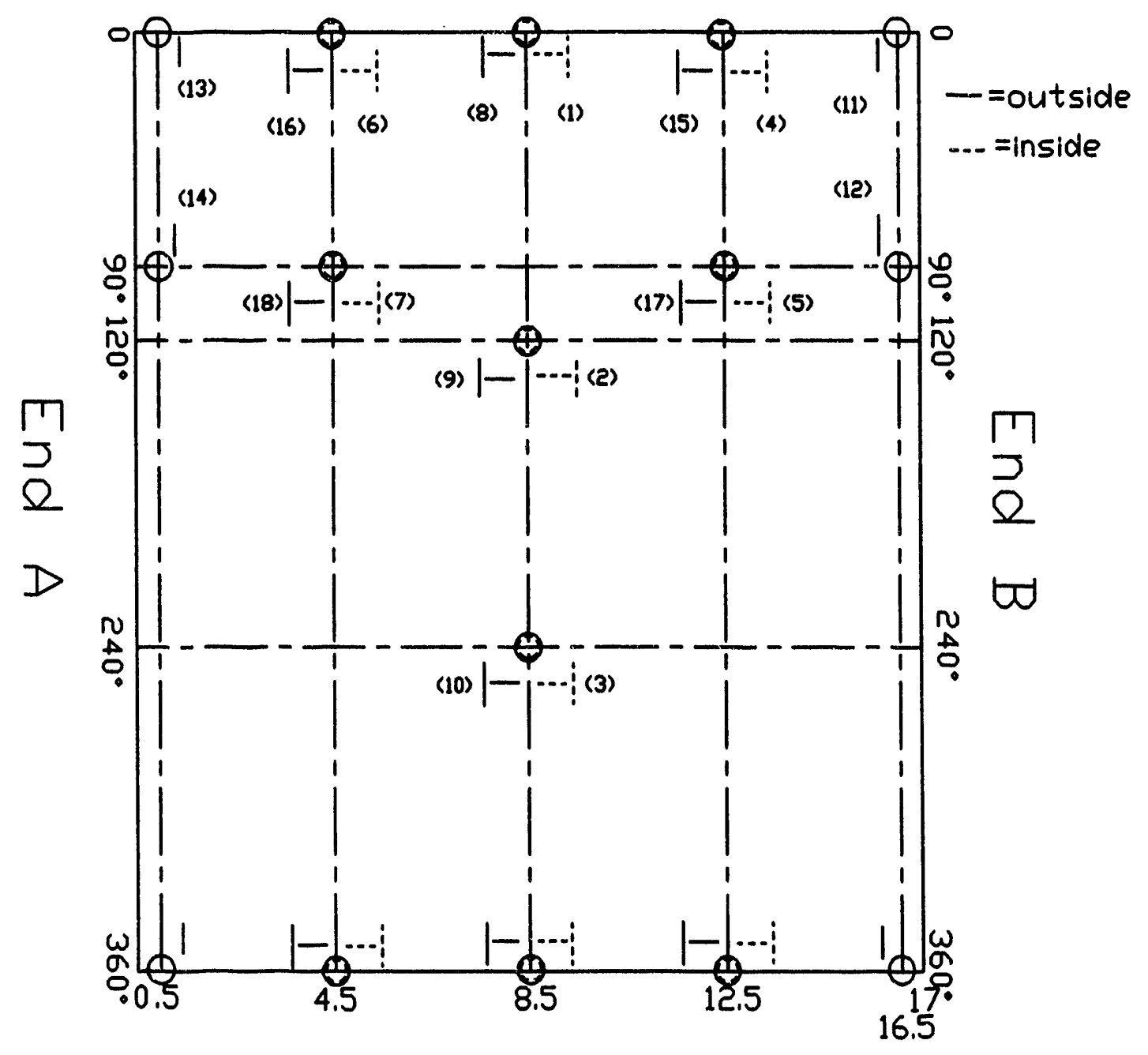

Fig. 3.1-1. Location of strain gages for G6-1. 


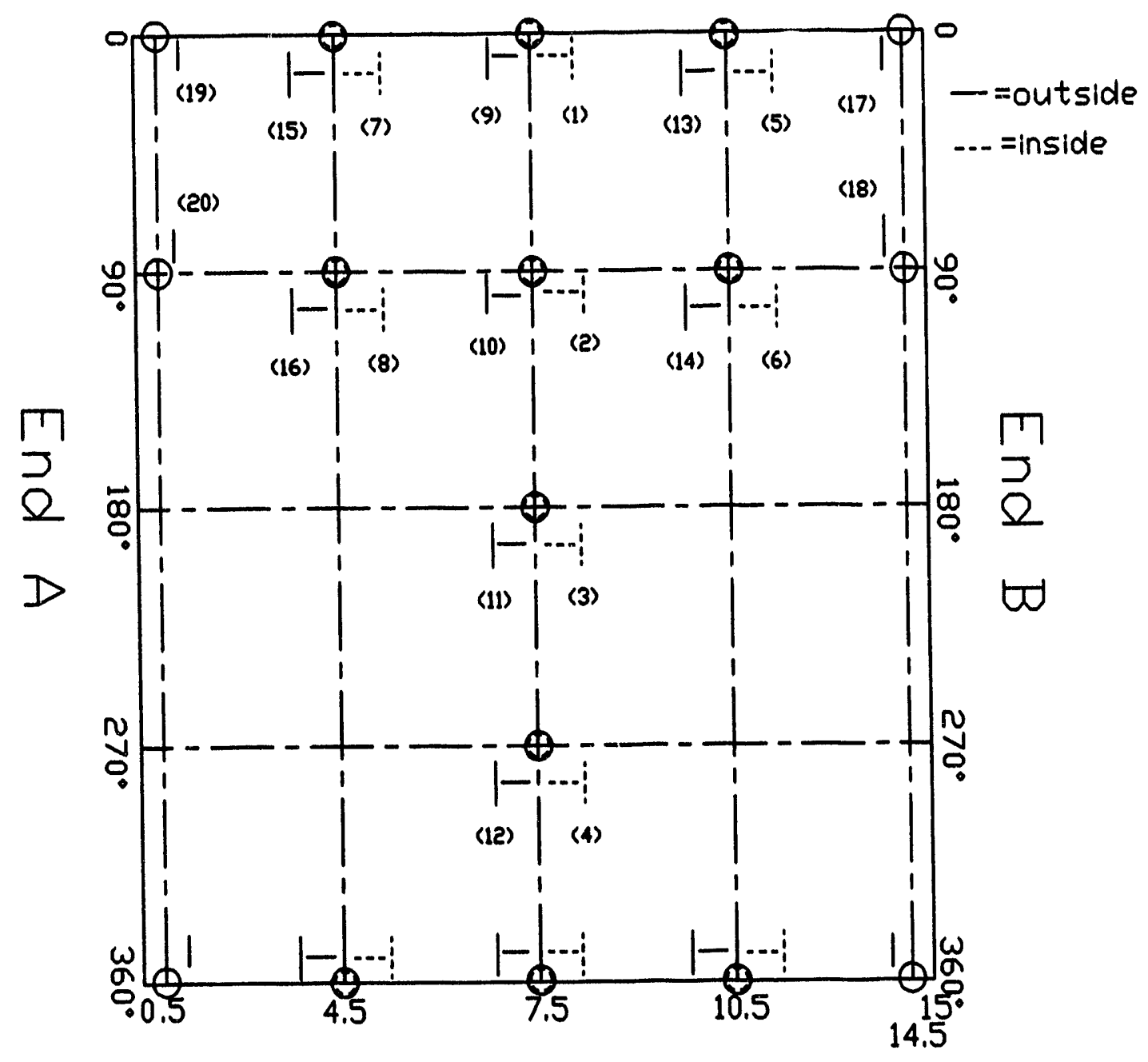

Fig. 3.1-2. Location of strain gages for G6-2, G6-3, G6-4, and C6-4.

\subsection{TEST FACILITY}

The cylinders were tested under contract with Hydrospace Engineering Services of Richardson, Texas, at the Stachiw Associates facility in El Cajon, California. The test facility consisted of a pressure vessel rated for use up to 20,000 psi hydraulic pressure. Pressure control was achieved manually by starting and stopping the pressurization system and by observing an analog gage indicating vessel pressure. The test articles were pressurized at $1000 \mathrm{psi}$ intervals at an approximate rate of $2000 \mathrm{psi} / \mathrm{min}$, with slower pressurization at the higher pressures. The pressure level was monitored by a pressure transducer and plotted versus time on a strip-chart recorder. The 'essel had associated feedthroughs for multichannel strain gage readout. Strain gage readout consisted of decade boxes connected to a single channel digisal strain indicator. Individual gage readings were made manually at the ${ }_{1000}$-psi pressure intervals by switching in the appropriate gage and recording the reading on a data sheet. Photographs of the test facility pressure vessel and instrumentation are shown in Figs. 3.2-1 and 3.2-2. 


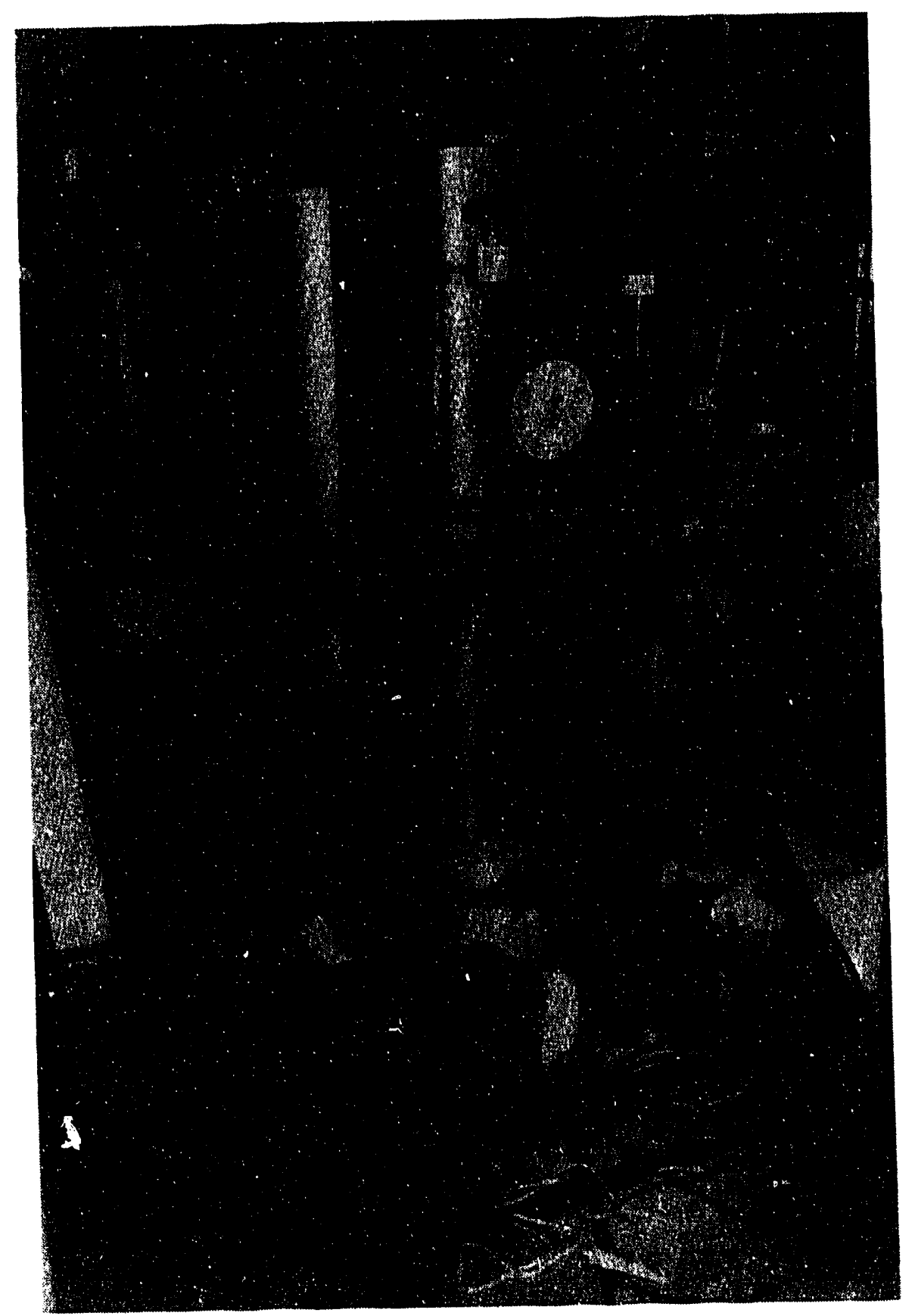

Fig. 3.2-1. Stachiw Associates test facility pressure vessel (20,000-psi capcity). 


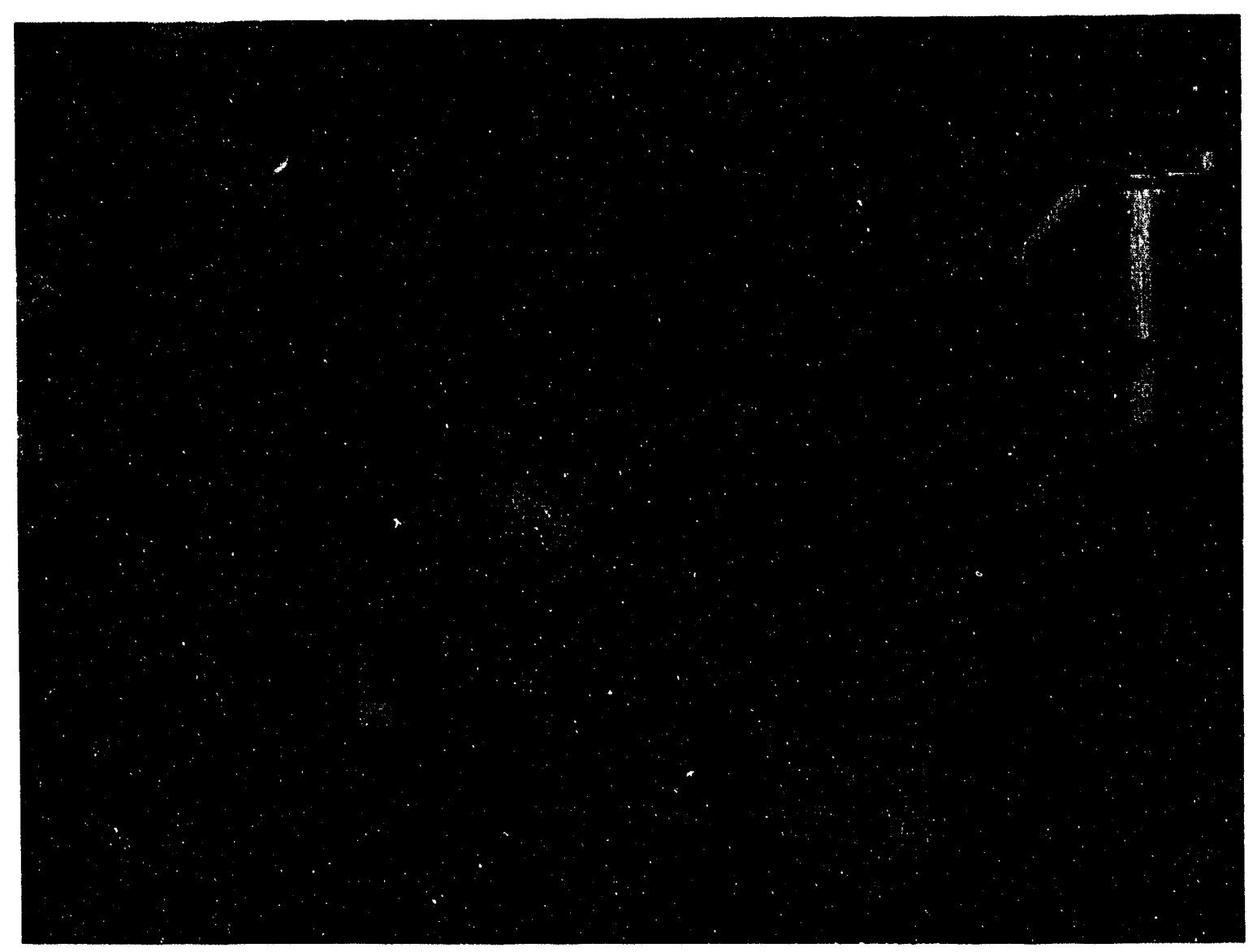

Fig. 3.2-2. Test facility instrumentation. 


\subsection{TEST ASSEMBLY}

The cylinders were assembled to the steel and aluminum end plugs prior to testing (see test cylinder assembly drawing in Fig. 1-1). The internal strain gage wires were passed through the end plug, and the wires were potted and sealed in place. Steel tie rods were attached to both end plugs to assist in holding the assembly together. Finally, the junction between the cylinder and the end plugs was sealed with a rubber potting compound to provide the initial seal for pressurization. The cylinder was placed into the pressure vessel (see Fig. 3.2-1), the strain gage wires were fed out through a high-pressure feedthrough, and the pressure vessel was sealed. Photographs of the cylinder assemblies are shown in Figs. 3.3-1 through 3.3-4, for G6-1, G6-2, G6-3, and G6-4, respectively.

\subsection{TEST RESULTS}

Pressurization of each test cylinder began, with stops for strain gage readings made at each 1000-psi interval. All of the strain gage channels plus the acoustic emission count were recorded at each 1000-psi interval. Pressurization continued until the test articles imploded or the limit of the facility, which was 20,000 psi, was reached. The strain data were tabulated and average strain gage readings were calculated. The cumulative acoustic emission count was also tabulated and plotted as a function of pressure. The test reports prepared by Hydrospace Engineering Services are given in Appendix B.

Plots of the acquired strain versus pressure data are presented in Figs. 3.4-1 through 3.4-9 for cylinder G6-1. As shown in Fig. 3.4-1, interior wall midbay hoop strain levels of $0.7-0.8 \%$ were achieved with this specimen. The gage located at the 240-degree location (gage \#3) recorded an increasingly greater compressive hoop strain with pressure than did the gages located at 0 degrees or 120 degrees (gages \#1 and \#2, respectively). However, on the exterior of the cylinder (see Fig. 3.4-2), the gage at the 240-degree location (gage \#10) shows an increasingly smaller compressive hoop strain with pressure than the gages at the 0 -degree or the 120 -degree locations (gages \#8 and \#9, respectively). This would suggest that circumferential bending, producing tension on the exterior wall and compression on the inner wall, was occurring as a function of pressure at the 240-degree location.

The midbay interior and exterior axial strains for G6-1 are shown in Figs. 3.4-3 and $3.4-4$, respectively. The axial strains appear to be uniform across the wall with strain levels of $0.75-0.85 \%$ measured at both the inner and outer radii. The axial strain versus pressure traces are nonlinear and exhibit a degree of material softening in the cylinder axial direction.

The four interior gages at the axial location of 4.5 in. from each end of the cyliniter (gages \#4, \#5, \#6, and \#7) measured the interior hoop and axial strains 0.5 in. from the end of the contoured end closures. The design of the end closures is such that at 20,000 psi the interior of the cylinder wall is supported by the end closures along their entire 4-in. length. The results in Fig. 3.4-5 for the interior hoop strains at 4.5 in. from the end are nearly identical to the midbay interior hoop strains shown in Fig. 3.4-1. Comparing the interior axial strain results in Figs. 3.4-7 and 3.4-3 shows that the strains 4.5 in. from the end are also nearly identical to the midbay strains. 


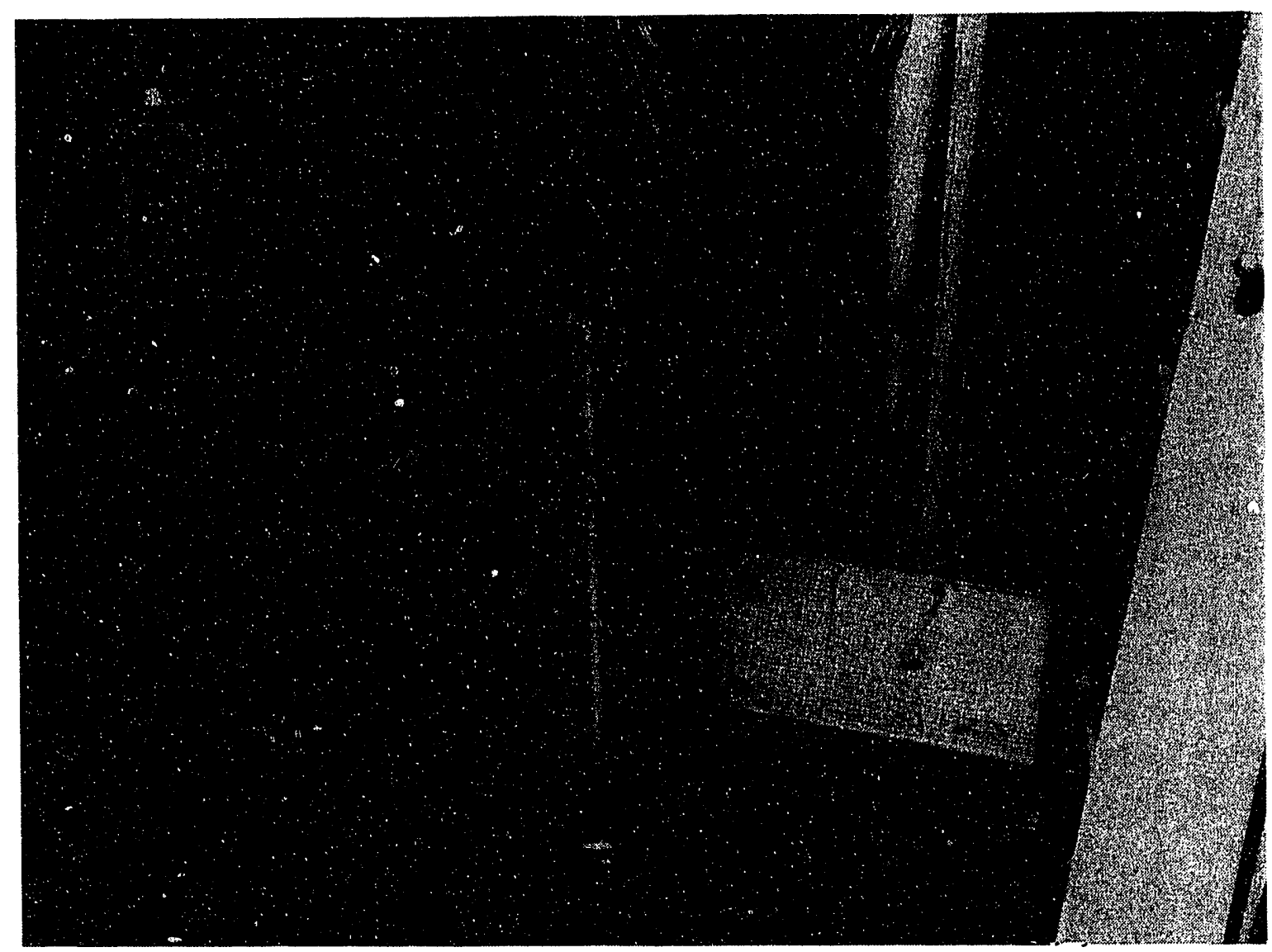

Fig. 3.3-1. Cylinder G6-1 test assembly. 


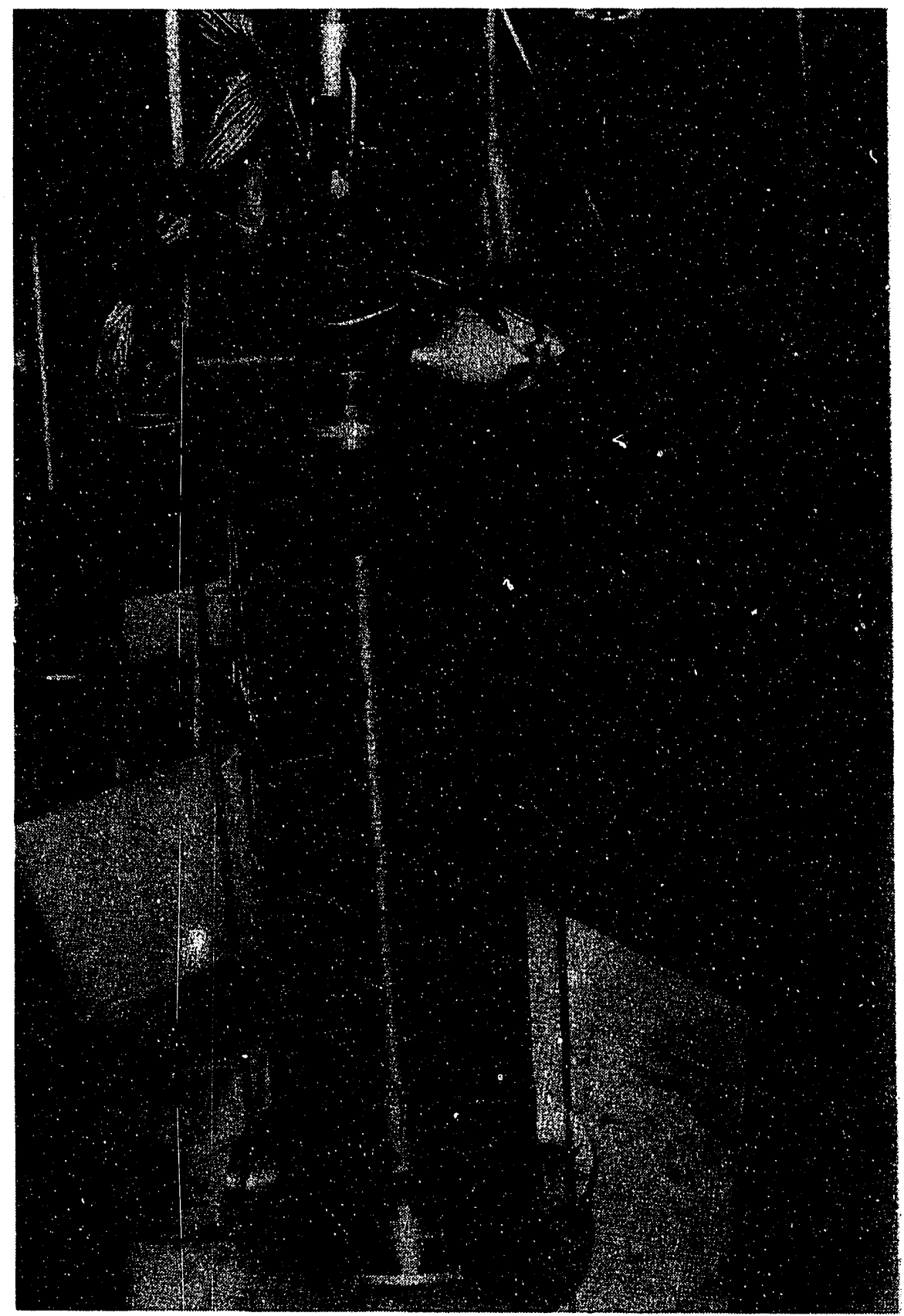

Fig. 3.3-2. Cylinder G6-2 test assembly. 


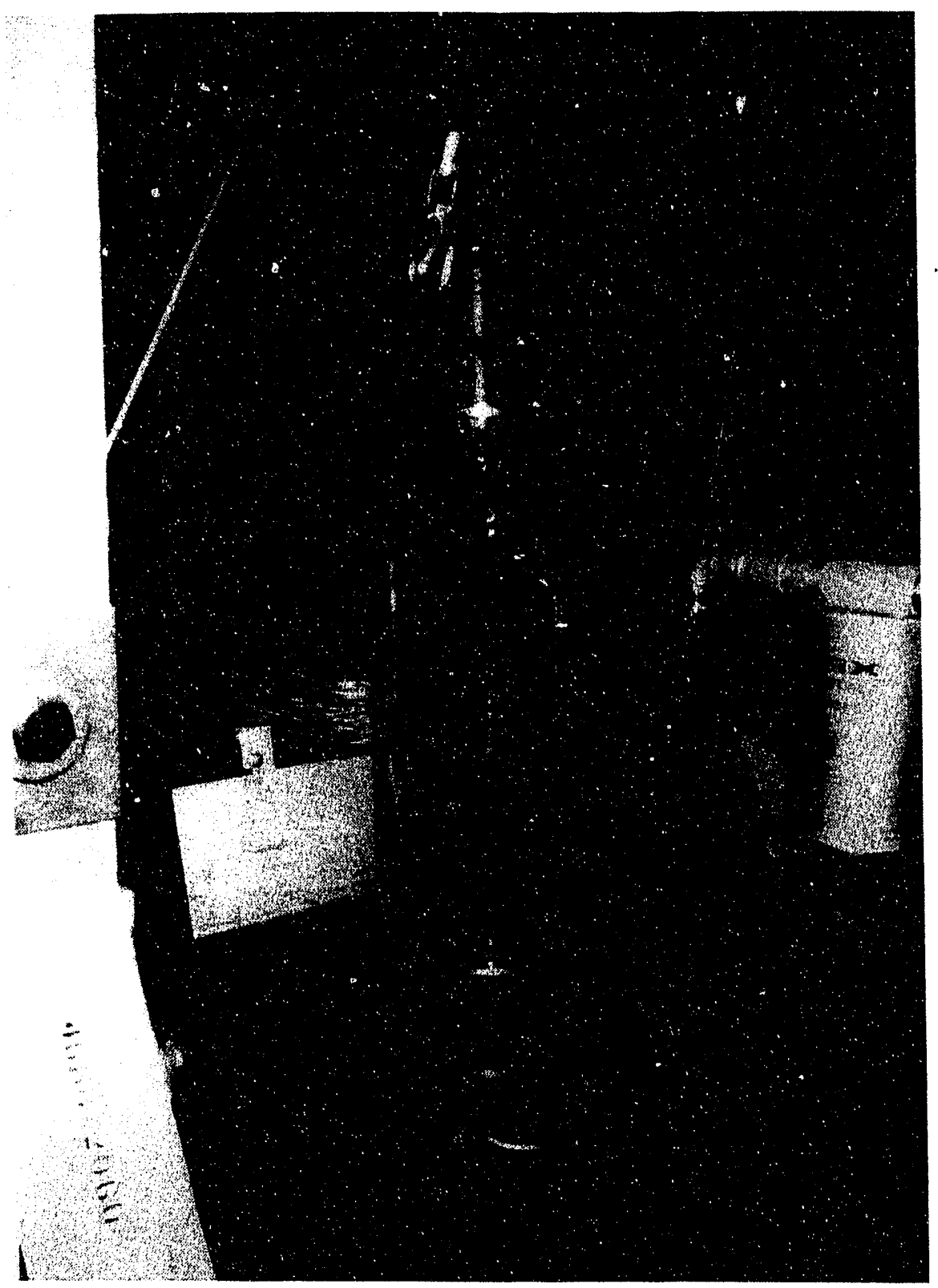

Fig. 3.3-3. Cylinder G6-3 test assembly. 


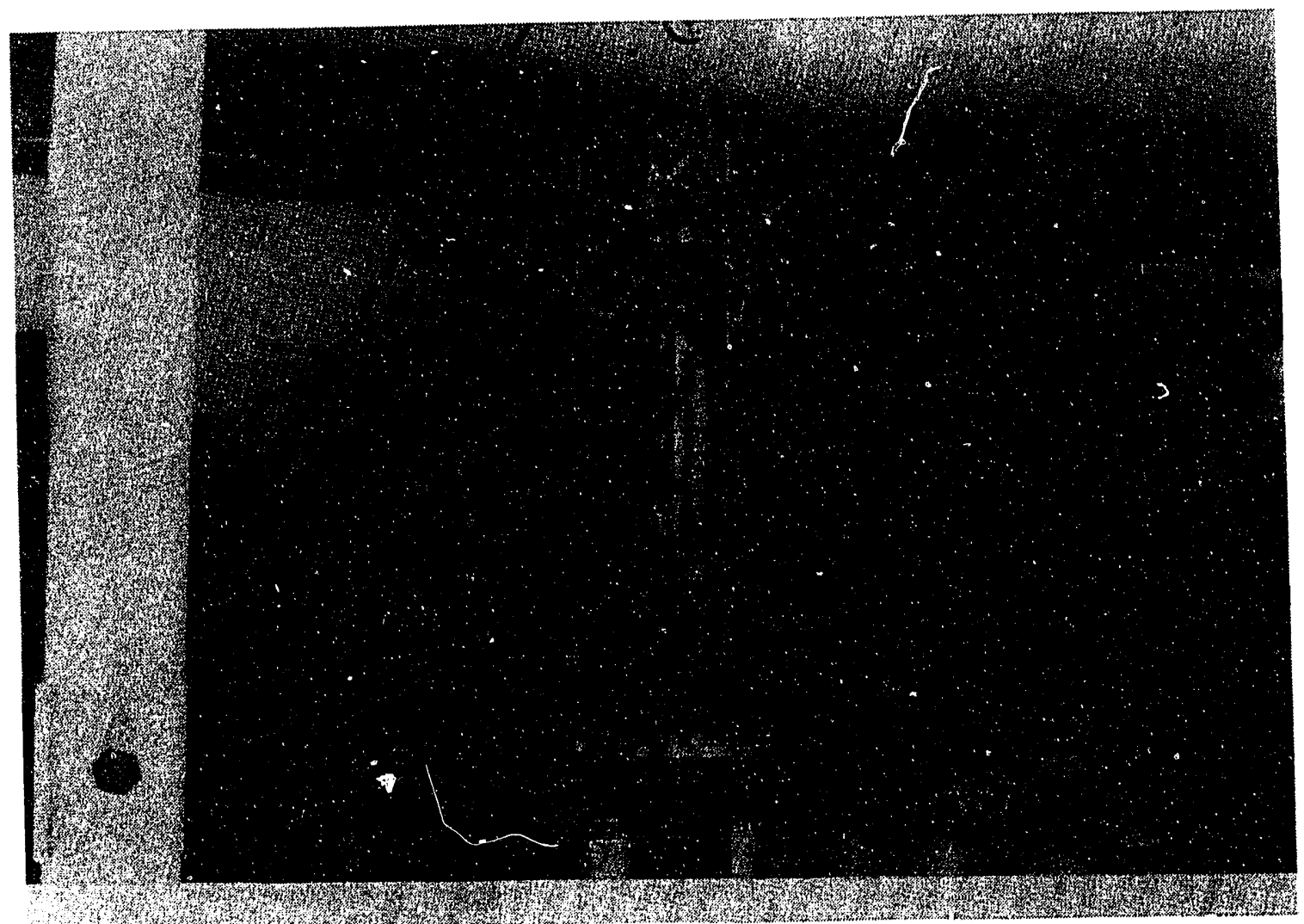

Fig. 3.3-4. Cylinder G6-4 test assembly. 
The contoured end closures were designed to have an initial radial clearance between the plug and the interior of the cylinder. A change in slope in the pressure versus strain plot (for gages located at 0.5 in. from the ends of the cylinder) corresponds to the point at which the radial clearance is eliminated and the cylinder starts to be supported along the length of the contoured end closure. In Fig. 3.4-9, the hoop strains at 0.5 in. from the cylinder end do not show a change of slope indicative of when the contracting cylinder begins to contact the internal plug, thus providing increased hoop stiffness to the assembly. This result suggests that the initial radial clearance was set to high for this particular cylinder given the final failure pressure.

The midbay interior and exterior hoop strains for G6-2 are illustrated in Figs. 3.4-10 and 3.4-11, respectively. Two of the interior gages, \#2 and \#4, are lost at a pressure level of $11,000 \mathrm{psi}$, and a third gage, \#1, is lost at $16,000 \mathrm{psi}$. The remaining interior hoop gage, \#3, shows a slight stiffening effect in the hoop direction. The plot of the exterior hoop strains in Fig. 3.4-11 demonstrates a possible circumferential buckling mode of failure with a divergence in hoop strains shown for the gages located 90 degrees apart. The gages located 180 degrees apart measure nearly identical exterior hoop strains. The plots for the midbay axial strains are shown in Fig. 3.4-12 for the interior gages and in Fig. 3.4-13 for the exterior gages. Three out of the four interior axial strains are also lost prior to failure of the test specimen. Both the interior and the exterior axial strains exhibit a slight softening behavior as demonstrated by the nonlinear pressure versus strain plots in Figs. 3.4-12 and 3.4-13. The magnitudes of the midbay axial strains and hoop strains are shown in Figs. 3.4-10 through 3.4-13 to be nearly equal.

The interior and exterior hoop strains at 4.5 in. from the end of cylinder G6-2 are shown in Figs. 3.4-14 and 3.4-15, respectively. The axial strains at 4.5 in. from the end are shown in Fig. 3.4-16 for the interior of the cylinder and in Fig. 3.4-17 for the exterior. All of the interior strain gages are lost prior to the ultimate collapse of the test article. The cylinder behavior in the axial direction appears to be more nonlinear than in the hoop direction. However, the apparent nonlinearity could be caused by the slight axial bending of the cylinder wall near the end of the plug. The exterior hoop strains at $0.5 \mathrm{in}$. from the end of G6-2 are plotted in Fig. 3.4-18. This figure illustrates that the cylinder starts to be supported by the contoured end closure at an applied hydrostatic pressure of 12,000 psi.

The experimentally measured strains for cylinder G6-3 are shown in Figs. 3.4-19 through 3.4-27. The midbay interior hoop strains in Fig. 3.4-19 demonstrate a slight amount of circumferential bending with the strain gages located 180 degrees apart measuring approximately equal strains. However, there is not any evidence of circumferential bending in the exterior hoop strains as shown in Fig. 3.4-20. The midbay interior and exterior axial strains are plotted in Figs. 3.4-21 and 3.4-22, respectively. The four interior axial strain gages located 90 degrees apart are shown to track to each other, whereas the four exterior gages begin to diverge at a very low pressure.

The hoop strains at 4.5 in. from the end of G6-3 are plotted in Figs. 3.4-23 and 3.4-24 for the interior and exterior gages, respectively. The interior and exterior axial strains at 4.5 in. from the end are shown in Figs. 3.4-25 and 3.4-26, respectively. In these four figures, the gages that are located 90 degrees apari record comparable strain levels. The interior hoop strains are shown to be larger than the exterior hoop strains, but the interior and exterior axial strains are nearly equal. In Fig. 3.4-27, the measured exterior hoop strains at 0.5 in. from the end show the cylinder to come in contact with the end plug at 9000 psi. 
For the all circ-wound graphite-reinforced cylinder, C6-4, the midbay interior hoop strains are shown in Fig. 3.4-28, and the midbay exterior hoop strains are shown in Fig. 3.4-29. The interior hoop strains exhibit an almost linear behavior, whereas the exterior hoop strains exhibit a nonlinear stiffening type of behavior. The exterior hoop strains are very low in magnitude, less than $1000 \mu \mathrm{in}$./in.. The midbay interior and exterior axial strains are plotted in Figs. 3.4-30 and 3.4-31, respectively. Axial strains approaching $2 \%$ at failure are obtained for this test. The interior and exterior axial strains show the effect of material softening in the axial direction. All of the midbay strains appear to be uniform around the circumference of the cylinder.

The interior hoop strains at $4.5 \mathrm{in}$. from the end of cylinder C6-4 are shown in Fig. 3.4-32. Three out of the four gages have equal strains and show a slight material nonlinearity indicative of material softening. The exterior hoop strains at $4.5 \mathrm{in}$. from the end are shown in Fig. 3.4-33 and, as was described for the midbay exterior hoop strains, exhibit a material stiffening behavior. The interior and exterior axial strains at 4.5 in. from the end are uniform around the circumference and are plotted in Figs 3.4-34 and 3.4-35, respectively. The exterior hoop strains at 0.5 in. from the end are plotted in Fig. 3.4-36 and show a change of slope at $₫ 000$ psi that indicates contact with the end closures.

The experimentally neasured strains for G6-4 are plotted in Figs. 3.4-37 through 3.4-46. The midbay interior and exterior hoop strains are shown in Figs. 3.4-37 and 3.4-38, respectively. The hoop strains are nearly uniform around the circumference of the cylinder and demonstrate linear material behavior. The measured hoop strains on the interior surface are approximately $28 \%$ larger than the exterior hoop strains. The midbay axial strains are plotted in Fig. 3.4-39 for the interior and in Fig. 3.4-40 for the exterior surface. The axial strains appear to be uniform across the wall thickness and, in contrast to the linear behavior of the hoop strains, demonstrate a nonlinear softening type of behavior.

The interior and exterior hoop strains at 4.5 in. from the end of cylinder G6-4 are illustrated in Figs. 3.4-41 and 3.4-42, respectively. These results are almost identical to the midbay hoop strains plotted in Figs. 3.4-37 and 3.4-38. Similarly, the interior and exterior axial strains at 4.5 in. from the end (see Figs. 3.4-43 and 3.4-44) are in agreement with the midbay axial strains. One of the interior biaxial strain gages is lost at a pressure level of 16,000 psi.

The results for the exterior hoop and axial strains at 0.5 in. from the end of cylinder G6-4 are shown in Figs. 3.4-45 and 3.4-46, respectively. The change in slope of the hoop strain plots indicates the cylinder wall is in contact with the end plugs at 10,000 psi. This result, in conjunction with the comparable results at the midbay and $4.5 \mathrm{in}$. from the end, indicates a well-designed contoured end plug for this test.

Average values for the midbay axial and hoop strains are calculated from the different results measured around the circumference of the test articles. The average interior and exterior hoop strains for the six cylinders are compared in Figs. 3.4-47 and 3.4-48, respectively. These results show the largest hoop strain is in the 2:1 hoop:axial glass-reinforced cylinder, G6-4. As expected, the all circ-wound graphite-reinforced cylinder, C6-4, measures the lowest hoop strain. All of the cross-ply glass-reinforced cylinders have larger hoop strains than the two graphite-reinforced cylinders. 
The average midbay interior axial strains are plotted versus pressure in Fig. 3.4-49, and the average midbay exterior axial strains are plotted in Fig. 3.4-50. For the axial strains, the results for the glass-reinforced cylinders are bracketed by the graphite-reinforced cylinder results. The all circ-wound graphite-reinforced cylinder has the highest axial strain and the 2:1 hoop:axial graphite-reinforced cylinder, C6-1, has the lowest axial strain. The axial strain results for the glass-reinforced cylinders have a very similar behavior.

At the conclusion of each test the cylinder test assemblies were carefully removed from the pressure vessel and photographed. Figure 3.4-51 shows the failed G6-1 cylinder. The failure primarily consisted of circumferential matrix cracking produced by transverse compressive and shear stresses in the cylinder wall. The cylinder was extremely tight on the end closures and was destroyed in the process of removing the end closures. The failed G6-2 cylinder is shown in Fig. 3.4-52. Both circumferential and axial cracks are evident and the cylinder wall buckled radially inward. In Fig. 3.4-53, the failed G6-3 cylinder is shown. In removing this cylinder from the pressure vessel, there was very extensive damage and it fractured into two parts. The flange on the bottom end closure also suffered damage with a section of it being completely broken off. Figure 3.4-54 illustrates the failure mode for the G6-4 cylinder. The cylinder had both circumferential and axial cracks in the gage section. This cylinder did not show any evidence of global buckling and failure is velieved to be material strength related. There were axial cracks oriented at $\mathbf{4 5}$ degrees through the cylinder wall that propagated to the ends of the cylinder. The failed C6-4 cylinder is shown in Fig. 3.4-55. During disassembly the cylinder fractured into three parts with the fractures occurring just past the ends of the end closures. The three parts consisted of the gage section and one section on each of the two end closures. The failure mode was predominately circumferential matrix cracking. 


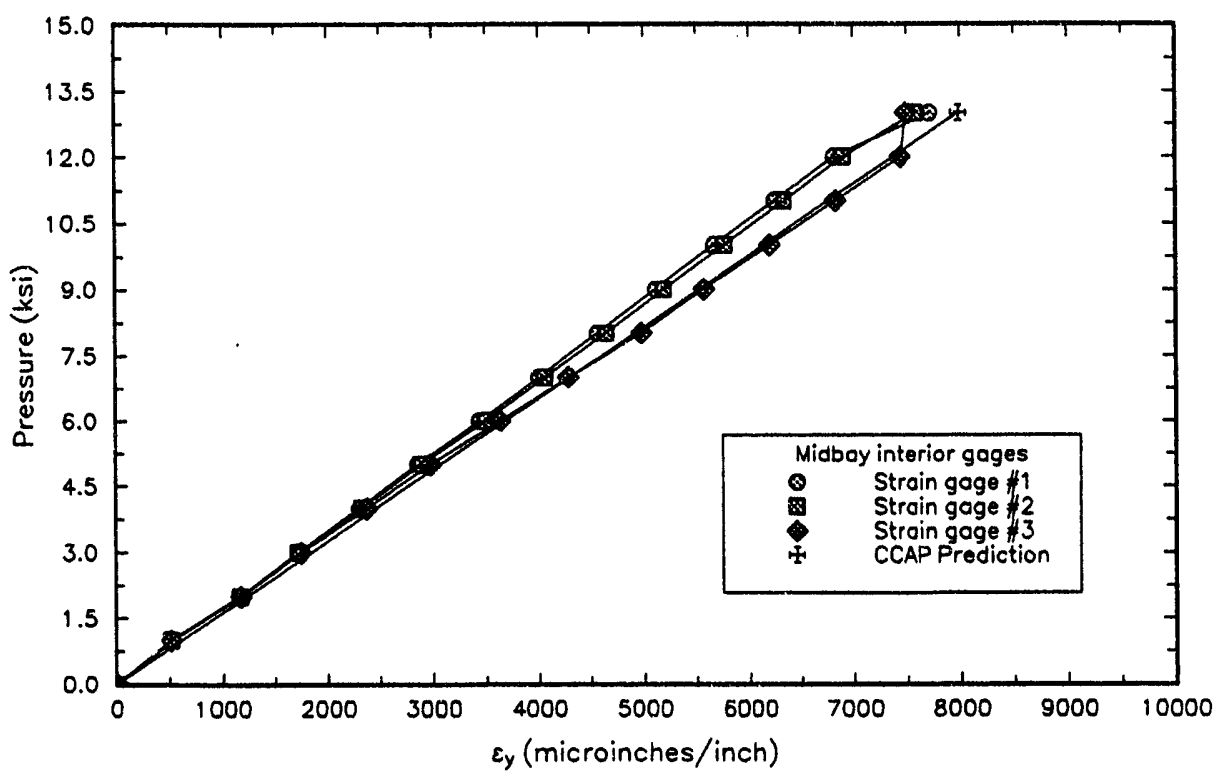

Fig. 3.4-1. Midbay interior hoop strains versus pressure for G6-1.

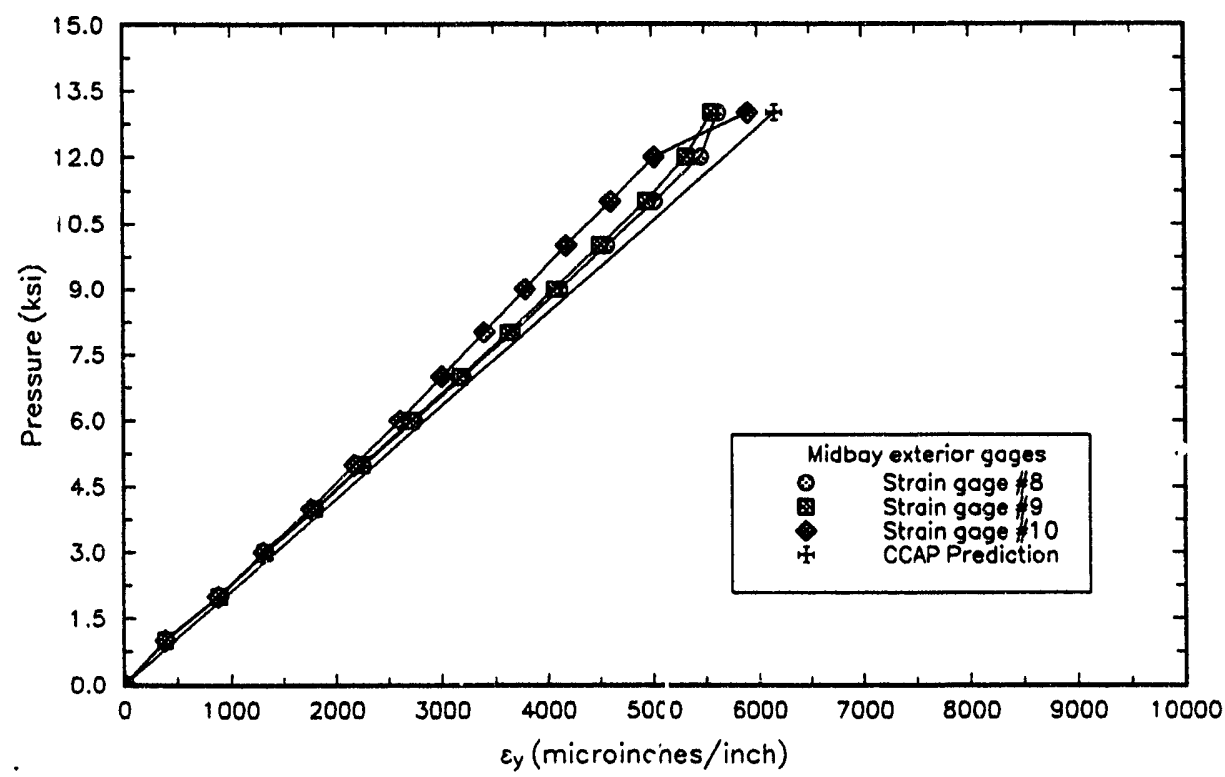

Fig. 3.4-2. Midbay exterior hoop strains versus pressure for G6-1. 


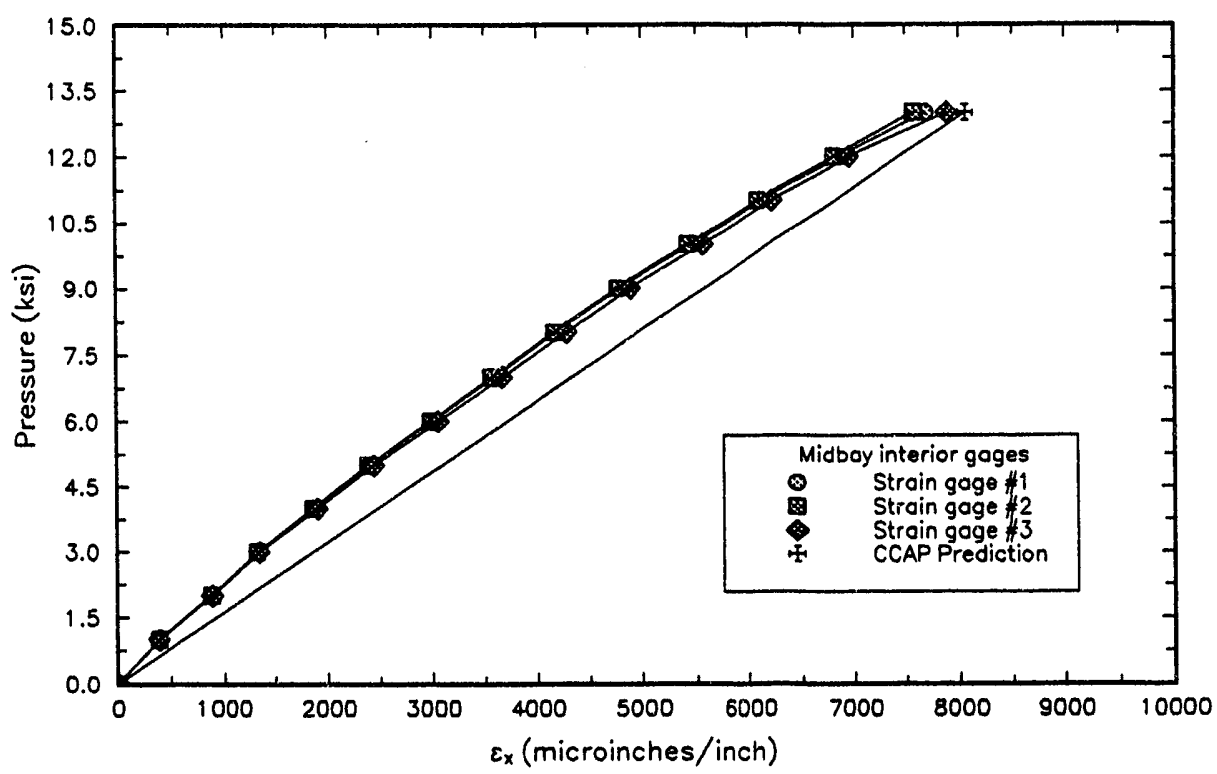

Fig. 3.4-3. Midbay interior axial strains versus pressure for G6-1.

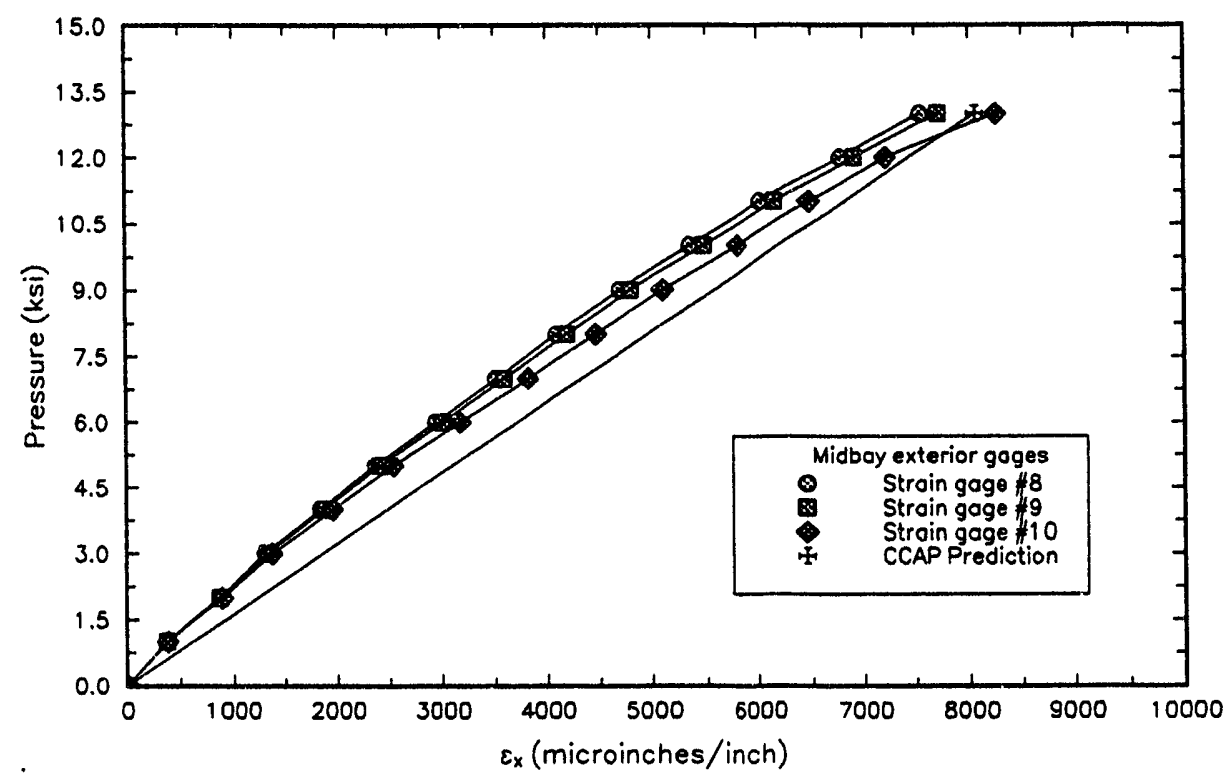

Fig. 3.4-4. Midbay exterior axial strains versus pressure for $\mathbf{G 6 - 1}$. 


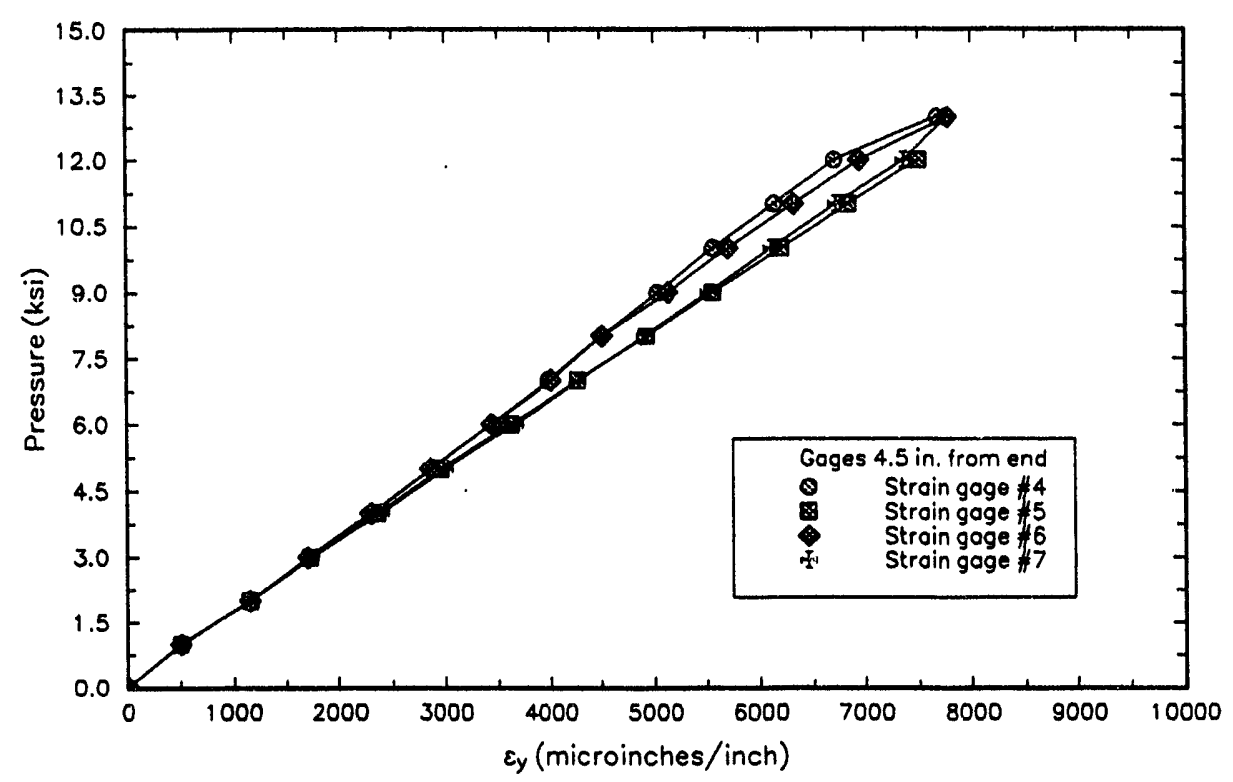

Fig. 3.4-5. Interior hoop strains at 4.5 in. from end versus pressure for G6-1.

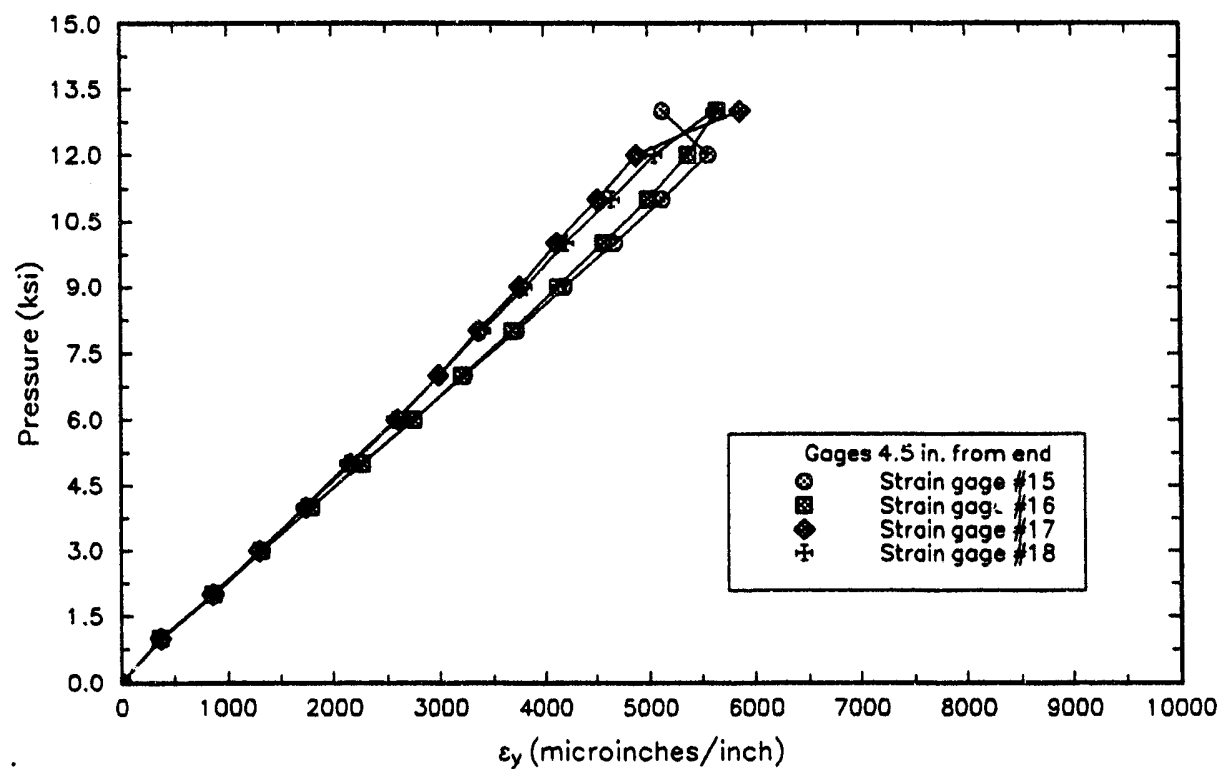

Fig. 3.4-6. Exterior hoop strains at 4.5 in. from end versus pressure for G6-1. 


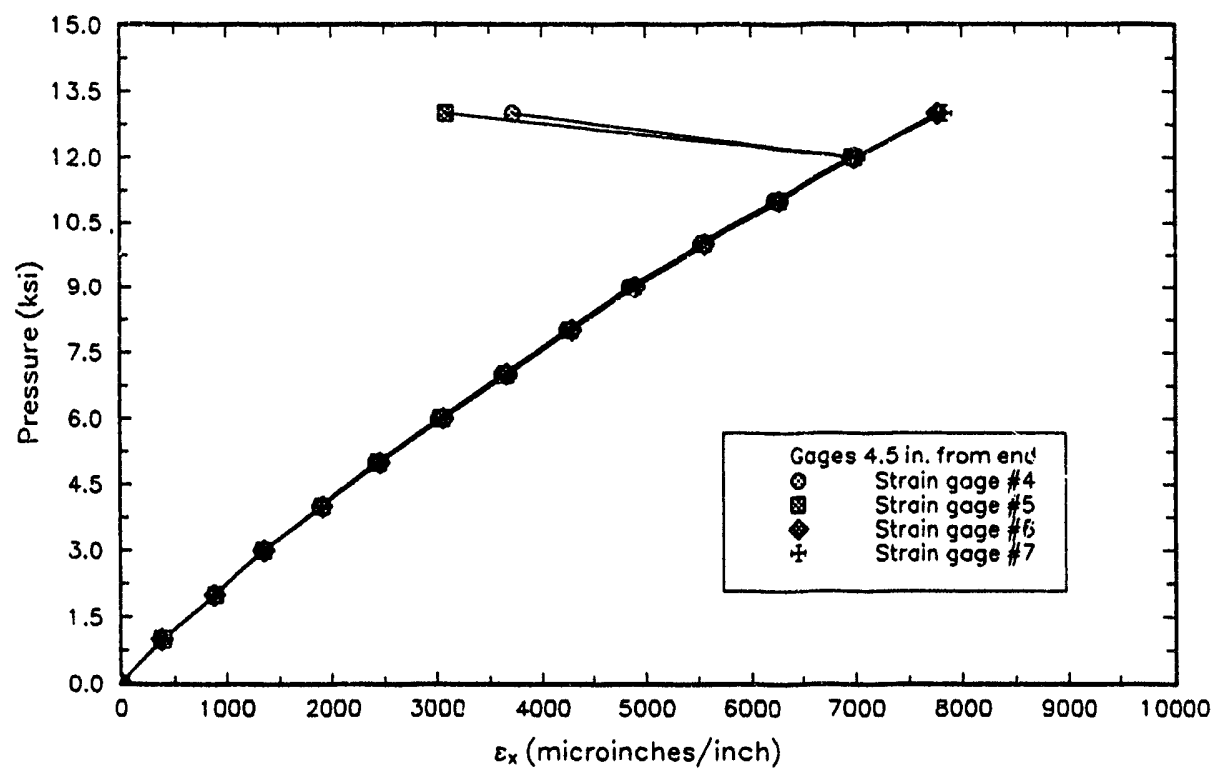

Fig. 3.4-7. Interior axial strains at 4.5 in. from end versus pressure for G6-1.

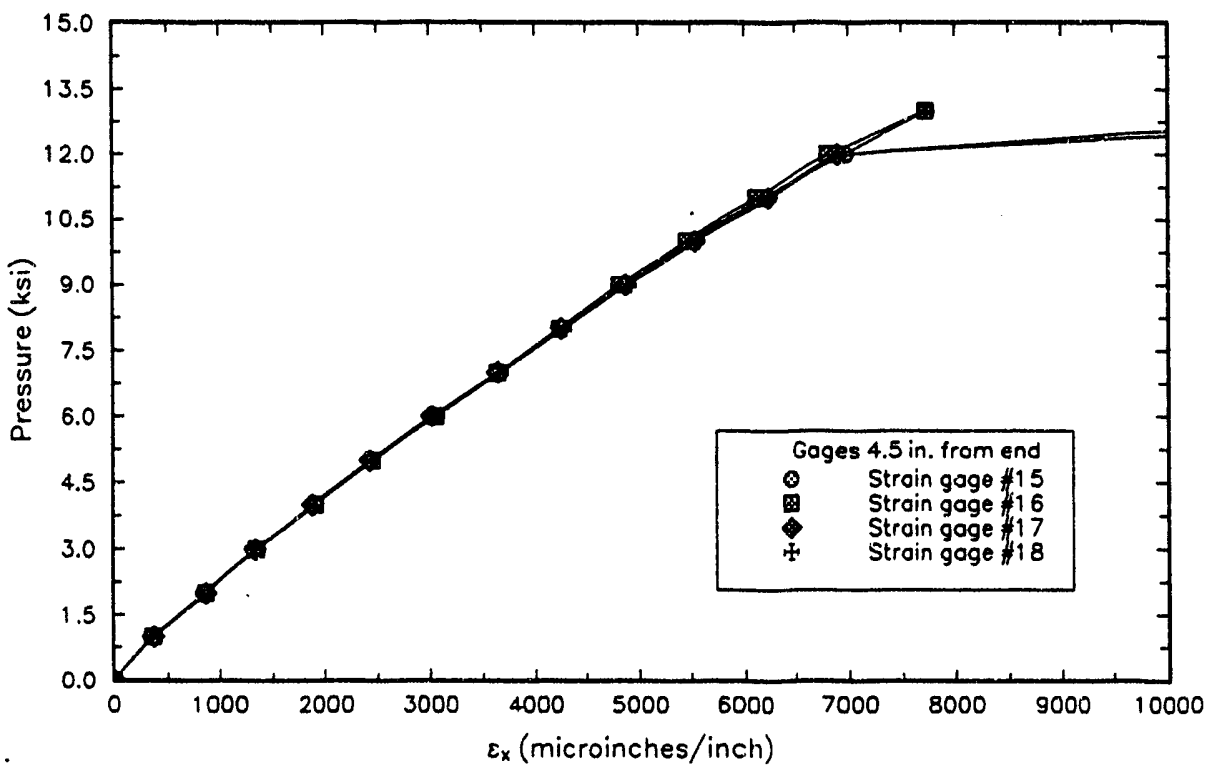

Fig. 3.4-8. Exterior axial strains at 4.5 in. from end versus pressure for G6-1. 


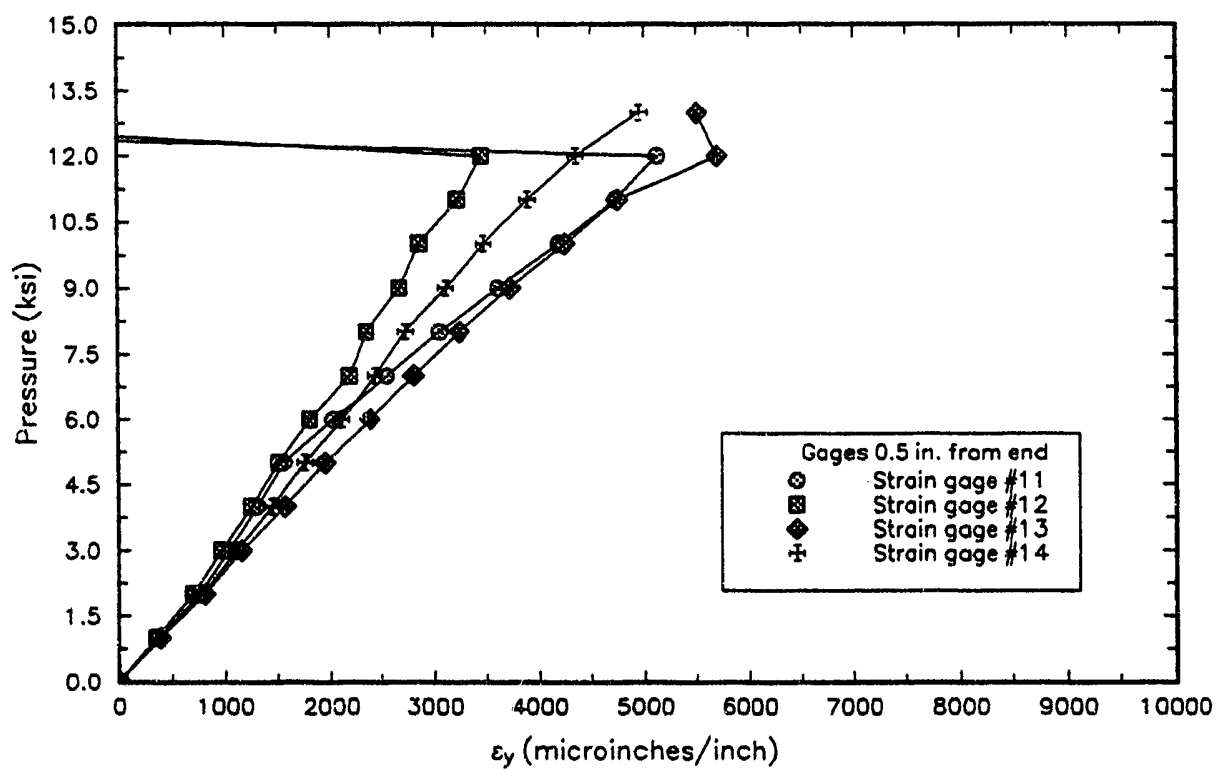

Fig. 3.4-9. Exterior hoop strains at 0.5 in. from end versus pressure for G6-1.

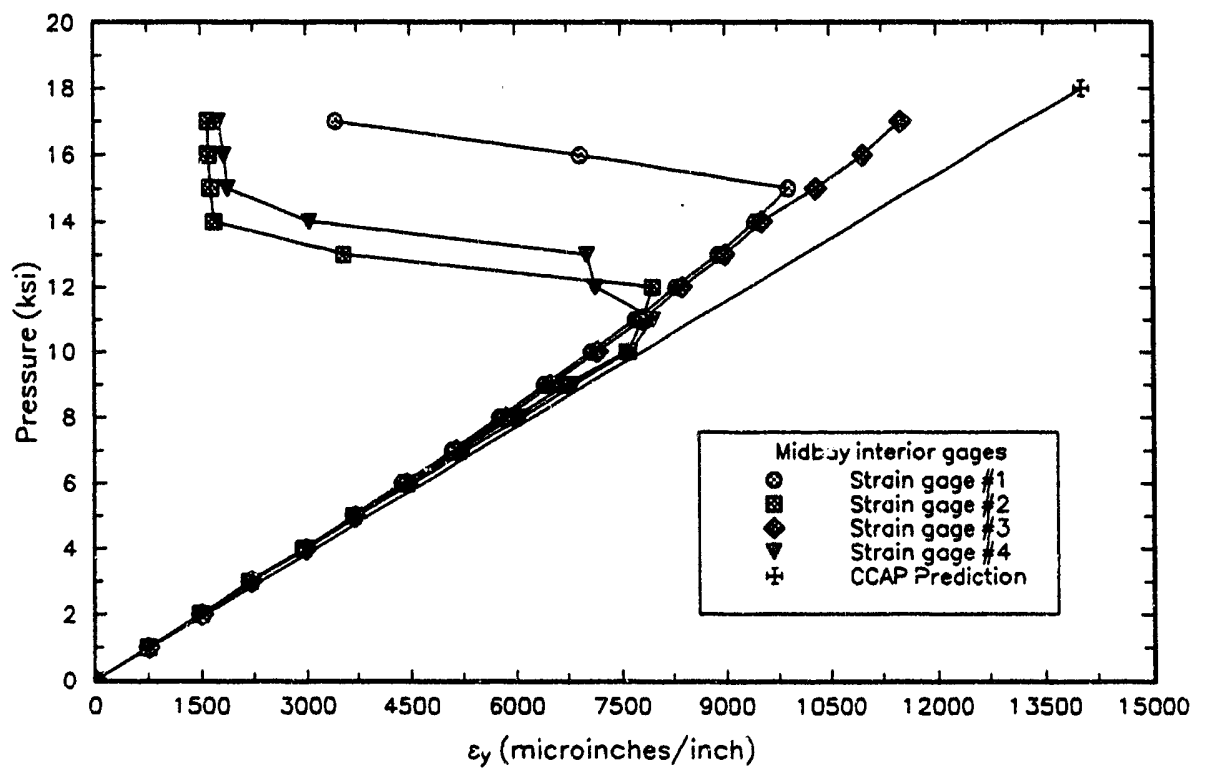

Fig. 3.4-10. Midbay interior hoop strains versus pressure for G6-2. 


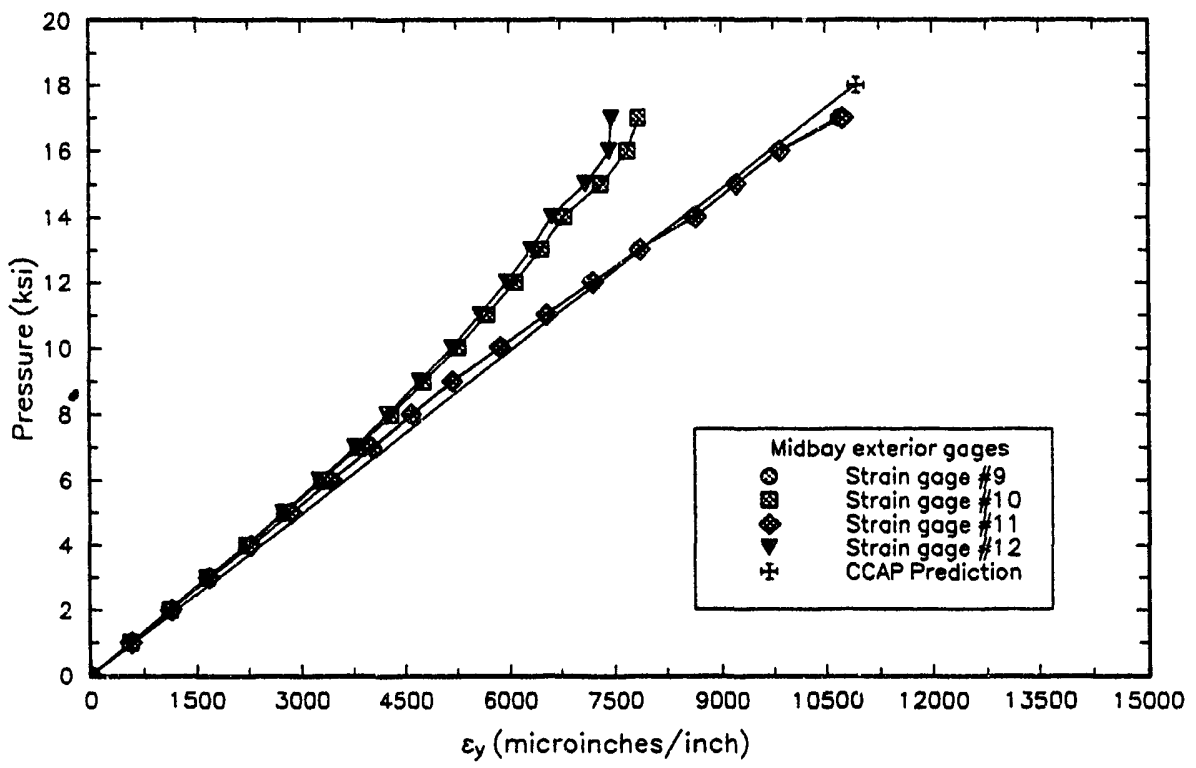

Fig. 3.4-11. Midbay exterior hoop strains versus pressure for G6-2.

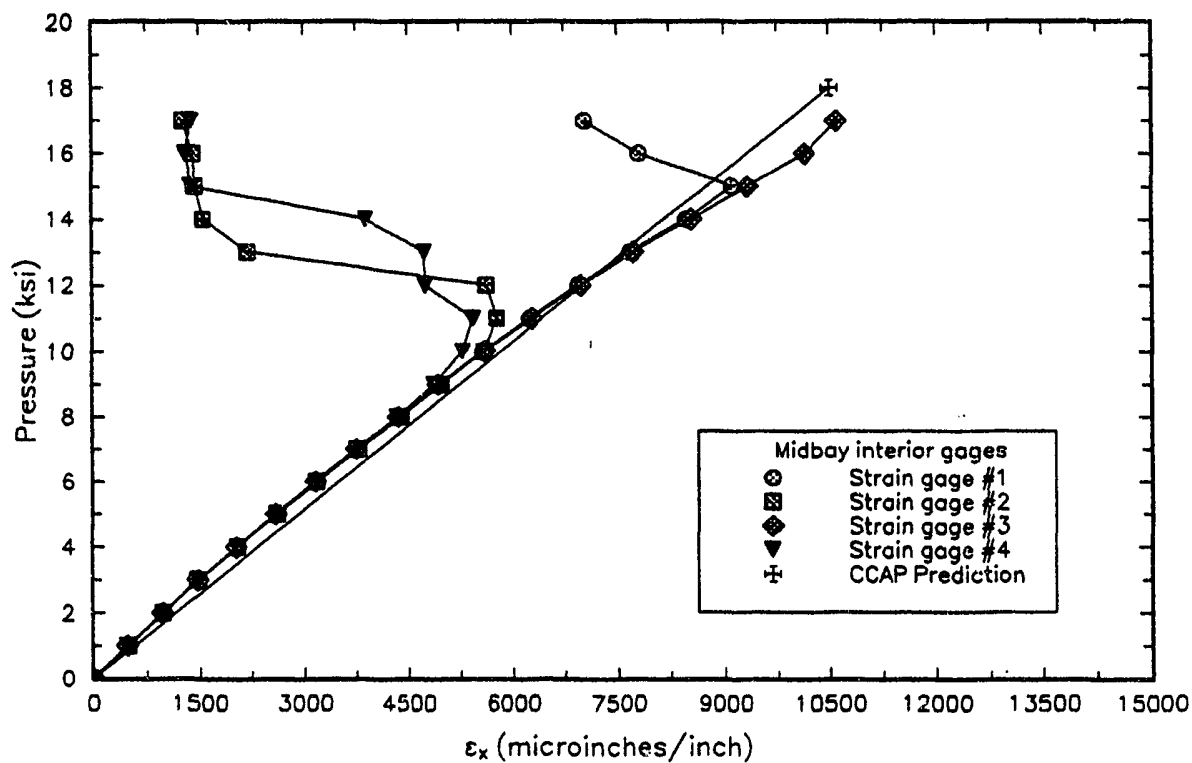

Fig. 3.4-12. Midbay interior axial strains versus pressure for G6-2. 


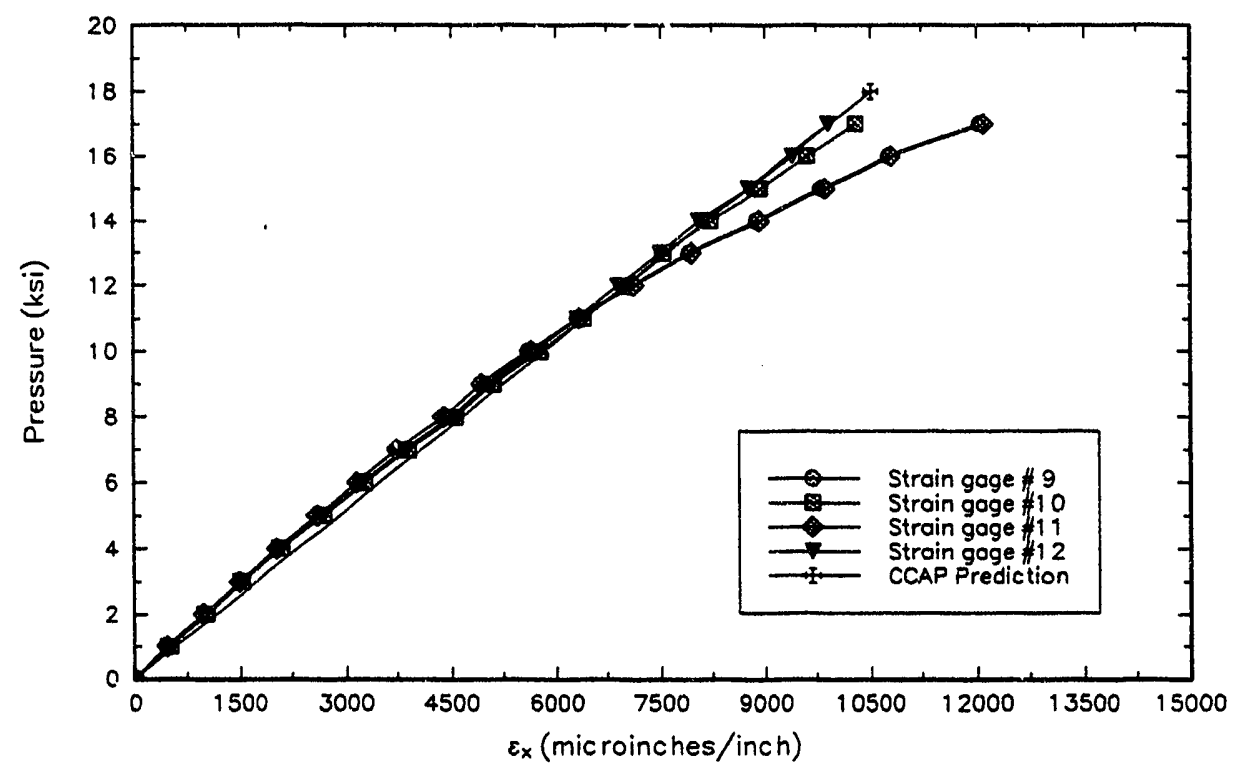

Fig. 3.4-13. Midbay exterior axial strains versus pressure for G6-2.

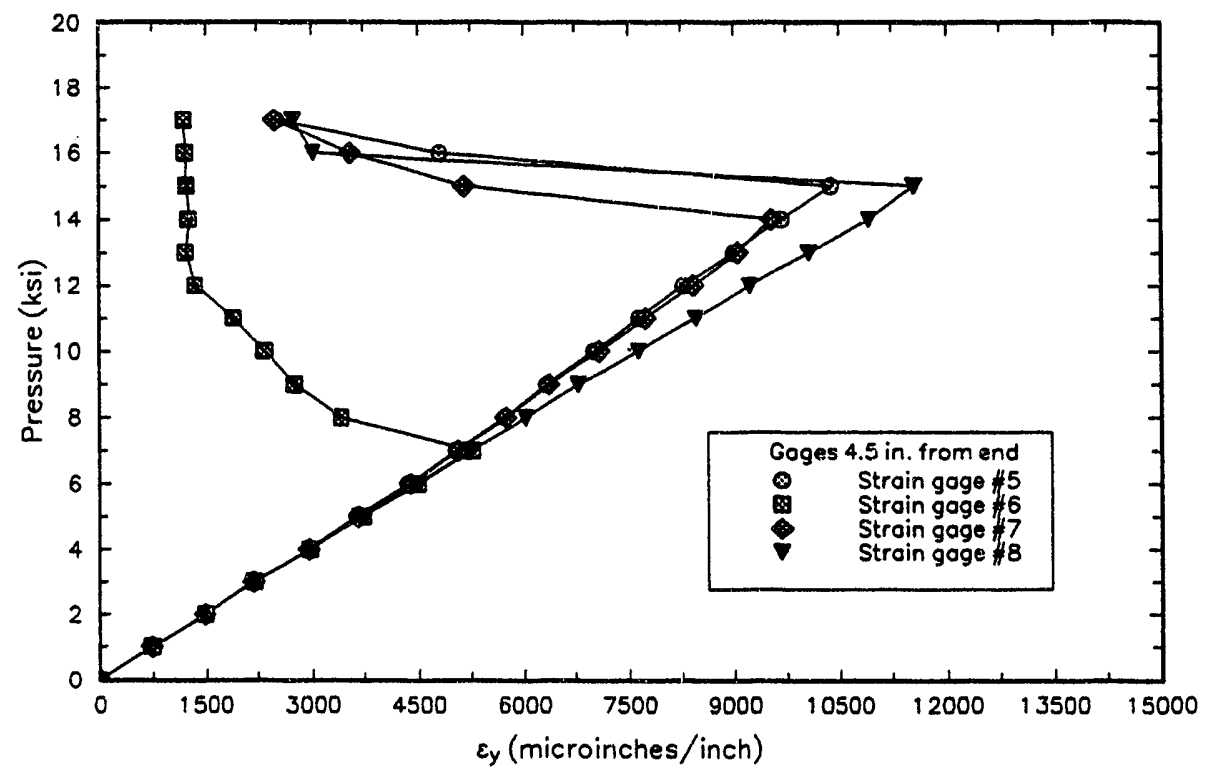

Fig. 3.4-14. Interior hoop strains at 4.5 in. from end versus pressure for G6-2. 


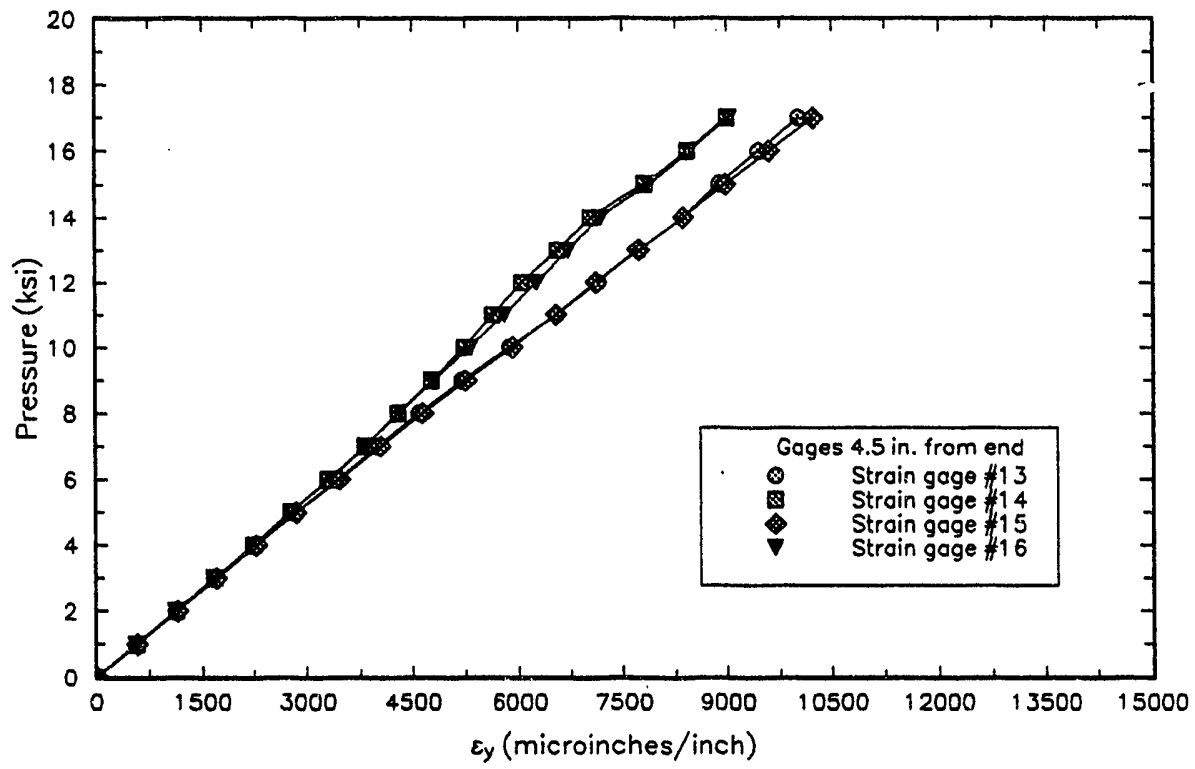

Fig. 3.4-15. Exterior hoop strains at 4.5 in. from end versus pressure for G6-2.

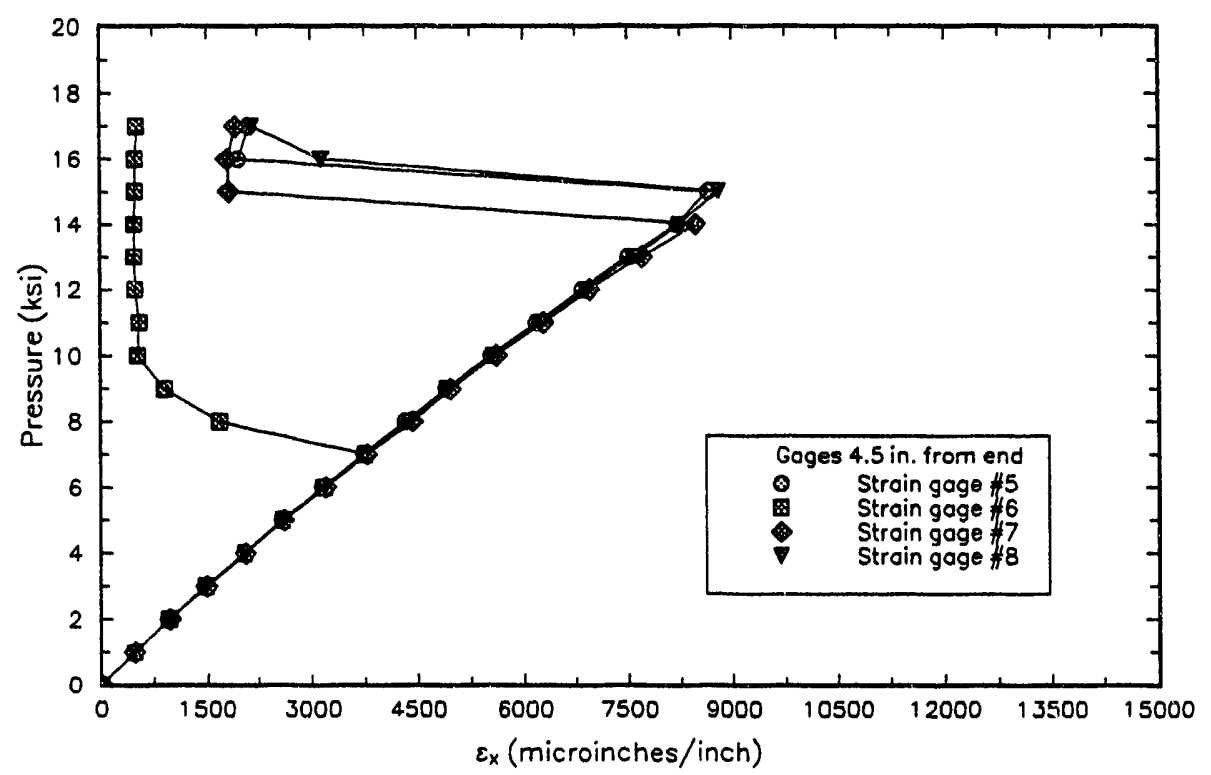

Fig. 3.4-16. Interior axial strains at 4.5 in. from end versus pressure for G6-2. 


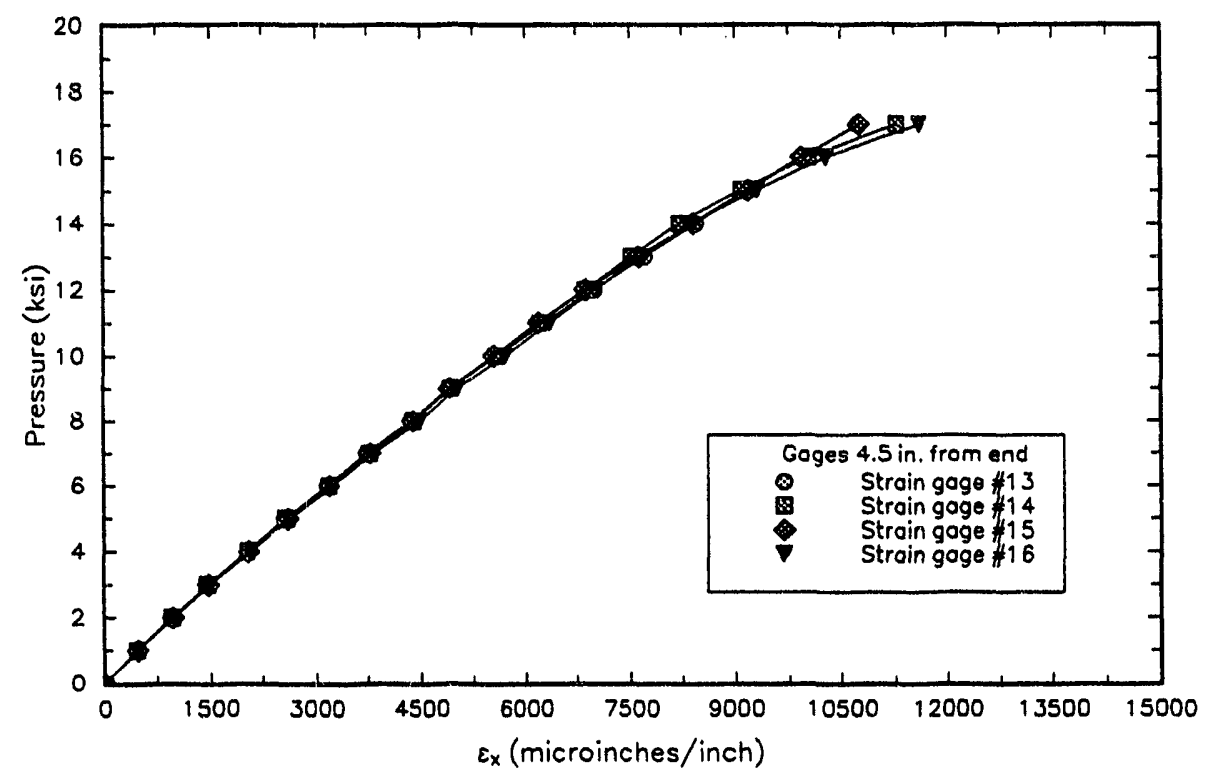

Fig. 3.4-17. Exterior axial strains at 4.5 in. from end versus pressure for G6-2.

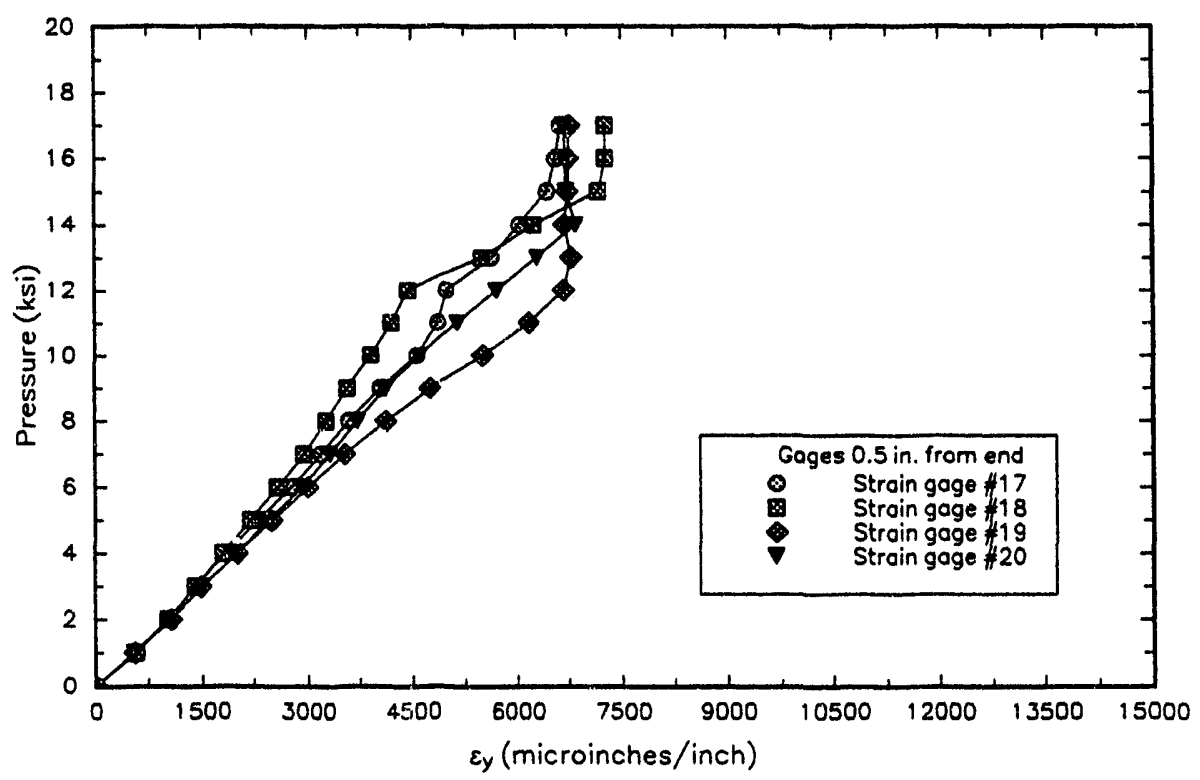

Fig. 3.4-18. Exterior hoop strains at 0.5 in. from end versus pressure for G6-2. 


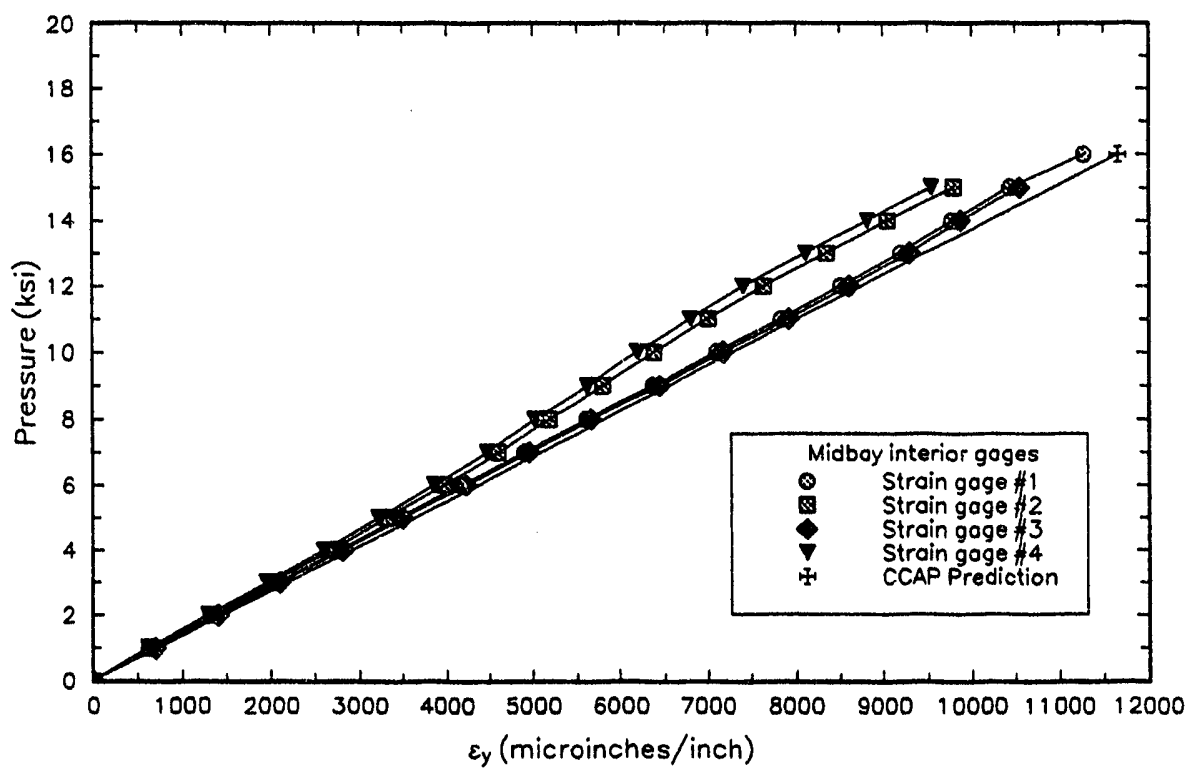

Fig. 3.4-19. Midbay interior hoop strains versus pressure for G6-3.

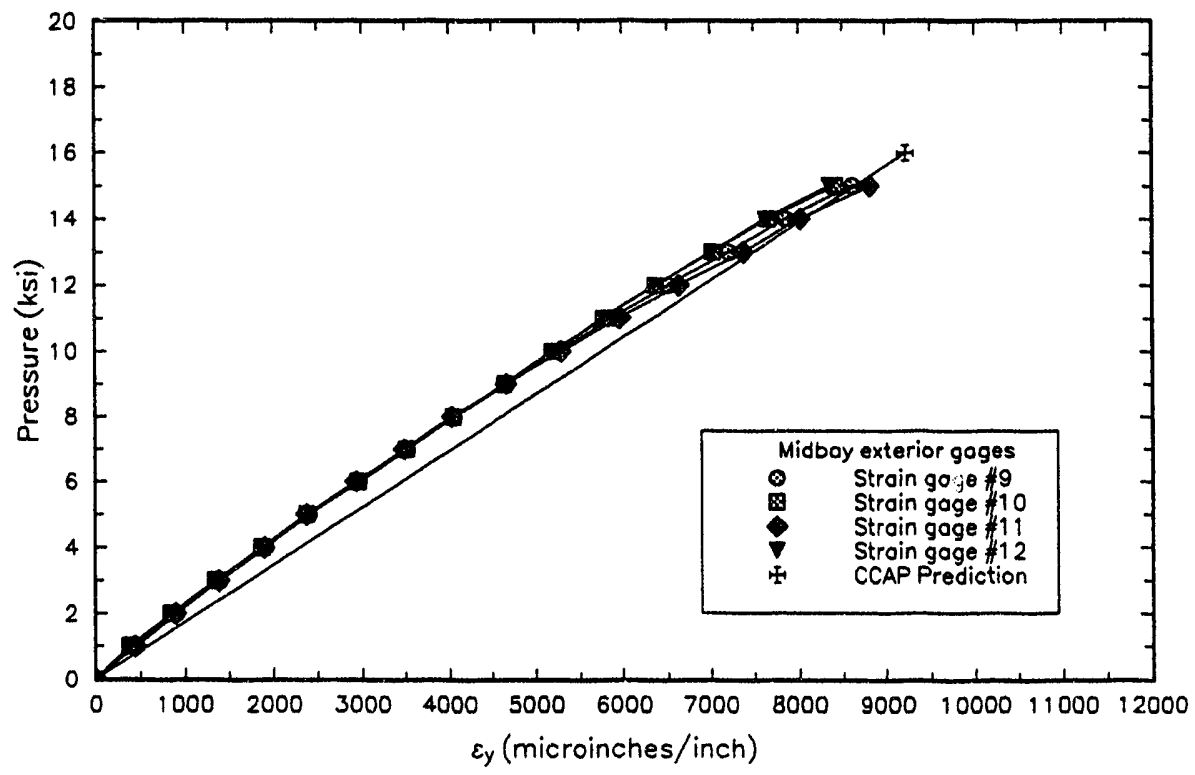

Fig. 3.4-20. Midbay exterior hoop strains versus pressure for G6-3. 


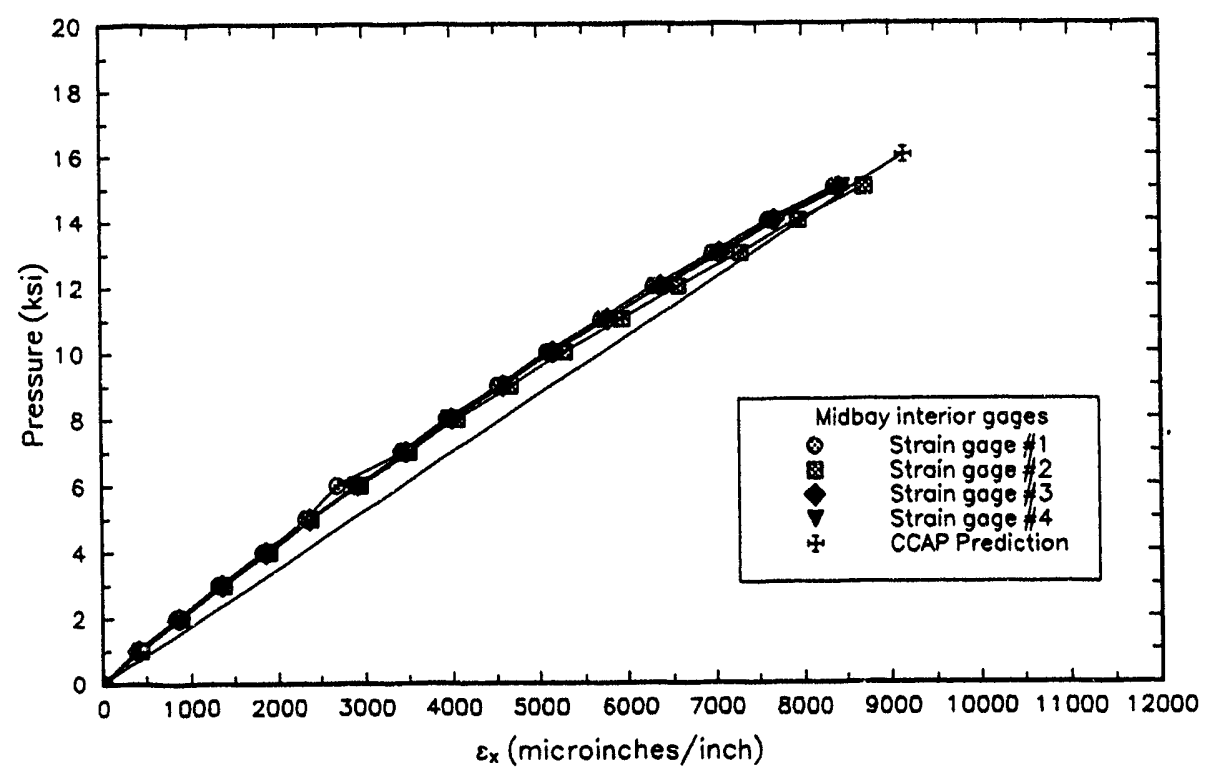

Fig. 3.4-21. Midbay interior axial strains versus pressure for G6-3.

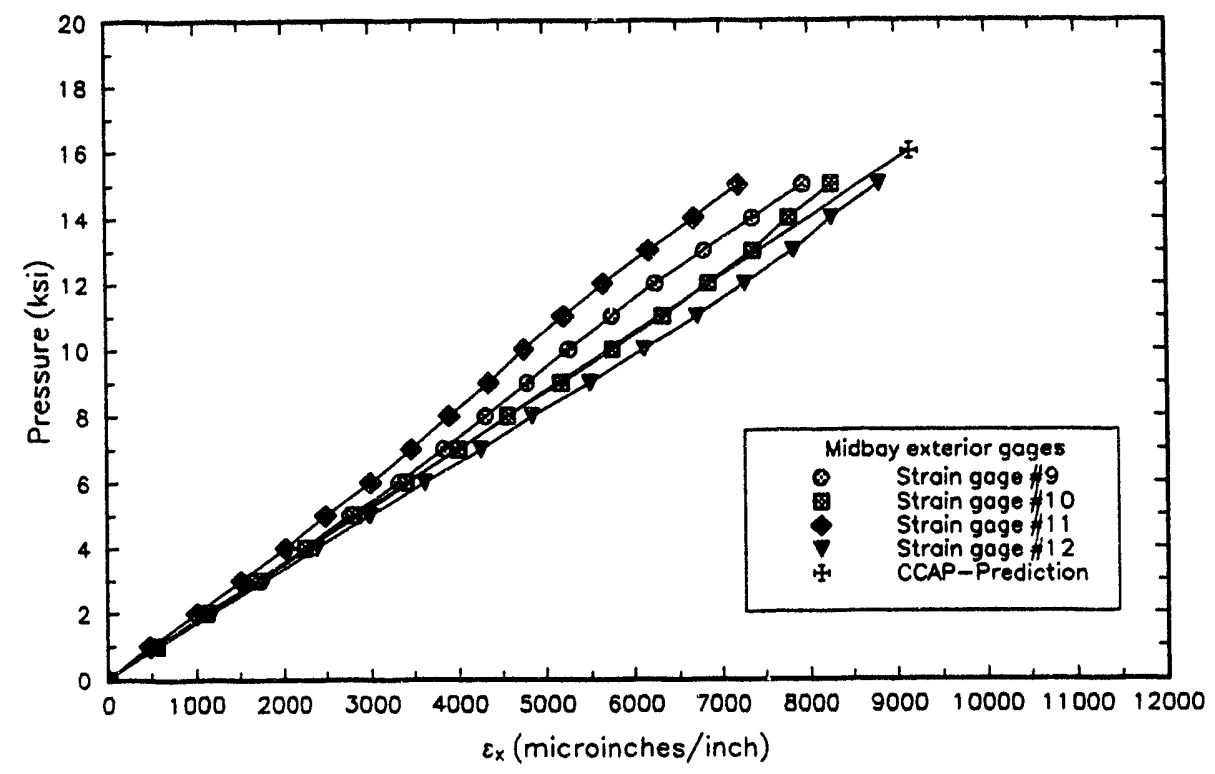

Fig. 3.4-22. Midbay exterior axial strains versus pressure for G6-3. 


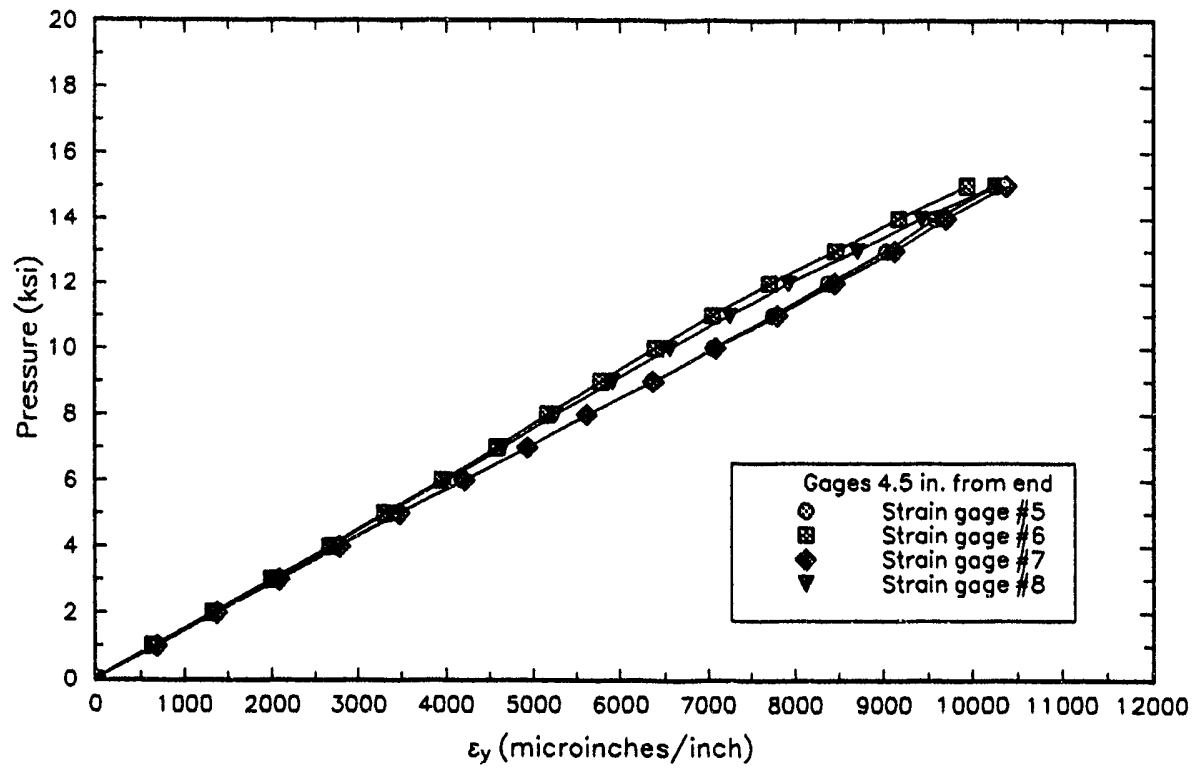

Fig. 3.4-23. Interior hoop strains at 4.5 in. from end versus pressure for G6-3.

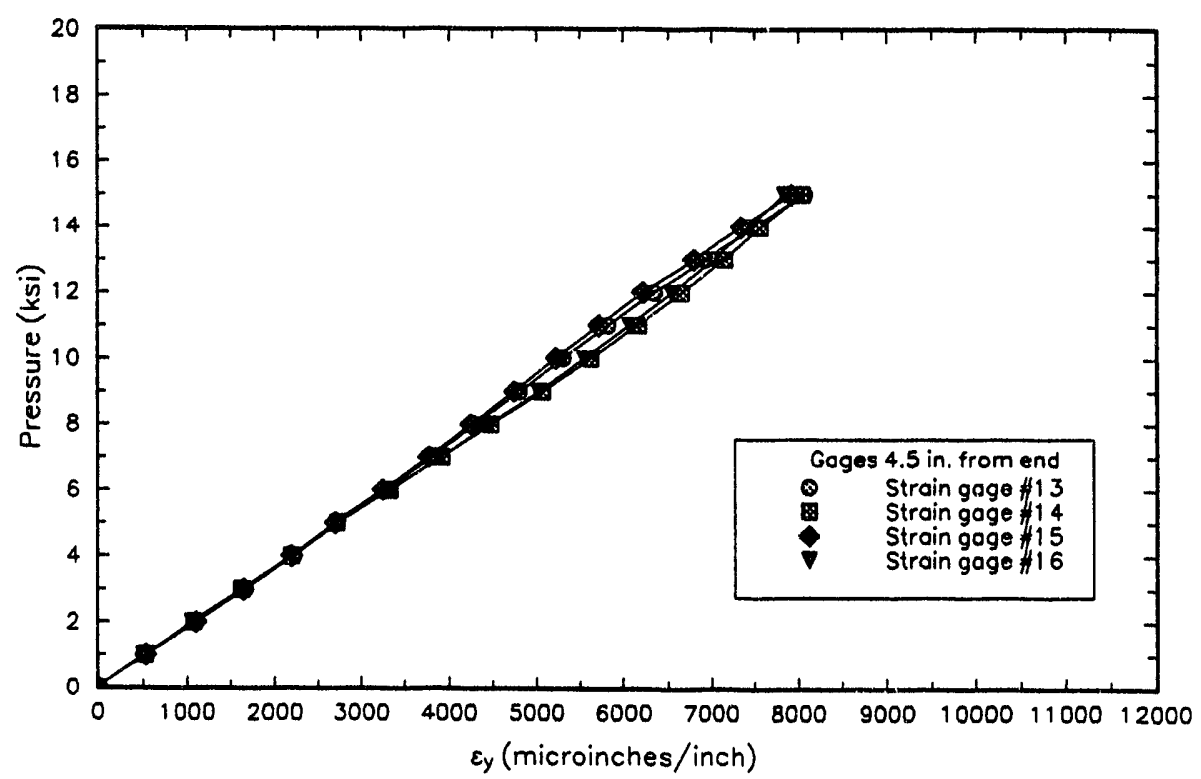

Fig. 3.4-24. Exterior hoop strains at 4.5 in. from end versus pressure for G6-3. 


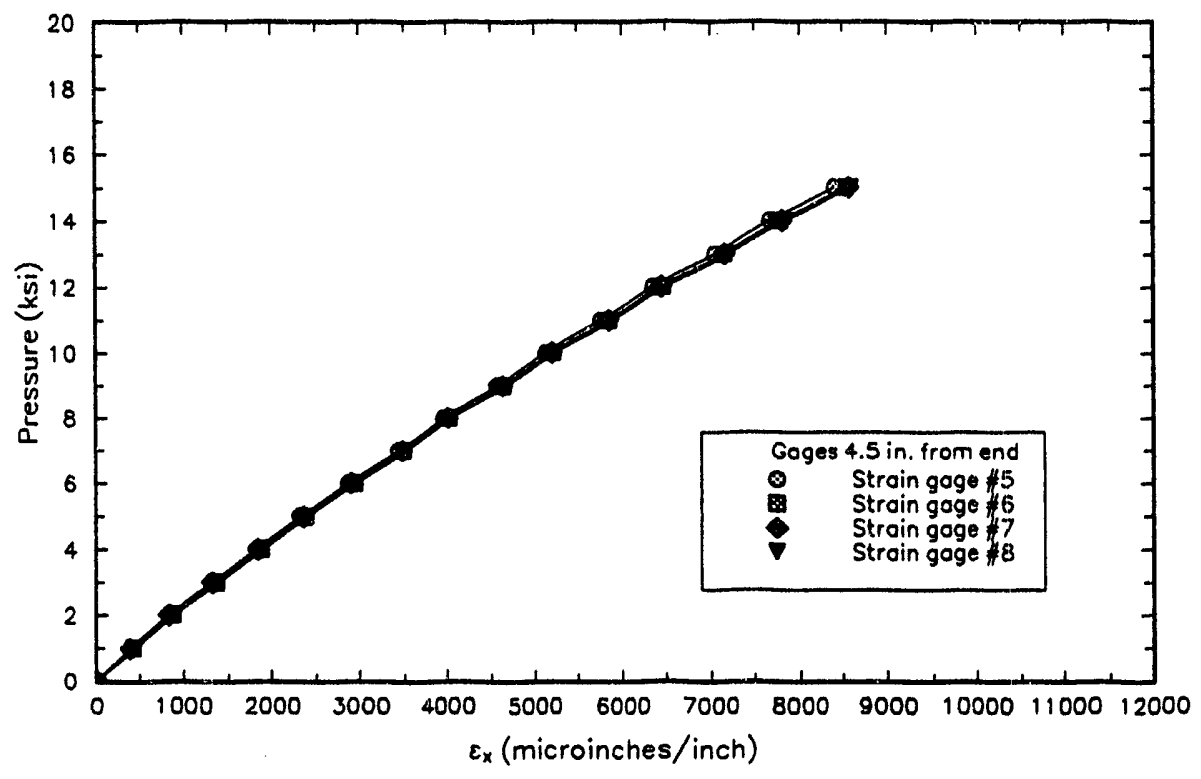

Fig. 3.4-25. Interior axial strains at 4.5 in. from end versus pressure for G6-3.

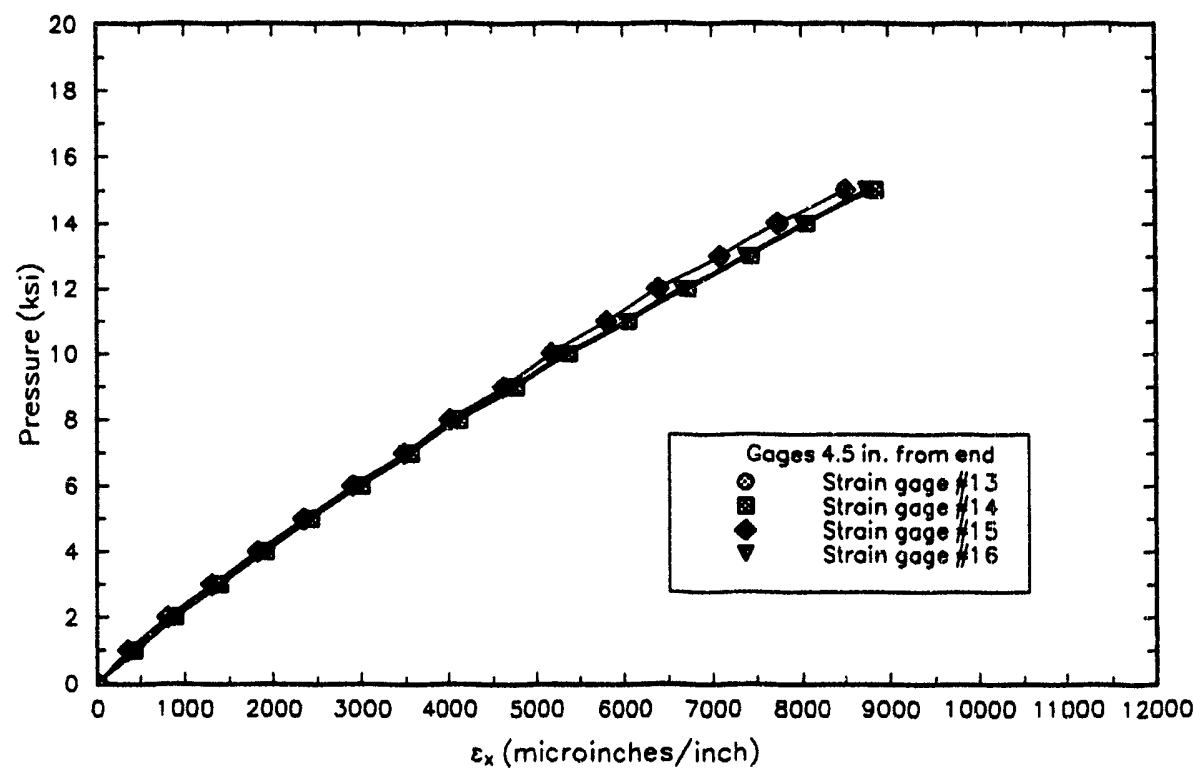

Fig. 3.4-26. Exterior axial strains at 4.5 in. from end versus pressure for G6-3. 


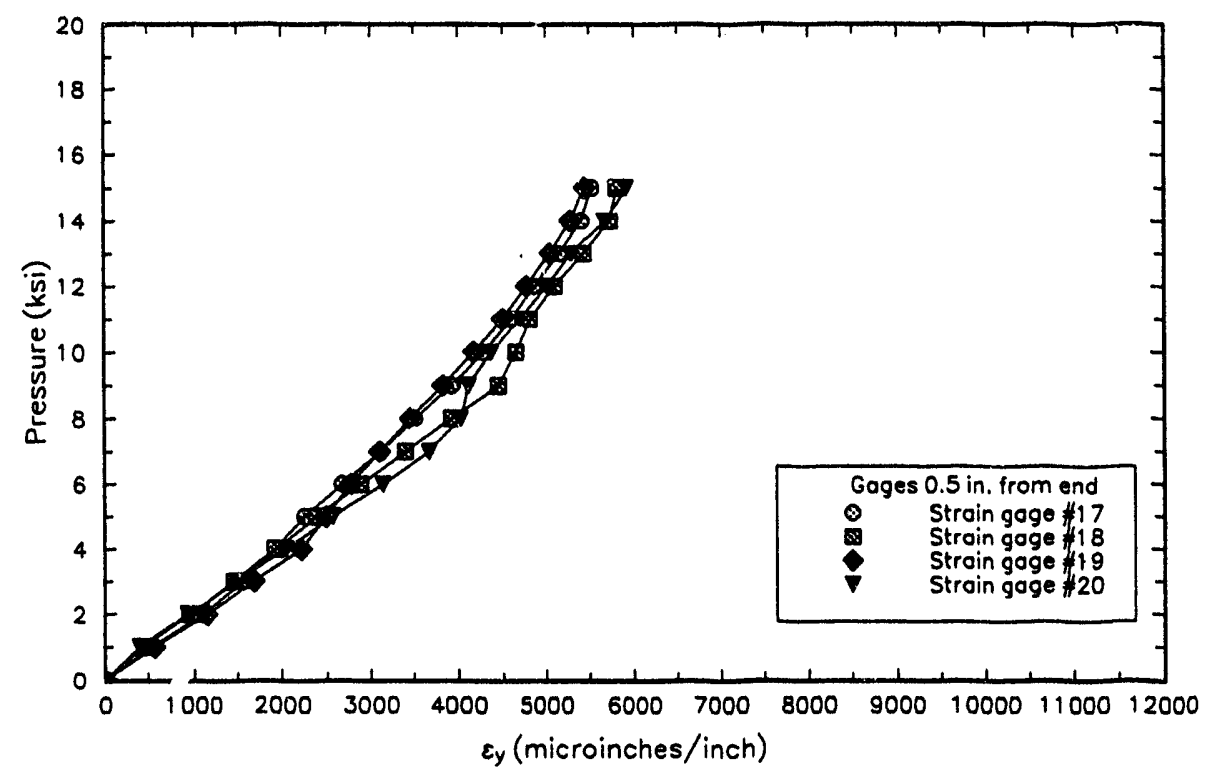

Fig. 3.4-27. Exterior hoop strains at 0.5 in. from end versus pressure for G6-3.

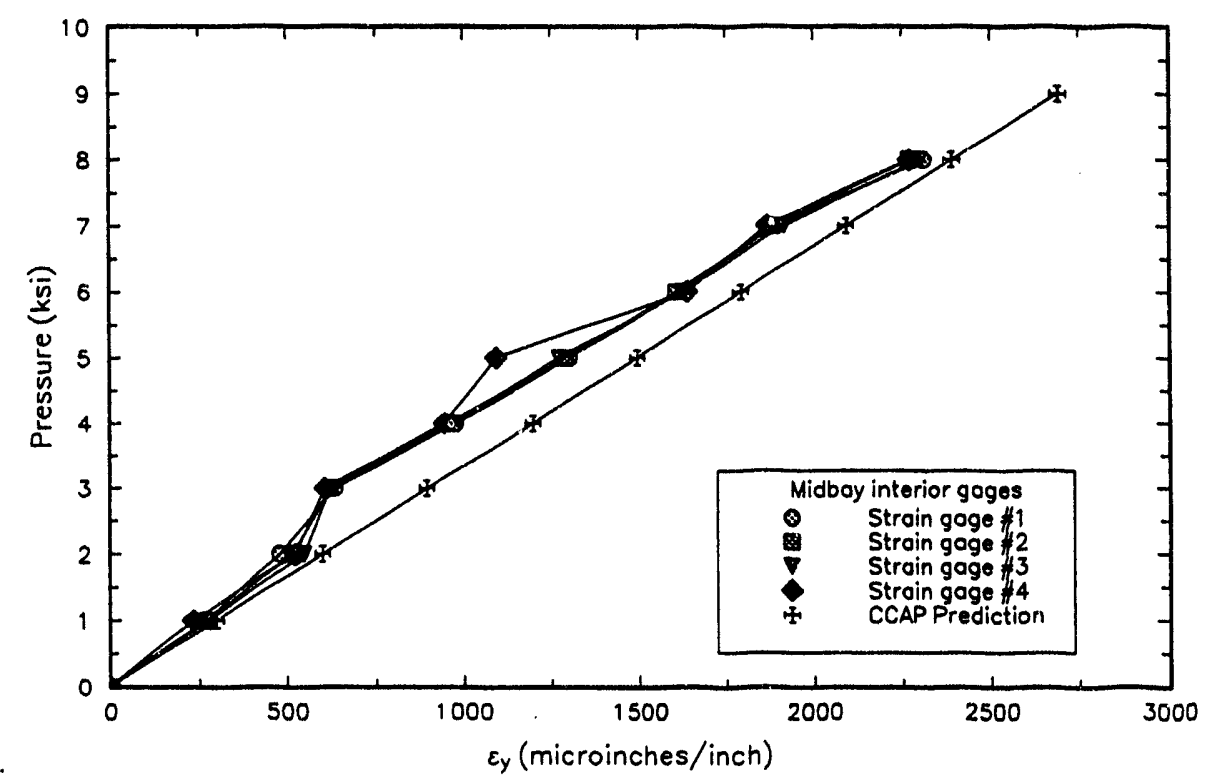

Fig. 3.4-28. Midbay interior hoop strains versus pressure for C6-4. 


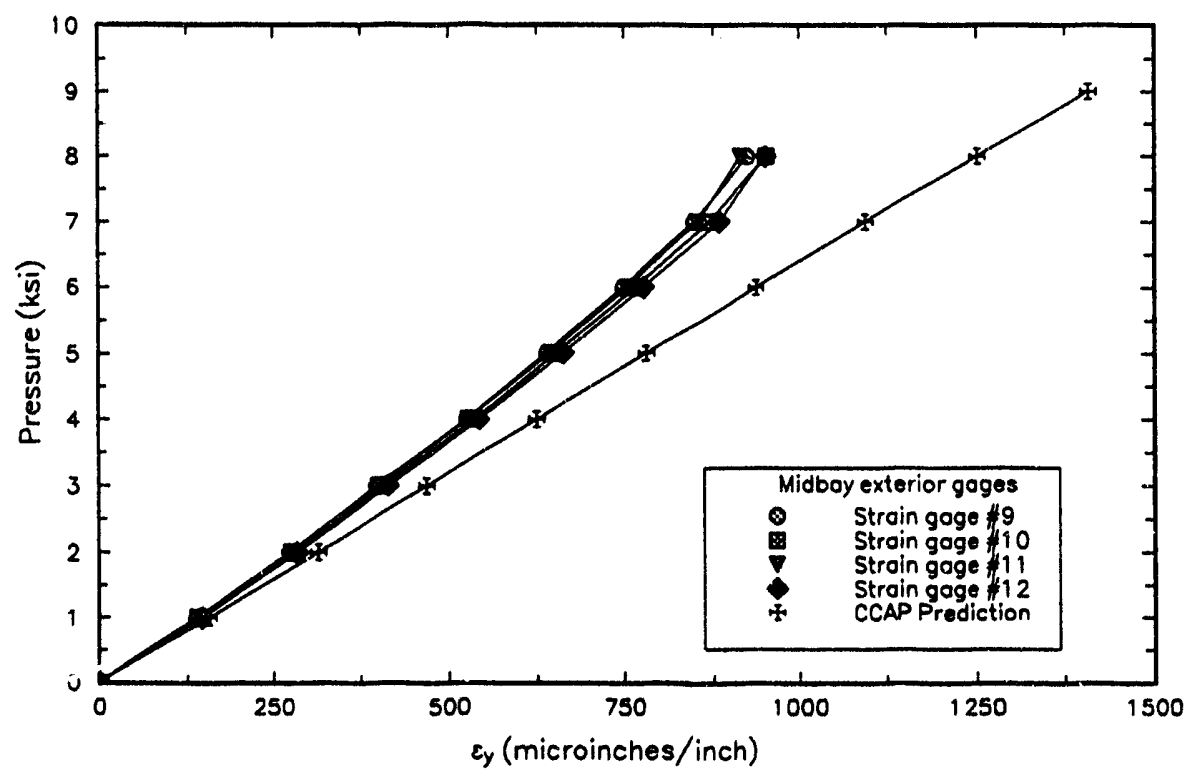

Fig. 3.4-29. Midbay exterior hoop strains versus pressure for C6-4.

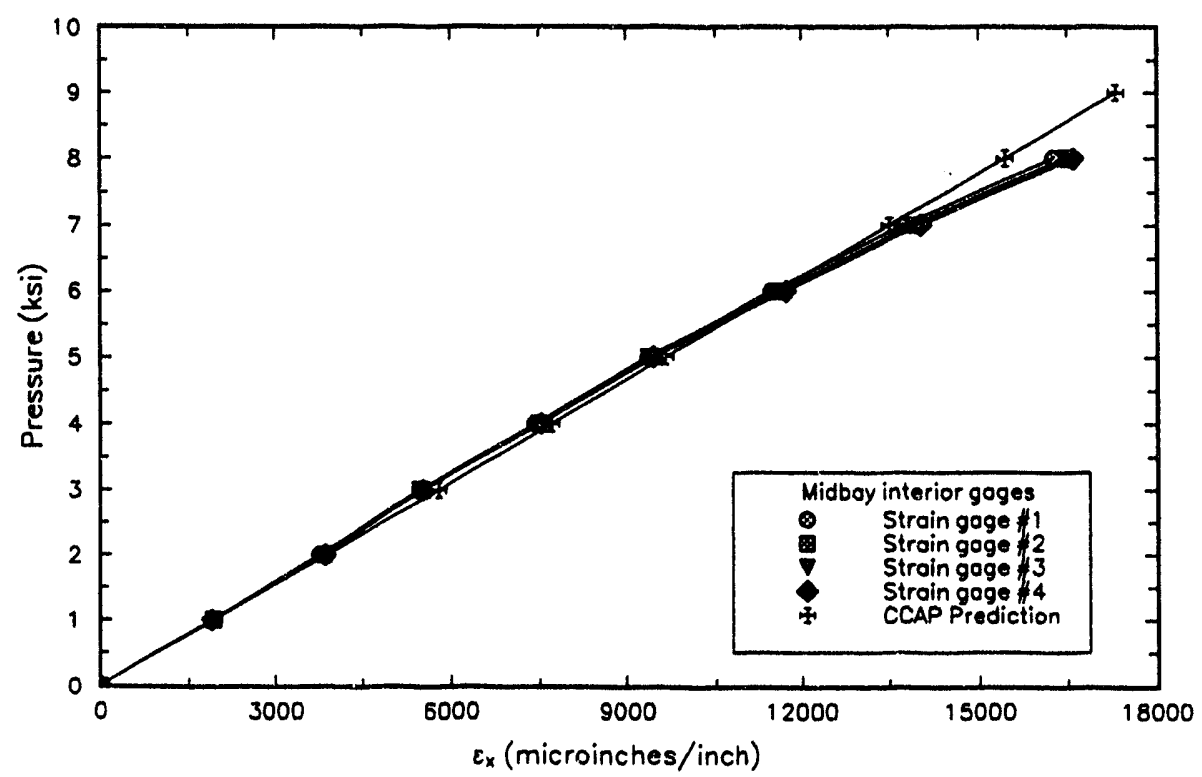

Fig. 3.4-30. Midbay interior axial strains versus pressure for $\mathbf{C 6 - 4}$. 


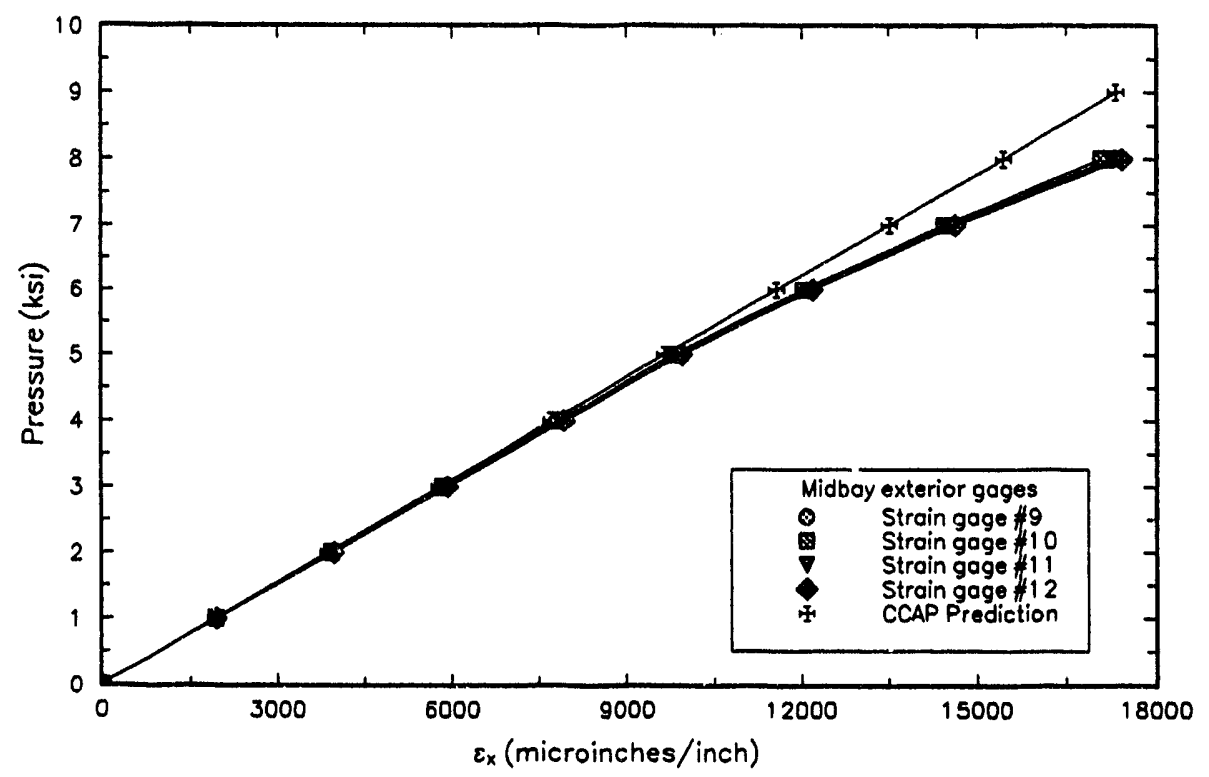

Fig. 3.4-31. Midbay exterior axial strains versus pressure for $\mathrm{C6}-4$.

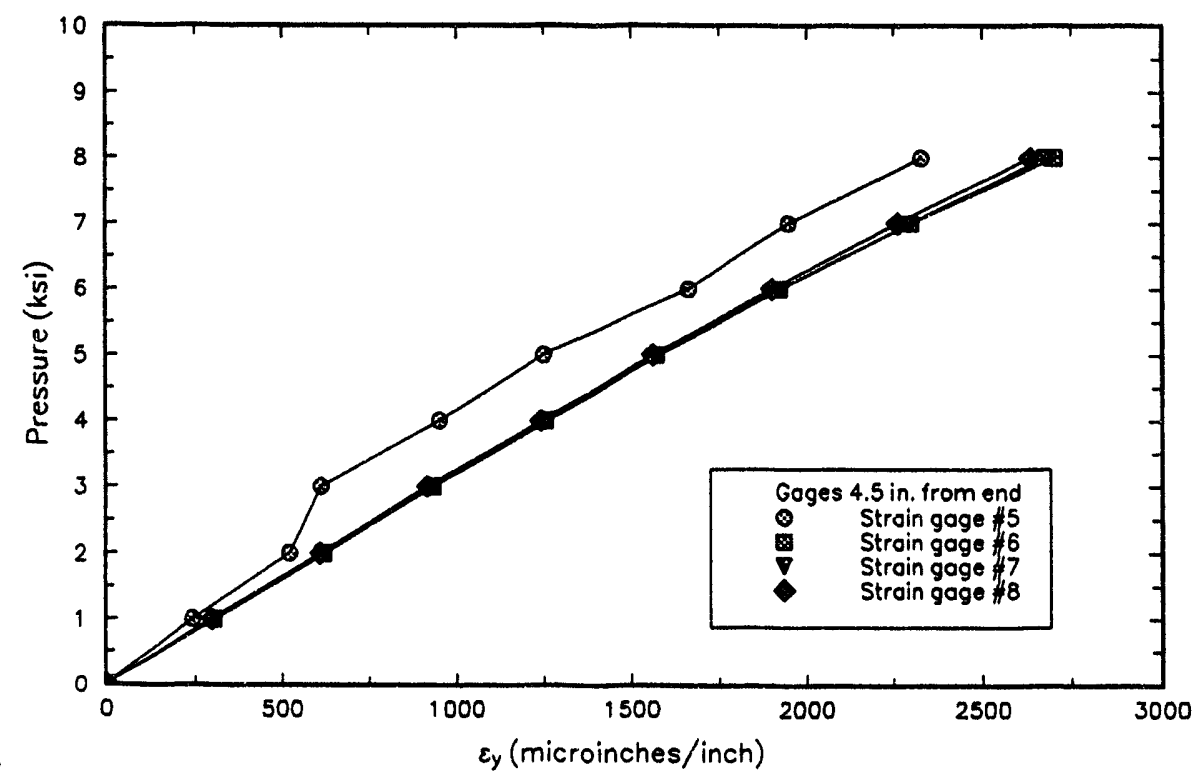

Fig. 3.4-32. Interior hoop strains at 4.5 in. from end versus pressure for C6-4. 


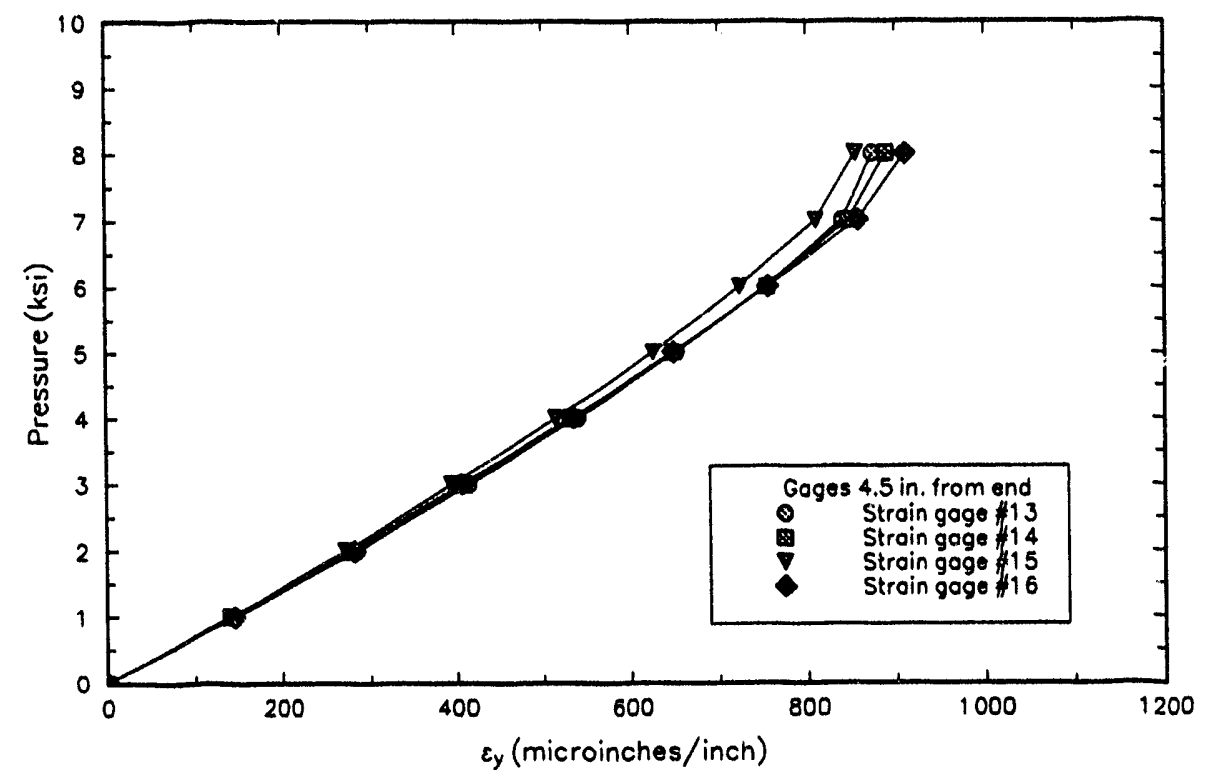

Fig. 3.4-33. Exterior hoop strains at $4.5 \mathrm{in}$. from end versus pressure for $\mathrm{C6-4}$.

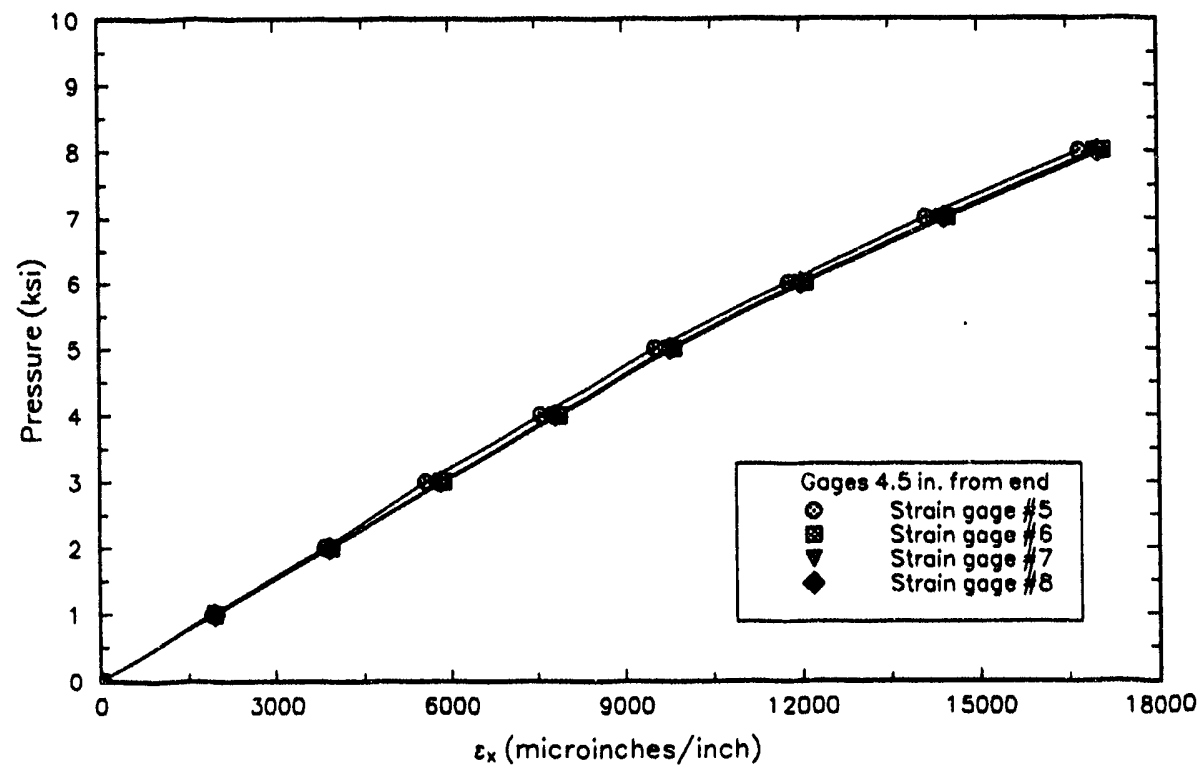

Fig. 3.4-34. Interior axial strains at $4.5 \mathrm{in}$. from end versus pressure for $\mathrm{C6}-4$. 


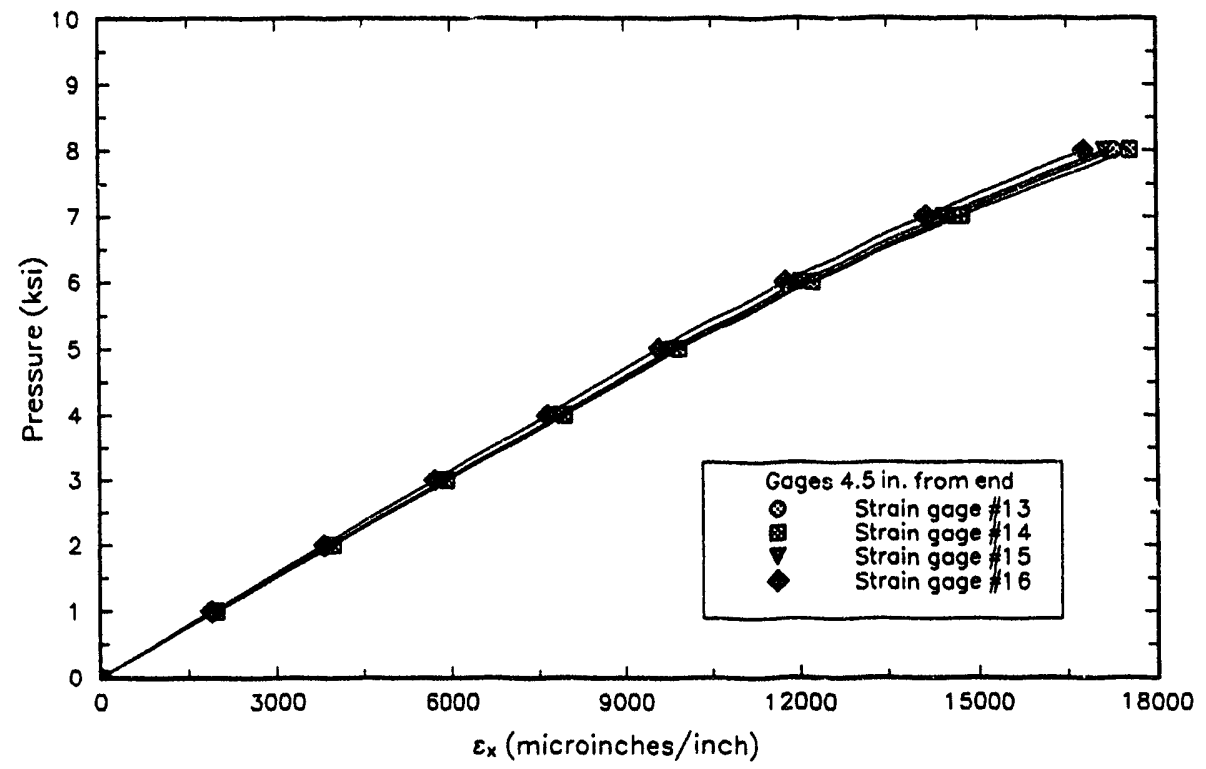

Fig. 3.4-35. Exterior axial strains at 4.5 in. from end versus pressure for C6-4.

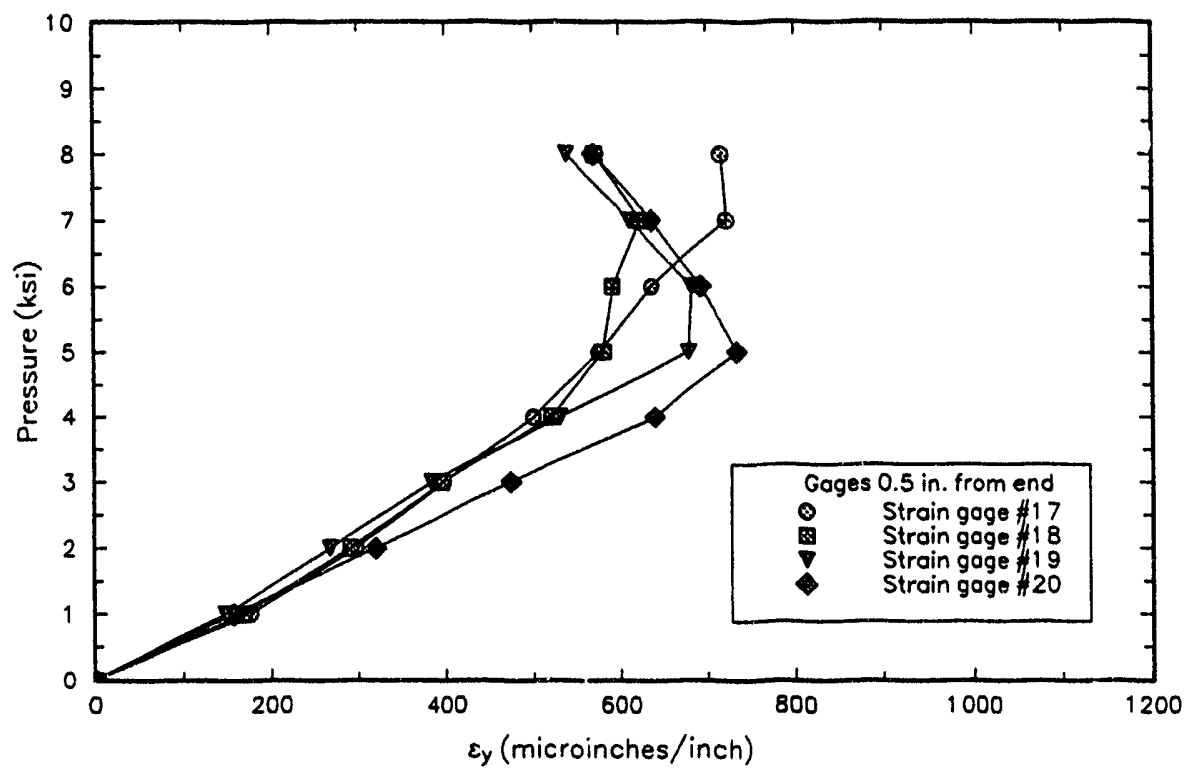

Fig. 3.4-36. Exterior hoop strains at 0.5 in. from end versus pressure for C6-4. 


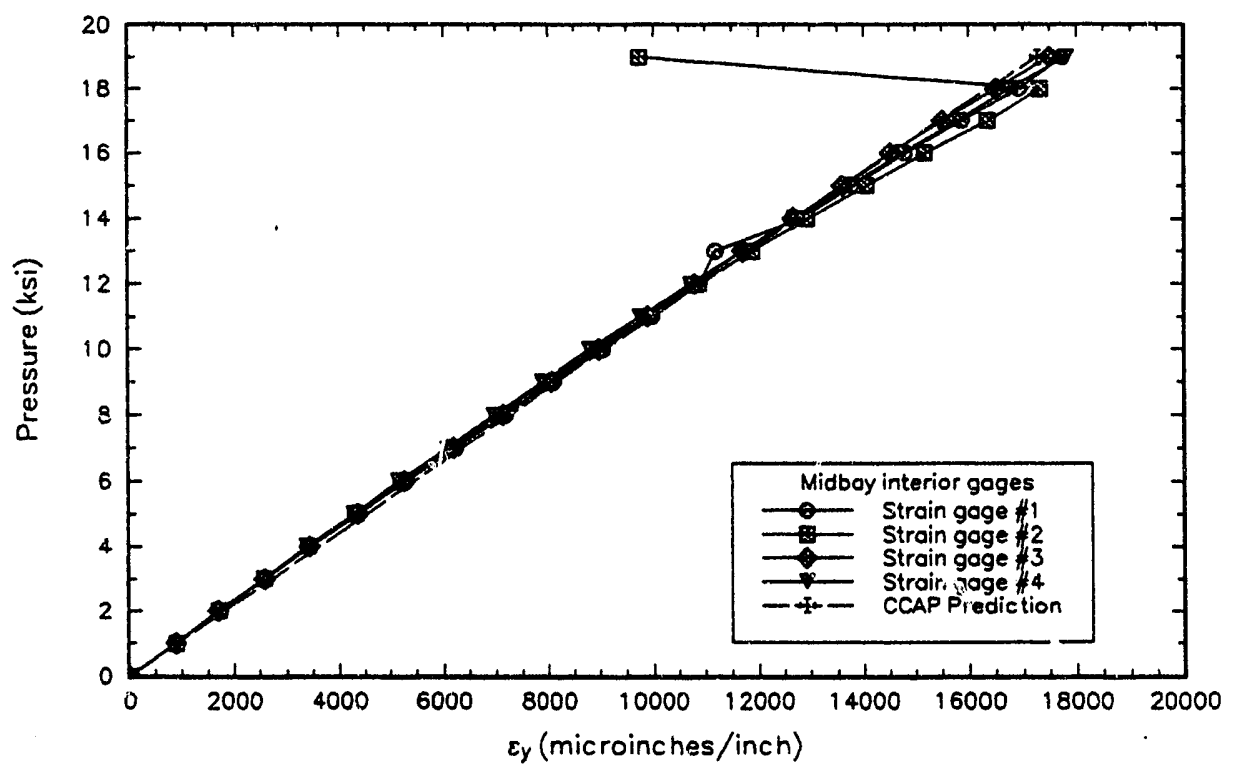

Fig. 3.4-37. Midhay interior hoop strains versus pressure for $\mathrm{G} 6-4$.

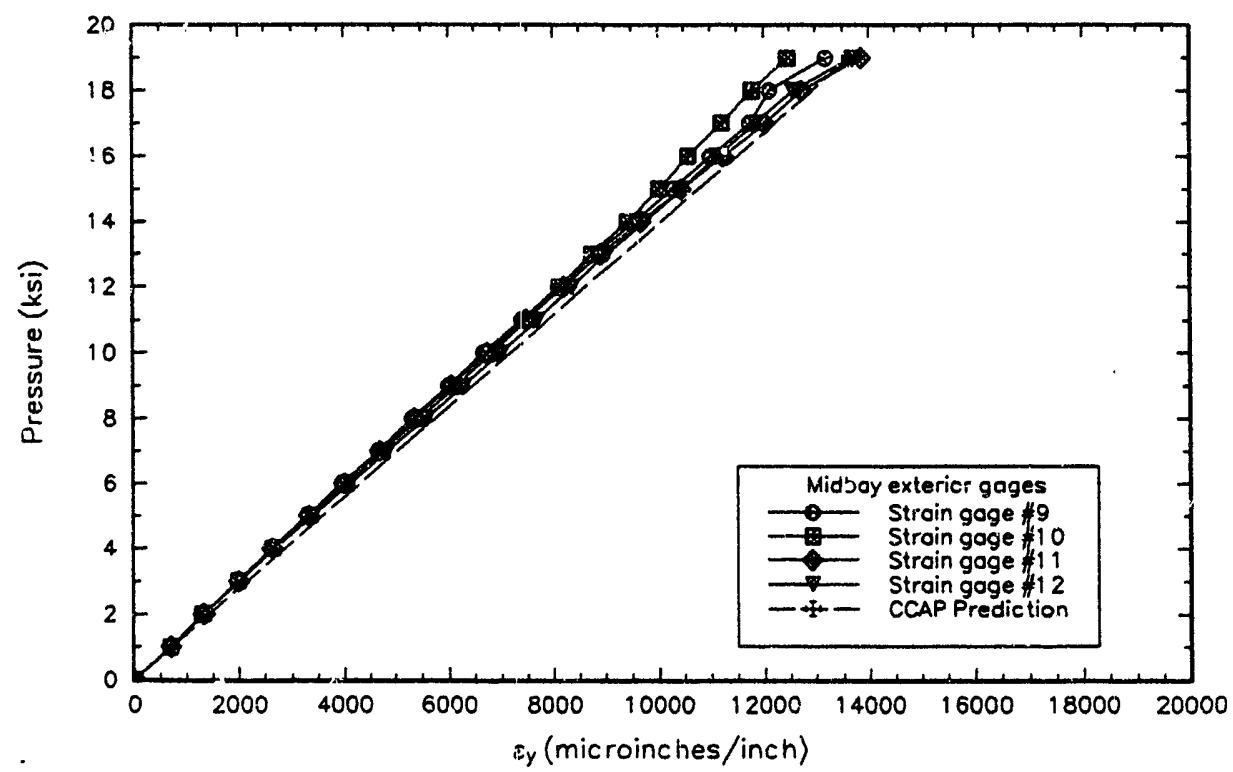

Fig. 3.4-38. Midbay exterior hoop strains versus pressure for G6-4. 


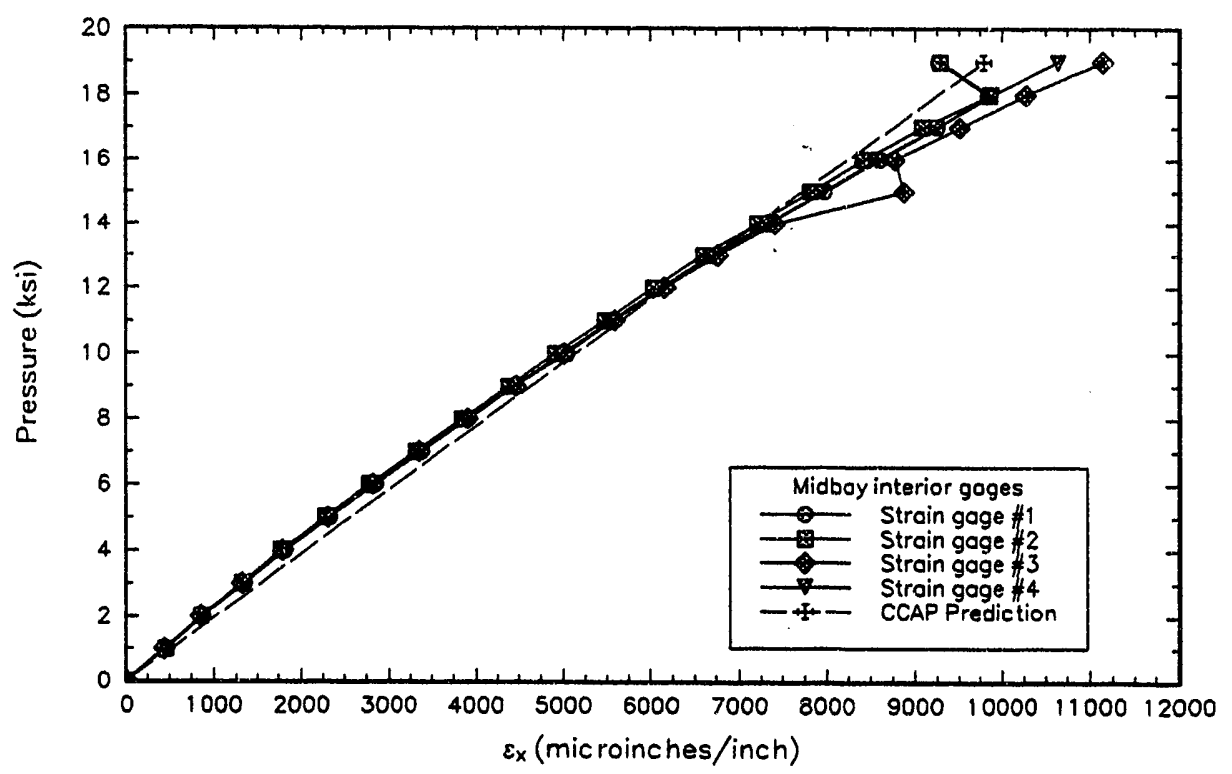

Fig. 3.4-39. Midbay interior axial strains versus pressure for G6-4.

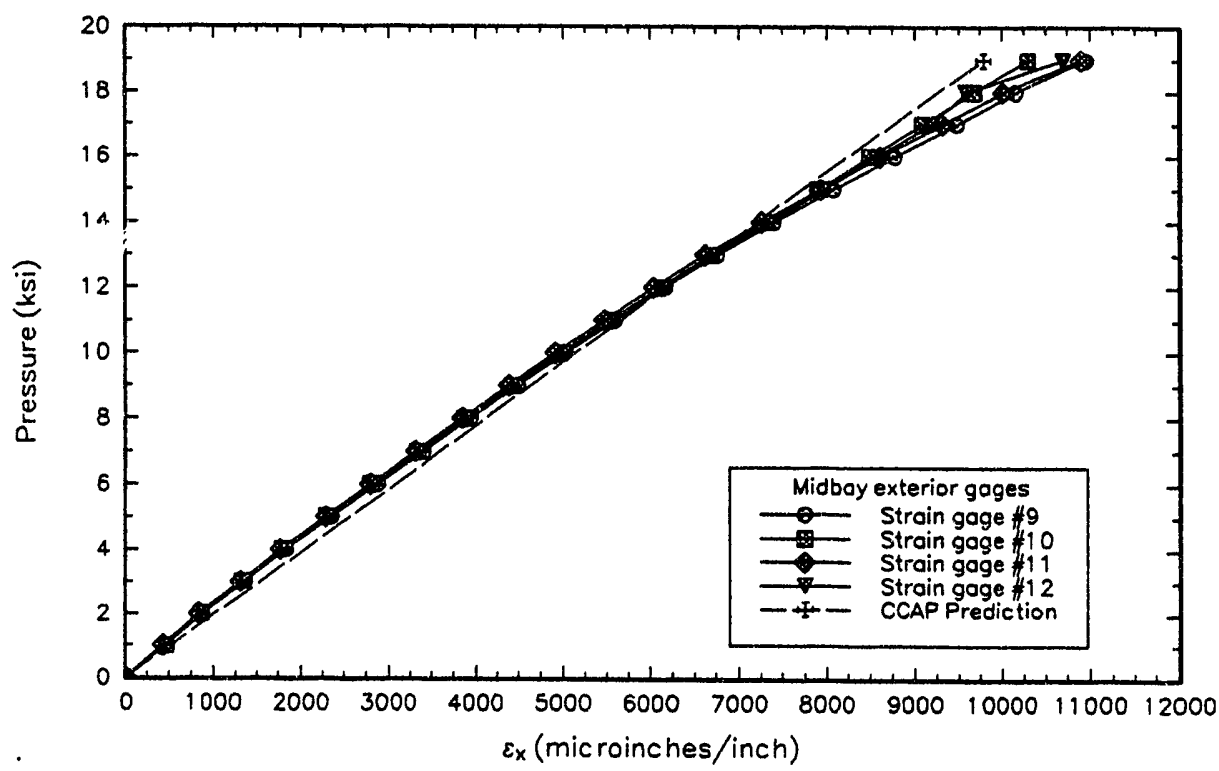

Fig. 3.4-40. Midbay exterior axial strains versus pressure for G6-4. 


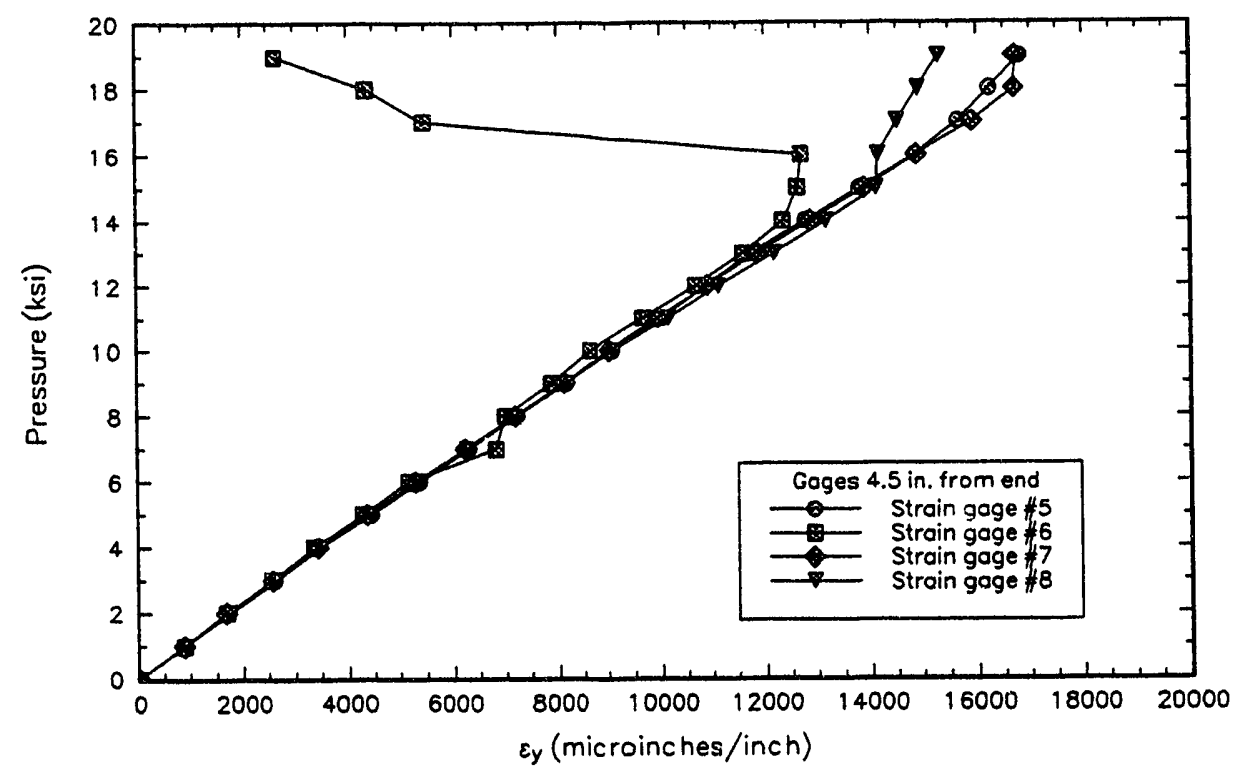

Fig. 3.4-41. Interior hoop strains at 4.5 in. from end versus pressure for G6-4.

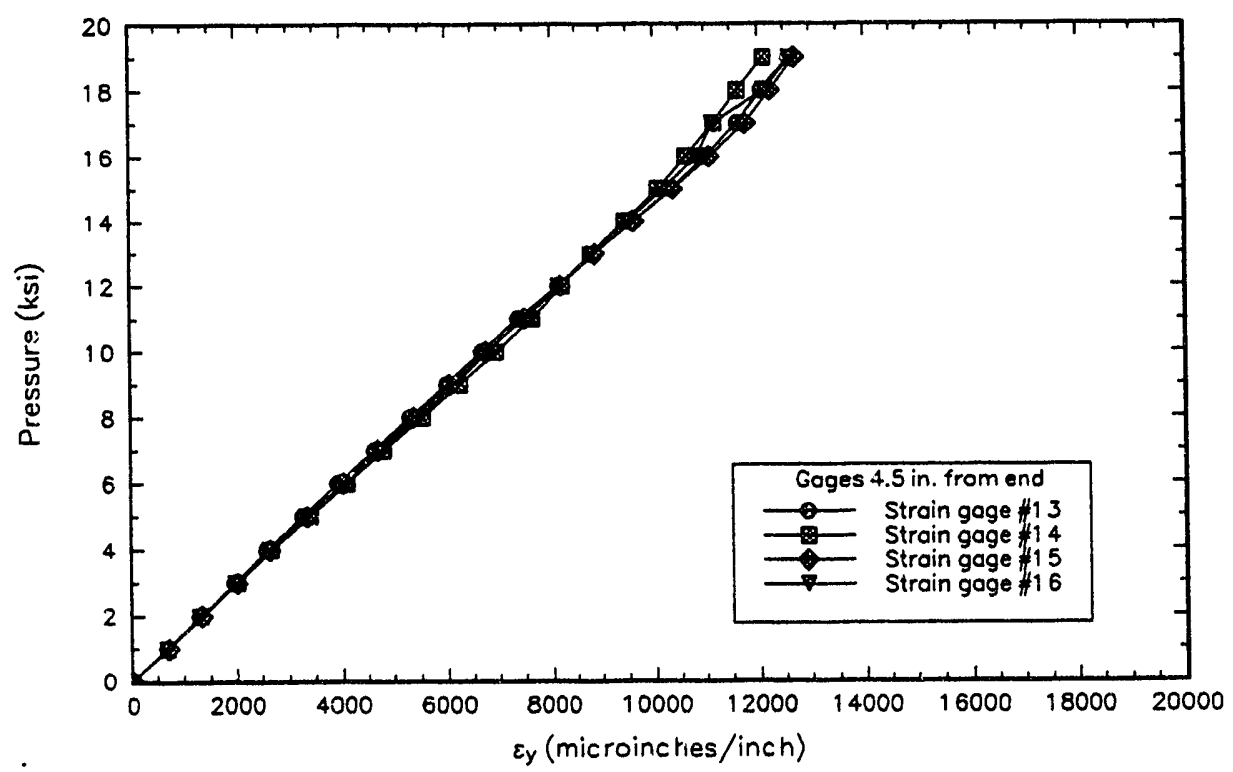

Fig. 3.4-42. Exterior hoop strains at 4.5 in. from end versus pressure for G6-4. 


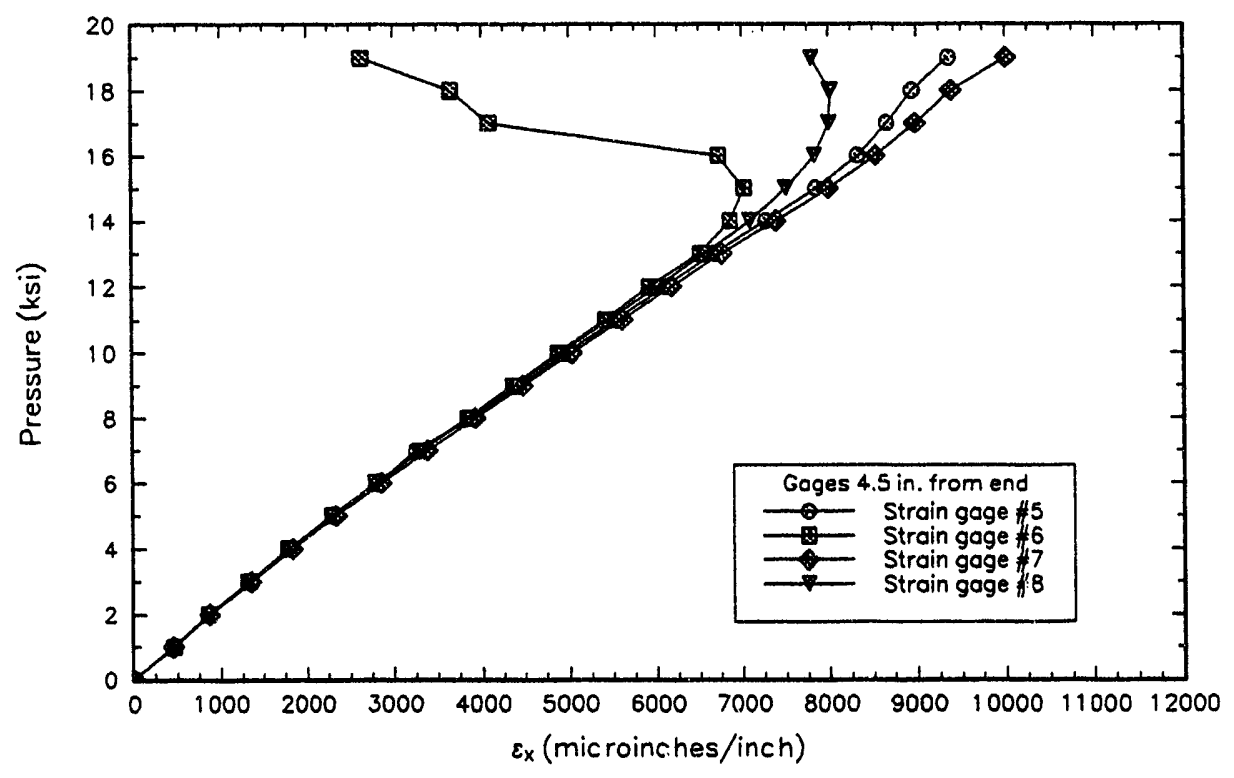

Fig. 3.4-43. Interior axial strains at 4.5 in. from end versus pressure for G6-4.

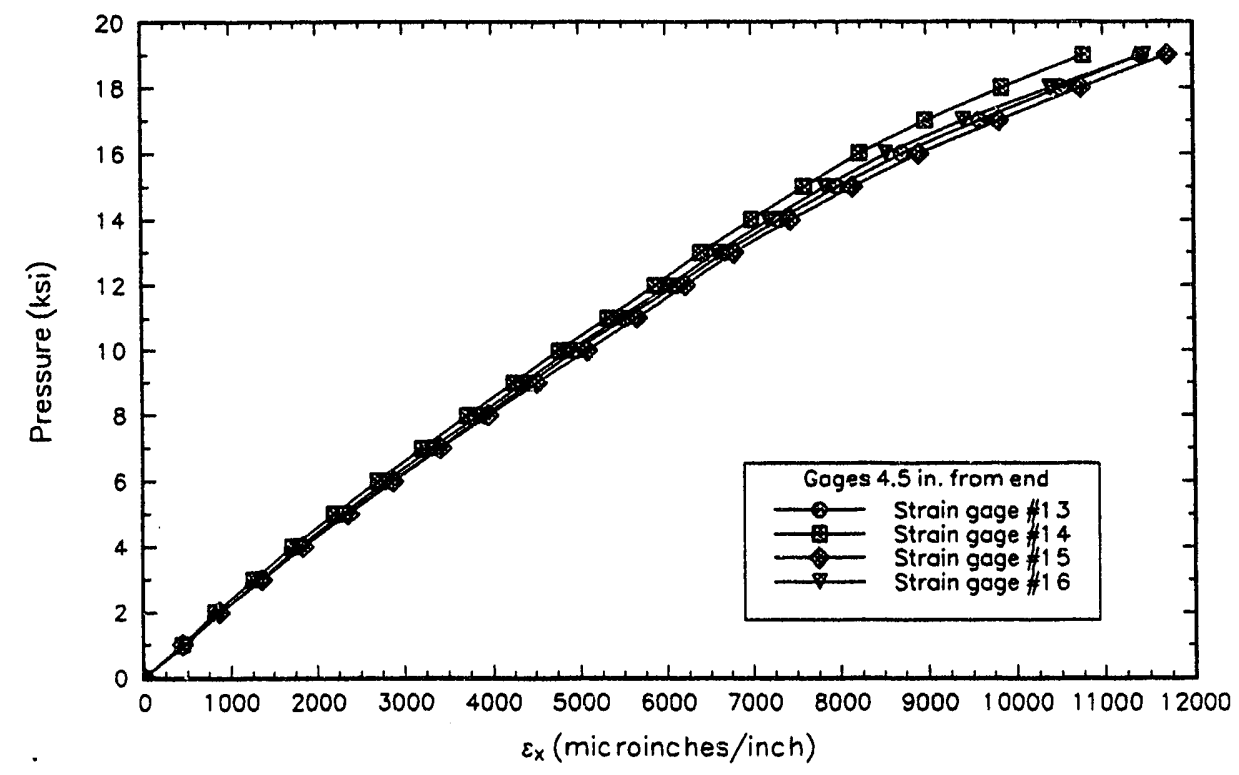

Fig. 3.4-44. Exterior axial strains at 4.5 in. from end versus pressure for G6-4. 


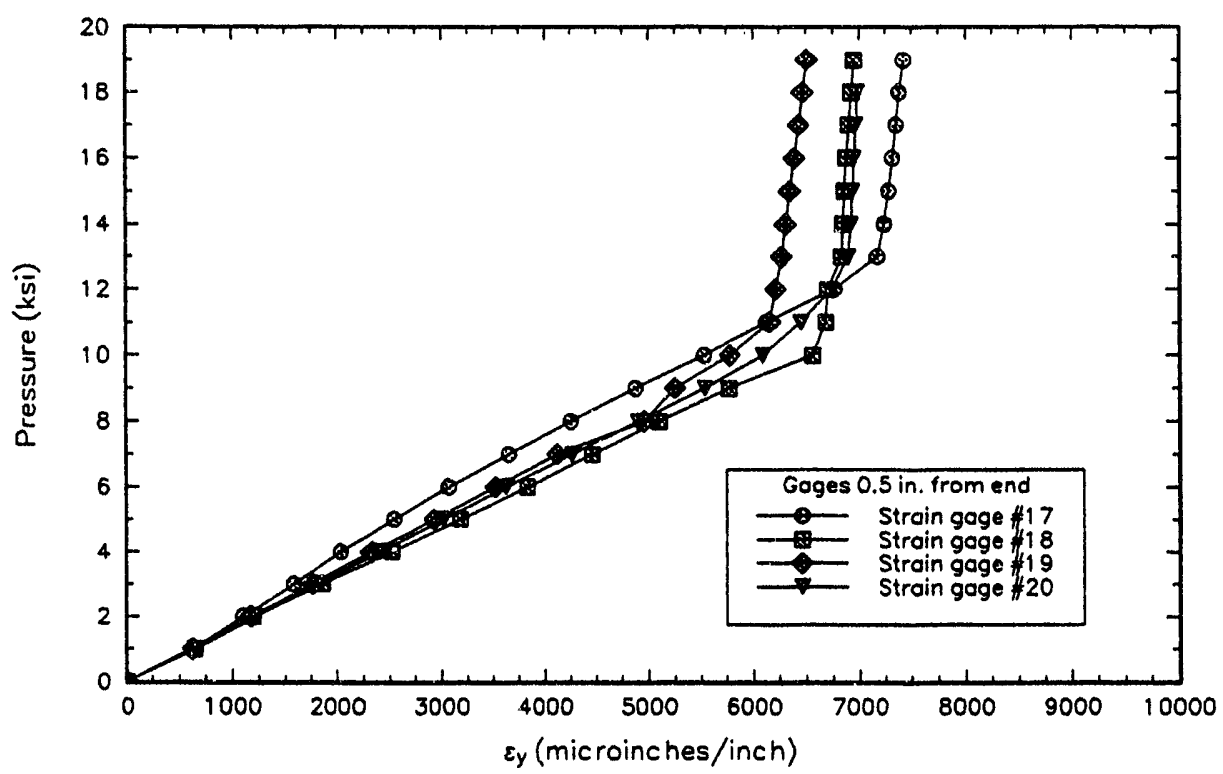

Fig. 3.4-45. Exterior hoop strains at 0.5 in. from end versus pressure for G6-4.

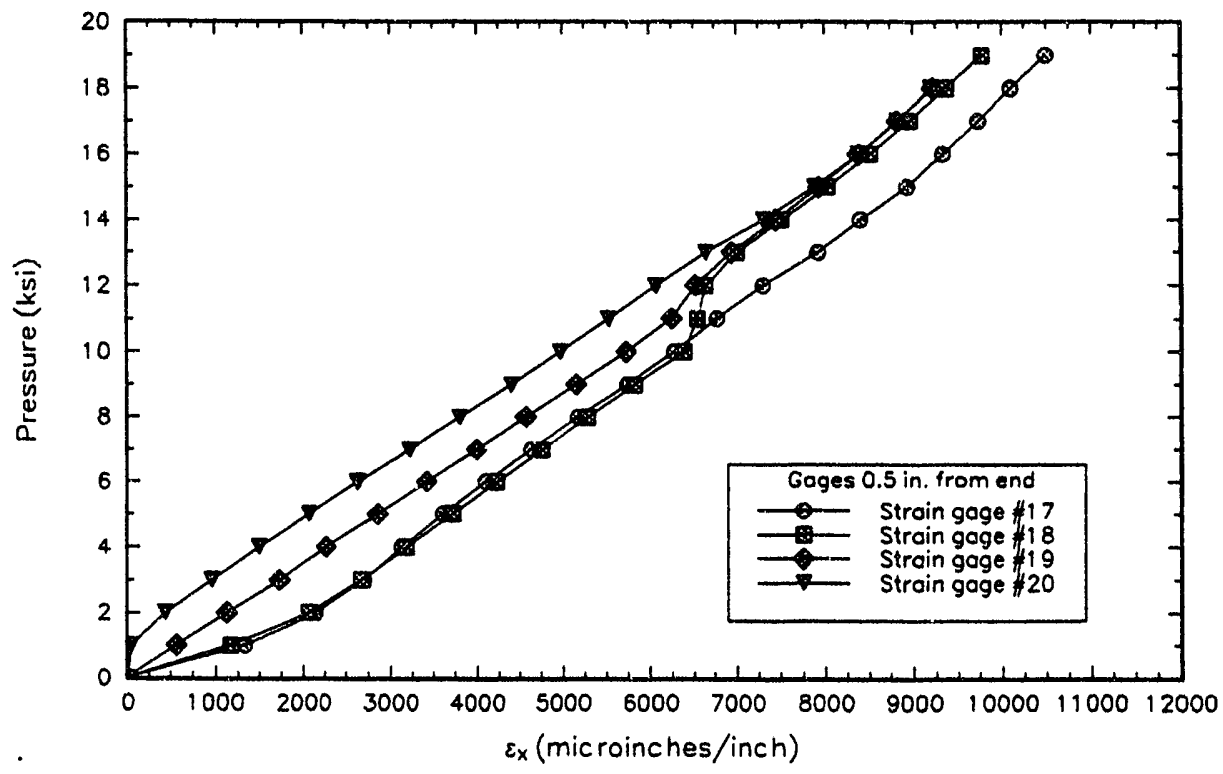

Fig. 3.4-46. Exterior axial strains at 0.5 in. from end versus pressure for G6-4. 


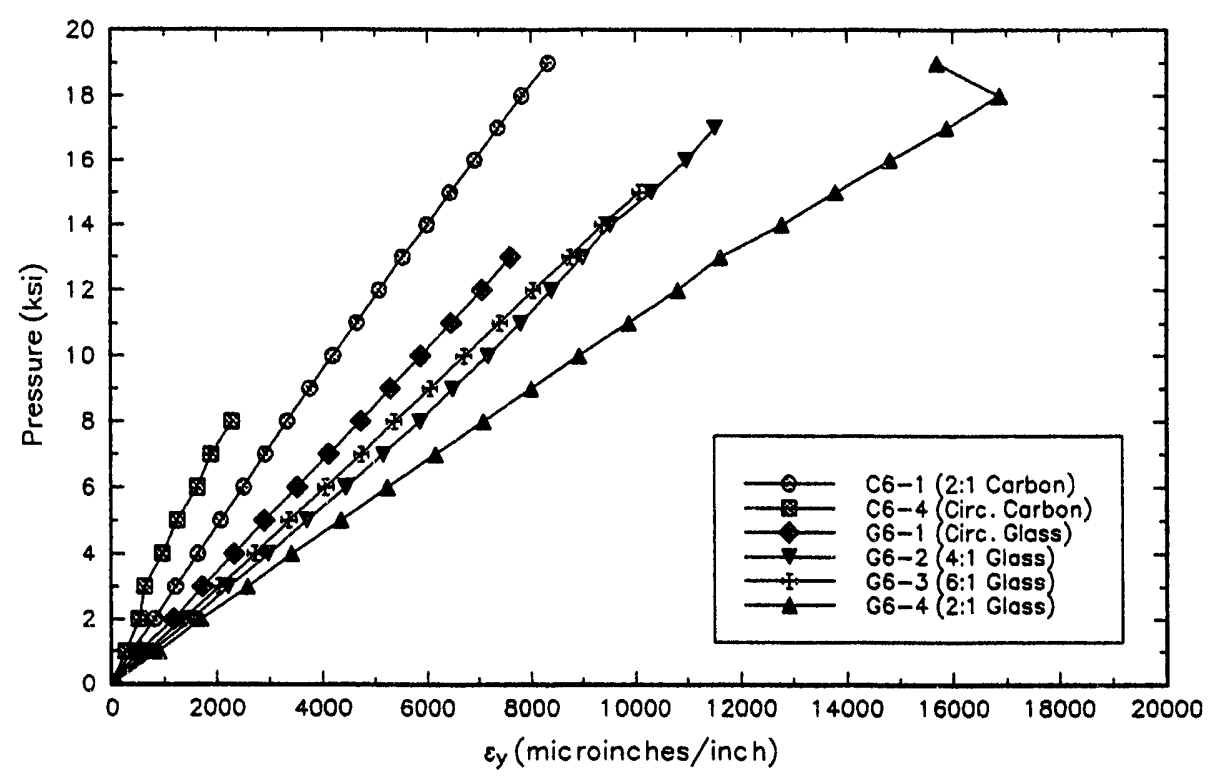

Fig. 3.4-47. Average midbay interior hoop strains versus pressure.

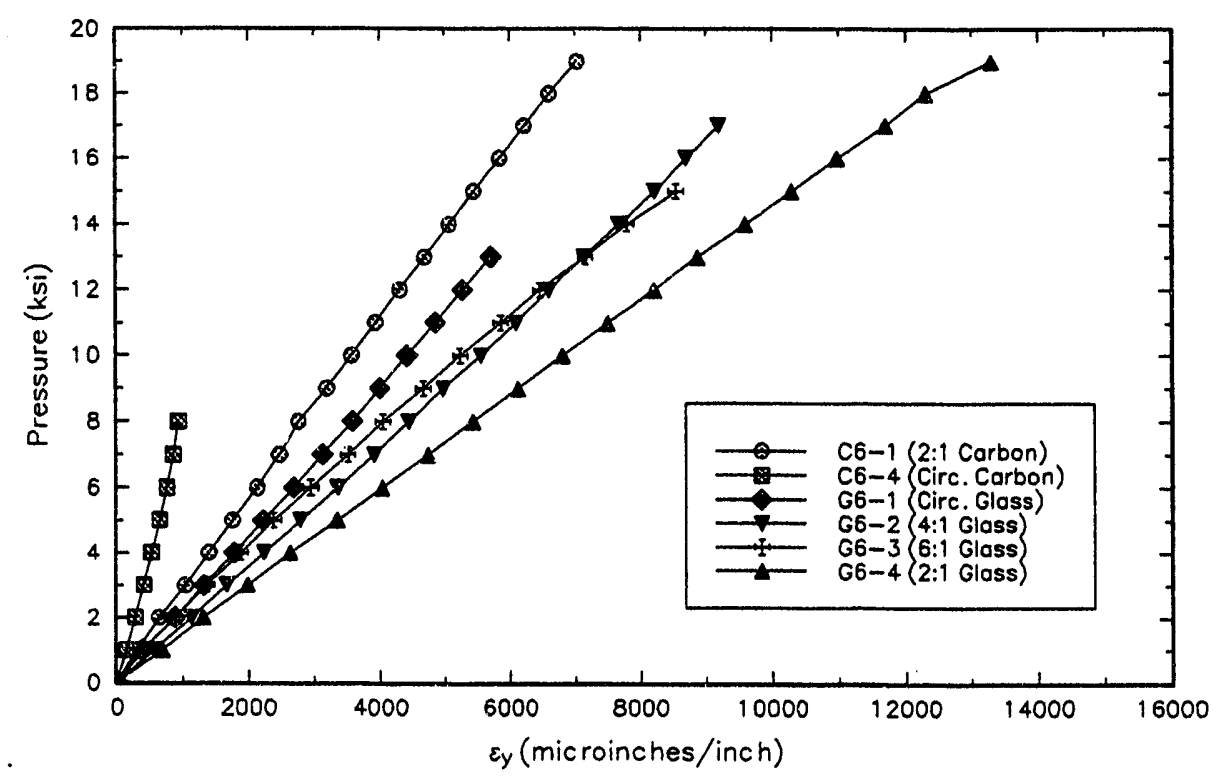

Fig. 3.4-48. Average midbay exterior hoop strains versus pressure. 


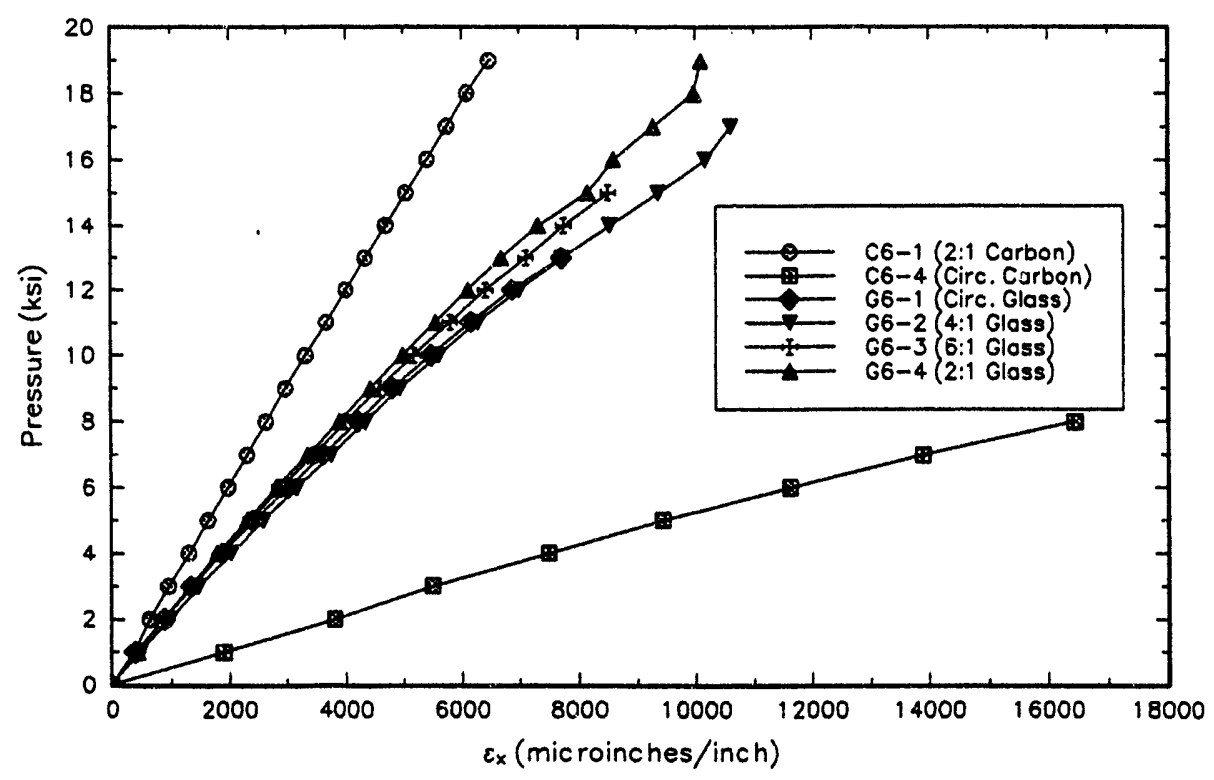

Fig. 3.4-49. Average midbay interior axial strains versus pressure.

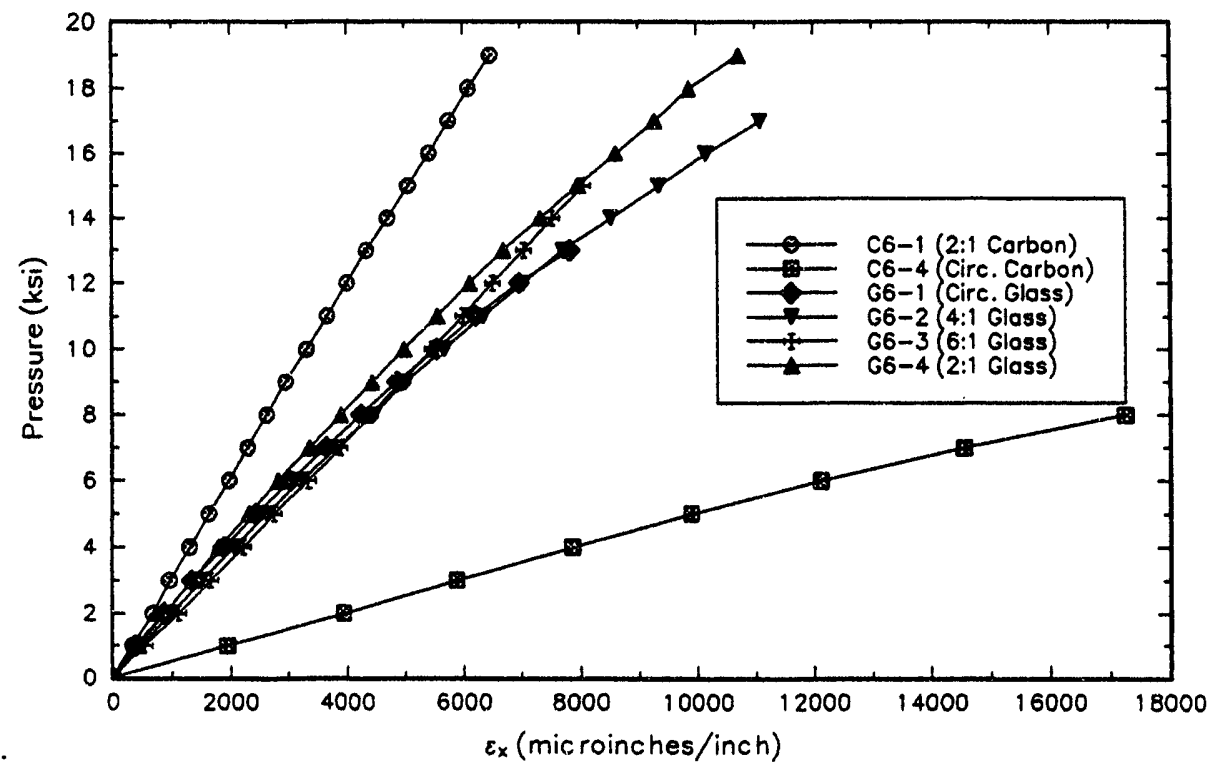

Fig. 3.4-50. Average midbay exterior axial strains versus pressure. 


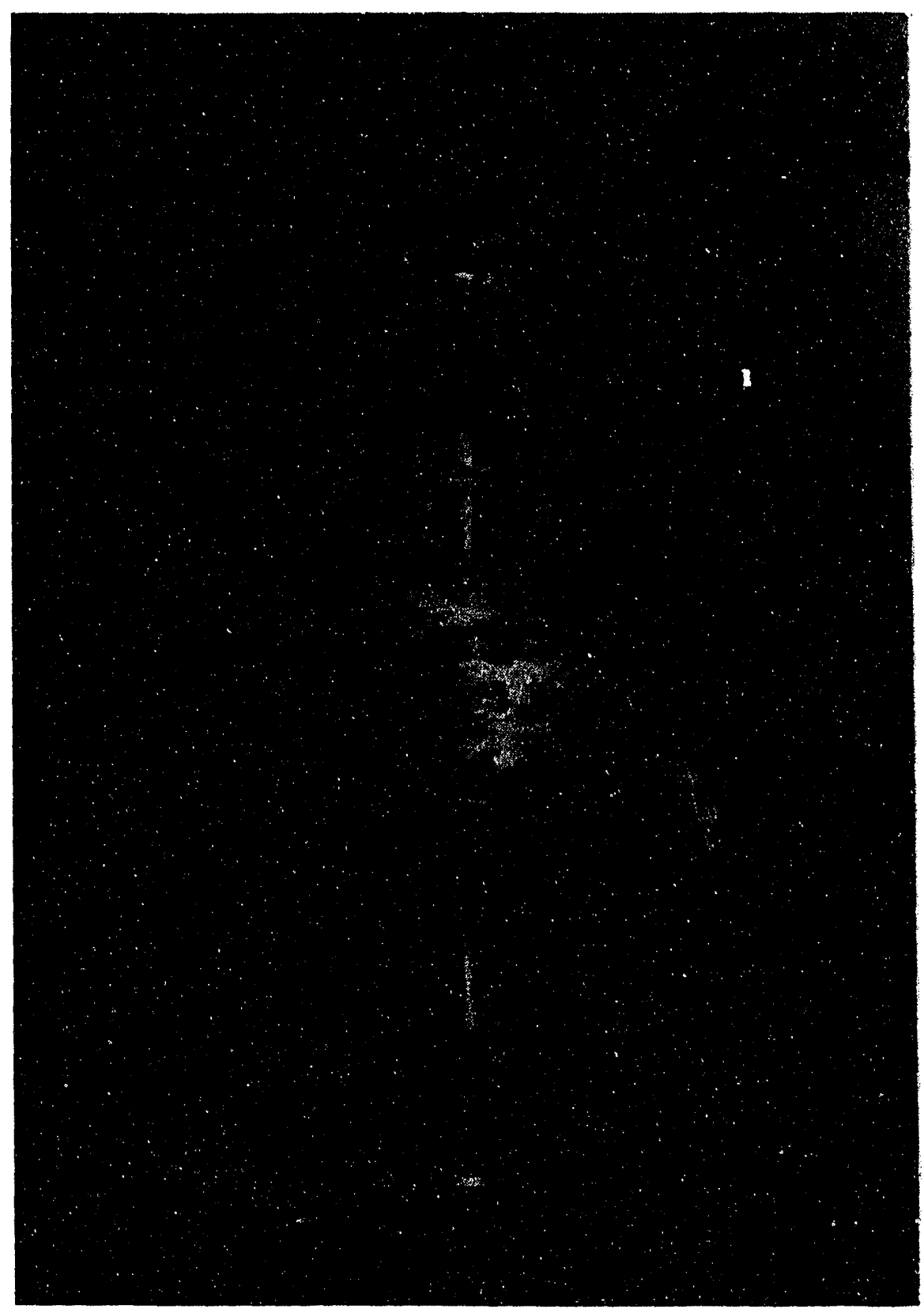

Fig. 3.4-51. Photograph of failed G6-1 cylinder. 


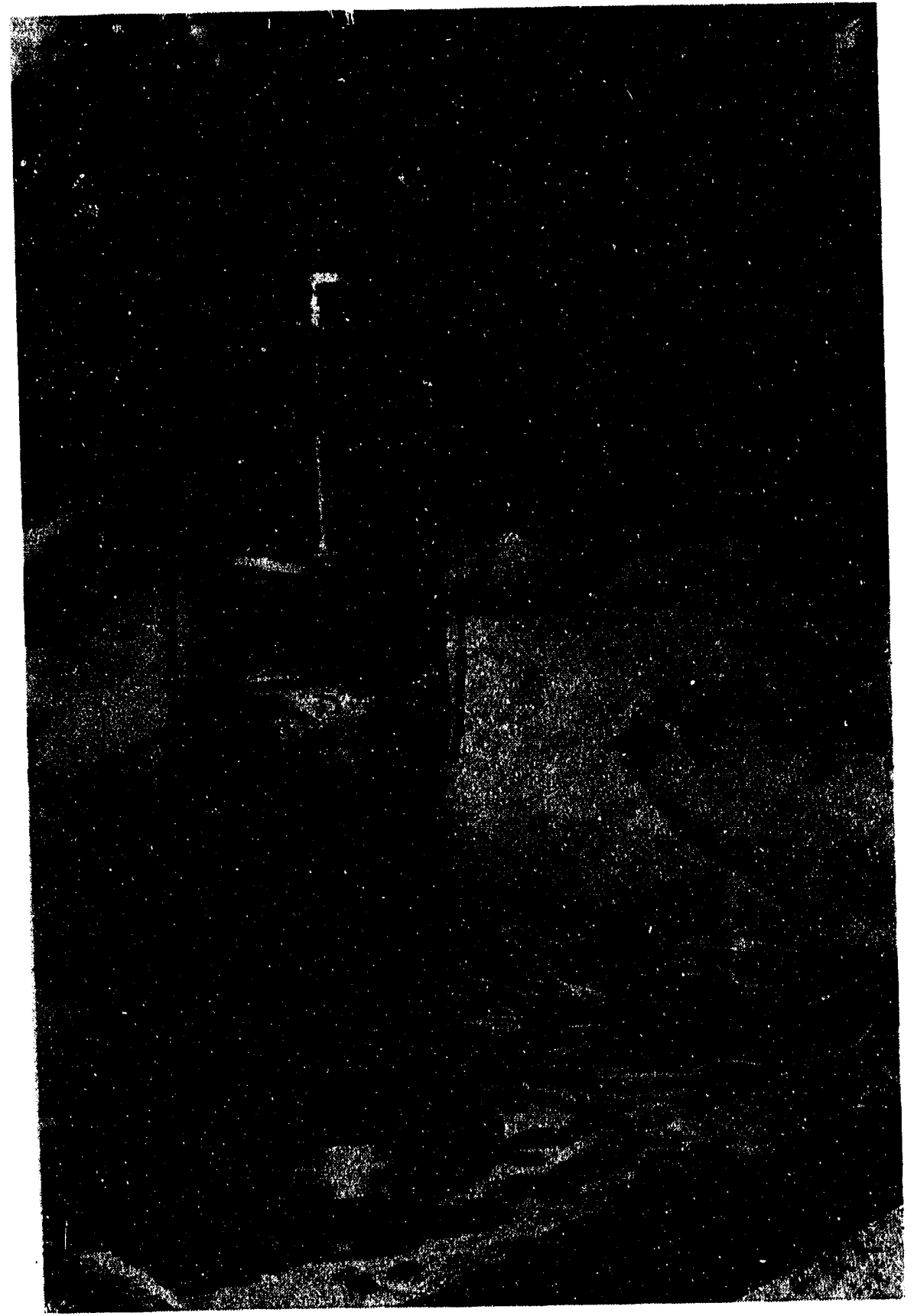

Fig. 3.4-52. Photograph of failed G6-2 cylinder. 


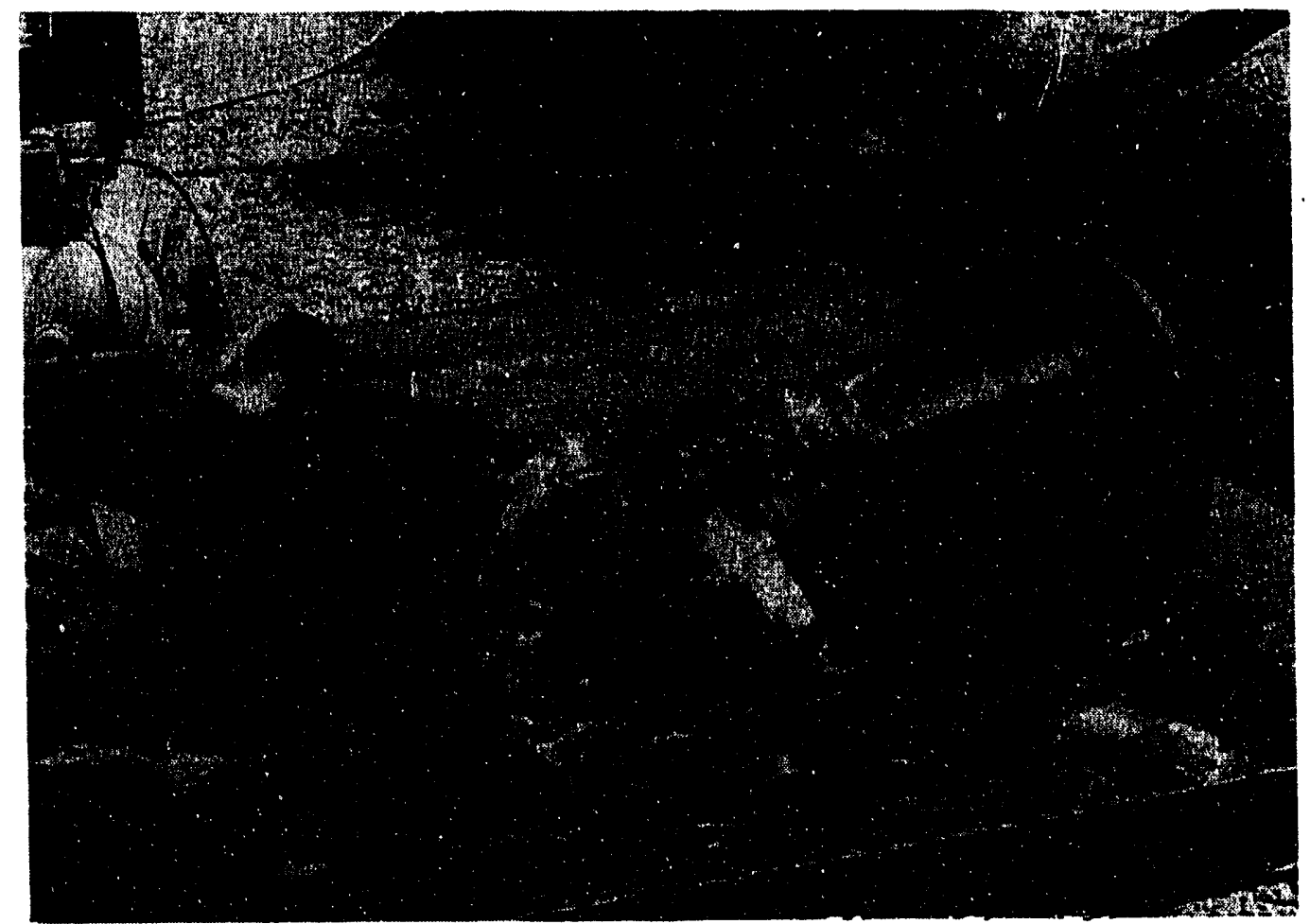

Fig. 3.4-53. Photograph of failed G6-3 cylinder. 


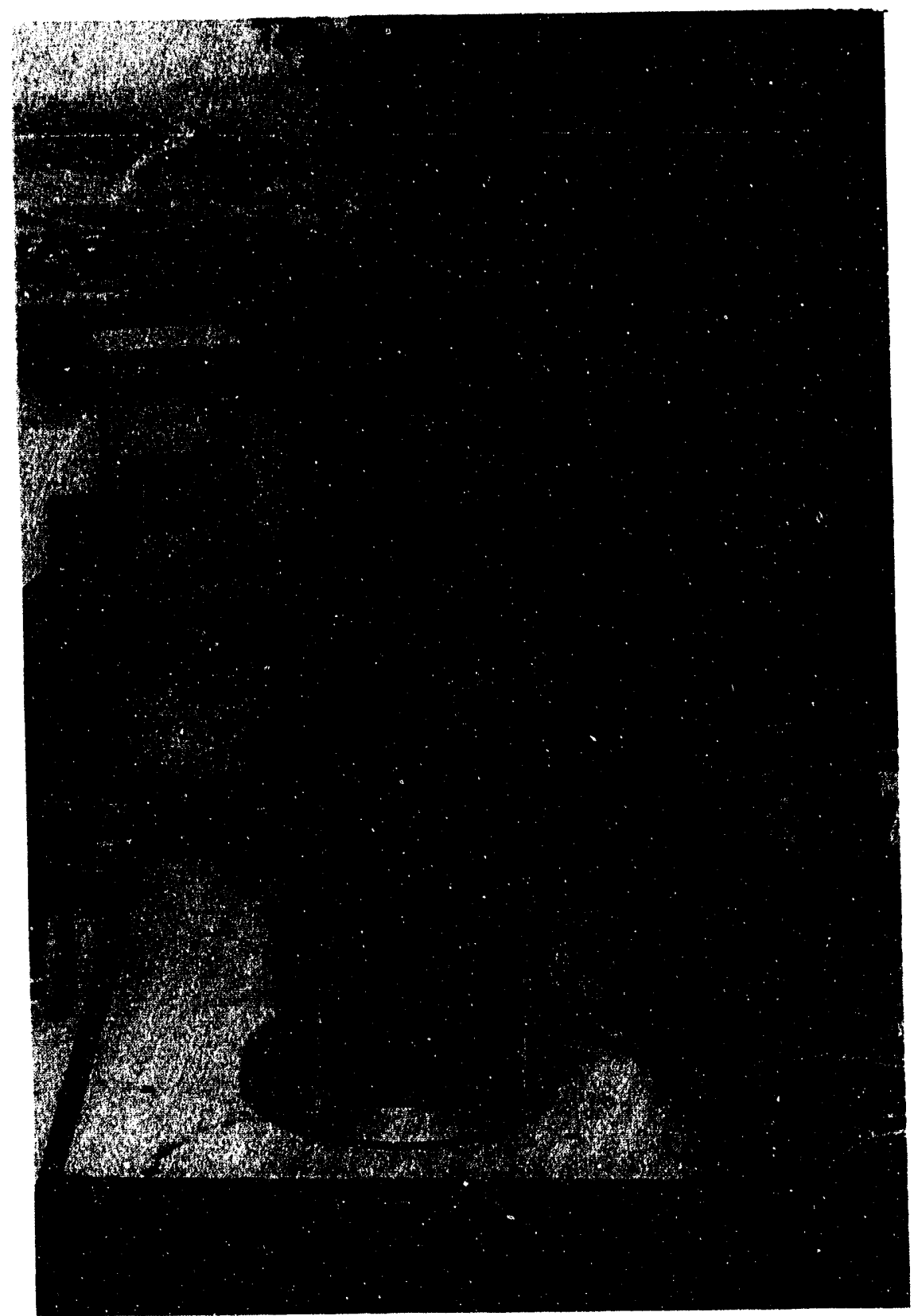

Fig. 3.4-54. Photograph of failed G6-4 cylinder. 


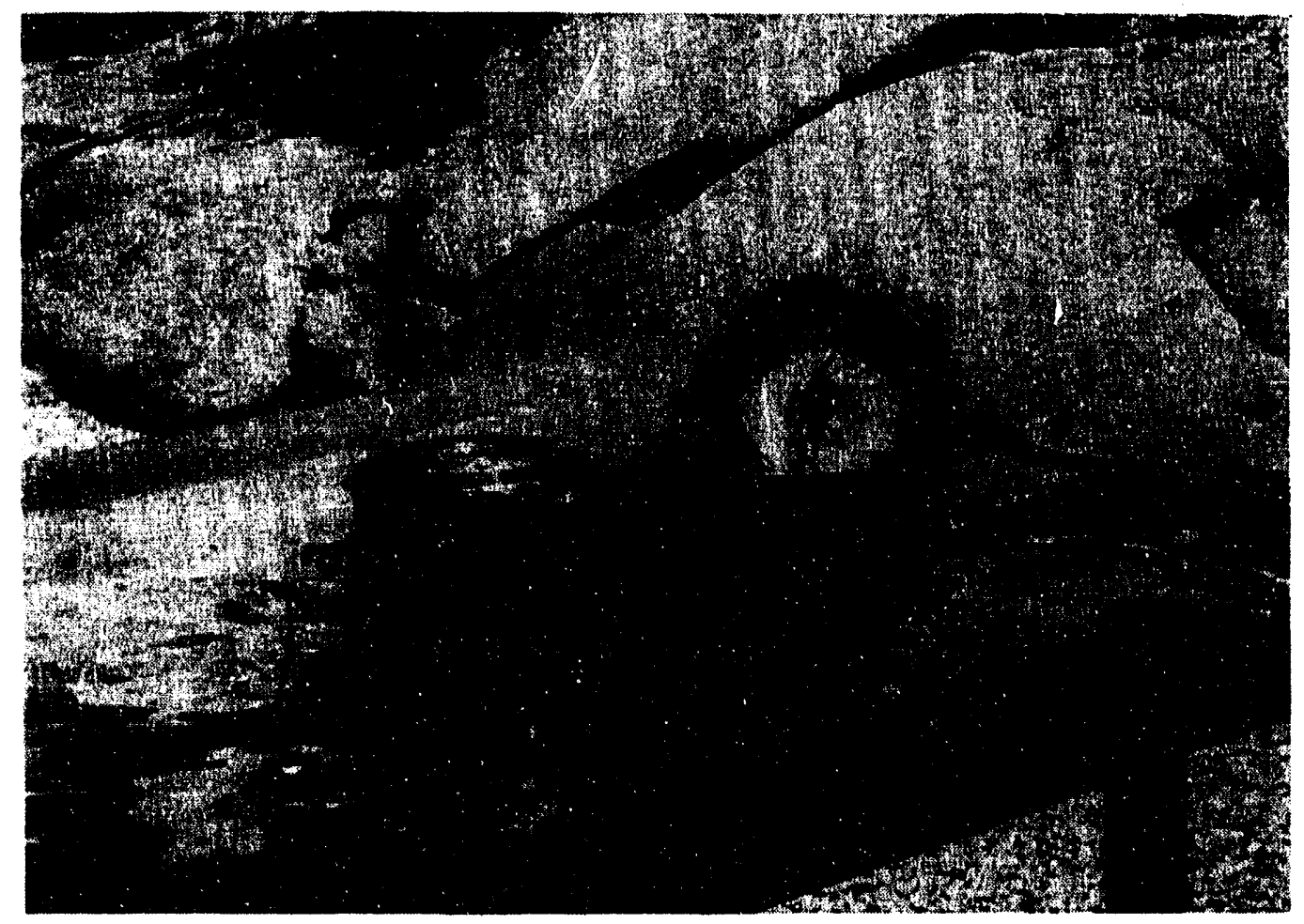

Fig. 3.4-55. Photograph of failed C6-4 cylinder. 


\section{PERFORMANCE MODEL VALIDATION}

The performance model consists of three distinct modules: a stress module, a stability module, and a material failure module. A flow chart for the performance model is shown in Fig. 4-1. The required input quantities are the three-dimensional layer properties, the cylinder dimensions, the exact stacking sequence used in the cylinder construction, and the three-dimensional material strengths. The results obtained from the stress module are the ply-level stresses, and in conjunction with the material strengths, are required input for the material failure module. The output quantities consist of a predicted strength-related failure load and a predicted buckling load, from which the performance and failure mode are determined.

The stress module consists of the program CCAP described in Sect. 1.3 and the stability module consists of the program CYBUCK described in Sect. 1.4. Hashin's criteria were selected for use in the material failure module. The use of Hashin's criteria, as described in Sect. 1.5, provided the added flexibility of distinguishing between four distinct failure modes. The results of the experimental program were discussed in Sect. 3.4.

The capabilities of various analytical tools in the design and analysis of composite cylinder test articles were demonstrated in Sect. 1 . In addition to these analytical capabilities, the development of a performance model required the fabrication and testing of test articles as discussed in Sects. 2 and 3. In correlating the analytical results with the experimental results, the initial analyses performed for the cylinder designs must be repeated for the as-fabricated cylinder compositions and geometries. It is also important to develop and test representative test articles for determining the required strength parameters in the failure criteria. The methodology of assembling these experimental and analytical tools into a model for accurately predicting the performance of composite cylinders is described in this section (also see Starbuck and Blake ${ }^{24}$ ).

\subsection{EXPERIMENTAL STRANN CORRELATION}

The experimentally determined failure pressures were applied to the cylinder models in CCAP, and maximum stresses, strains, and radial displacements were calculated. The ply-level stress results were discussed in detail in Sect. 1.3.1. In Sect. 3.4, the theoretical strain results from CCAP are compared with the experimental midbay hoop and axial strains. The formulation in CCAP is based on a linear-elastic analysis of an infinitely long cylinder, and therefore the results are only valid in the midbay region of the cylinder. The length of the cylinder is assumed to be such that the effects of the end constraints do not effect the stress results at the midbay. The peak and average experimental hoop and axial strains at the midbay of the test cylinders are compared with the theoretical values in Tables 4.1-1 and 4.1-2, respectively. The comparisons are made at both the inner radius (IR) and the outer radius (OR) of the cylinders.

In Figs. 3.4-1 and 3.4-2 the midbay interior and exterior hoop strains, respectively, are plotted for cylinder G6-1. The predicted interior strain is in excellent agreement with one of the three strain gages. The average value of the three midbay interior gages at a pressure of $13 \mathrm{ksi}$ is equal to $0.76 \%$, which is slightly less than the calculated strain of $0.80 \%$. The comparison between theory and experiment for the midbay exterior hoop strains is presented in Figure 3.4-2. The average measured strains are again slightly less 


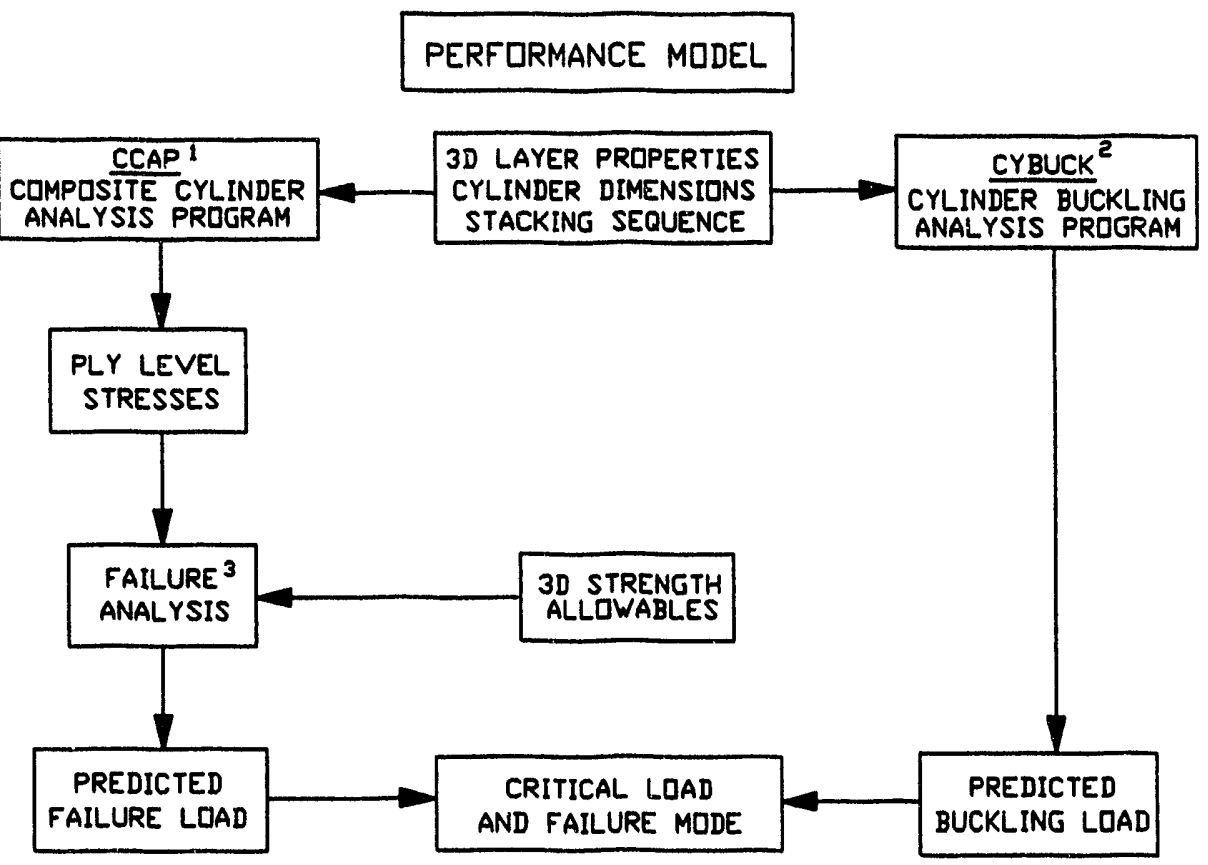

1. STRESS MODULE: ANISDTROPIC ELASTICITY SOLUTION FOR AXISYMMETRIC LOADING

2. STABLLITY MODULE: LAMINATED ORTHOTROPIC SHELL. THEORY WITH TRANSVERSE SHEAR DEFDRMATIDNS

3. FAILURE MODULEI HASHIN TSAI-WU, MAXIMUM STRESS, MAXIMUM STRAIN CRITERIA

Fig. 4-1. Performance model flow chart. 
than the theoretical strains with the agreement between the two being acceptable. Figures 3.4-3 an 1 3.4-4 illustrate the correlation between theory and experiment for the midbay interior and exterior axial strains, respectively. The theoretical results for the axial strains slight:y overpredict the measured results but are considered to be in satisfactory agreement with each other.

The midbay interior and exterior hoop strains for G6-2 are compared with the CCAP prerlictions in Figs. 3.4-10 and 3.4-11, respectively. In Figs. 3.4-12 and 3.4-13 the midbay interior and exterior axial strains are compared with the CCAP results, respectively. The theoretical results for the exterior hoop and axial strains are in good agreement with two (located 180 degrees apart) of the four strain gage traces. The other two hoop strain gages show a decreasing rate of strain with increasing pressure which the linear-elastic CCAP analysis cannot predict. Similarly, the other two axial strain gages show an increasing rate of strain with increasing pressure which CCAP also cannot predict. On the interior of the cylinder, three out of the four gages are lost prior to failure, two at a pressure level of $10 \mathrm{ksi}$ and the third at $15 \mathrm{ksi}$. At pressure levels below the pressure at which the gages are lost, the theoretical predictions appear to be in reasonably good agreement with the experimental results.

The CCAP strain predictions for G6-3 are compared with the experimental results in Figs. 3.4-19 through 3.4-22. The CCAP results for the interior hoop strains are in excellent agreement with two of the four gages. For the exterior hoop strairs, the peak strain level is accurately predicted by CCAP but the nonlinear pressure versus strain response is not. Similarly for the interior axial strains, the magnitude of the peak strain is accurately predicted but the experimental strain trace is not accurately followed. In the case of the exterior axial strains, there is a large amount of scatter in the four gages. However, the average peak strain is accurately predicted by the CCAP analysis.

For the all circ-wound graphite-reinforced cylinder, C6-4, the CCAP predictions are compared with the experimental strains in Figs. 3.4-28 through 3.4-31. The interior and exterior hoop strains from the CCAP analysis are larger than the experimental results. This is especially true for the exterior strains where the experimental results demonstrate a large amount of material stiffening. Conversely, the interior and exterior axial strains are underpredicted by the CCAP analysis, and the experimental results display a material softening type of behavior. The axial strain are more accurately predicted than the hoop strains.

Excellent agreement between theory and experiment is seen in Figs. 3.4-37 through 3.4-40 for the hoop and axial strains in cylinder G6-4. The pressure versus hoop strain traces in Figs. 3.4-37 and 3.4-38 are almost identical for the experimental results and the CCAP results. There is a slight amount of nonlinear behavior for the axial strains, and the CCAP results for the peak strain are less than the experimental values. 
Table 4.1-1. Experimental and theoretical hoop strain comparison

\begin{tabular}{cccccccc}
\hline \multirow{2}{*}{$\begin{array}{c}\text { Cylinder } \\
\text { ID }\end{array}$} & $\begin{array}{c}\text { Pressure } \\
\text { (ksi) }\end{array}$ & \multicolumn{3}{c}{ Hoop strain @ IR (\%) } & \multicolumn{3}{c}{ Hoop strain @ OR (\%) } \\
\cline { 3 - 8 } & exp. & $\begin{array}{c}\text { Avg. } \\
\text { exp. }\end{array}$ & Theory & $\begin{array}{c}\text { Peak } \\
\text { exp. }\end{array}$ & $\begin{array}{c}\text { Avg. } \\
\text { exp. }\end{array}$ & Theory \\
\hline C6-1 & 19.0 & 0.92 & 0.83 & 0.80 & 0.73 & 0.70 & 0.67 \\
C6-4 & 8.0 & 0.23 & 0.23 & 0.24 & 0.095 & 0.094 & 0.12 \\
G6-1 & 13.0 & 0.77 & 0.76 & 0.80 & 0.59 & 0.57 & 0.62 \\
G6-2 & 17.0 & 1.15 & $*$ & 1.32 & 1.07 & 0.92 & 1.03 \\
G6-3 & 15.0 & 1.06 & 1.01 & 1.09 & 0.88 & 0.81 & 0.87 \\
G6-4 & 19.0 & 1.78 & 1.77 & 1.73 & 1.38 & 1.33 & 1.36 \\
\hline
\end{tabular}

Table 4.1-2. Experimental and theoretical axial strain comparison

\begin{tabular}{lccccccc}
\hline \multirow{2}{*}{$\begin{array}{c}\text { Cylinder } \\
\text { ID }\end{array}$} & $\begin{array}{c}\text { Pressure } \\
\text { (ksi) }\end{array}$ & \multicolumn{3}{c}{ Axial strain @ IR (\%) } & \multicolumn{3}{c}{ Peak } \\
\cline { 3 - 8 } & exp. & $\begin{array}{c}\text { Avg. } \\
\text { exp. }\end{array}$ & Theory & $\begin{array}{c}\text { Peak } \\
\text { exp. }\end{array}$ & $\begin{array}{c}\text { Avg. } \\
\text { exp. }\end{array}$ & Theory \\
\hline C6-1 & 19.0 & 0.65 & 0.65 & 0.69 & 0.68 & 0.65 & 0.69 \\
C6-4 & 8.0 & 1.66 & 1.65 & 1.54 & 1.74 & 1.73 & 1.54 \\
G6-1 & 13.0 & 0.79 & 0.77 & 0.81 & 0.83 & 0.78 & 0.81 \\
G6-2 & 17.0 & 1.06 & $*$ & 0.99 & 1.21 & 1.11 & 0.99 \\
G6-3 & 15.0 & 0.87 & 0.85 & 0.86 & 0.88 & 0.86 & 0.86 \\
G6-4 & 19.0 & 1.11 & 1.01 & 0.98 & 1.09 & 1.07 & 0.98 \\
\hline
\end{tabular}

* Interior gages were lost prior to failure 


\subsection{FAILURE PRESSURE CORREILATION}

The test objective for the two all-circ-wound cylinders, C6-4 and G6-1, was to measure the transverse compressive strength for the S-GLASS/ERL2258 and IM6/ERL2258 material systems. The CCAP calculated maximum ply transverse stresses (global axial stresses) in the all circ-wound cylinder constructions were used as the experimentally determined values for the allowable transverse compressive strengths. A slightly conservative approximation was made, and it was assumed that the IM6/ERL2258 material had a transverse compressive strength of 30,000 psi and the S-GLASS/ERL2258 material had a transverse compressive strength of 45,000 psi. The test objective for the four cross-ply cylinders, C6-1, G6-2, G6-3, and G6-4, was to validate the performance model. The as-fabricated cylinder dimensions and composition data were used to determine the input quantities in the performance model for the failure pressure correlation.

The performance of the test articles was initially determined using the material strengths given in Table 1.1-1. The same procedure was followed as in the parametric design study (see Sect. 1.1) where three modes of failure were predicted: Hashin's compressive matrix mode, Hashin's compressive fiber mode, and a buckling mode. The predicted failure pressure and associated critical mode was the minimum value of the three predictions. The results from these analyses are given in Table 4.2-1 and indicate that the performance of all the test articles was governed by the compressive matrix mode of failure. Included in this table are the results for the 2:1 hoop:axial ply ratio IM6/ERL2258 graphite/epoxy cylinder, C6-1.

Table 4.2-1 also shows the revised predictions based on the measured transverse compressive strengths from the circ-wound cylinder tests. The results from Hashin's criteria for the compressive fiber mode are unchanged because this mode is independent of the transverse compressive strength. The buckling predictions are also unchanged. However, for the compressive matrix mode of failure, Hashin's criteria predicts an increase in performance when the transverse compressive strength is increased. The performance of the four S-GLASS/ERL2258 glass/epoxy cylinders and the all circ-wound IM6/ERL2258 graphite/epoxy cylinder are still governed by the compressive matrix mode of failure. The increase in the predicted pressure for a compressive matrix mode of failure in C6-1 results in the compressive fiber mode becoming the critical strength-related failure mode. However, for the 10-in. unsupported test length, the C6-1 cylinder performance is governed by the buckling prediction.

The minimum values of the three predictions for each cylinder are given in Table 4.2-2 along with the measured performance and the ratio of the two results. The predicted performance for $\mathrm{C} 6-1$ is approximately $6 \%$ greater than the experimentally measured pressure. The performance model predicts that the C6-1 cylinder design is buckling limited and, even though the test article did not fail, the strain gage results indicate an increasing cylinder out-of-roundness as the pressure was increased up to the test facility capacity of 20,000 psi. The failure pressures of the three cross-ply glass/epoxy cylinders, G6-2, G6-3, and G6-4 are underpredicted by $8.3 \%, 10.5 \%$, and $24.7 \%$, respectively. The critical mode of failure for these three cylinder designs is a transverse compressive matrix mode which is related to the material strengths. The underprediction is consistent with the strength-related failure mode because the predicted performance is based on a first-ply failure analysis which does not include any ply-degradation schemes. The greater-than- 
predicted experimental results are also consistent with the parametric design results which indicate the glass/epoxy cylinders have a significant amount of progressive damage prior to ultimate failure. 
Table 4.2-1. Predicted failure pressures from the performance model

\begin{tabular}{lcccc}
\hline \multirow{2}{*}{ Cylinder ID } & \multicolumn{4}{c}{ Performance pressure (ksi) } \\
\cline { 2 - 5 } & $\begin{array}{c}\text { Matrix mode } \\
\left(Y_{c}-\text { Preliminary }\right)\end{array}$ & Fiber mode & Buckling & $\begin{array}{c}\text { Matrix mode } \\
\left(Y_{c}-\text { Measured }\right)\end{array}$ \\
\hline C6-1 & 20.219 & 25.720 & 21.238 & 40.439 \\
C6-4 & 4.6418 & 31.133 & 23.687 & 9.284 \\
G6-1 & 6.0847 & 34.174 & 21.224 & 13.691 \\
G6-2 & 6.7819 & 32.676 & 18.120 & 15.963 \\
G6-3 & 6.0422 & 32.126 & 24.888 & 14.326 \\
G6-4 & 6.1785 & 28.944 & 22.447 & 14.309 \\
\hline
\end{tabular}

Table 4.2-2. Performance model validation

\begin{tabular}{|c|c|c|c|}
\hline \multirow{2}{*}{ Cylinder ID } & \multicolumn{2}{|c|}{ Performance pressure (ksi) } & \multirow{2}{*}{ Predicted/Measured } \\
\hline & Predicted & Measured & \\
\hline C6-1 & $21.238^{a}$ & $20.0^{c}$ & 1.062 \\
\hline C6-4 & $9.284^{b}$ & 9.0 & 1.032 \\
\hline G6-1 & $13.691^{b}$ & 13.8 & 0.992 \\
\hline G6-2 & $15.963^{b}$ & 17.4 & 0.917 \\
\hline G6-3 & $14.326^{b}$ & 16.0 & 0.895 \\
\hline G6-4 & $14.309^{b}$ & 19.0 & 0.753 \\
\hline
\end{tabular}

a Buckling mode

${ }^{b}$ Compressive matrix mode

${ }^{c}$ Facility limit - not a failure 


\section{CONCLUSIONS}

This report describes the hydrotesting of five composite cylinders for the purpose of developing a performance model for compression response. The work, as described, covers the design, analyses, fabrication, and testing for performance model validation and test method standardization. Two of the test articles, C6-4 and G6-1, had an all circ-wound construction to experimentally determine the transverse compressive strength for the IM6/ERL2258 graphite/epoxy and S-GLASS/ERL2258 glass/epoxy material systems, respectively. The remaining three test articles had a cross-ply construction where cylinder G6-2 had a 4:1 hoop:axial ply ratio, cylinder G6-3 had a 6:1 hoop:axial ply ratio, and G6-4 had a 2:1 hoop:axial ply ratio. An improved metal end closure design was utilized in the tests to minimize the axial bending and shear stresses during pressurization.

A performance model consisting of a stress module, a material failure module, and a stability module was developed to study the behavior of thick-section composite cylinders under hydrostatic pressure. Closed-form analytic solutions based on the theory of anisotropic elasticity were used in the stress module to accurately determine the ply-level stresses. Composite stresses were obtained by using the closed-form solution with smeared laminate properties and also by finite elements. Closed-form analytic solutions were also used to calculate the buckling pressure and to determine the required unsupported length for a strength critical design. The model was used to perform a parametric design study for cross-ply glass/epoxy and graphite/epoxy filament wound cylinder constructions.

The performance model was validated by fabricating and testing the specific cylinder designs described above. The correlation of the experimental results with the analytical predictions indicated that the performance of thick-section composite cylinders could be accurately predicted. The first-ply failure predictions using Hashin's criteria underpredicted the maximum pressures achieved during testing of the glass/epoxy cylinders. These results were in agreement with the parametric design study for glass/epoxy constructions where a significant amount of progressive damage was predicted before ultimate collapse of the cylinder. The results also indicate that the Hashin criteria for first-ply failure gives a conservative estimate for the failure pressure.

The good correlation is attributable to the use of representative tests for measuring the compressive strengths and to the use of analytical tools which accurately represent the multiaxial stress state in the composite cylinder test articles. Also, the use of Hashin's criteria in the material failure module added the needed flexibility to distinguish between a compressive matrix mode and a compressive fiber mode of first-ply failure. The data base is still very limited and continued effort is needed toward designing, fabricating, and testing thick-section composite cylinders for further validation of the performance model. Based on further evaluations of the analytical and experimental results, the following conclusions and recommendations are made.

1. The ply-level stresses in the as-fabricated cylinder models are accurately calculated using an anisotropic elasticity formulation that assumes generalized plane deformation and axisymmetry. 
2. The results from the parametric study illustrated the two material systems to have drastically different material responses and ultimate performance. For the IM6/ERL2258 graphite/epoxy system, an increase in the transverse compressive strength from $15 \mathrm{ksi}$ to $30 \mathrm{ksi}$ changed the first-ply failure mode in Hashin's criteria from compressive matrix to compressive fiber. Consequently, the performance of these cylinder constructions is controlled by the fiber direction compressive strength. For hoop:axial ply ratios ranging from 35:1 to $1: 35$, the maximum failure pressure was predicted for the $2: 1$ ply ratio.

3. For the S-GLASS/ERL2258 glass/epoxy system, increasing the transverse compressive strength from $20 \mathrm{ksi}$ to $45 \mathrm{ksi}$ did not change the first-ply failure mode from the compressive matrix mode. Also, in contrast to the graphite/epoxy cylinders, based on first-ply failure there was not a clear optimum design but rather a wide range of ply ratios where the failure pressures were comparable.

4. The 2:1 hoop:axial graphite/epoxy cylinder is the only design considered in this investigation to have a larger radial contraction at the outer radius than at the inner radius. The maximum compressive radial displacement (corresponding to the maximum test pressure) is experienced by the 2:1 hoop:axial glass/epoxy cylinder. This cylinder design also has the largest hoop strain and the largest radial strain at the corresponding maximum test pressure.

5. In all of the cylinders analyzed, with the exception of the 2:1 graphite/epoxy cylinder, the elasticity solution results for the radial strain are tensile across the entire wall thickness. The 2:1 graphite/epoxy cylinder has a tensile radial strain at the inner radius and a compressive radial strain at the outer radius.

6. The hoop strain gradient across the cylinder wall is less when predicted using LST as compared with the elasticity solution results.

7. For the four cross-ply cylinder constructions considered in this study, accurate strains are predicted when the cylinders are modeled as a single layer having equivalent smeared orthotropic properties. However, the maximum in-plane hoop and axial stresses are severely underpredicted when a single-layer smeared property analysis is used.

8. The calculated maximum axial stresses in the all circ-wound cylinder constructions, at the maximum test pressure, are used as the experimentally determined values for the transverse compressive strength. The transverse compressive strengths were $45 \mathrm{ksi}$ and $30 \mathrm{ksi}$ for the glass/epoxy and graphite/epoxy material systems, respectively.

9. The radial displacements calculated using the $\mathrm{FE}$ analysis are in excellent agreement with the elasticity solution results. The FE contour plots for radial displacement demonstrate that at the maximum test pressure the clearance between the end closure and the cylinder wall is completely consumed for the C6-1 and G6-4 cylinders.

10. The FE results show the axial bending stress is typically less than 5000 psi and the maximum shear stress is less than 1000 psi for all the cylinders. These low values were achieved because of the improved design of the end closures. The values from LST are generally larger than the FE values. 
11. Buckling pressures are calculated using four different solutions. The different solutions are based on using Ambartsumyan's curvature expressions, modifications to Ambartsumyan's curvatures to include radial strain effects, modifications to Ambartsumyan's curvatures to include transverse shear effects, and the Donnell curvature approximations. The stability analysis using the theory based on Ambartsumyan's curvatures, modified to include transverse shear, gives the lowest result for the buckling pressure. This theory is used to select the unsupported length for each cylinder.

12. In modeling the cylinders by their as-fabricated geometry and composition, the analytical results for the buckling pressures are larger than the test pressure vessel capability of 20,000 psi with the exception of the $4: 1$ glass/epoxy cylinder.

13. The ply-level stresses calculated from the as-fabricated cylinder models are used to predict first-ply failure based on Hashin's criteria, the Tsai-Wu criterion, maximum stress, and maximum strain.

14. In comparing the results for the $2: 1$ graphite/epoxy cylinder, C6-1, to the $2: 1$ glass/epoxy cylinder, G6-4, results, much higher transverse compressive strengths are needed in the glass/epoxy system than in the graphite/epoxy system to achieve the same maximum pressure for first-ply failure. Also, the mode transition from compressive matrix mode to compressive fiber mode occurs at a much higher transverse compressive strength in the 2:1 glass/epoxy cylinder than in the 2:1 graphite/epoxy cylinder.

15. As the transverse compressive strength is increased, the predicted first-ply failure pressure based on the Tsai-Wu criterion begins to diverge from the Hashin criteria results, with very large discrepancies occurring when Hashin's criteria predict a change in failure mode from compressive matrix mode to compressive fiber mode.

16. An improved method of tensioning the axial layers was demonstrated in filament winding the 2:1 glass/epoxy cylinder, G6-4.

17. The composition data from the as-fabricated cylinders indicated the fiber volume fraction in the glass/epoxy cylinders decreased as the percentage of axial reinforcement increased. Therefore, the axial layers are believed to have a higher resin content than the circumferential layers.

18. The G6-1, G6-4, and C6-4 cylinders are believed to have failed in a material strength related mode, whereas the G6-2 and G6-3 cylinders may have failed in a combined material failure and buckling mode.

19. The analytical results for the strains at the cylinder midbay are, for the most part, in good agreement with the experimental results. This is especially true for the cylinders whose experimental strains were predominately lit iear. 
20. The predicted first-ply failure pressures of the three cross-ply glass/epoxy cylinders, G6-2, G6-3, and G6-4, underpredicted the ultimate failure by $8.3 \%, 10.5 \%$, and $24.7 \%$, respectively. These results indicate that the implementation of a progressive damage analysis using degraded material properties for the failed plies would more accurately predict the performance of these cylinders. 


\section{RECOMMENDATIONS}

The following recommendations are based on further evaluations of the analytical and experimental results.

1. The correlation between the experimental failure pressures and the analytical failure predictions for the cross-ply glass/epoxy cylinders could be improved by developing a ply degradation scheme. The approach would track the progression of ply failures using incremental loading and stiffness reduction for the failed plies. The reduced stiffnesses would be calculated at the micromechanics level and the specific stiffness terms that are reduced would depend upon the failure mode predicted by Hashin's criteria. This process could be automated by incorporating an incremental loading procedure in CCAP.

2. Additional hydro-testing of thick composite cylinders is needed for further validation of the performance model. Also, the applicability of the performance model for types of loading other than hydrostatic pressure should be investigated, e.g., flexure, torsion, and axial compression.

3. Advances in experimental techniques are needed for identifying damage initiation in thick composite cylinders and in developing standardized test methods for hydrostatic pressure loading.

4. The performance of the graphite/epoxy cylinders considered in this investigation was governed by first-ply failure in a compressive fiber mode, whereas the performance of the glass/epoxy cylinders was governed by a compressive matrix mode. To increase the performance of the graphite/epoxy cylinders would require the utilization of fibers which have a higher compressive strength. In the case of the glass/epoxy cylinders, the performance could be enhanced by using improved matrix systems such as a toughened resin based system. This also could lead to an optimized cylinder design that utilizes a hybrid construction of graphite and glass layers.

5. Tests of larger and smaller cylinders than evaluated in this study should be conducted to explore possible material size effects on cylinder performance in hydrostatic compression. 
Appendix A

CYLINDER WEIGHT-TO-DISPLACEMENT RATIOS 
The cylinder weight-to-displacement ratio calculations are summarized in this appendix. The metal end closures are not included in the ratio calculation. The end closures used in the cylinder test are not representative of end closures that would be used in a deep submergence application.

The cylinder dry weight is derived from the measured density and cylinder dimensions. Averaged measured values are used. The derived weight of the cylinder, $W_{c}$, is calculated as

$$
W_{c}=\rho_{c} L \pi\left(O R^{2}-I R^{2}\right)
$$

where $\rho_{c}$ is the measured composite density (see Tables 2-3 through 2-7), $\mathrm{L}$ is the machined test length, and $O R$ and IR are the outer and inner radii, respectively (see Table 1.2-2). The weight of seawater displaced, $W_{D}$, is equal to

$$
W_{D}=P_{W} L O R^{2},
$$

where $\rho_{\mathrm{W}}$ equals $0.03726851 \mathrm{lb}_{\mathrm{m}} / \mathrm{in}^{3}$ (the density of seawater). The weight-to-displacement ratio is then $W_{d} / W_{D}$. The values and calculation results are given in Table A-1.

\begin{tabular}{|c|c|c|c|c|c|}
\hline \multirow[b]{2}{*}{ Cylinder ID } & \multicolumn{2}{|c|}{ Density, $\rho_{c}$} & \multirow[b]{2}{*}{$\mathrm{w}_{\mathrm{c}}\left(\mathrm{lb}_{\mathrm{m}}\right)$} & \multirow[b]{2}{*}{$W_{D}\left(l b_{m}\right)$} & \multirow{2}{*}{$w_{d} / w_{D}$} \\
\hline & $\mathrm{g} / \mathrm{cc}$ & $\mathrm{lb}_{\mathrm{m}} / \mathrm{in}^{3}$ & & & \\
\hline G6-1 & 2.2222 & 0.080282 & 12.609 & 19.885 & 0.634 \\
\hline G6-2 & 2.1238 & 0.076727 & 12.260 & 19.988 & 0.613 \\
\hline G6-3 & 2.1946 & 0.079285 & 10.272 & 17.203 & 0.597 \\
\hline G6-4 & 2.1058 & 0.076075 & 10.347 & 17.457 & 0.593 \\
\hline C6-4 & 1.5665 & 0.056594 & 9.332 & 21.046 & 0.443 \\
\hline
\end{tabular}

Table A-1. Weight-to-displacement ratios

The measured weights for three of the cylinders are 12.187 for G6-2, 10.4 for G6-3, and 9.312 for $\mathrm{C6}-4$. Cylinders $\mathrm{G} 6-1$ and G6-4 were inadvertently not weighed prior to testing. 
Appendix B

HYDROSPACE ENGINEERING TEST REPORTS 


\section{HYDROSPACE ENGINEERING SERVICES}

Test Report for Cylinder G6-1 
January 3, 1991

\section{TEST REPORT}

\section{Instrumentation}

The cylinder was instrumented with a combination of 0.250 and 0.125 inch electric resistance straingage rosettes. The acoustic emission detector was bonded to the outside of the pressure vessel. The G6-1 cylinder was instrumented with a total of 14 strain gage rosettes. The rosettes were affixed to the cylinder a.s shown on the attached diagram supplied by the Mr. Don Welch of the Oak Ridge National Laboratory.

\section{Test Procedure}

The cylincer was tested in a 10 inch ID pressure vessel with 20,000 psi pressure capability. The pressurizing medium was Tellus 30 oil. Pressurization was accomplished with an air operated pump raising the pressure inside the vessel at 2,000 psi/minute rate. Pressurization was interrupted at 1,000 psi intervals and strains recorded at 2 seconds per channel rate. Peak strains were monitored at two points on the specimen: Axial - Exterior Mid?ay, Gage Number 10 and Hoop - One Half Inch from the Exterior End, Gage Number 13. Acoustic emission was recorded continuously.

\section{Test Results}

The pressure test on $66-1$ cylinder was terminated at 13,800 Psi, at which time the specimen imploded. The peak strains at the moment of implosion were: $-8845 / \mathrm{Axial}$ - Exterior Midbay, Gage Number 10, $-7645 /$ Hoop - One Half Inch from the Exterior End, Gage Number 13 . 


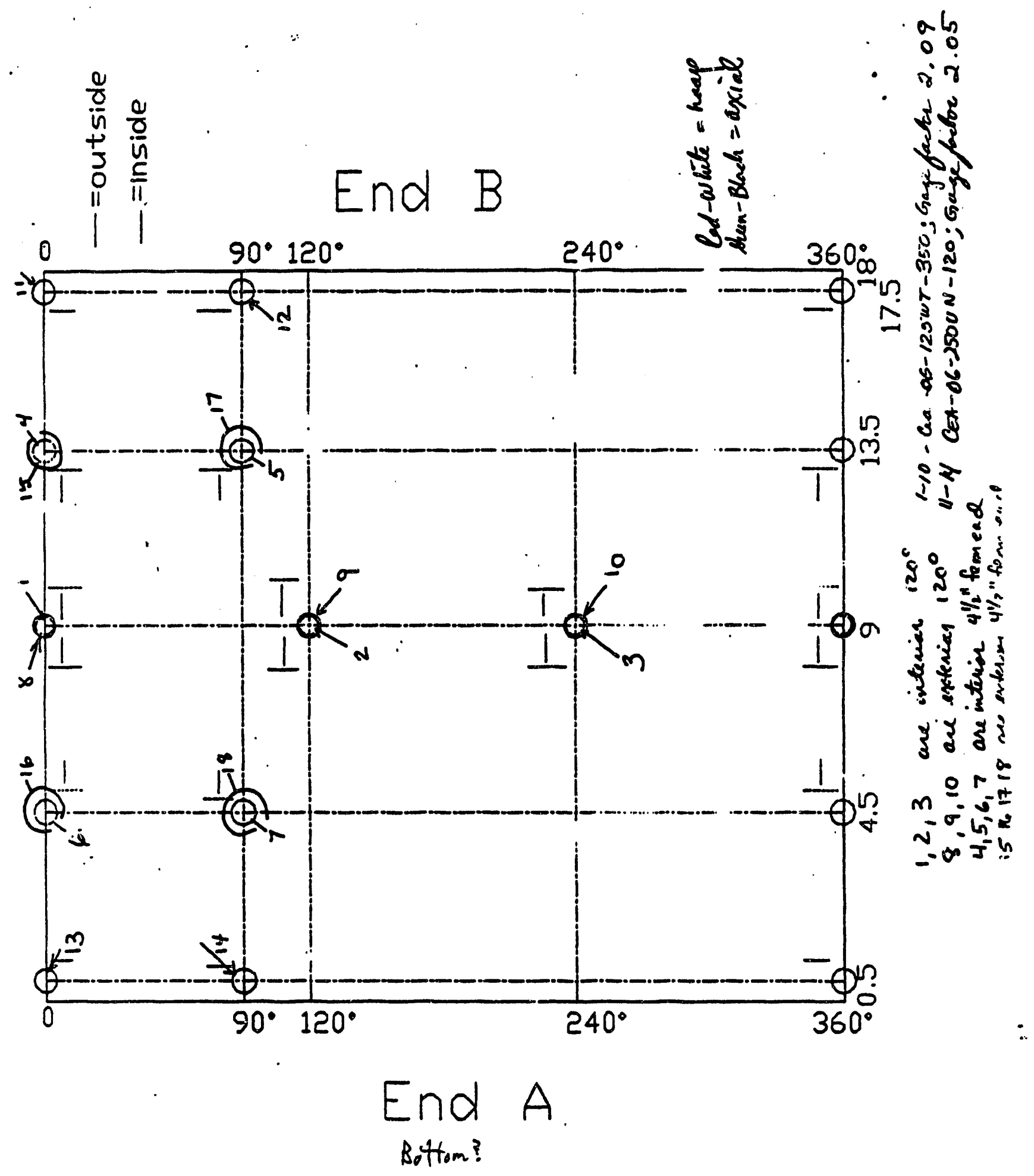




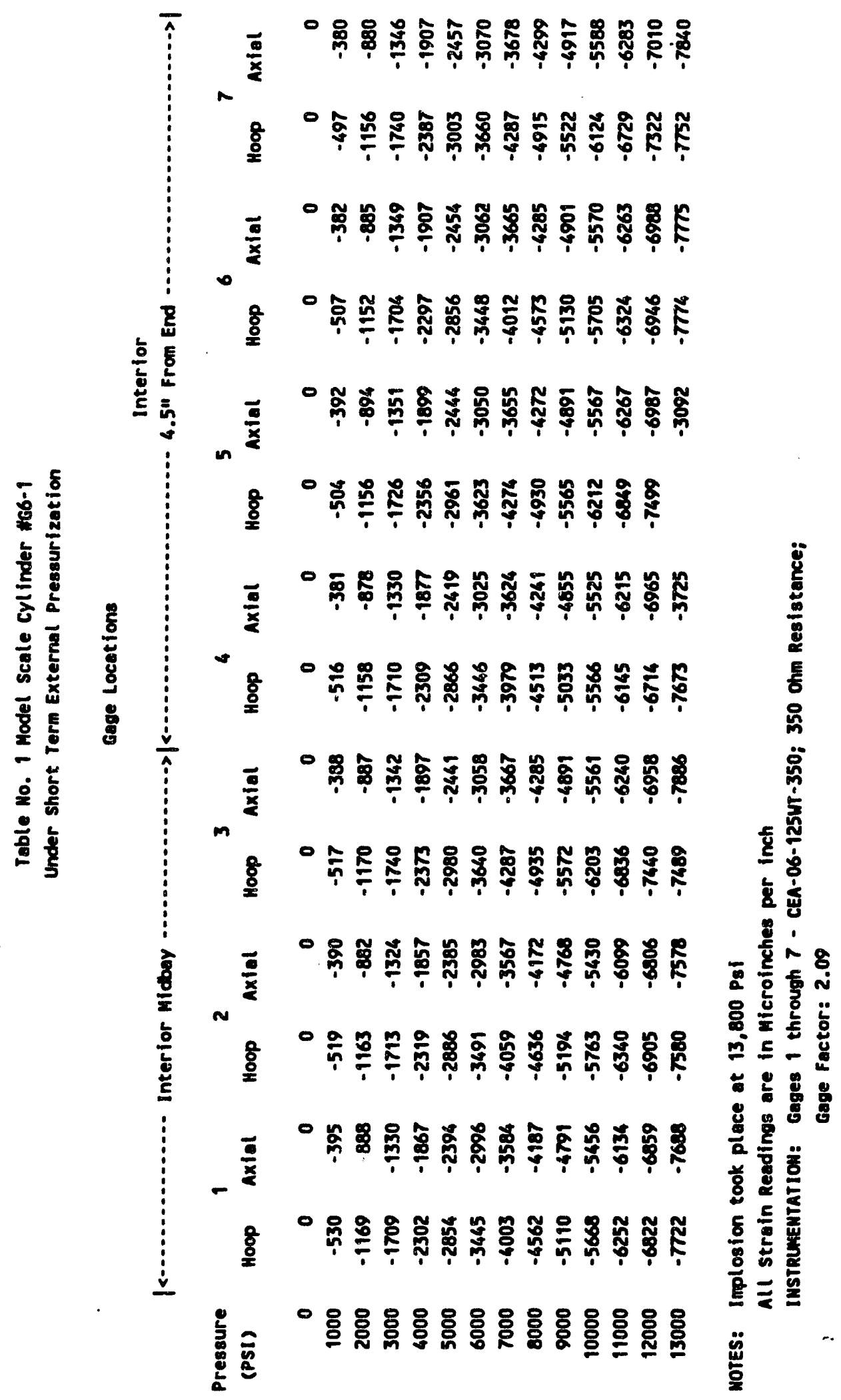




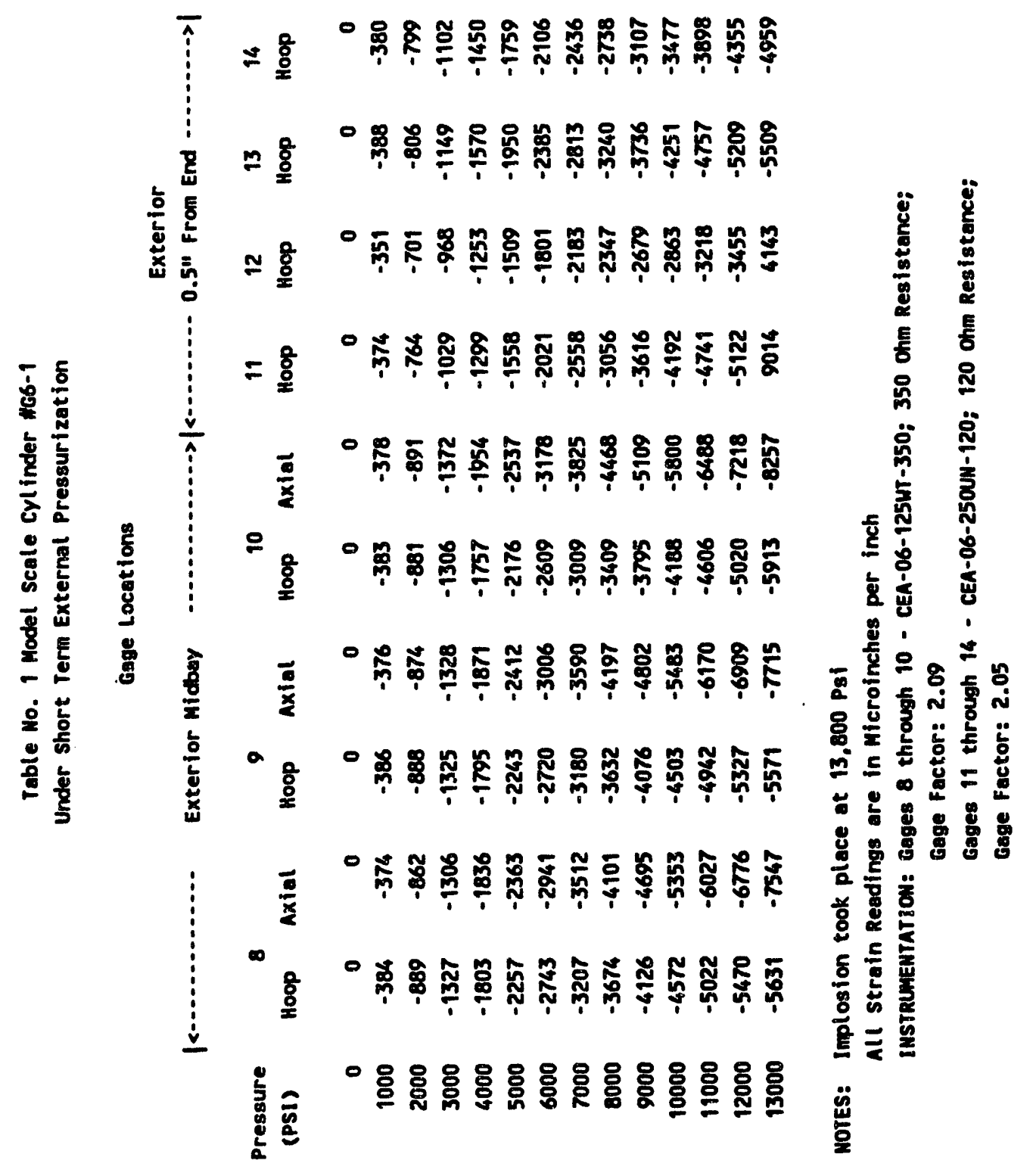




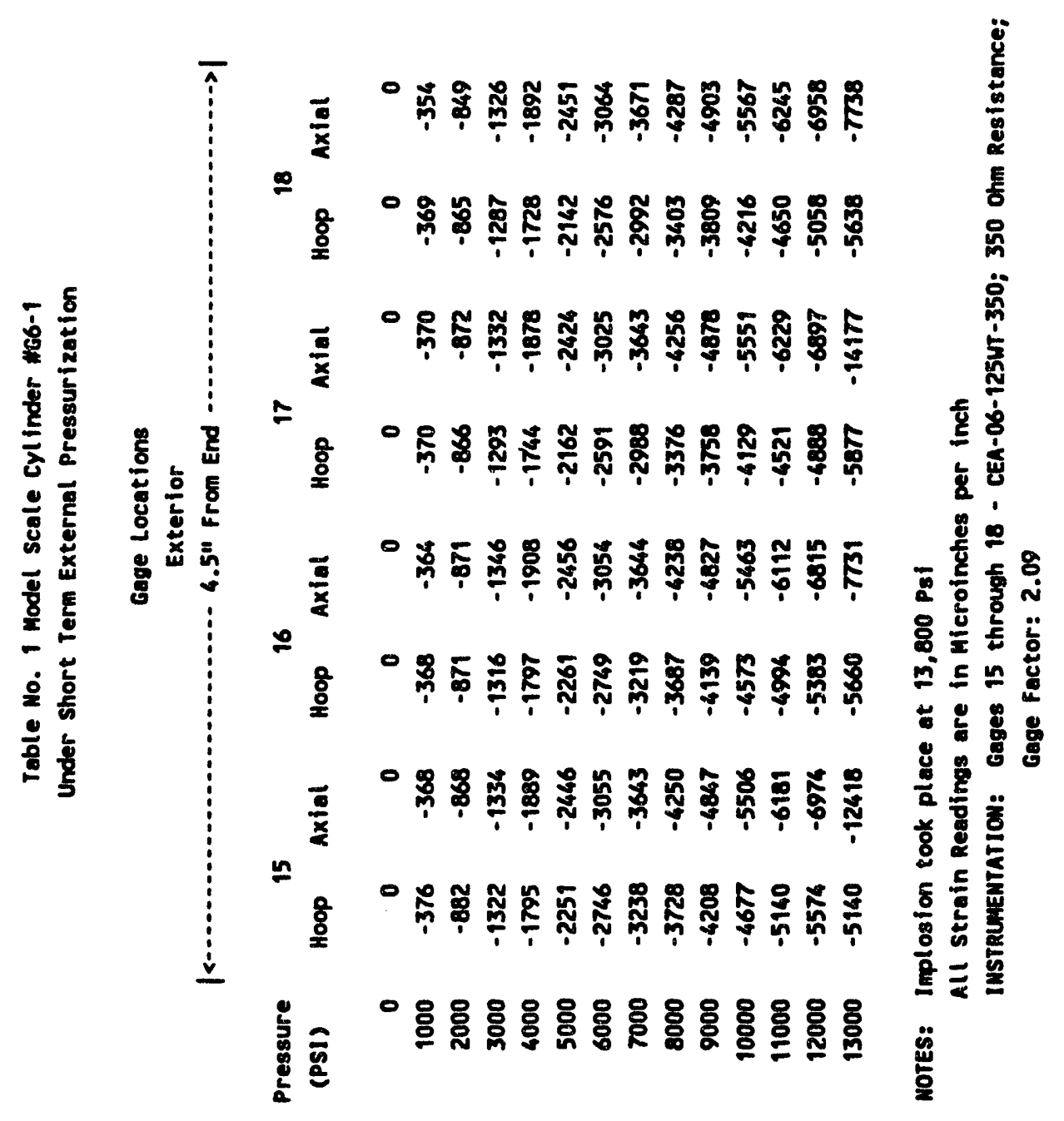




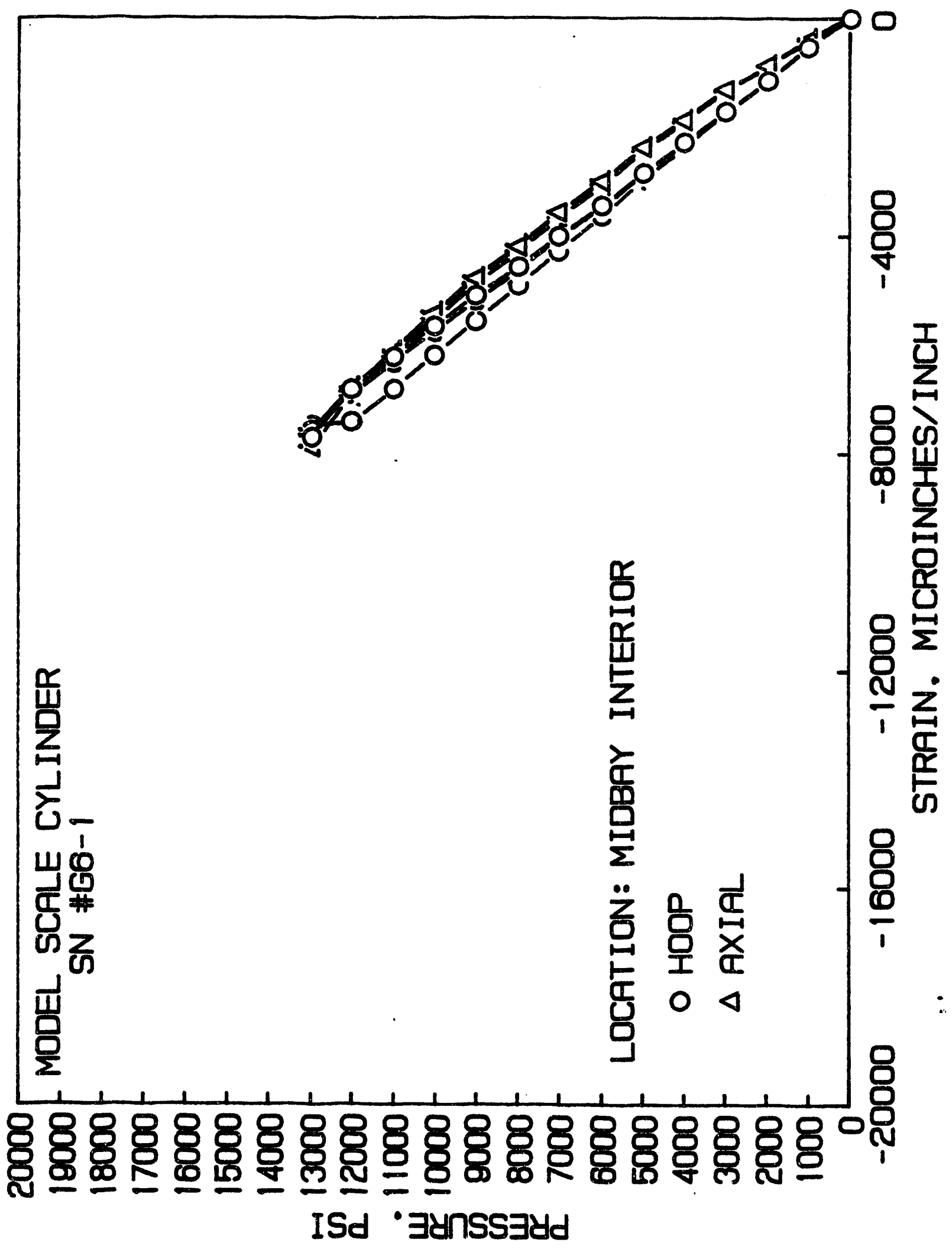




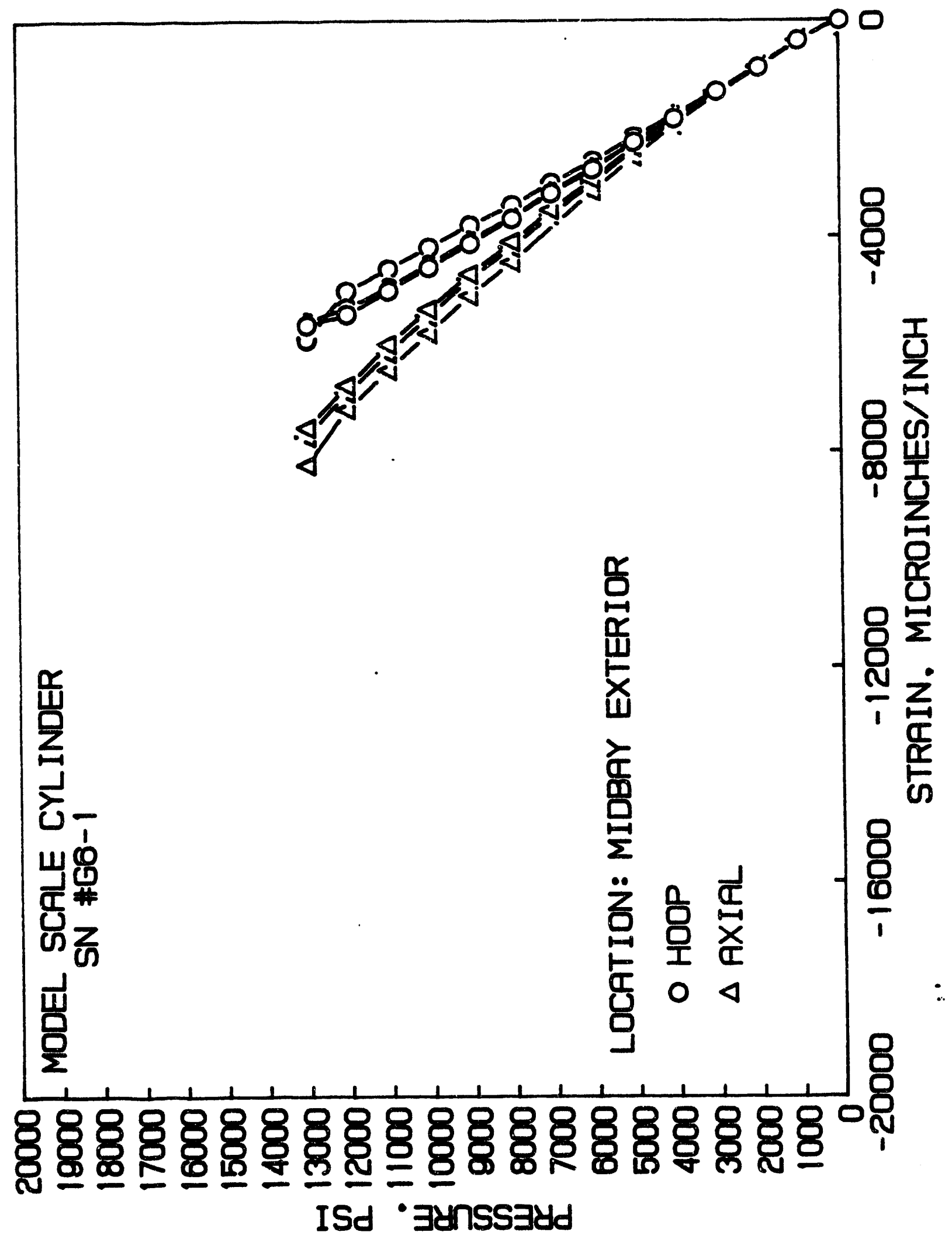




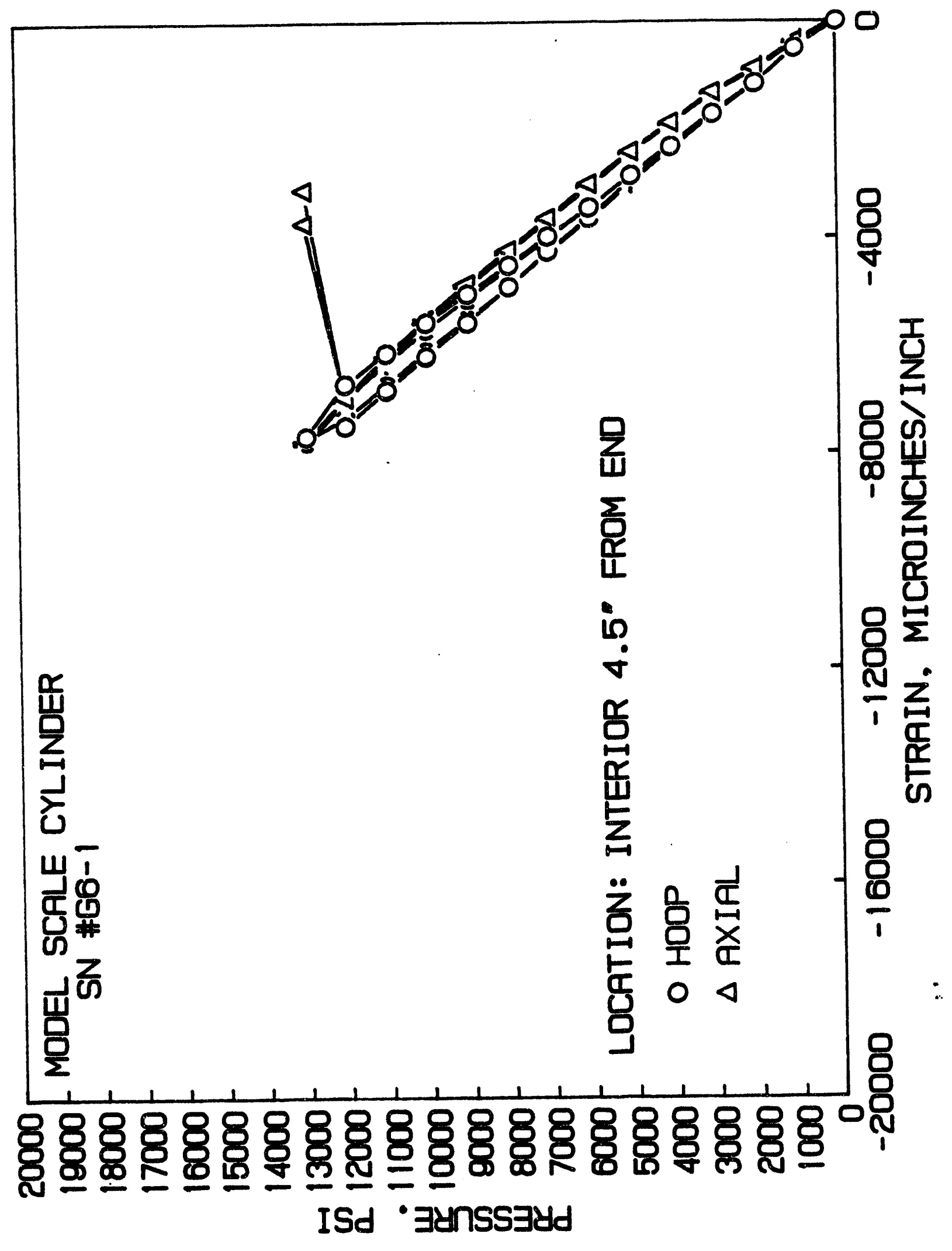




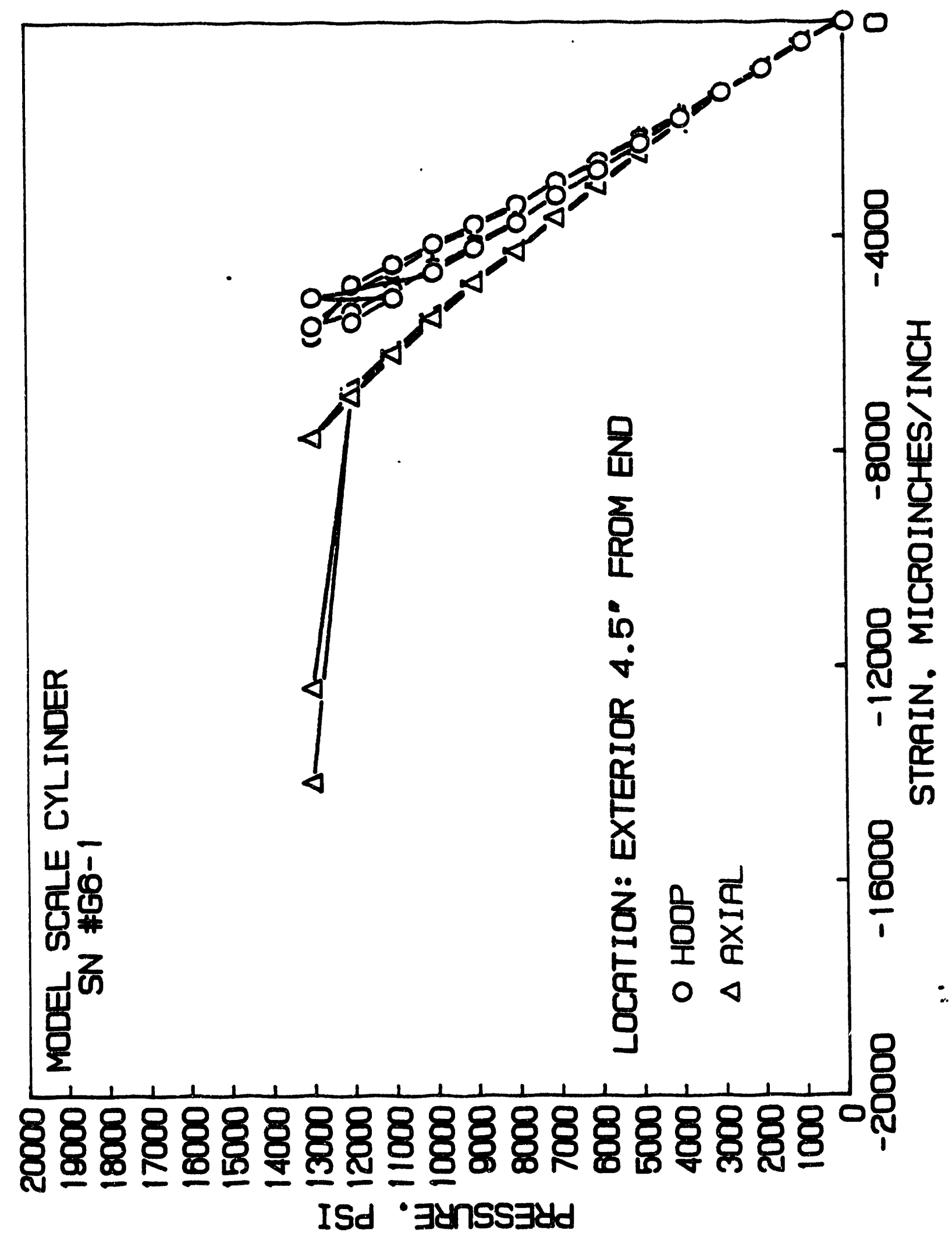




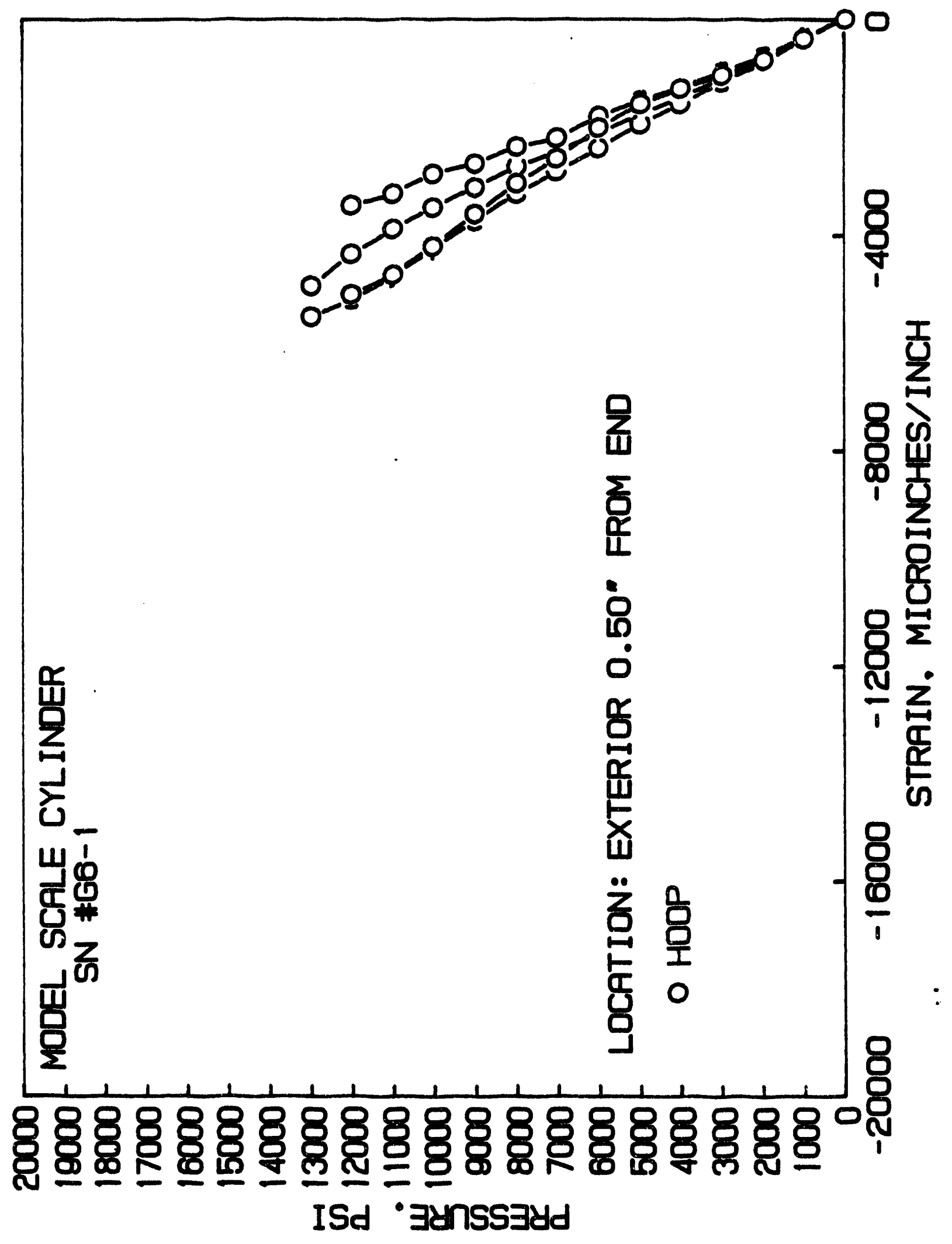




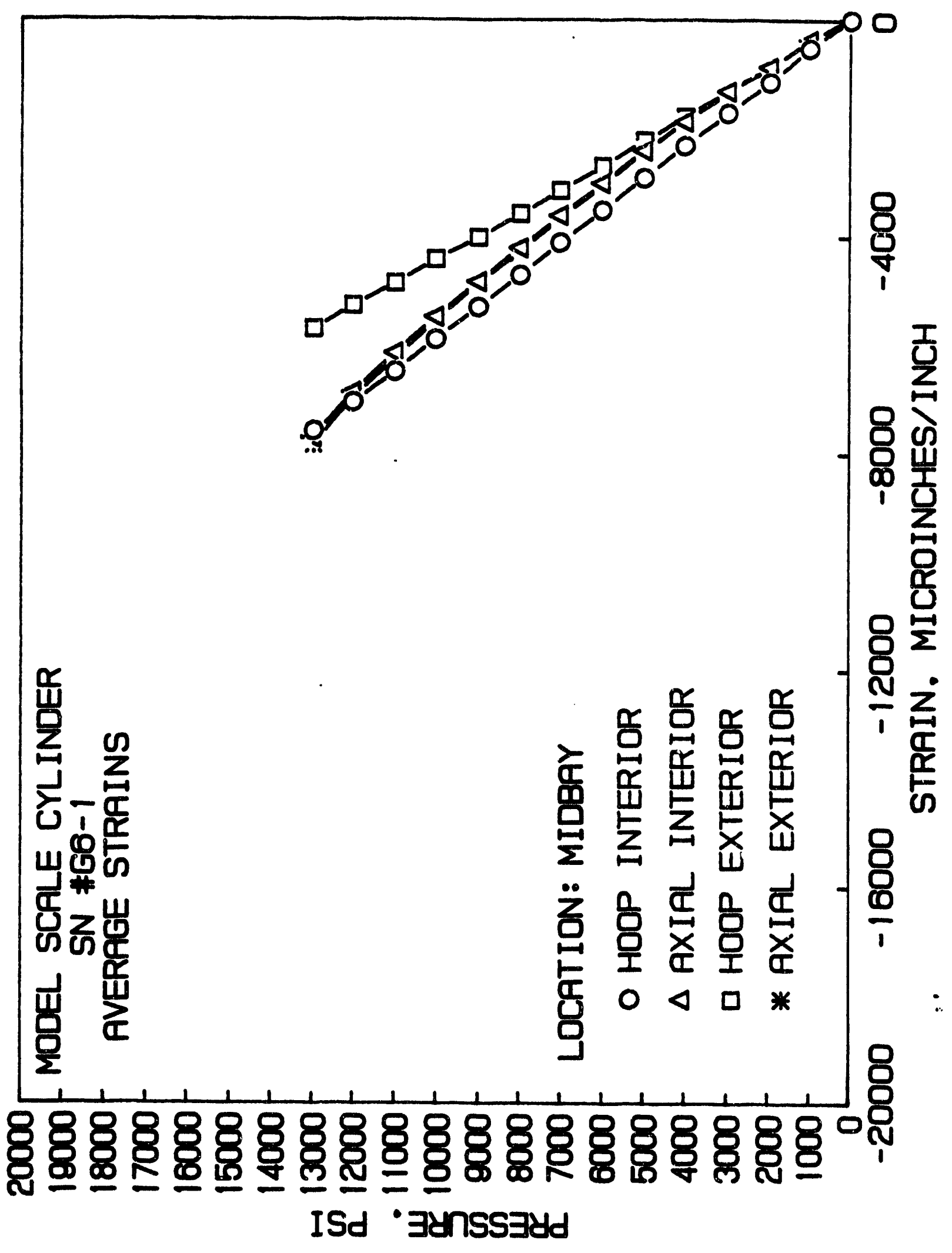




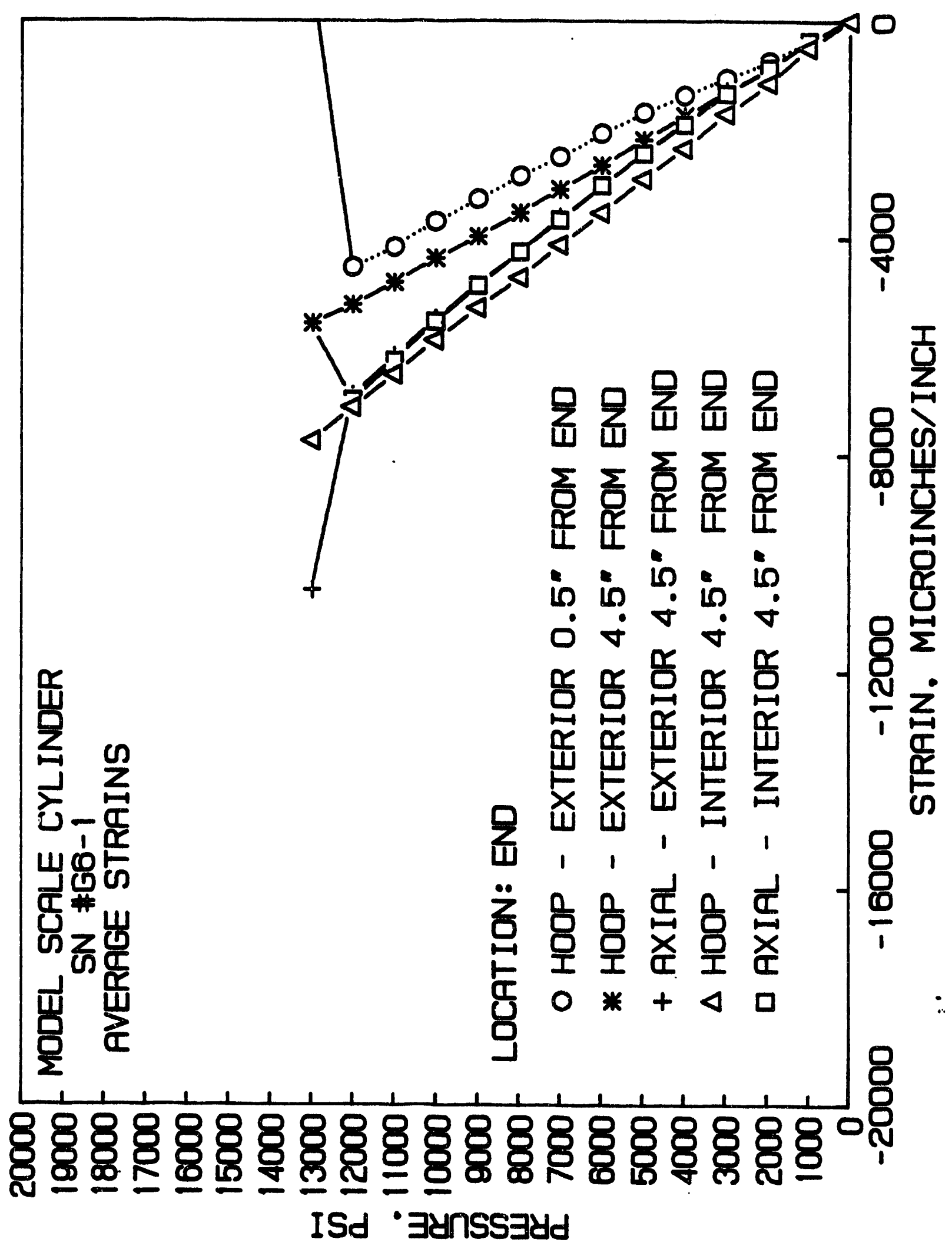




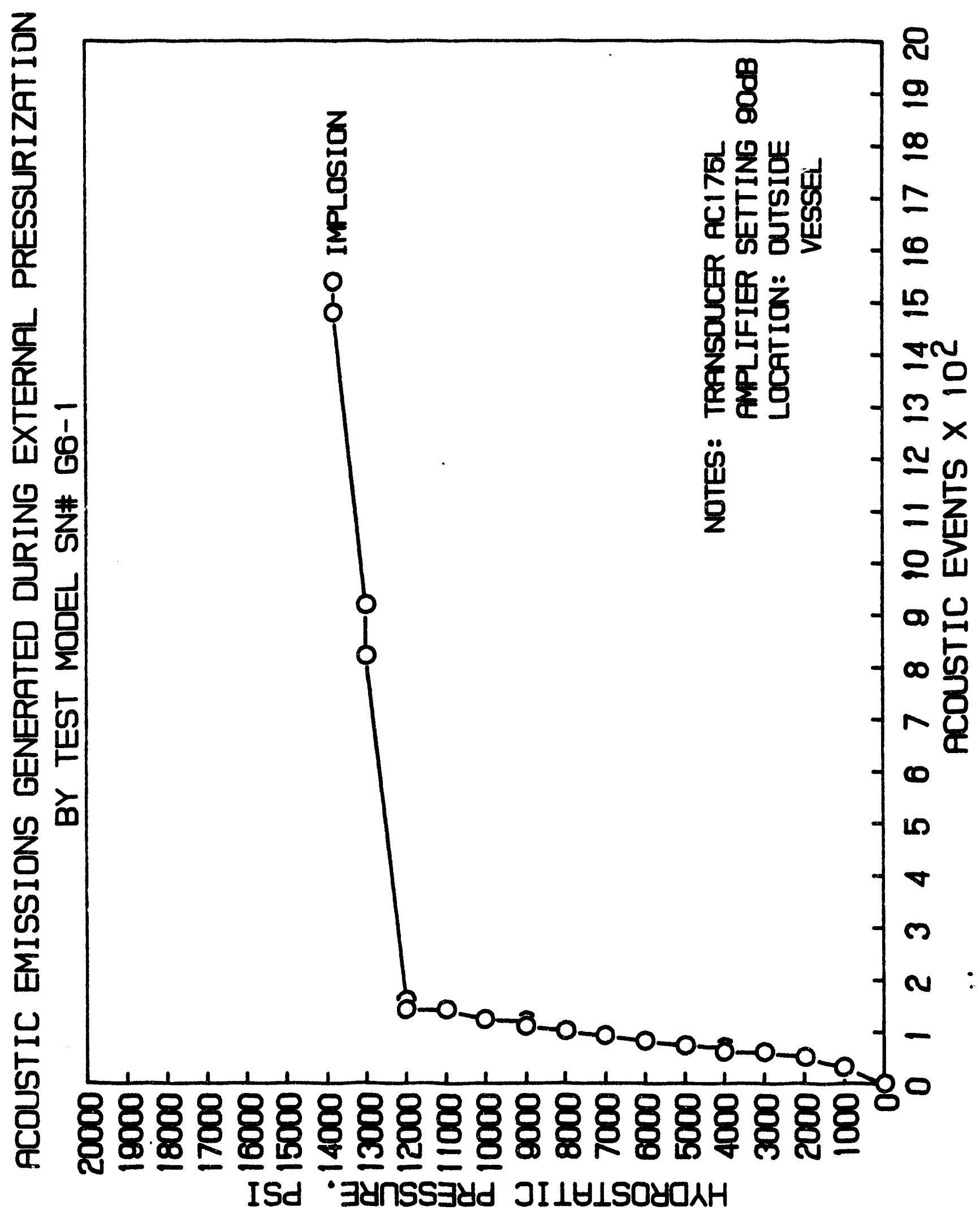


HYDROSPACE ENGINEERING SERVICES

Test Report for Cylinder G6-2 
June 3, 1991

\section{TEST REPORT}

\section{Instrumentation}

The cylinder was instrumented with 0.125 inch electric resistance straingage rosettes. The acoustic emission detector was bonded to the outside of the pressure vessel. The ORNL G6-2 cylinder was instrumented with a total of 20 strain gage rosettes (four of which only the hoop orientation were used). The rosettes were affixed to the cylinder as shown on the attached diagram supplied by the Mr. Mike starbuck of the Oak Ridge National Laboratory.

\section{Test Procedure}

The cylinder was tested in a 10 inch ID pressure vessel with 20,000 psi pressure capability. The pressurizing medium was Tellus 30 oil. Pressurization was accomplished with an air operated pump raising the pressure inside the vessel at 2,000 psi/minute rate. Pressurization was interrupted at 1,000 psi intervals and strains recorded at 2 seconds per channel rate. Acoustic emission was recorded continuously.

\section{Test Results}

The pressure test on SNE G6-2 cylinder was terminated at 17,400 Psi, at which time the specimen imploded. 


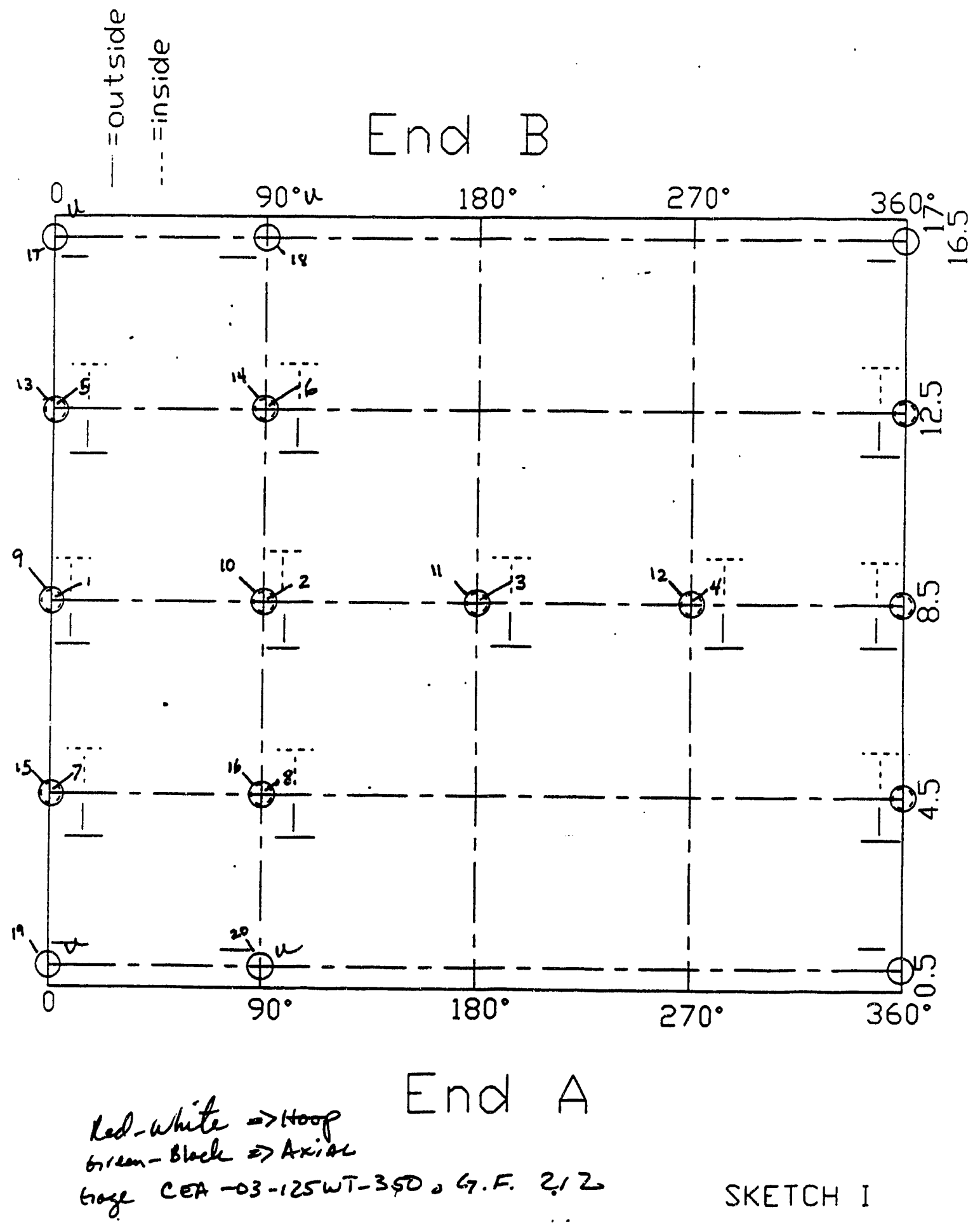


160

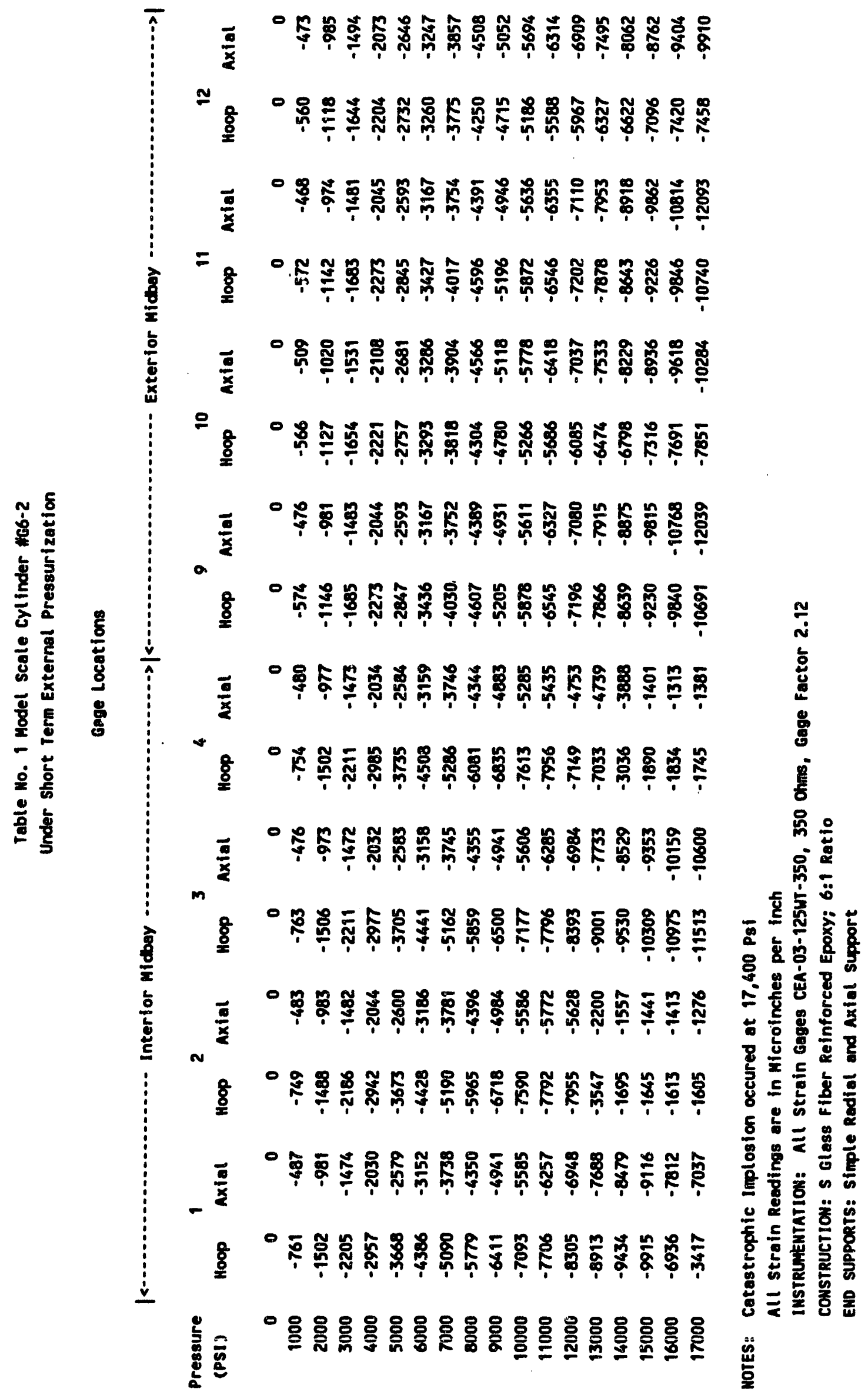


161

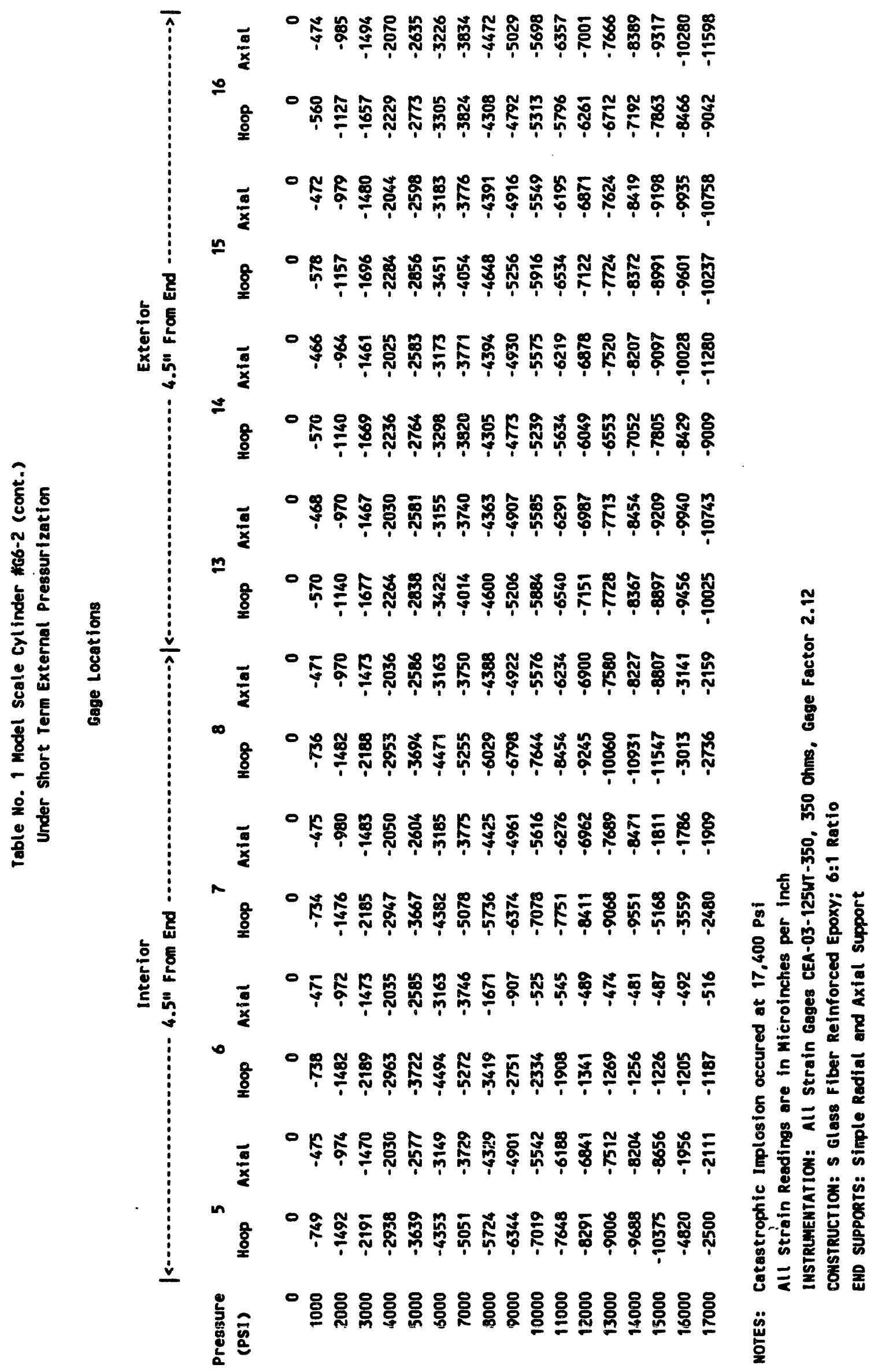




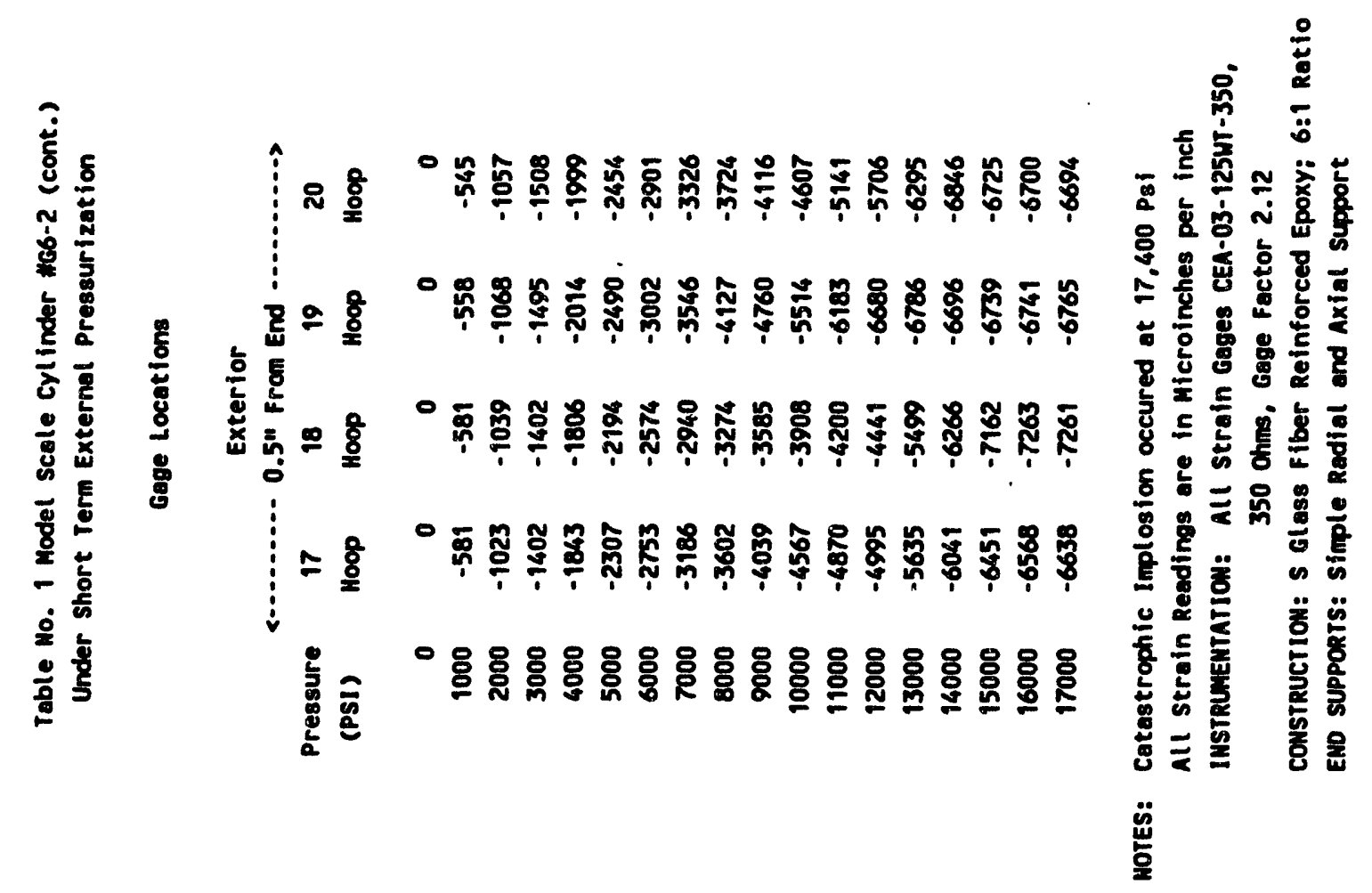


163

ACOUSTIC EMISSIONS DURING HYDROSTATIC TESTING OF MODEL CYLINDER SN\# G6-2

Pressuration \# 1

\begin{tabular}{|c|c|c|c|c|}
\hline Pressure & Events & Time & & Notes: \\
\hline 0000 & 0 & $10: 05$ & 1. & Transducer: AET AC175 \\
\hline 1000 & $3-3$ & $10: 11$ & & SN\# 77995 to $200 \mathrm{KHZ}$ \\
\hline 2000 & $3-3$ & $10: 15$ & 2. & Amplifer setting: \\
\hline 3000 & $4-5$ & $10: 19$ & & Rate: $\mathbf{T}$ \\
\hline 4000 & $5-5$ & $10: 23$ & & Gain: $60 \mathrm{DB}$ \\
\hline 5000 & $5-5$ & $10: 28$ & & Threshold: Automatic \\
\hline 6000 & $5-5$ & $10: 32$ & & Function: Events \\
\hline 7000 & $5-5$ & $10: 37$ & 3: & Recorder: \\
\hline 8000 & $5-8$ & $10: 45$ & & Channel "A" Events, \\
\hline 9000 & $10-11$ & $10: 48$ & & 4000 Full Range \\
\hline 10000 & $11-11$ & $10: 52$ & & Channel "B" Rms, \\
\hline 11000 & $11-11$ & $10: 55$ & & 50 MV Full scale, \\
\hline 12000 & $11-11$ & $10: 59$ & & $0.5 \mathrm{CM} / \mathrm{Min}$ Chart scale \\
\hline 13000 & $53-54$ & $11: 03$ & & \\
\hline 14000 & $55-55$ & $11: 07$ & & \\
\hline 15000 & $55-57$ & $11: 10$ & & \\
\hline 16000 & $61-61$ & $11: 15$ & & \\
\hline 17000 & $61-225$ & $11: 18$ & & \\
\hline 17400 & 463 & $11: 19$ & & \\
\hline
\end{tabular}

18000

19000

20000

Failed at $17,400 \mathrm{psig}$ 


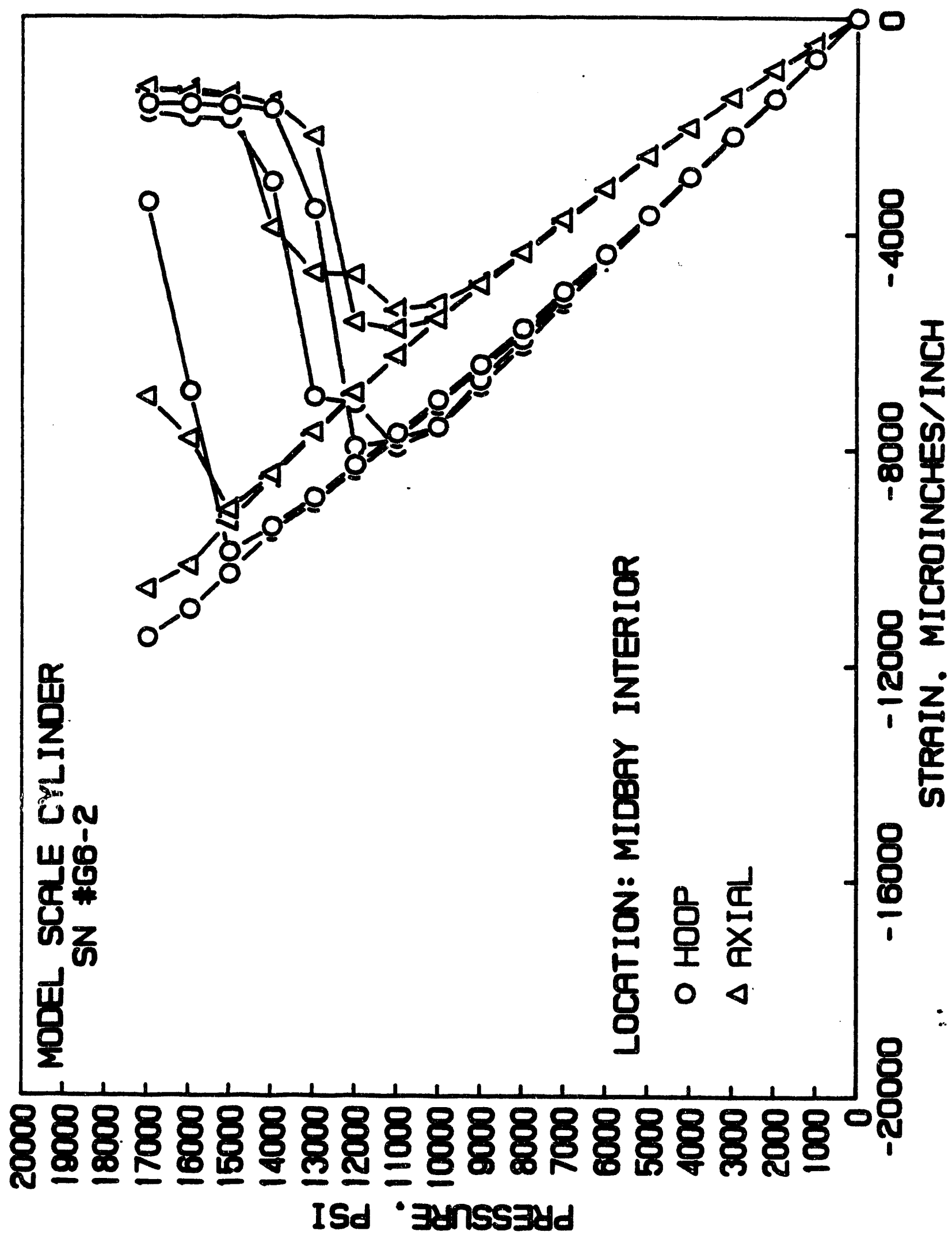




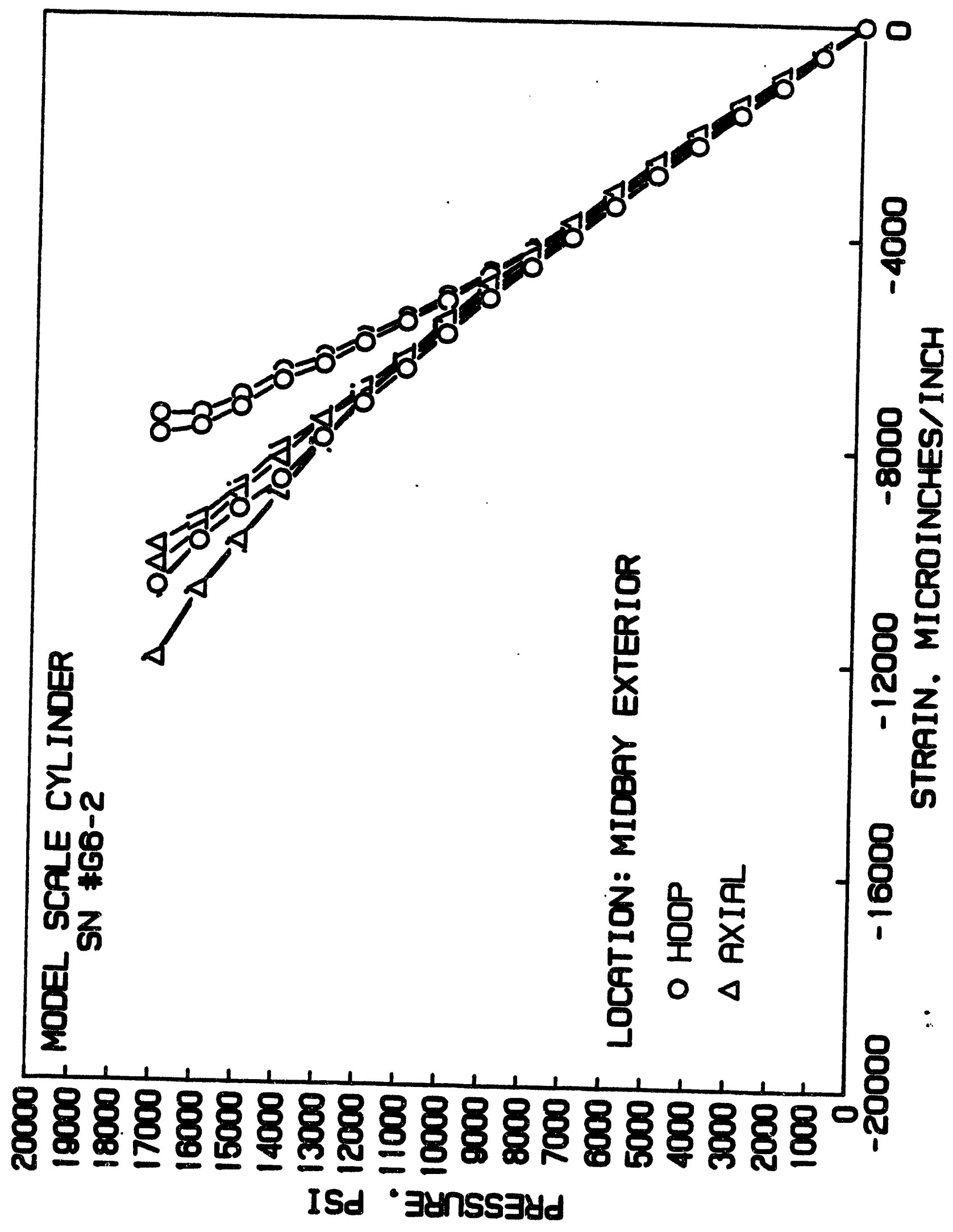




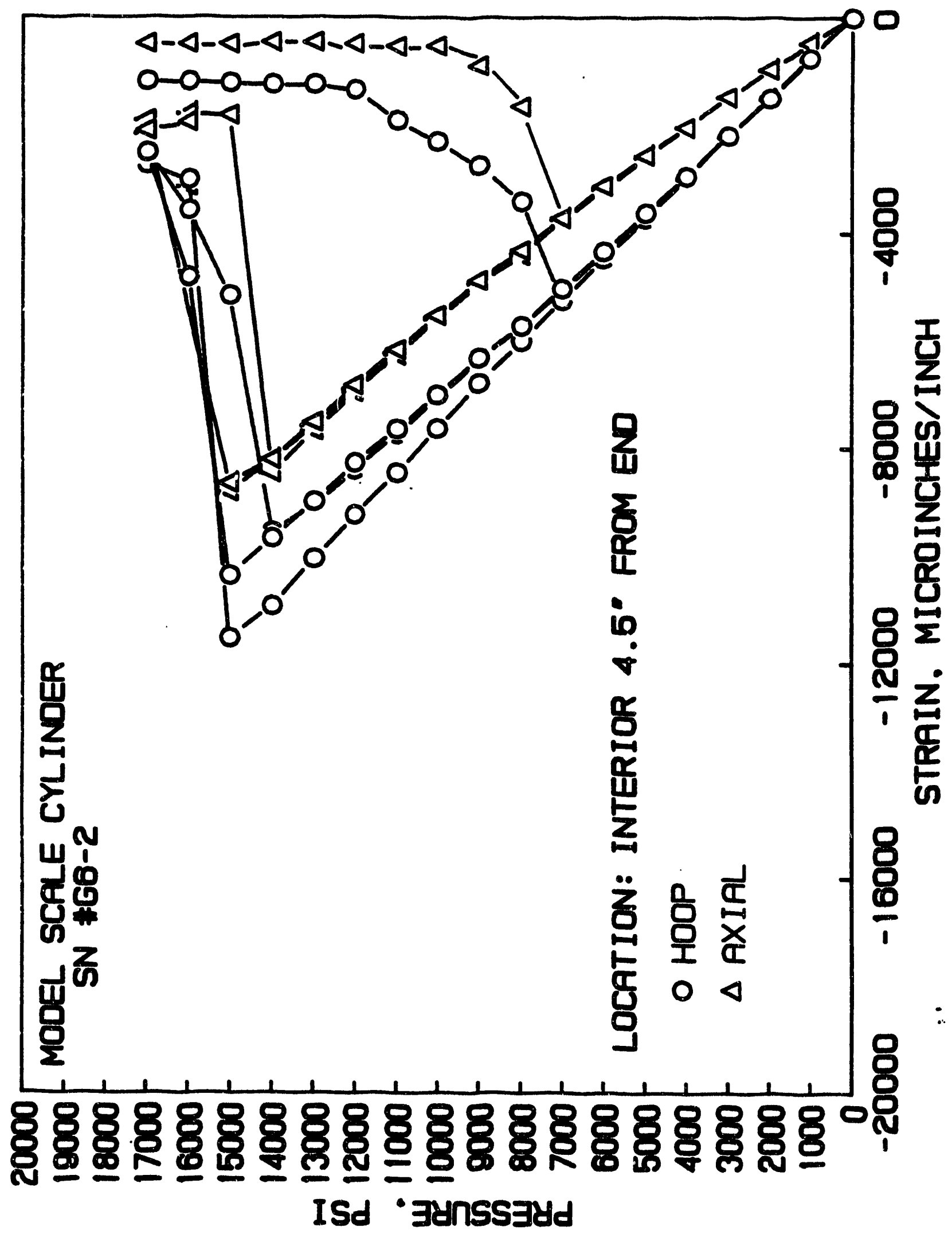




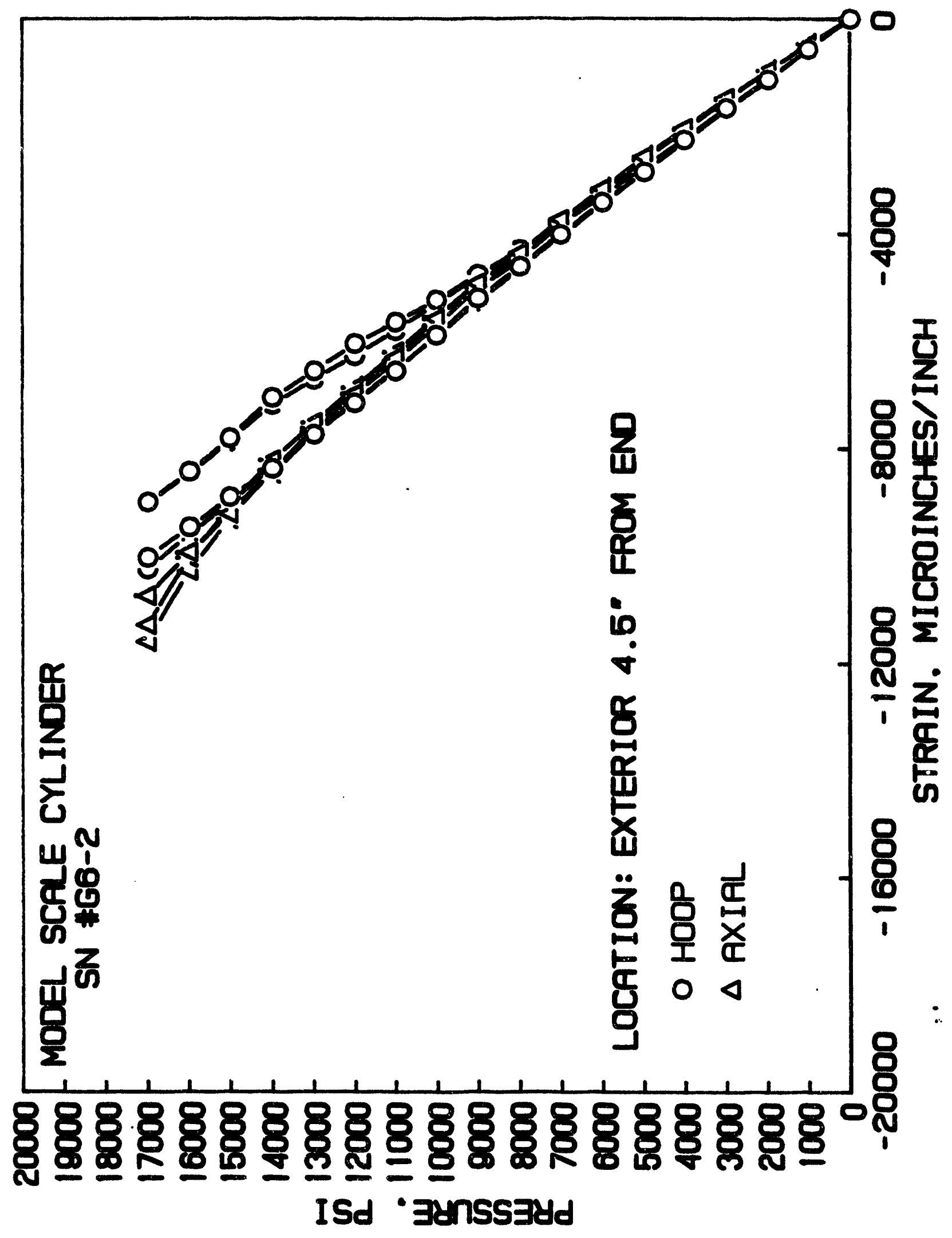




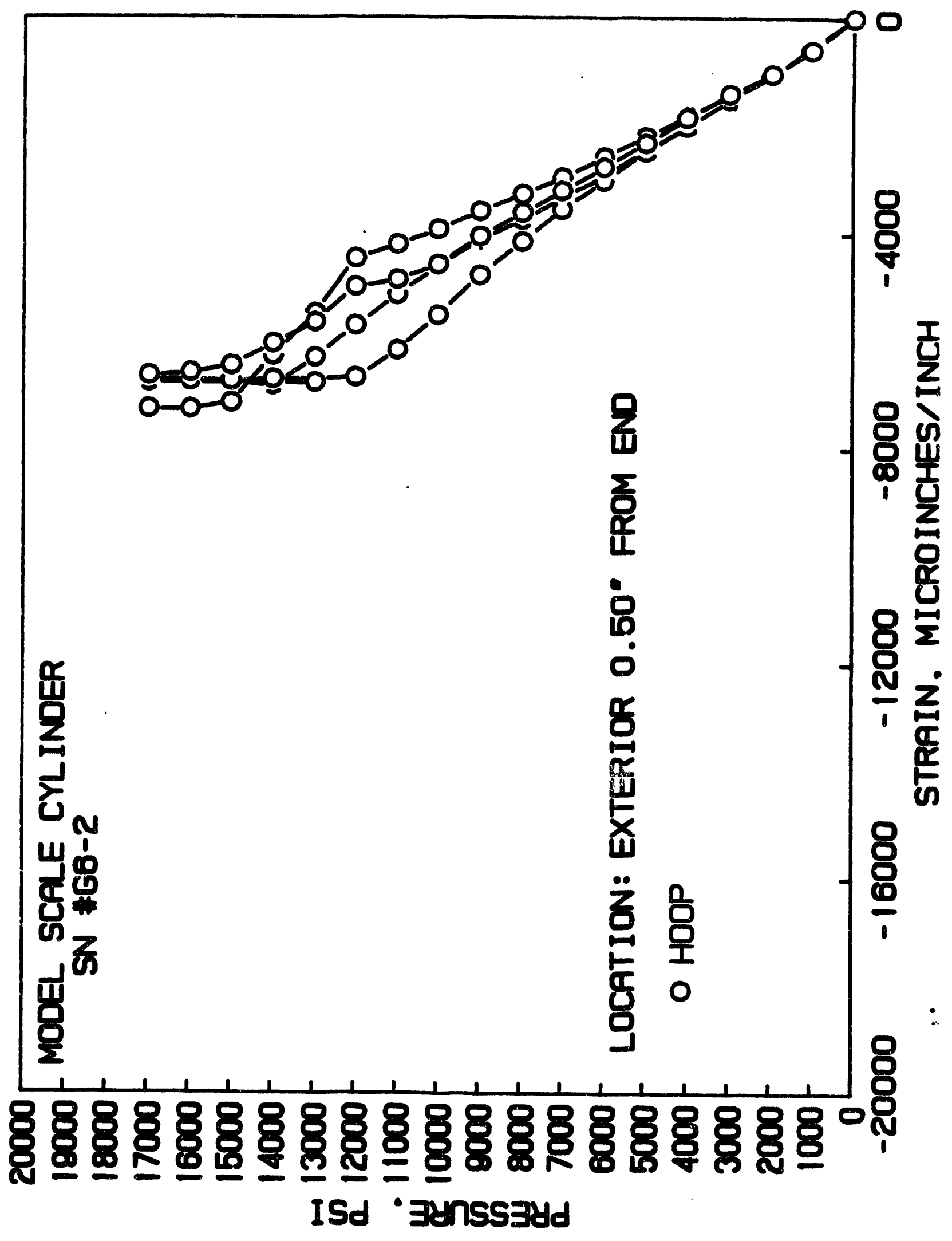




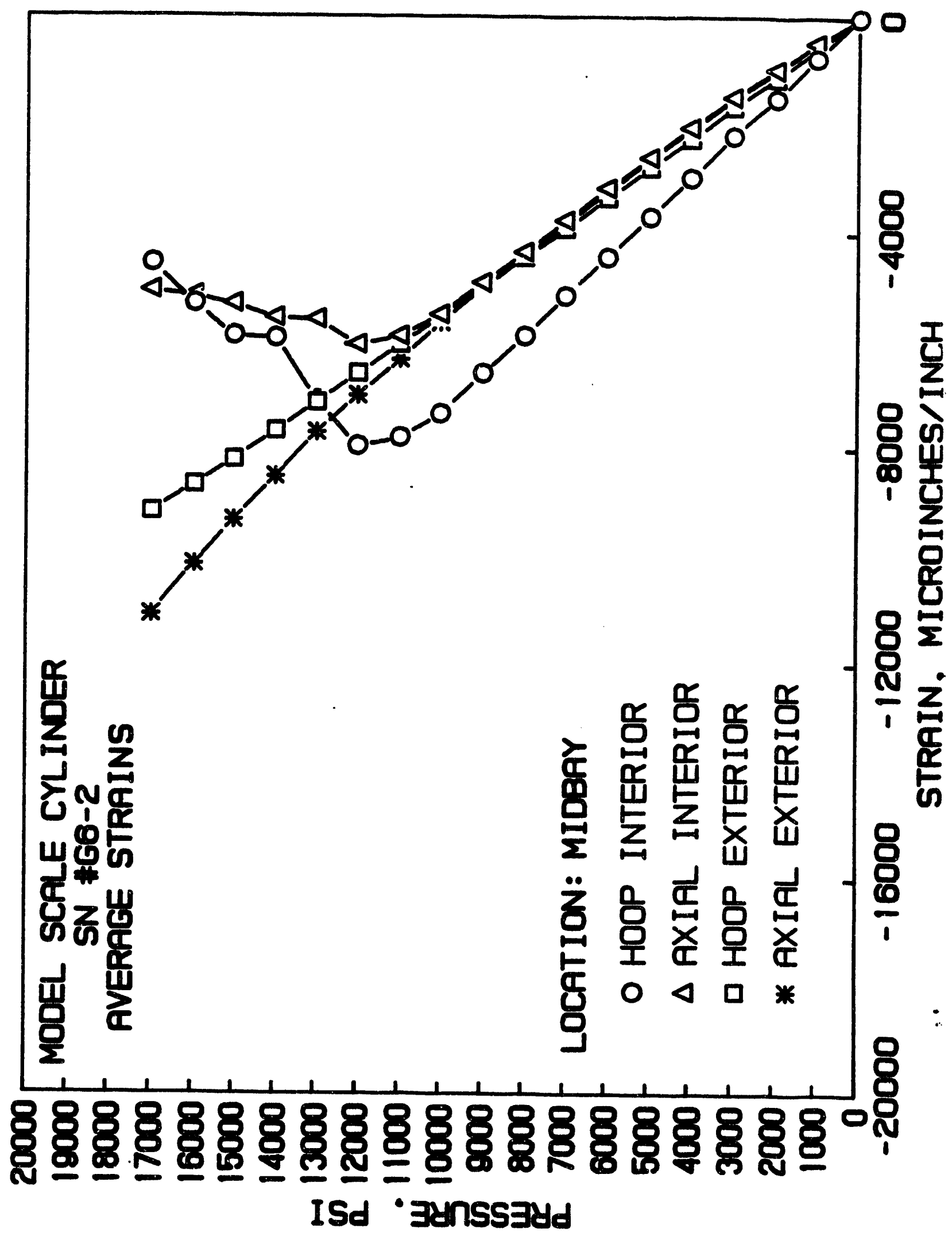




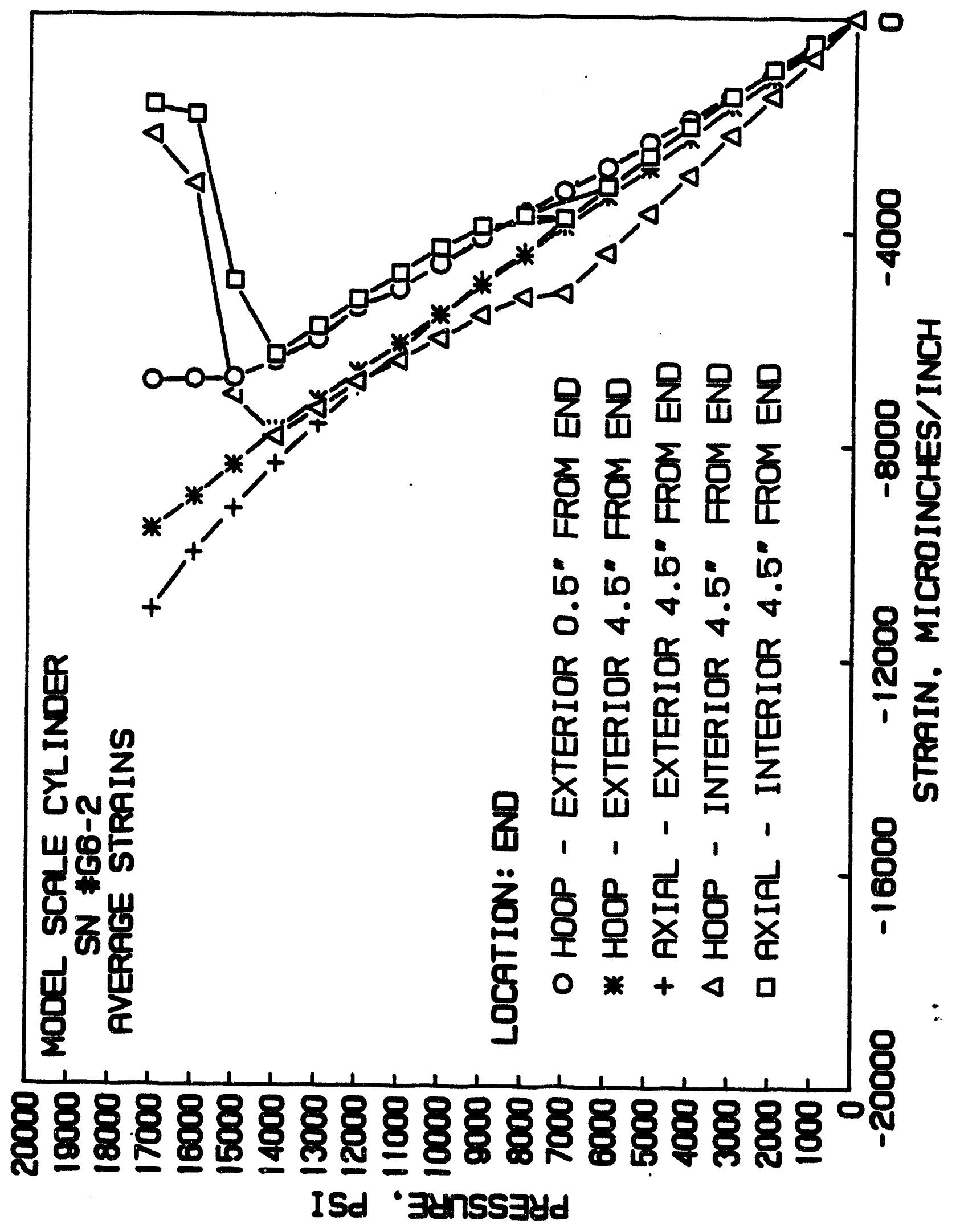




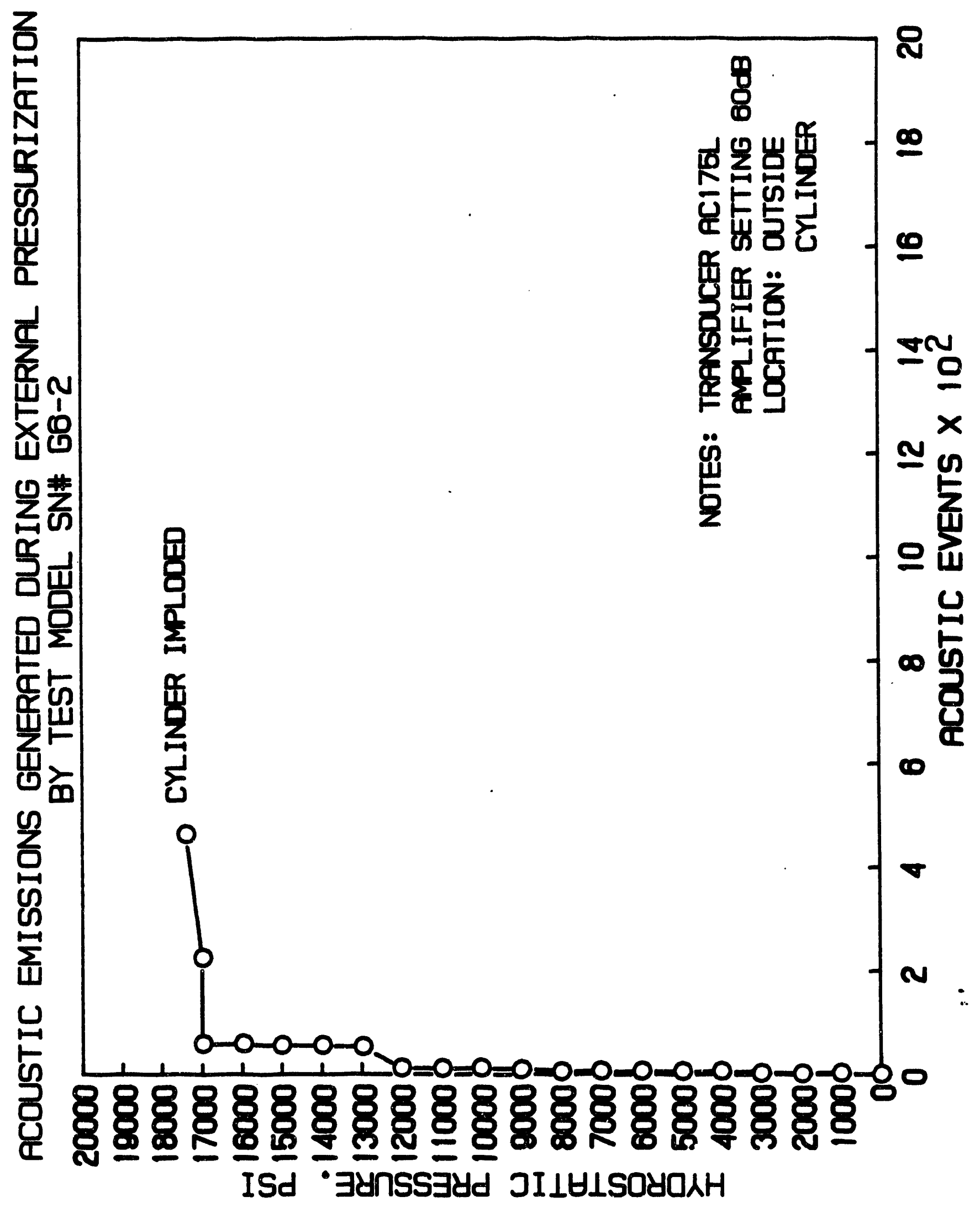




\section{HYDROSPACE ENGINEERING SERVICES}

Test Report for Cylinder G6-3 
September 11, 1991

\section{TEBT REPORT}

\section{Instrumentation}

The cylinder was instrumented with 0.125 inch electric resistance straingage rosettes. The acoustic emission detector was bonded to the outside of the pressure vessel. The ORNL G6-3 cylinder was instrumented with a total of 20 strain gage rosettes (four of which only the hoop orientation were used). The rosettes were affixed to the cylinder as shown on the attached diagram supplied by the Dr. Mike starbuck of the Oak Ridge National Laboratory.

\section{Test Procedure}

The cylinder was tested in a 10 inch ID pressure vessel with 20,000 psi pressure capability. The pressurizing medium was Tellus 30 oil. Pressurization was accomplished with an air operated pump raising the pressure inside the vessel at 2,000 psi/minute rate. Pressurization was interrupted at 1,000 psi intervals and strains recorded at 2 seconds per channel rate. Acoustic emission was recorded continuously.

\section{Test Results}

The pressure test on SN: G6-3 cylinder was terminated at 16,000 Psi, at which time the specimen imploded. 

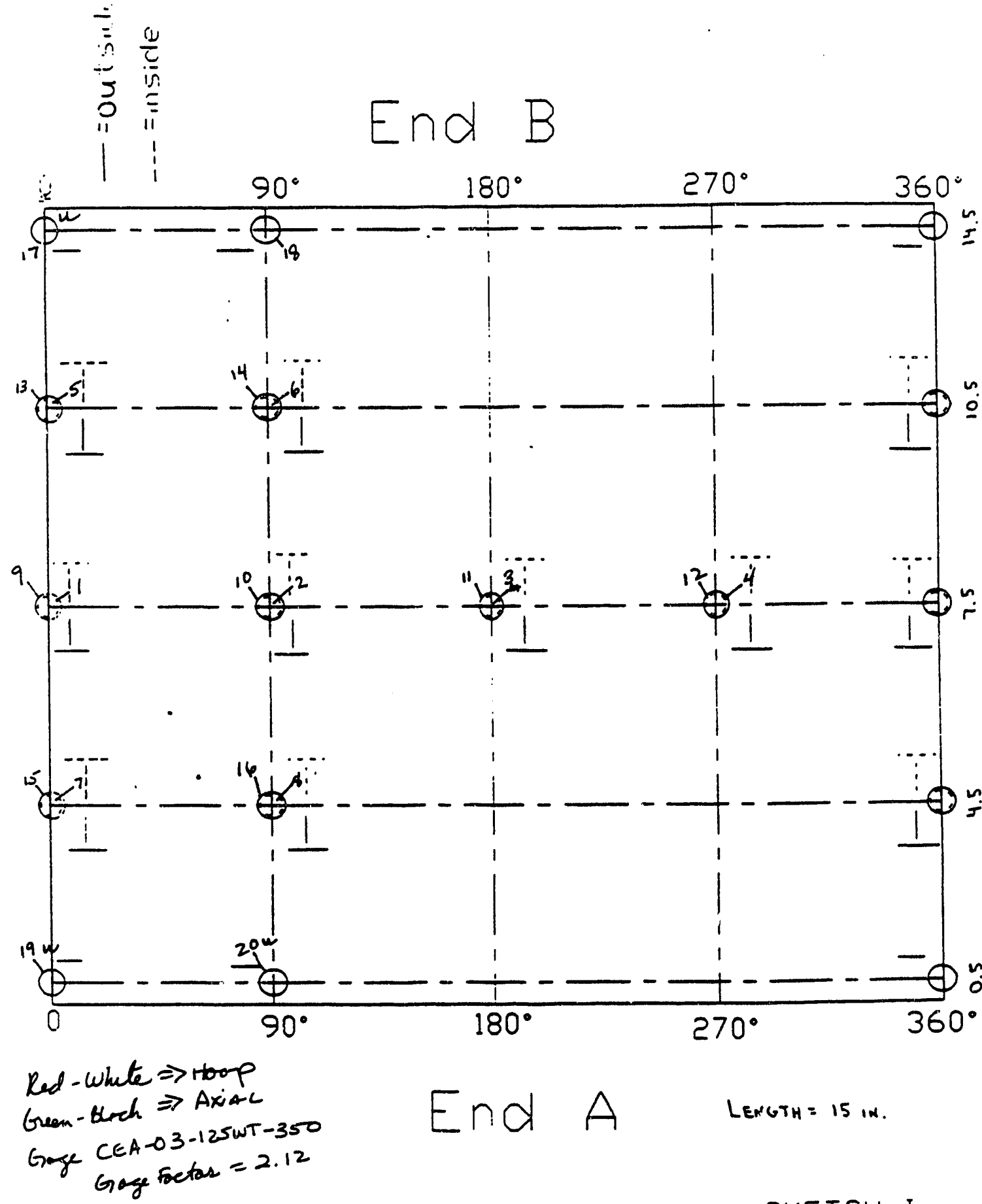

En A Length $=15 \mathrm{in}$.

SKETCH I 


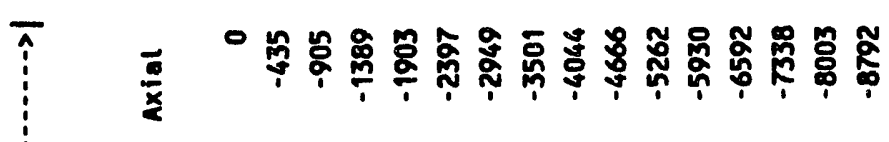

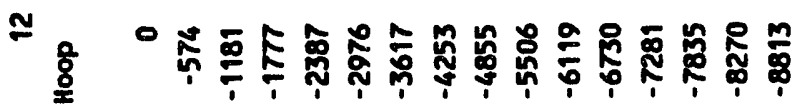

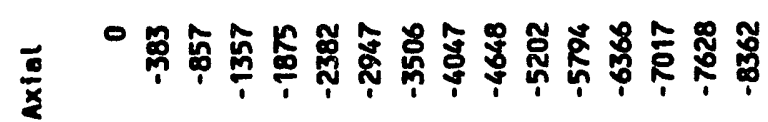

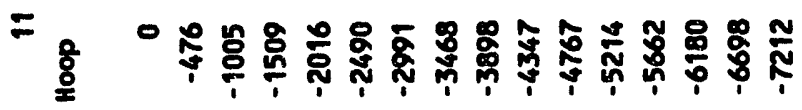

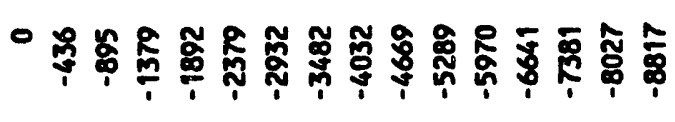

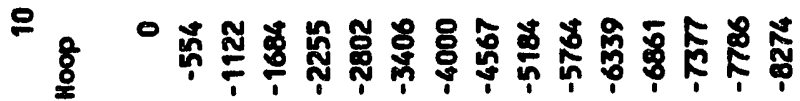

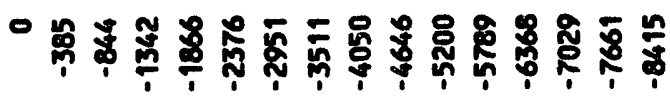

空

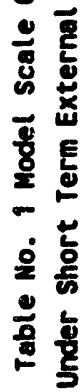

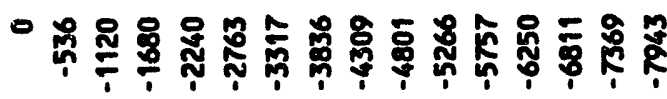

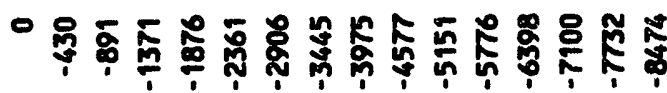

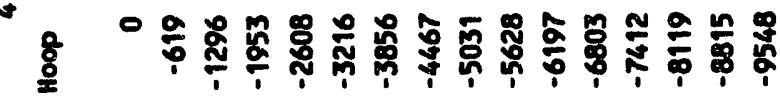

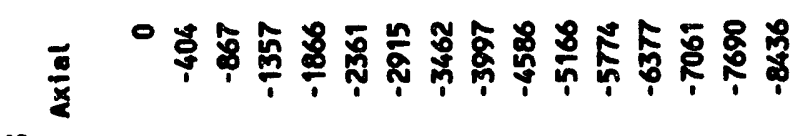

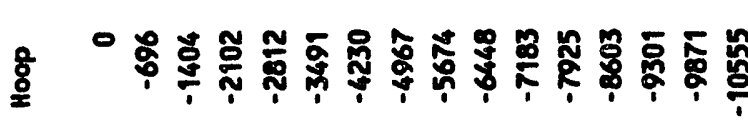

$\frac{8}{8}$

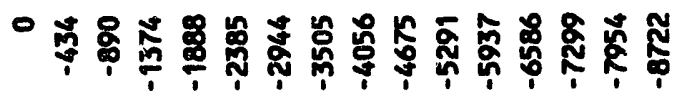

N

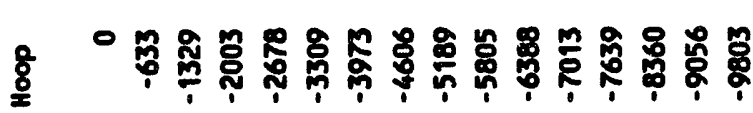

—

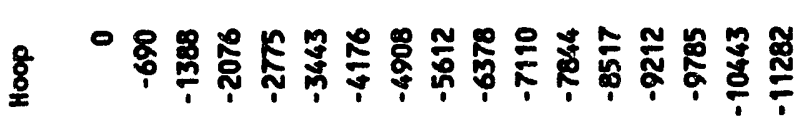

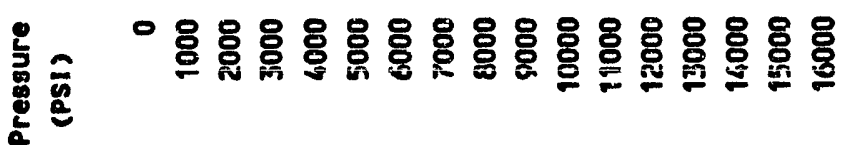

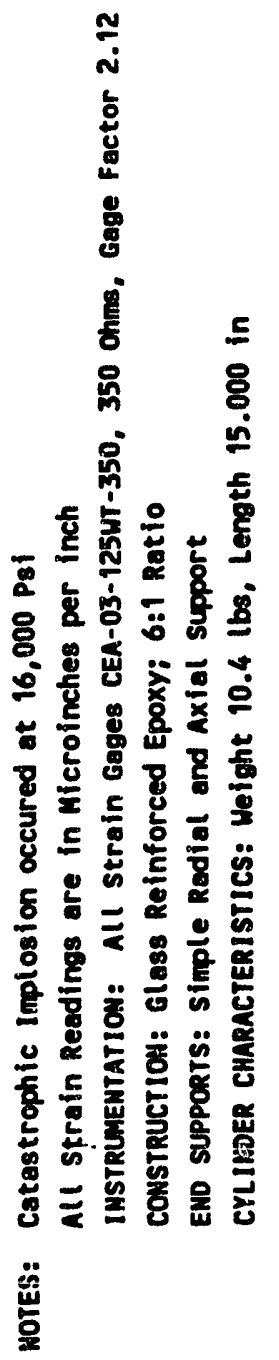




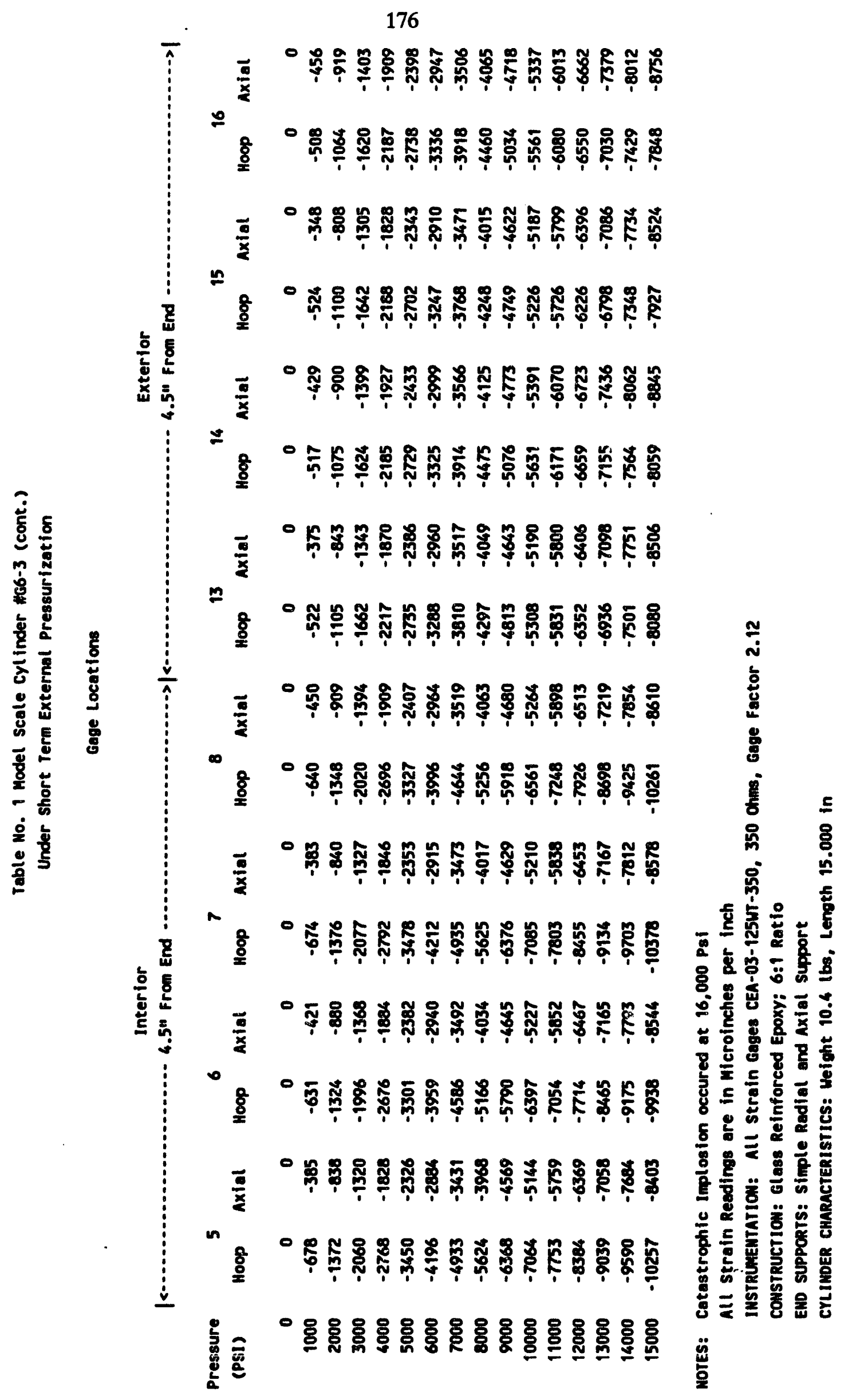




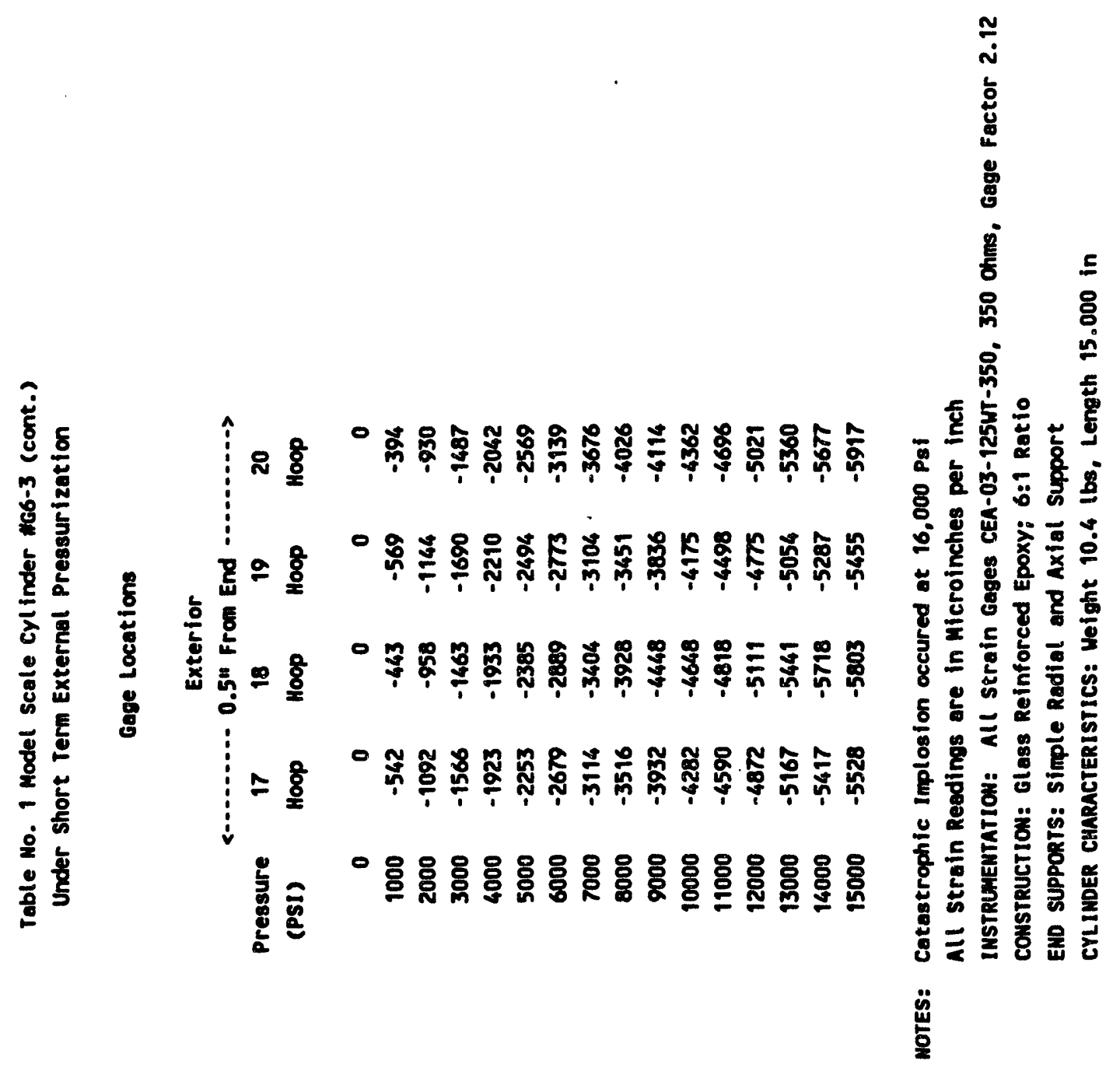


178

ACOUSTIC EMISSIONS DURING HYDROSTATIC TESTING OF MODEL CYLINDER SN\# G6-3

Pressurization \# 1

$\begin{array}{lcccc}\text { Pressure } & \text { Events } & \text { Time } & \text { Notes: } \\ 0000 & 0 & 9: 40 & 1 . & \text { Transducer: AET AC175 } \\ 1000 & 0-0 & 9: 44 & \text { SN\# } 77995 \text { to } 200 \mathrm{KHZ} \\ 2000 & 0-0 & 9: 46 & 2 \text {. Amplifer Setting: } \\ 3000 & 0-0 & 9: 49 & \text { Rate: T } \\ 4000 & 0-0 & 9: 52 & \text { Gain: 60 DB } \\ 5000 & 0-0 & 9: 55 & \text { Threshold: Automatic } \\ 6000 & 1-1 & 9: 58 & \text { Function: Events } \\ 7000 & 7-7 & 10: 02 & 3: \text { Recorder: } \\ 8000 & 7-7 & 10: 05 & \text { Channel "A" Events, } \\ 9000 & 10-10 & 10: 09 & 4000 \text { Full Range } \\ 10000 & 11-11 & 10: 13 & \text { Channel "B" Rms, } \\ 11000 & 14-14 & 10: 16 & 50 \text { Mv Full Scale, } \\ 12000 & 14-14 & 10: 20 & \text { 0.5 CM/Min Chart Scale } \\ 13000 & 20-20 & 10: 25 & \\ 14000 & 23-23 & 10: 28 & \\ 15000 & 24-62 & 10: 31 & \\ 16000 & 132-152 & 10: 32 & \end{array}$

Failed at 16,000 psig 


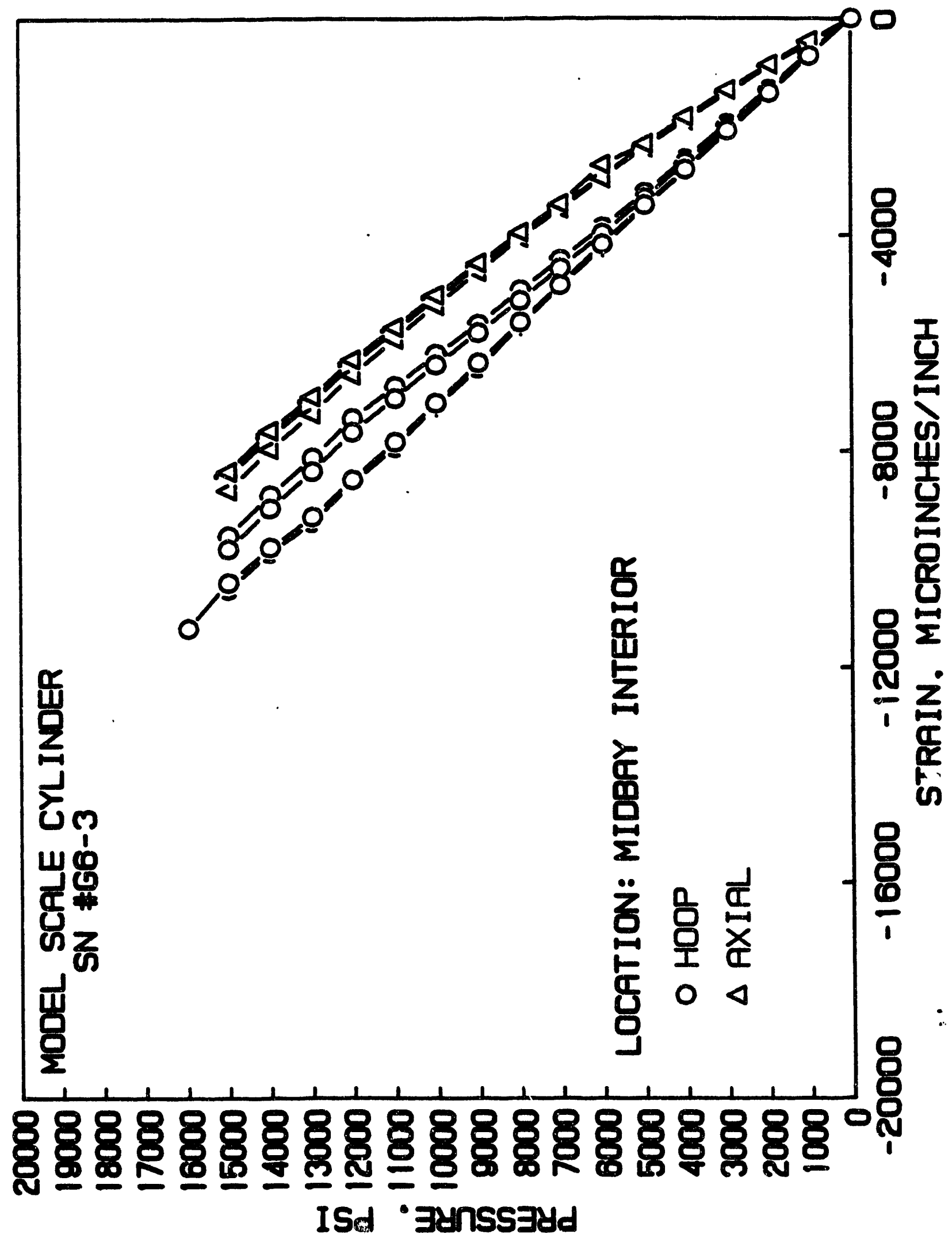




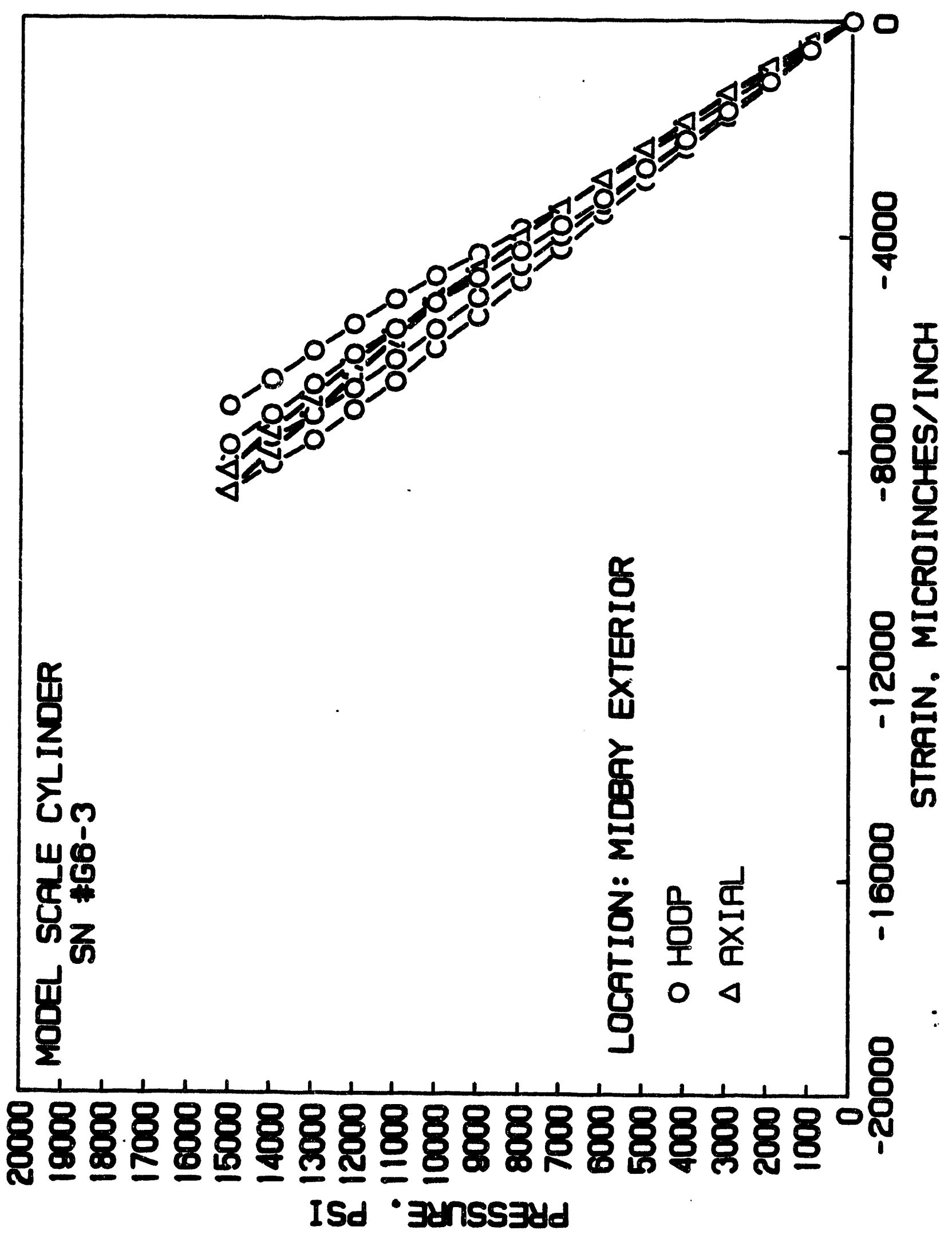




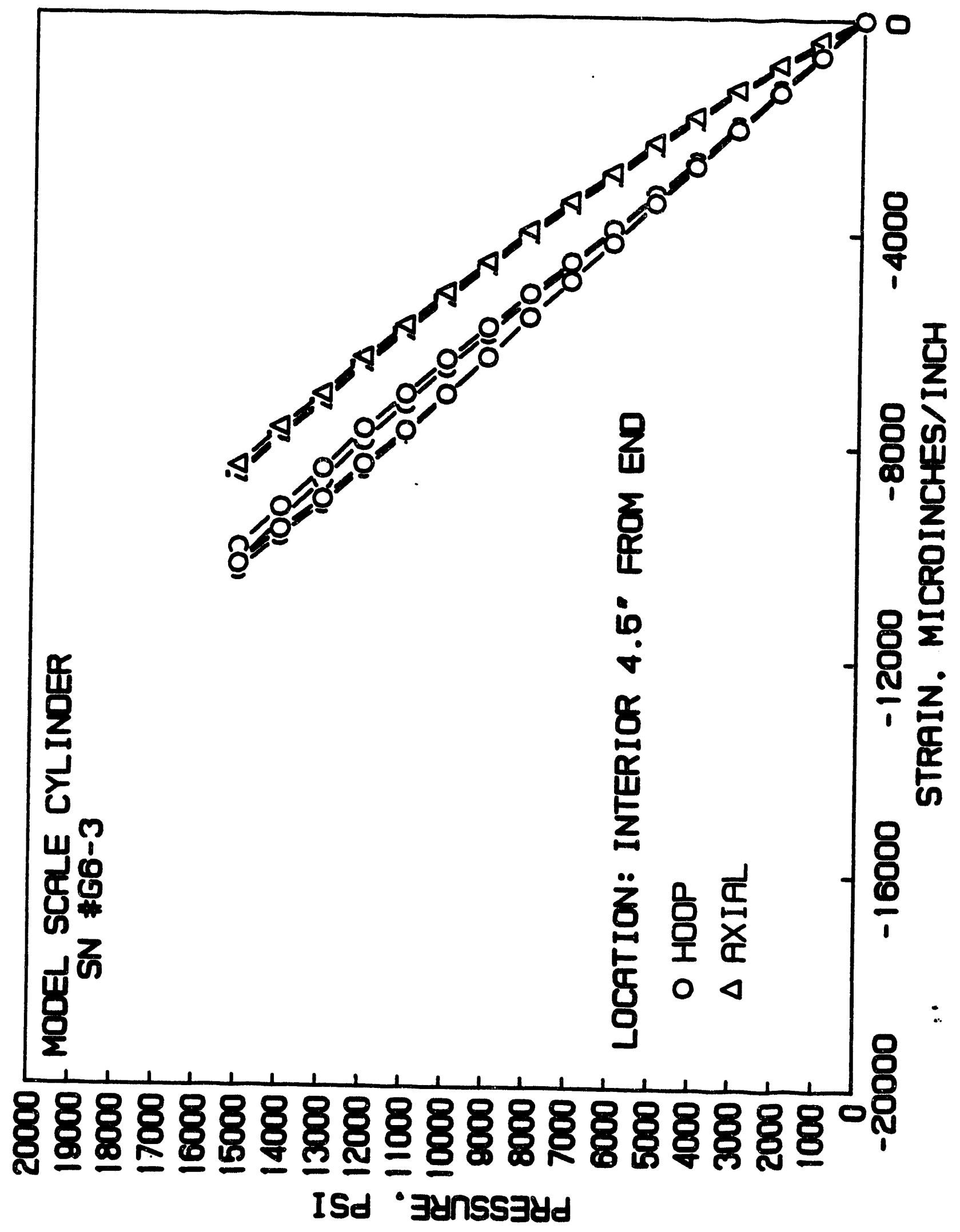




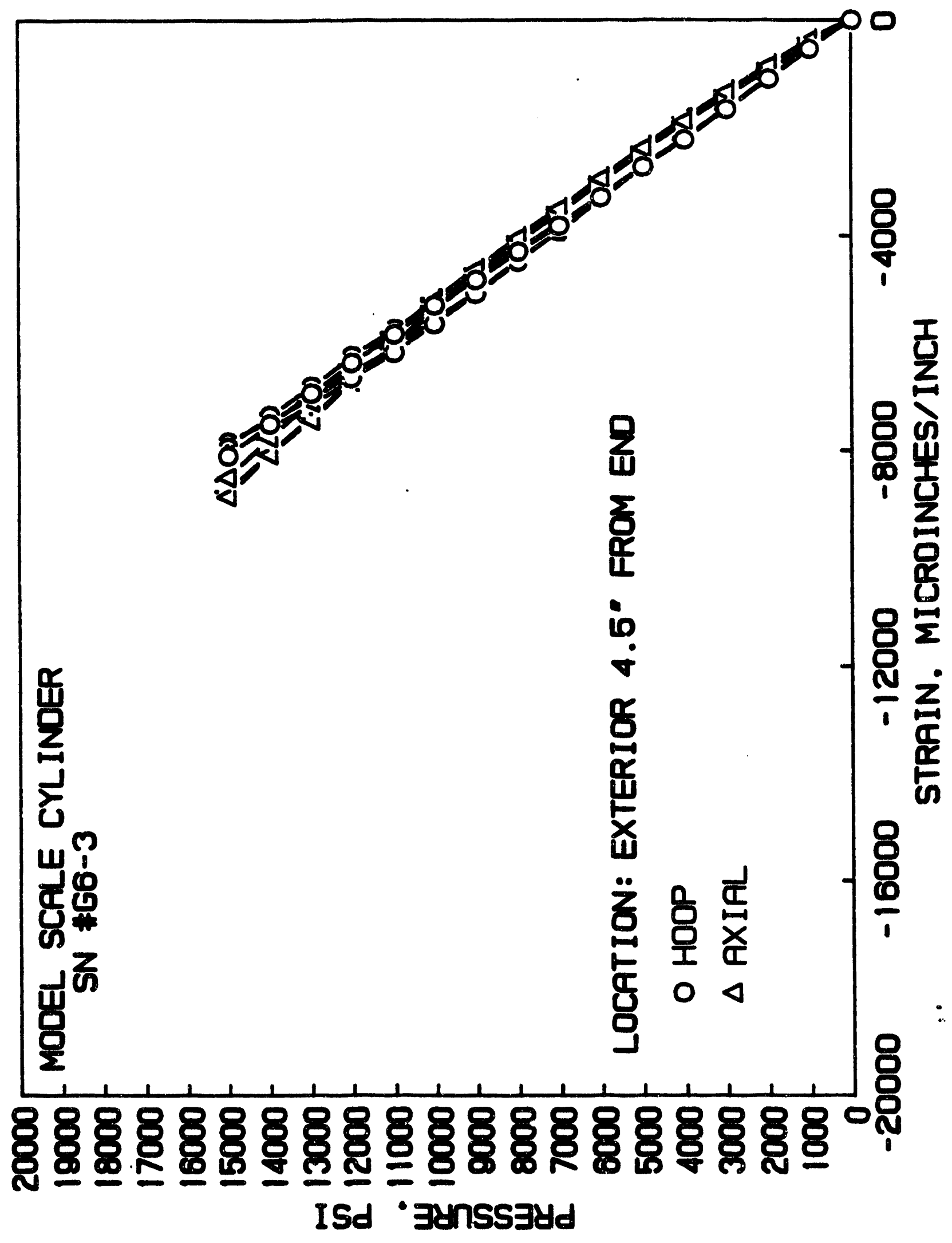




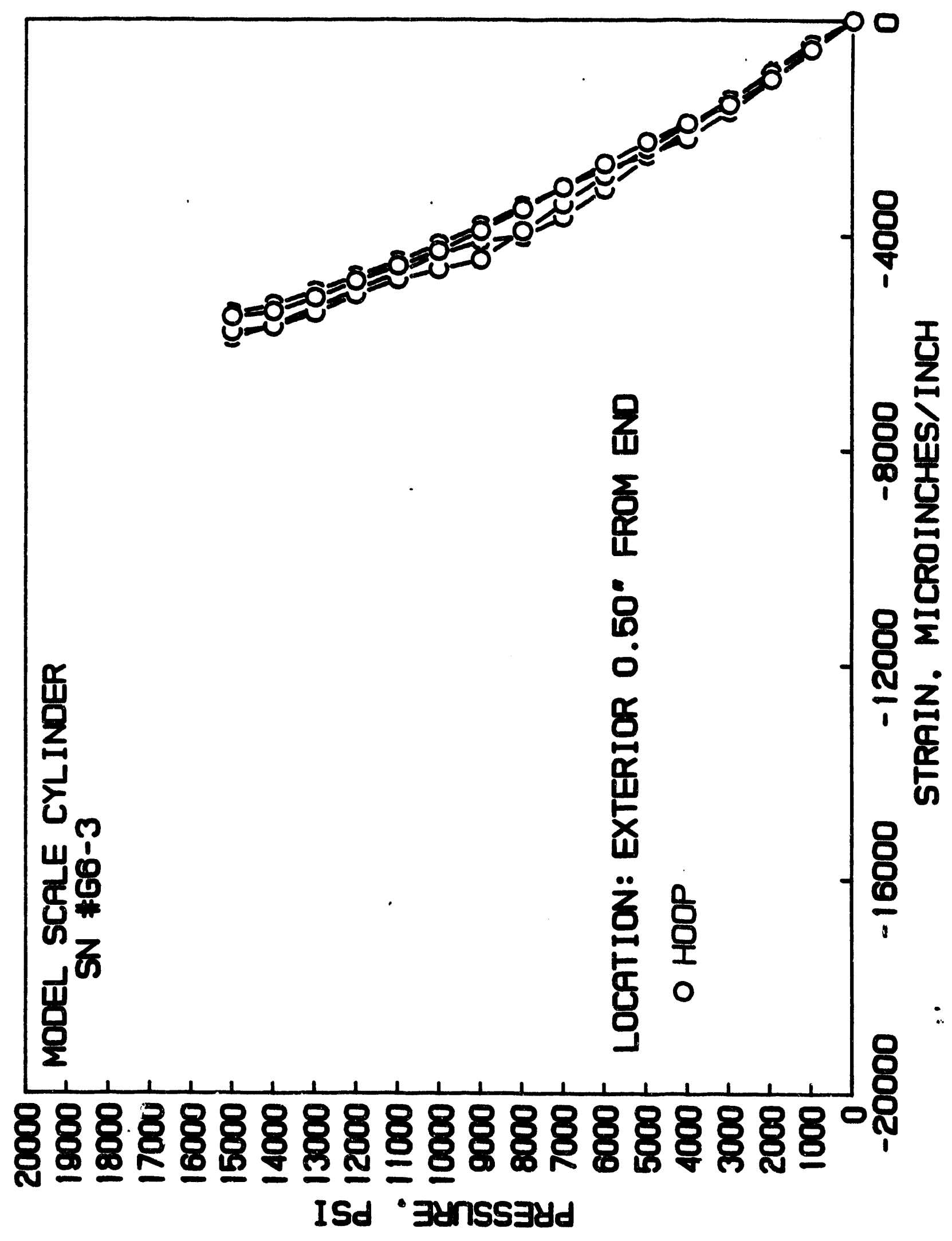




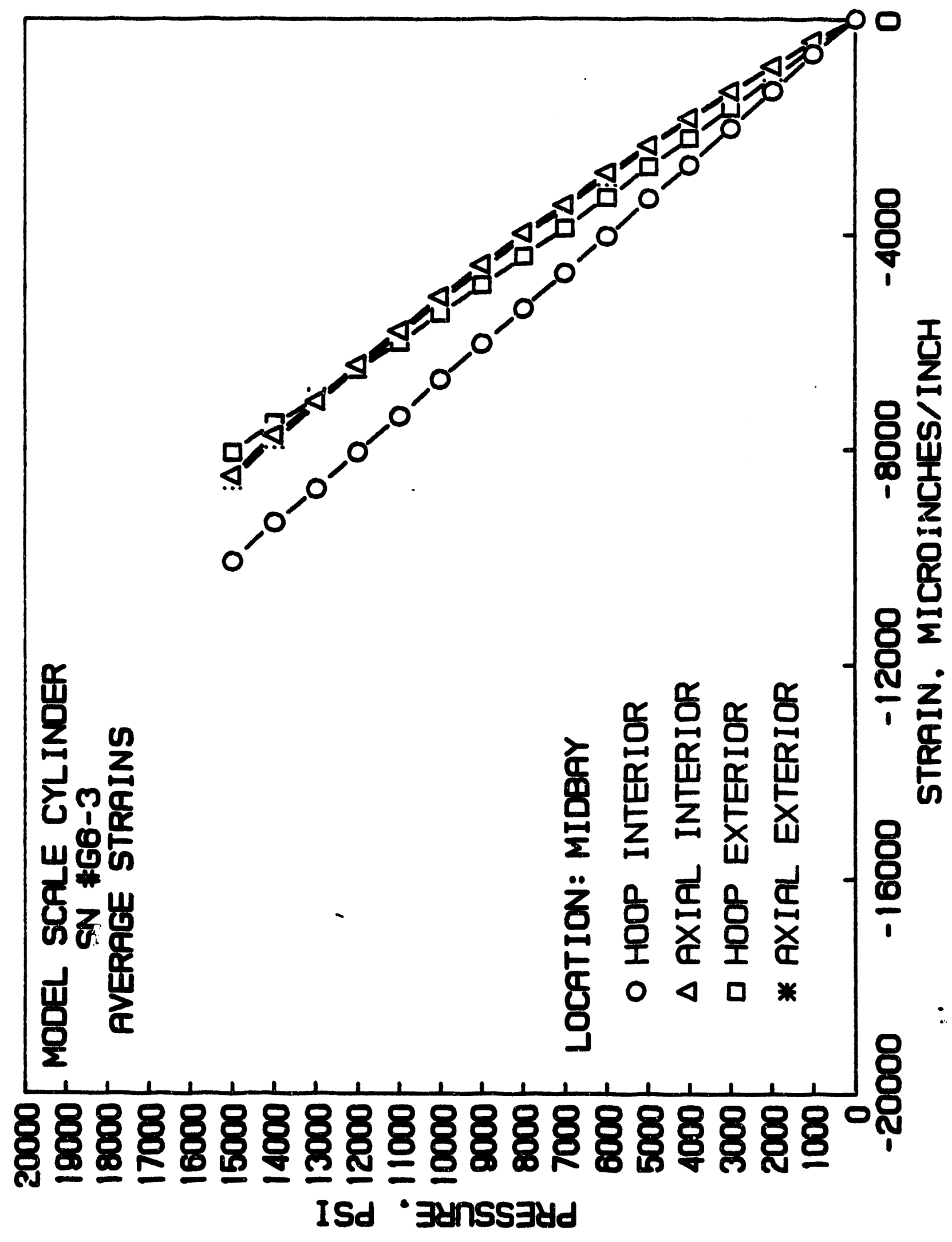




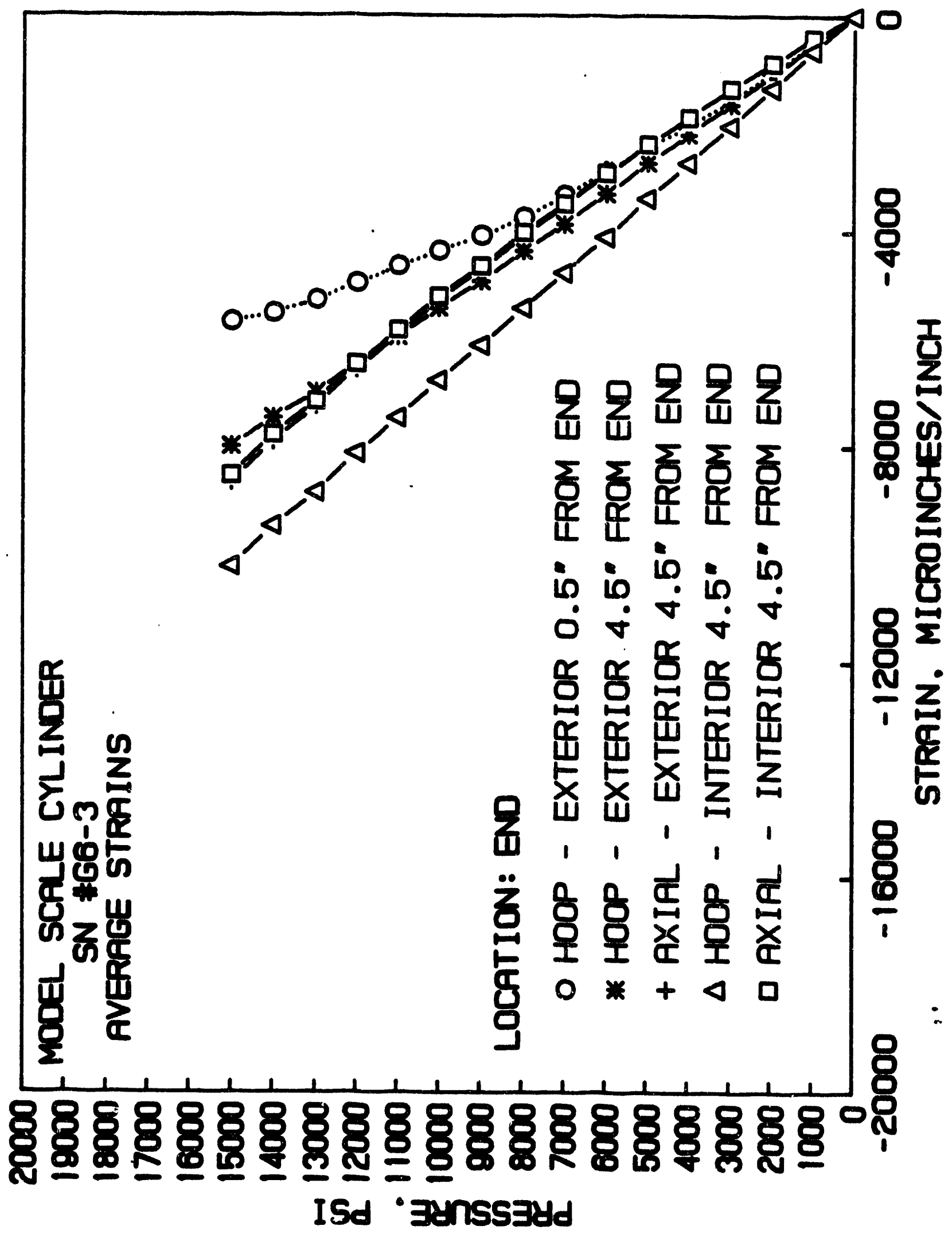




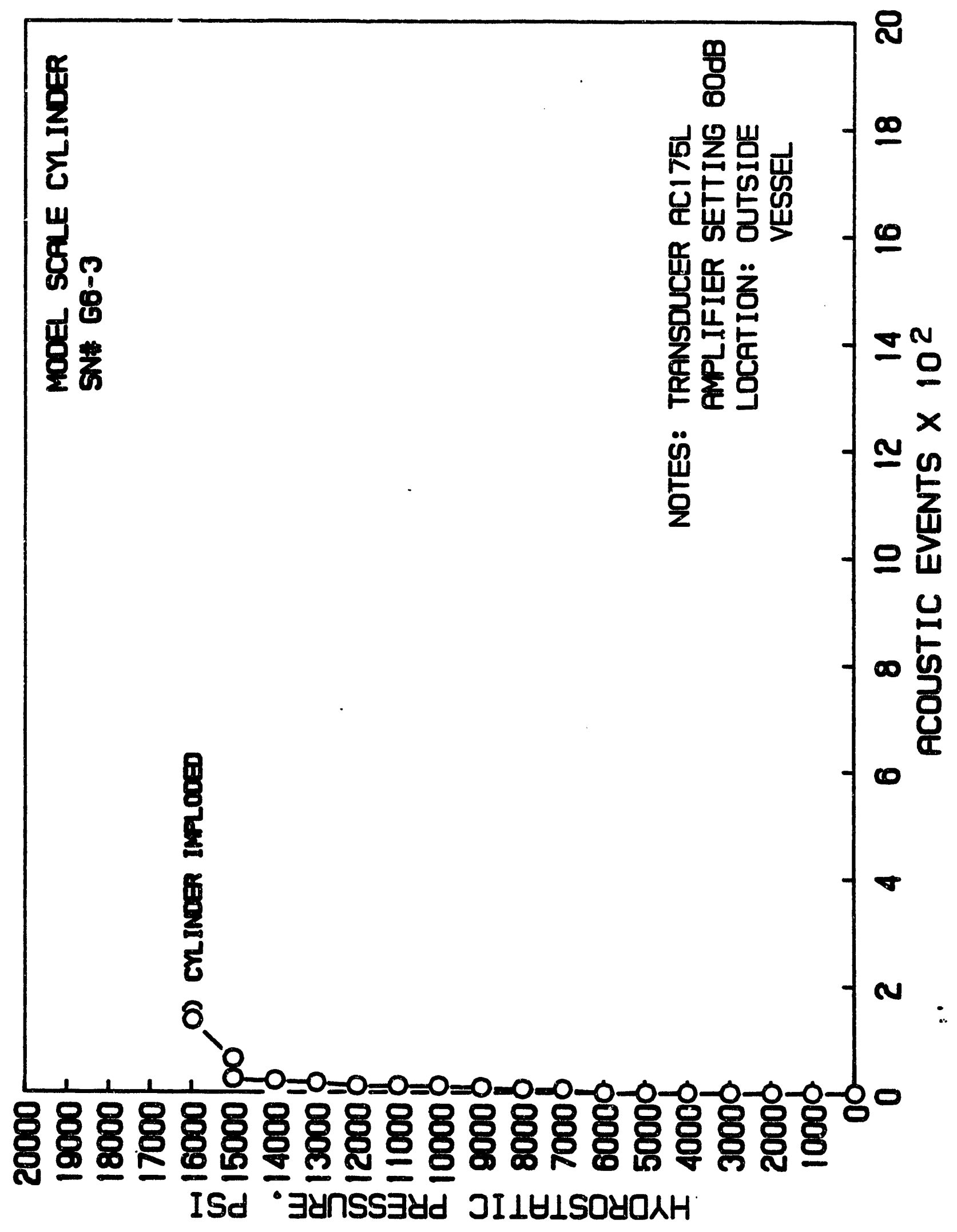


HYDROSPACE ENGINEERING SERVICES

Test Report for Cylinder G6-4 
September 12,1992

\section{TEST REPORT}

\section{Instrumentation}

The cylinder was instrumented with 0.125 inch electric resistance straingage rosettes. The acoustic emission detector was bonded to the outside of the pressure vessel. The ORNL G6-4 cylinder was instrumented with a total of 20 strain gage rosettes. The rosettes were affixed to the cylinder as shown on the attached diagram supplied by the Dr. Mike starbuck of the Oak Ridge National Laboratory.

\section{Test Procedure}

The cylinder was tested in a 10 inch ID pressure vessel with 20,000 psi pressure capability. The pressurizing medium was Tellus 30 oil. Pressurization was accomplished with an air operated pump raising the pressure inside the vessel at 2,000 psi/minute rate. Pressurization was interrupted at 1,000 psi intervals and strains recorded at 2 seconds per channel rate. Acoustic emission was recorded continuously.

\section{Test Results}

The pressure test on SN: G6-4 cylinder was terminated at 19,000 Psi, at which time the specimen imploded. 
189

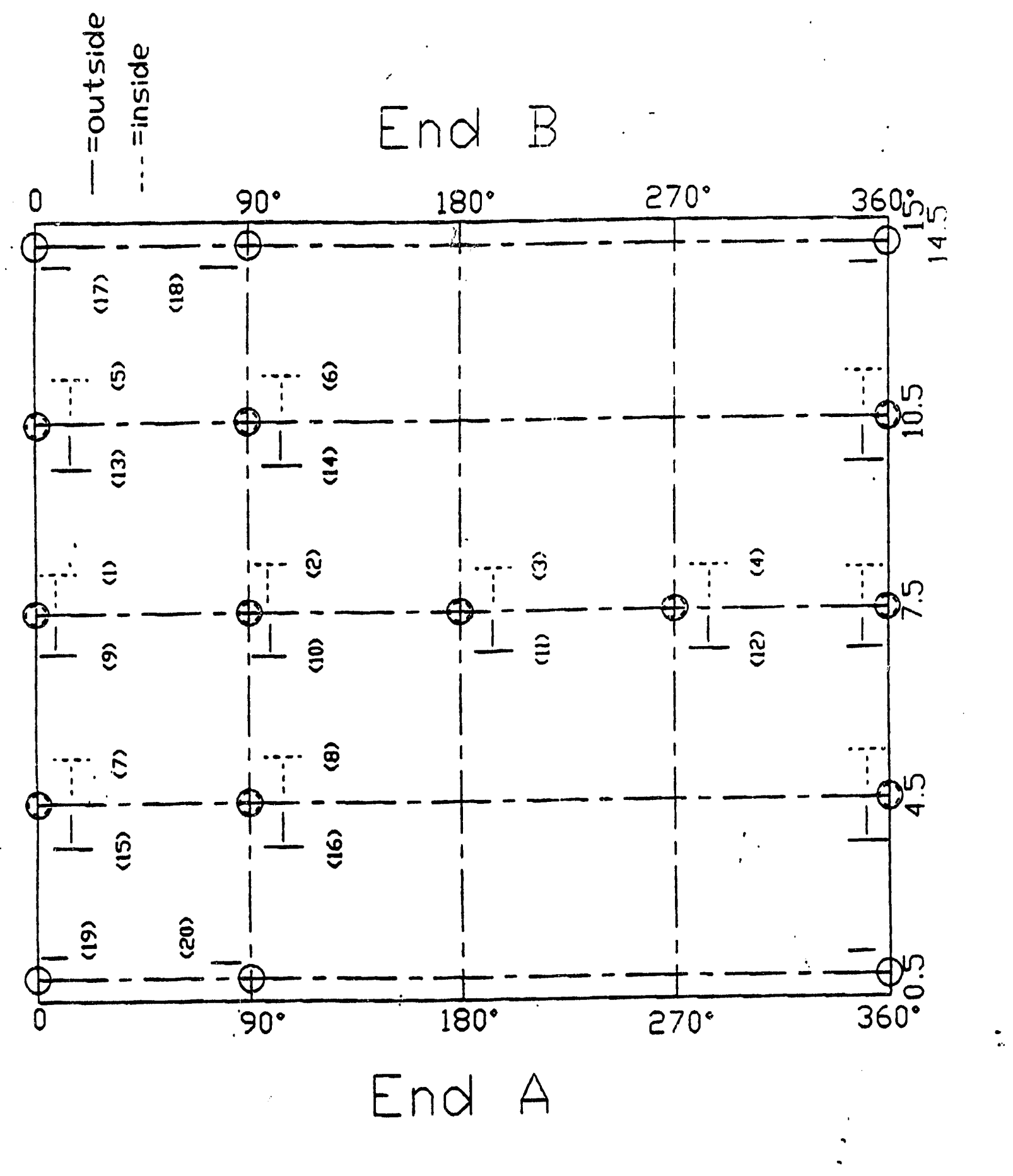

SKETCH. I

STRAIN GAGE LAY-DUT FOR G6-4 
190

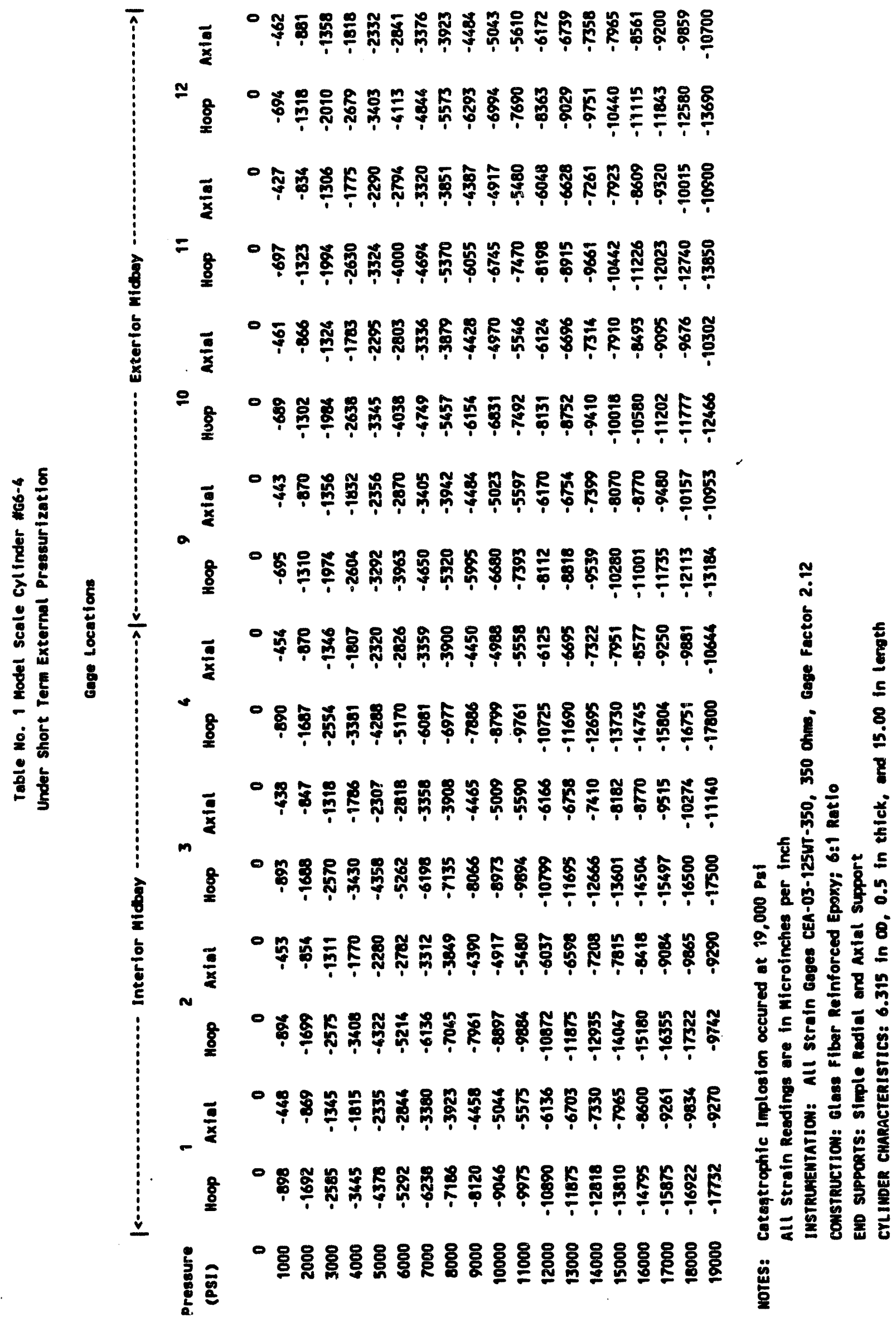




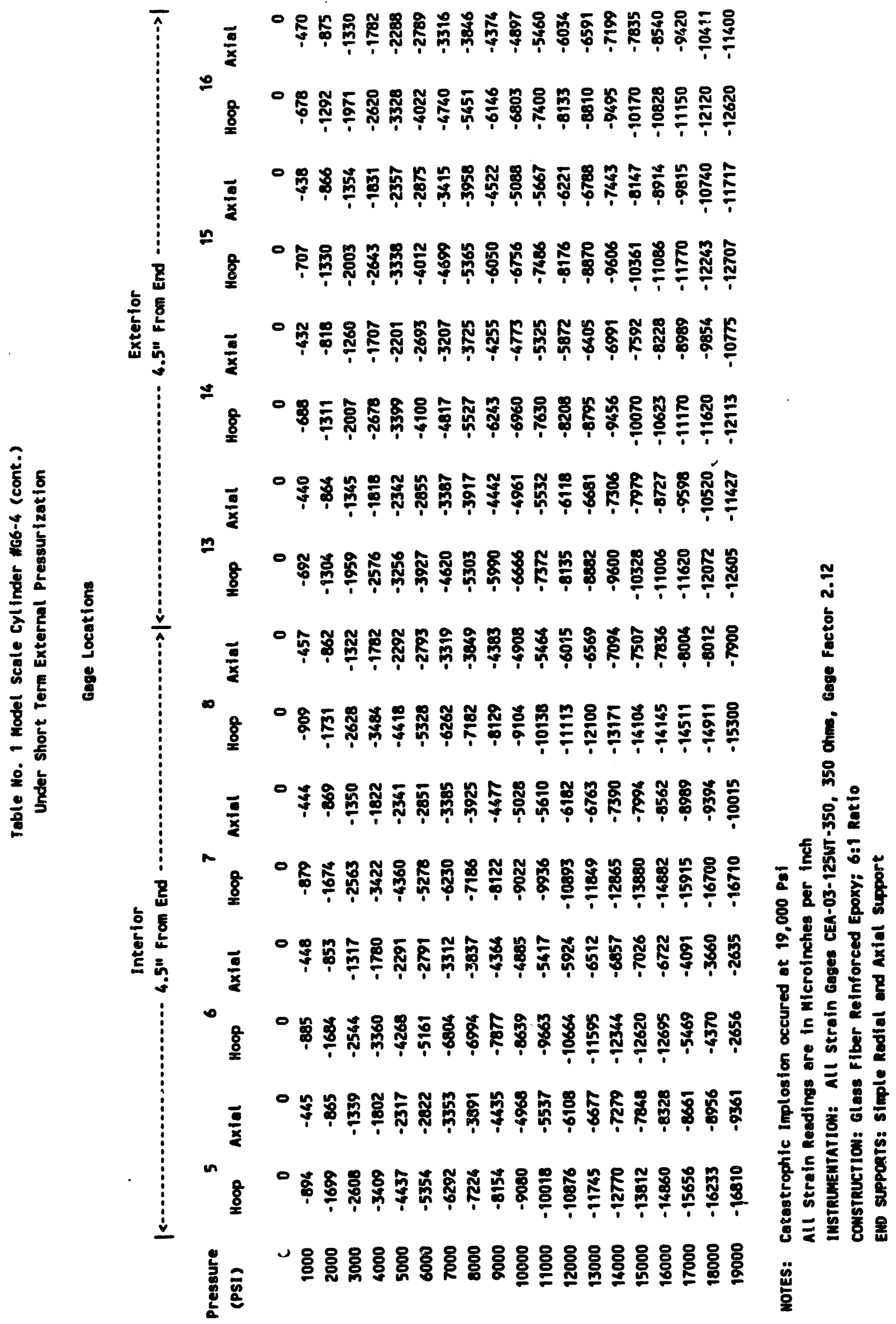




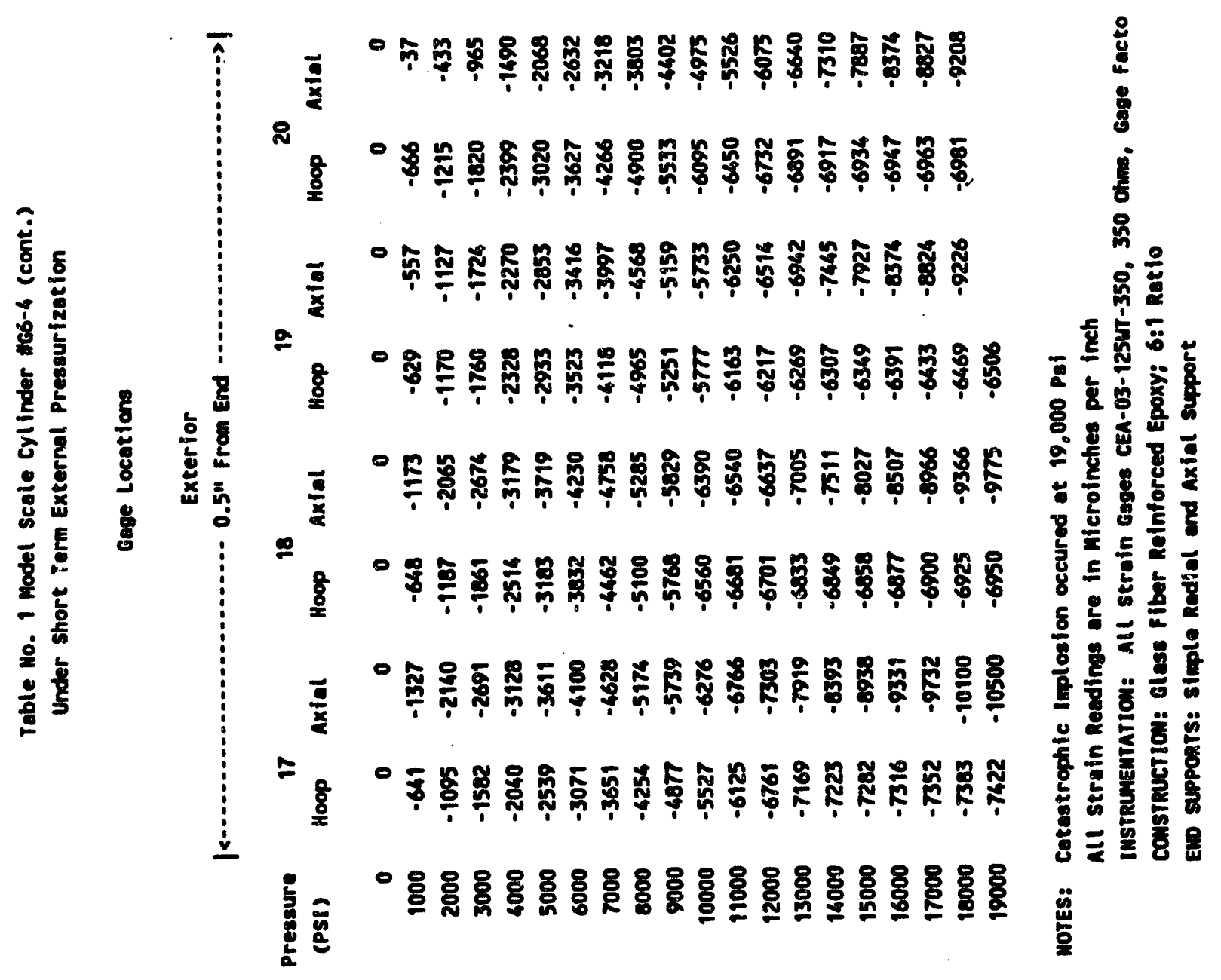


ACOUSTIC EMISSIONS DURING HYDROSTATIC TESTING

OF MODEL CYIINDER SN\# G6-4

\begin{tabular}{|c|c|c|c|c|}
\hline Pressure & Events & Time & & Noteis: \\
\hline 0000 & 0 & $9: 07$ & 1. & Transducer: AET ACI75 \\
\hline 1000 & 7 & $9: 09$ & & SN\# $7808 \quad 5$ to $200 \mathrm{kHz}$ \\
\hline 2000 & 18 & $9: 11$ & 2 & Amplifier setting: \\
\hline 3000 & $36-37$ & $9: 13$ & & Rate: $\mathbf{T}$ \\
\hline 4000 & 50 & $9: 16$ & & Gain: $60 \mathrm{DB}$ \\
\hline 5000 & 52 & $9: 18$ & & Threshold: Automatic \\
\hline 6000 & 58 & $9: 21$ & & Function: Events \\
\hline 7000 & 58 & $9: 23$ & 3. & Recorder: \\
\hline 8000 & $63-64$ & $9: 26$ & & Channel "A" Events, \\
\hline 9000 & $73-77$ & $9: 29$ & & 2000 Full Range \\
\hline 10000 & $83-84$ & $9: 31$ & & Channel "B" Rms, \\
\hline 11000 & 86 & $9: 34$ & & 50 MV Full scale, \\
\hline 12000 & 95 & $9: 37$ & & $0.5 \mathrm{CM} / \mathrm{Min}$ Chart scale \\
\hline 13000 & 96 & $9: 39$ & 4 & Events Scale: 1 \\
\hline 14000 & $98-99$ & $9: 42$ & & \\
\hline 15000 & 106 & $9: 44$ & & \\
\hline 16000 & 106 & $9: 47$ & & \\
\hline 17000 & $109-120$ & $9: 50$ & & \\
\hline 18000 & $166-293$ & $9: 53$ & & \\
\hline 19000 & $558-1553$ & $9: 56$ & & \\
\hline
\end{tabular}

Failed at 19,000 psig 


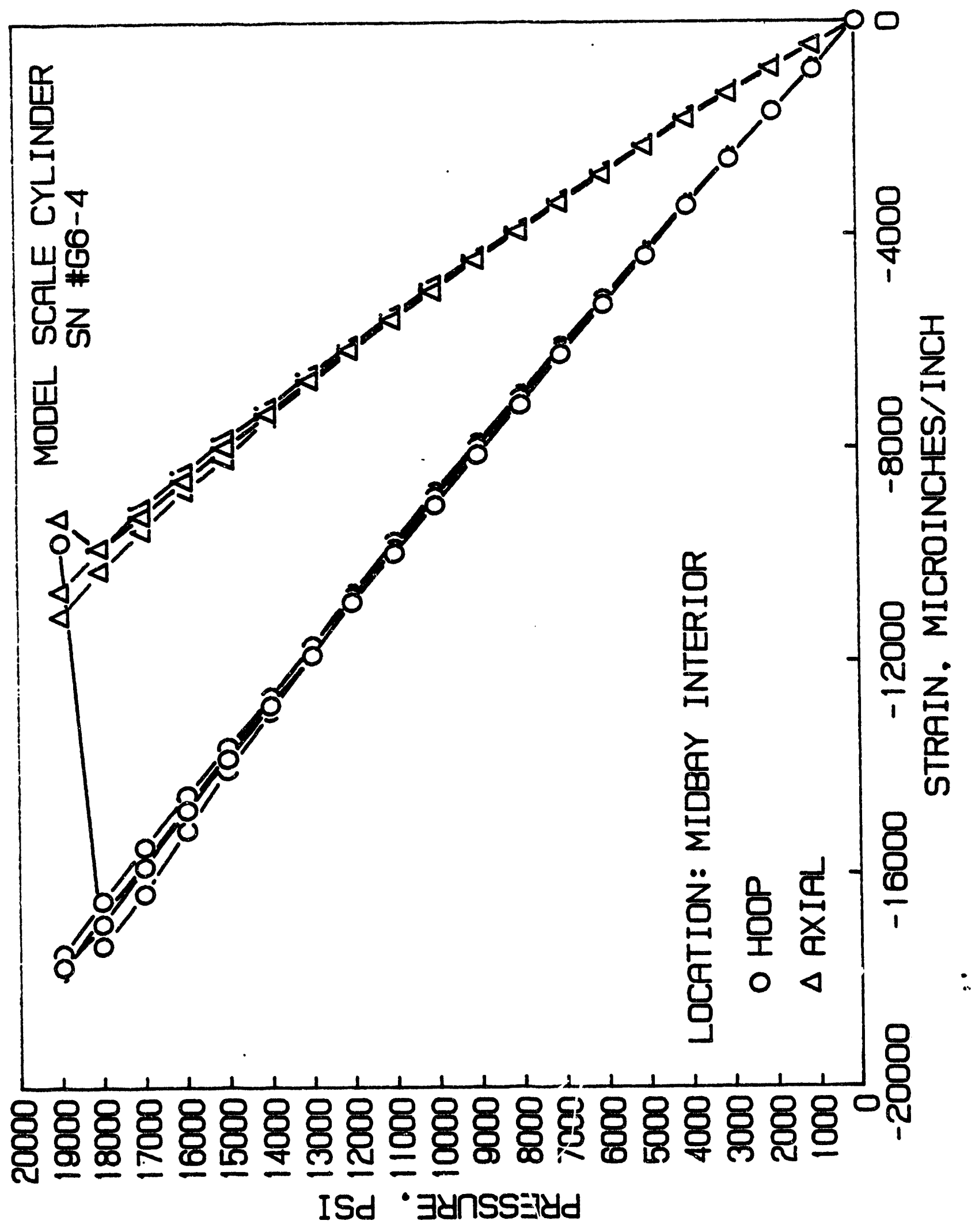




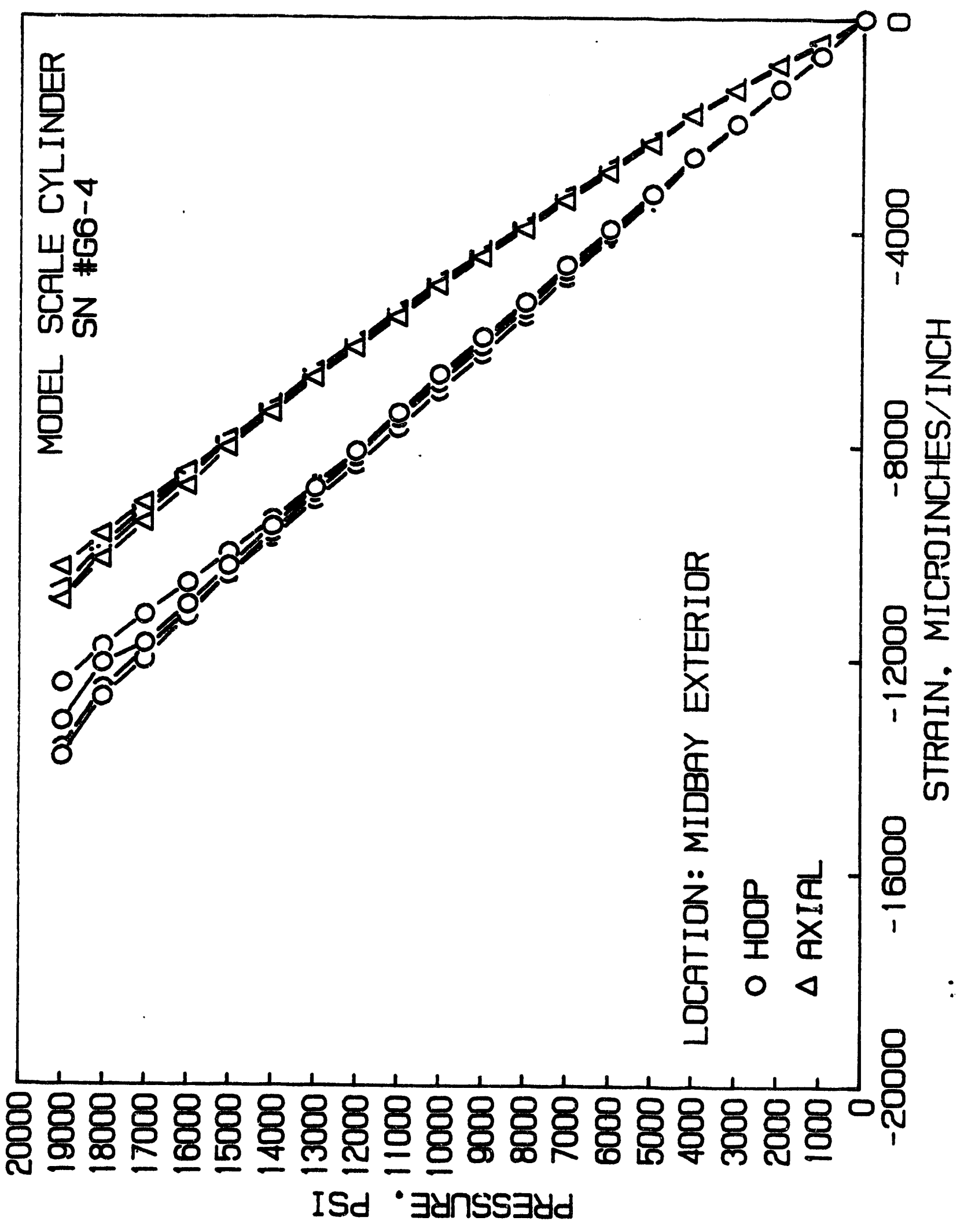




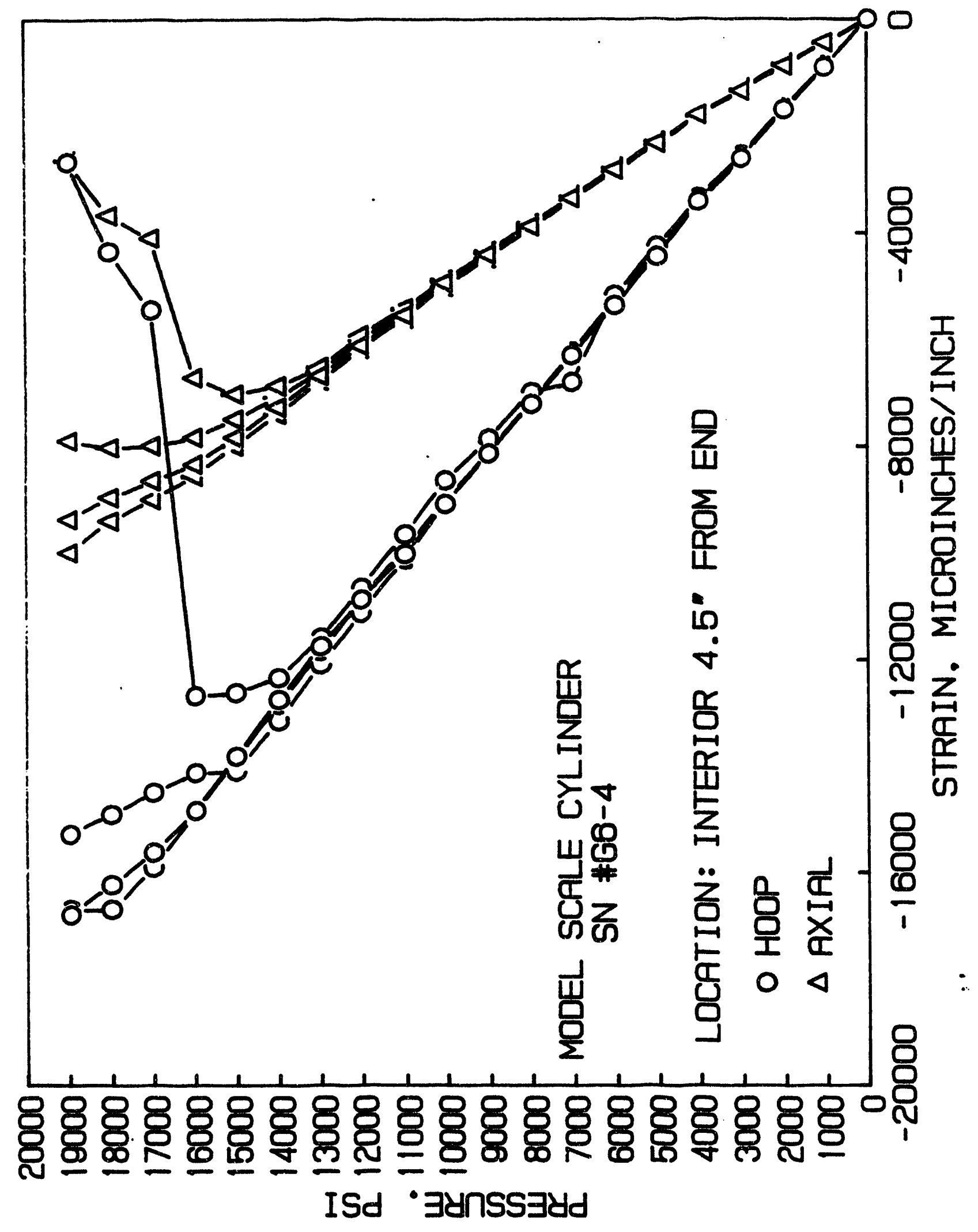




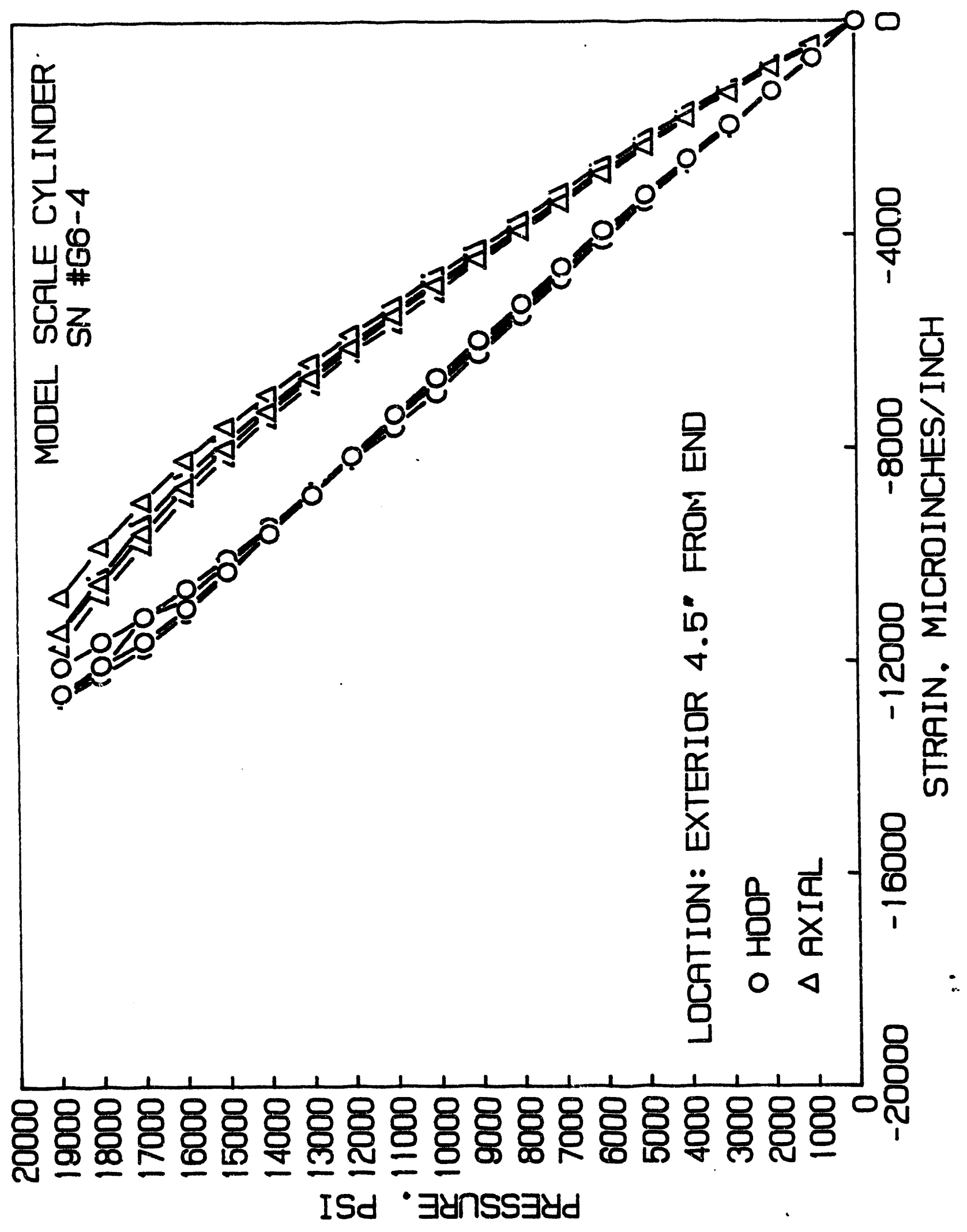




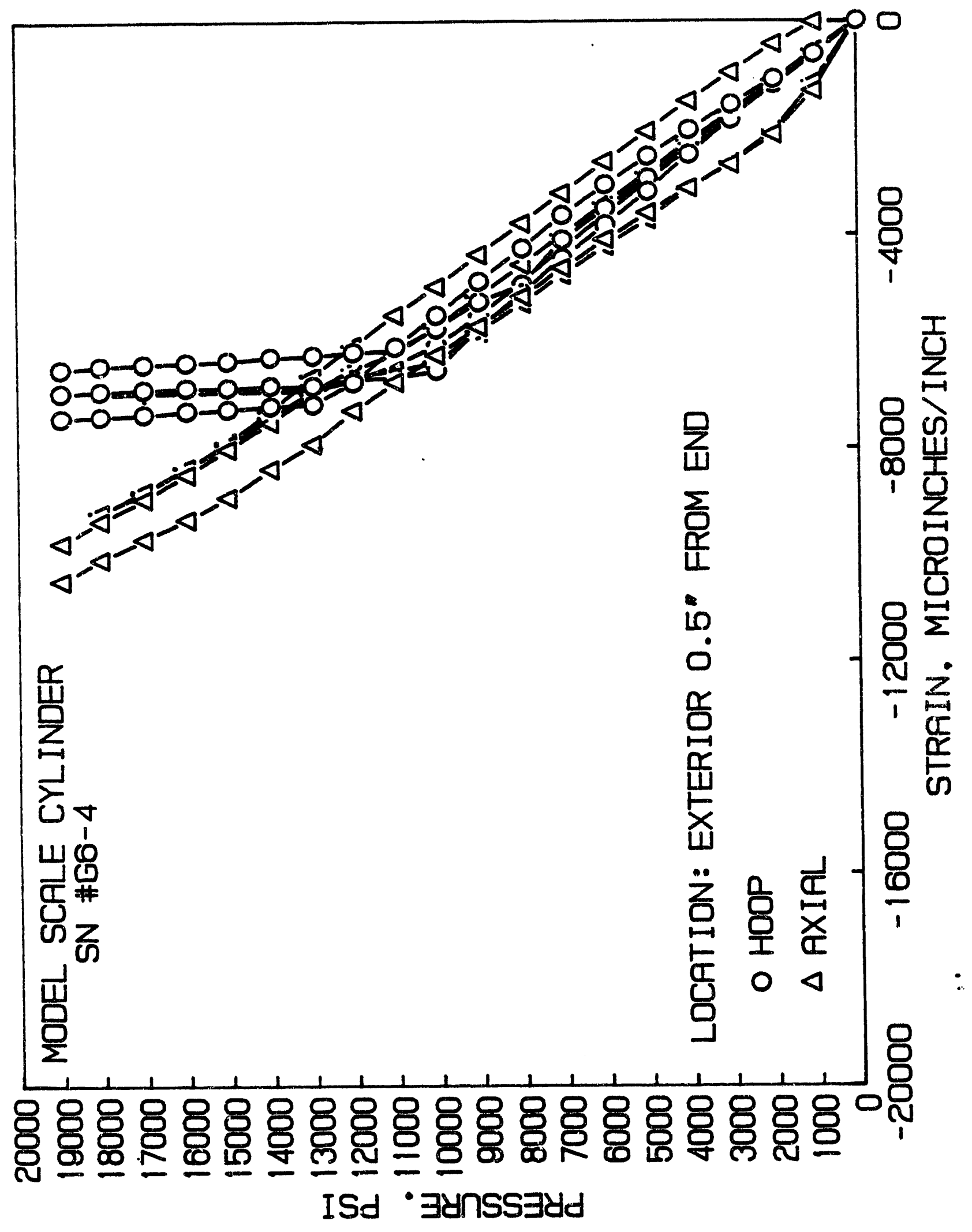




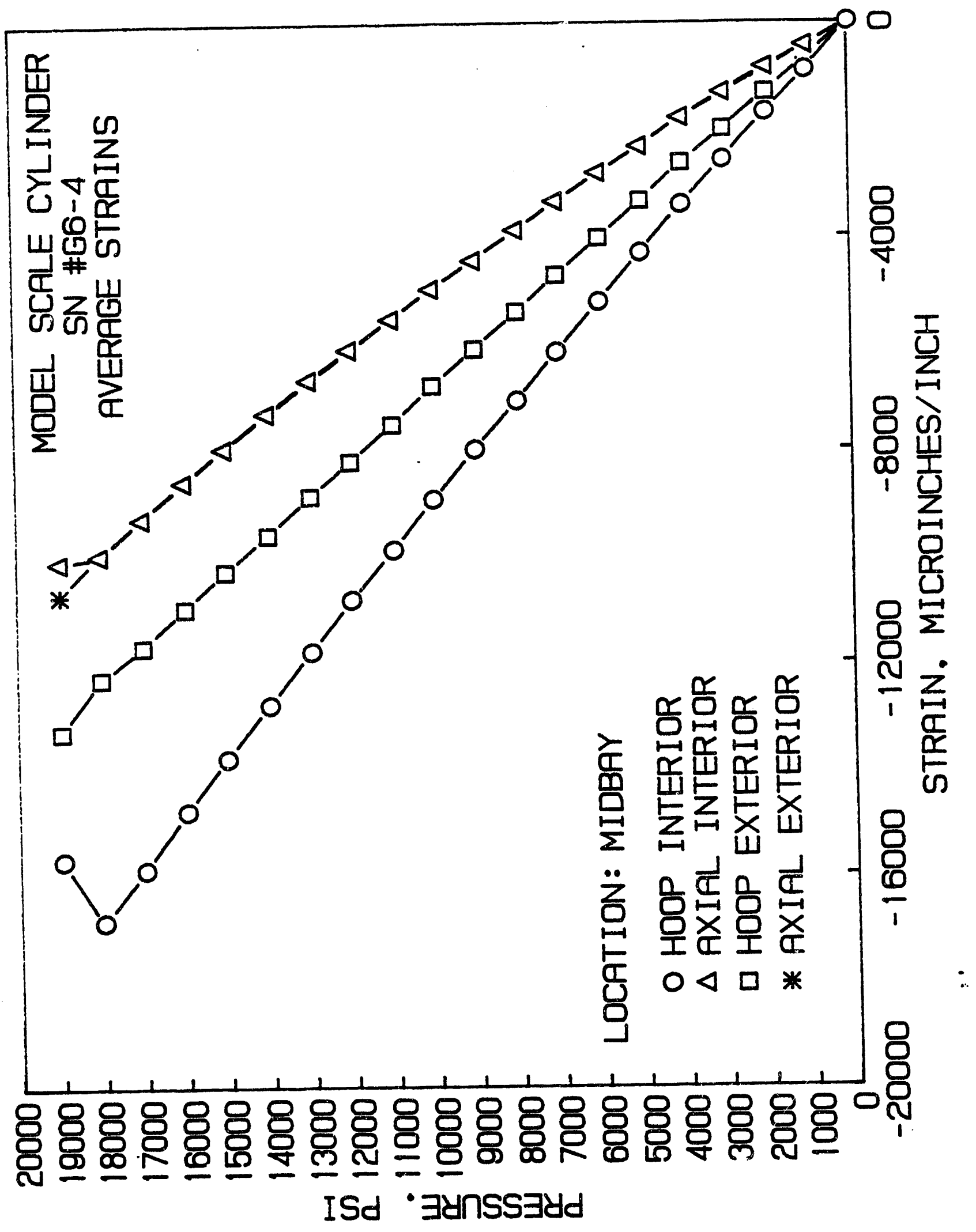




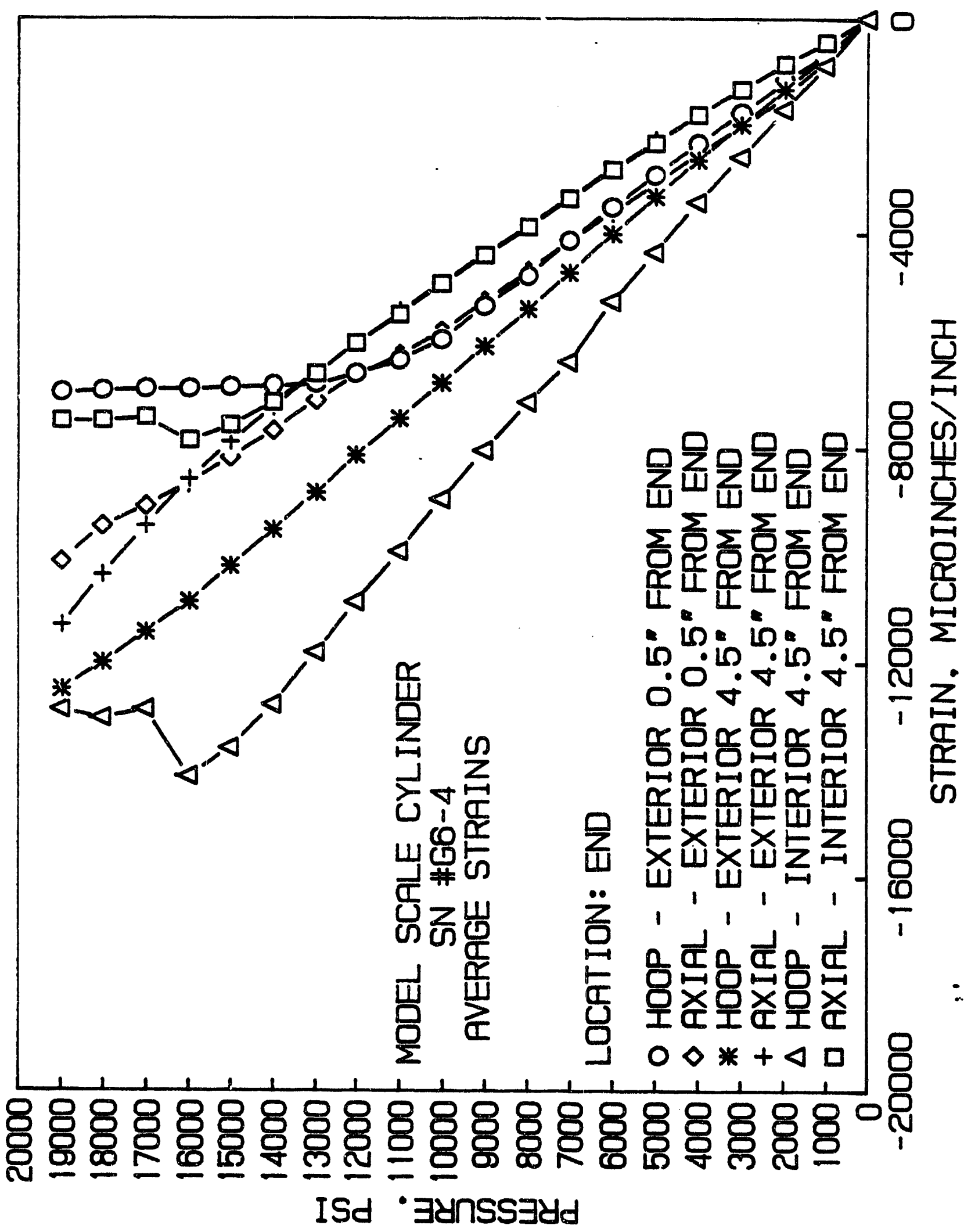




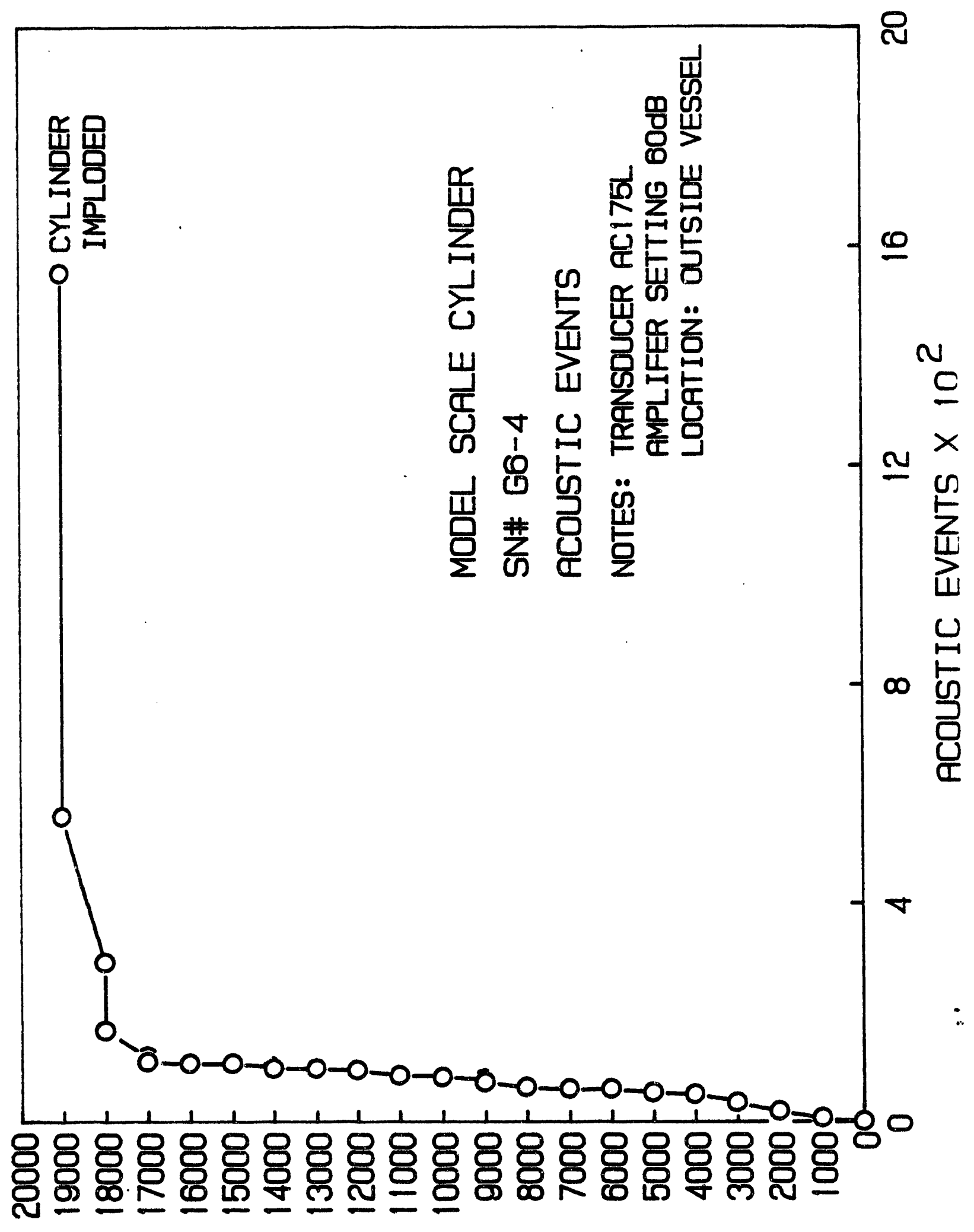




\section{HYDROSPACE ENGINEERING SERVICES}

Test Report for Cylinder C6-4 
August 3, 1991

\section{TE8T REPORT}

\section{Instrumentation}

The cylinder was instrumented with 0.125 inch electric resistance straingage rosettes. The acoustic emission detector was bonded to the outside of the pressure vessel. The ORNL C6-4 cylinder was instrumented with a total of 20 strain gage rosettes (four of which only the hoop orientation were used). The rosettes were affixed to the cylinder as shown on the attached diagram supplied by the Dr. Mike starbuck of the Oak Ridge National Laboratory.

\section{Test Procedure}

The cylinder was tested in a 10 inch ID pressure vessel with 20,000 psi pressure capability. The pressurizing medium was Tellus 30 oil. Pressurization was accomplished with an air operated pump raising the pressure inside the vessel at 2,000 psi/minute rate. Pressurization was interrupted at 1,000 psi intervals and strains recorded at 2 seconds per channel rate. Acoustic emission was recorded continuously.

\section{Test Results}

The pressure test on SN\# c6-4 cylinder was terminated at 9,000 Psi, at which time the specimen imploded. 
204

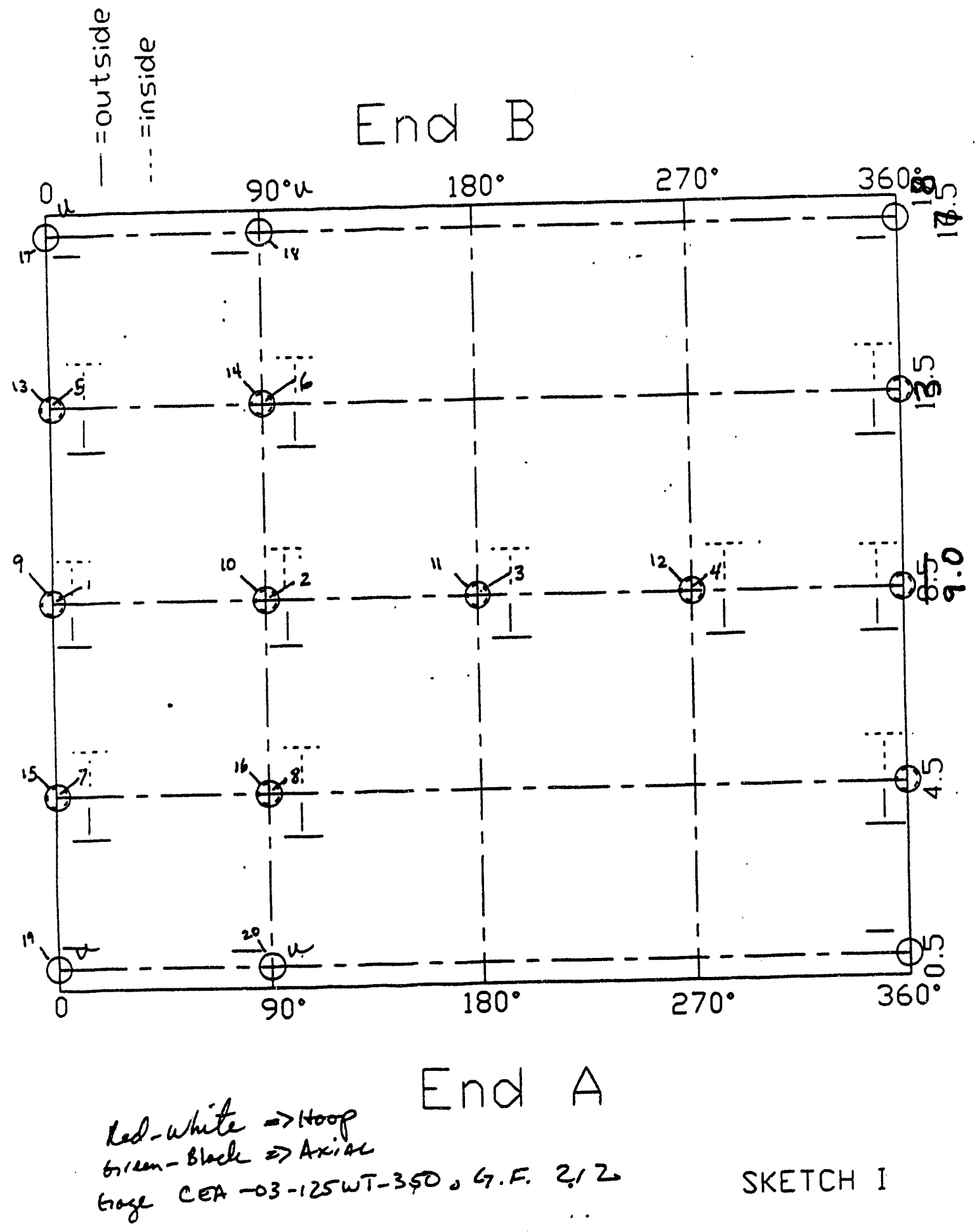




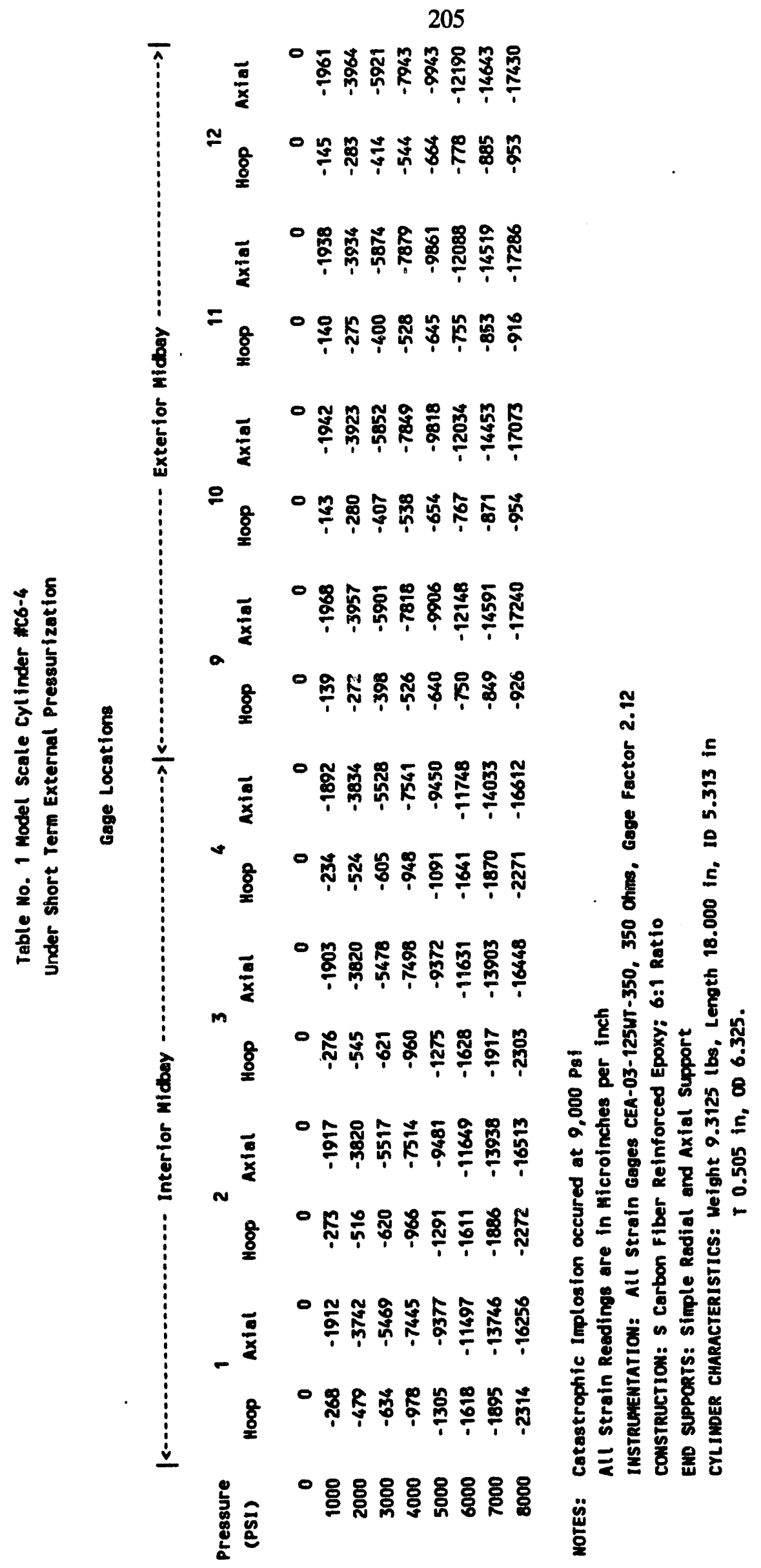




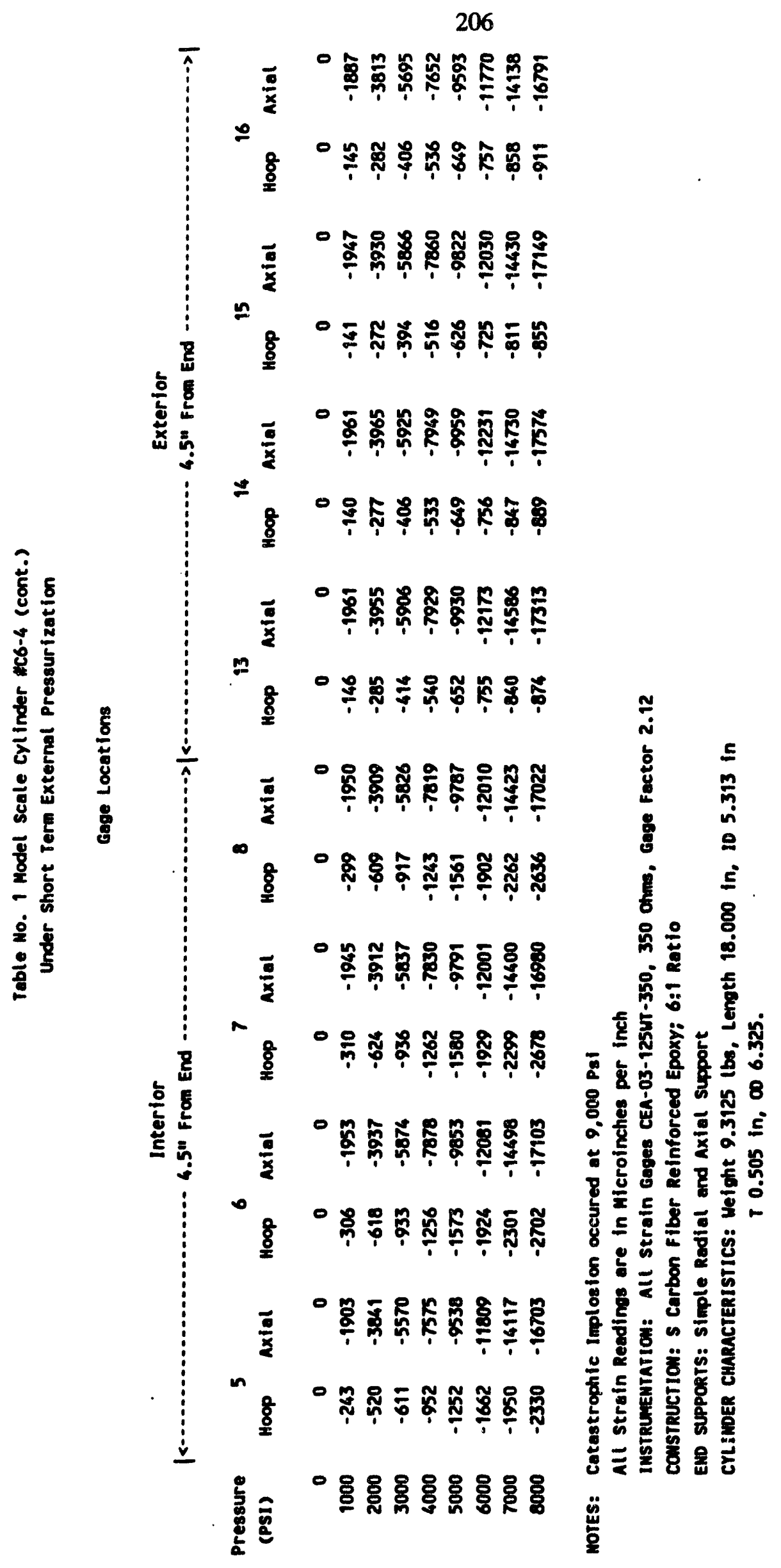




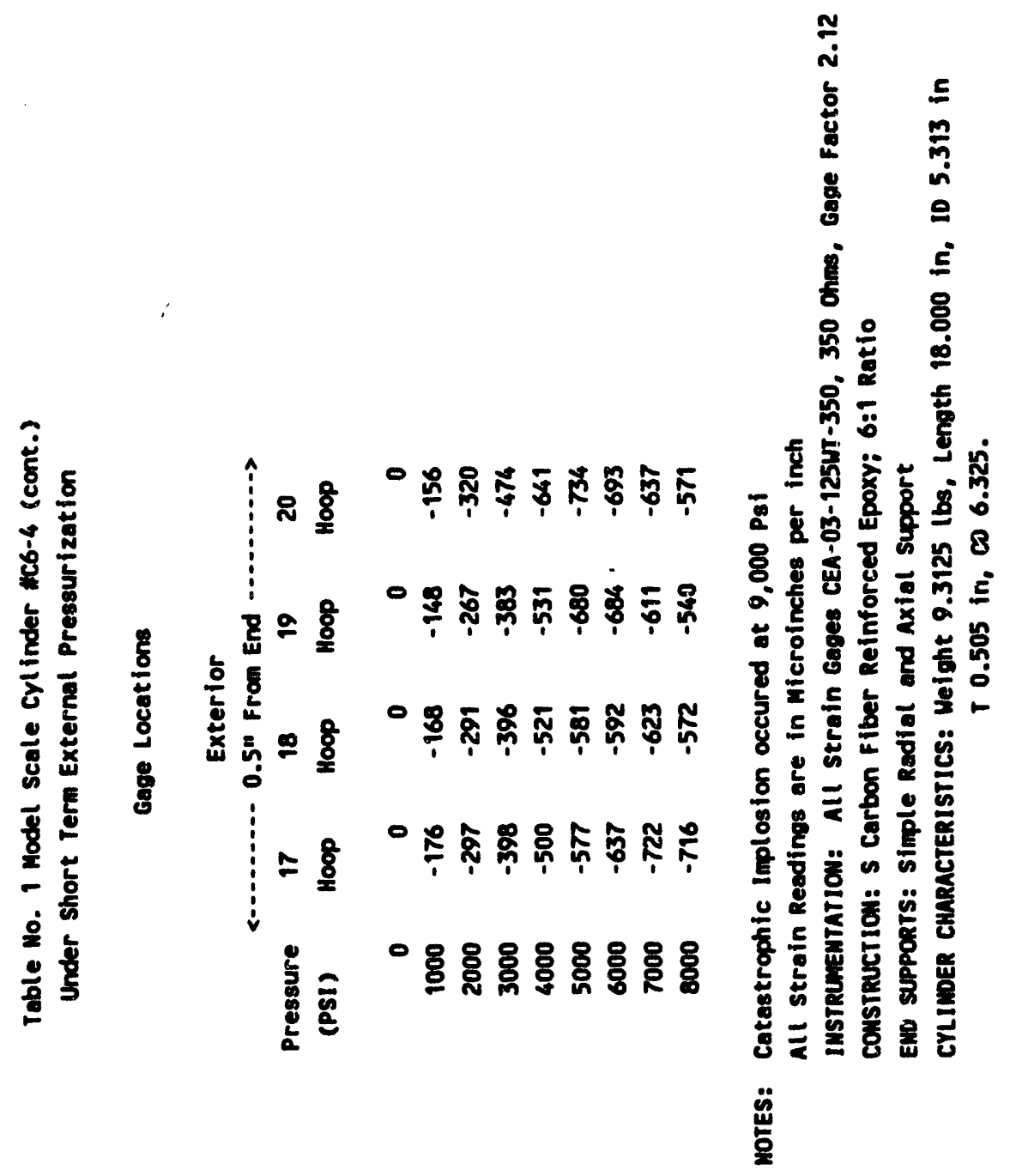


ACOUSTIC EMISSIONS DURING HYDROSTATIC TESTING OF MODEL CYLINDER SN \#6-4

$\begin{array}{lcccc}\begin{array}{l}\text { Pressuration \# } \\ \text { Pressure }\end{array} & \text { Events } & \text { Time } & \text { Notes: } \\ 0000 & 0 & 9: 55 & 1 . & \text { Transducer: AET AC175 } \\ 1000 & 0-0 & 9: 54 & \text { SN\# } 7799 \text { 5 to } 200 \mathrm{KHZ} \\ 2000 & 0-0 & 9: 57 & 2 \text {. Amplifer Setting: } \\ 3000 & 0-0 & 10: 00 & \text { Rate: T } \\ 4000 & 0-0 & 10: 03 & \text { Gain: } 60 \text { DB } \\ 5000 & 0-0 & 10: 06 & \text { Threshold: Automatic } \\ 6000 & 4-4 & 10: 09 & \text { Function: Events } \\ 7000 & 14-14 & 10: 12 & 3: \text { Recorder: } \\ 8000 & 57-68 & 10: 16 & \text { Channel "A" Events, } \\ 9000 & 102 & 10: 20 & 4000 \text { Full Range } \\ & & & \text { Channel "B" Rms, } \\ & & & 50 \text { MV Full Scale, } \\ & & & \text { 0.5 CY/Min Chart Scale }\end{array}$

Failed at 9,000 psig 


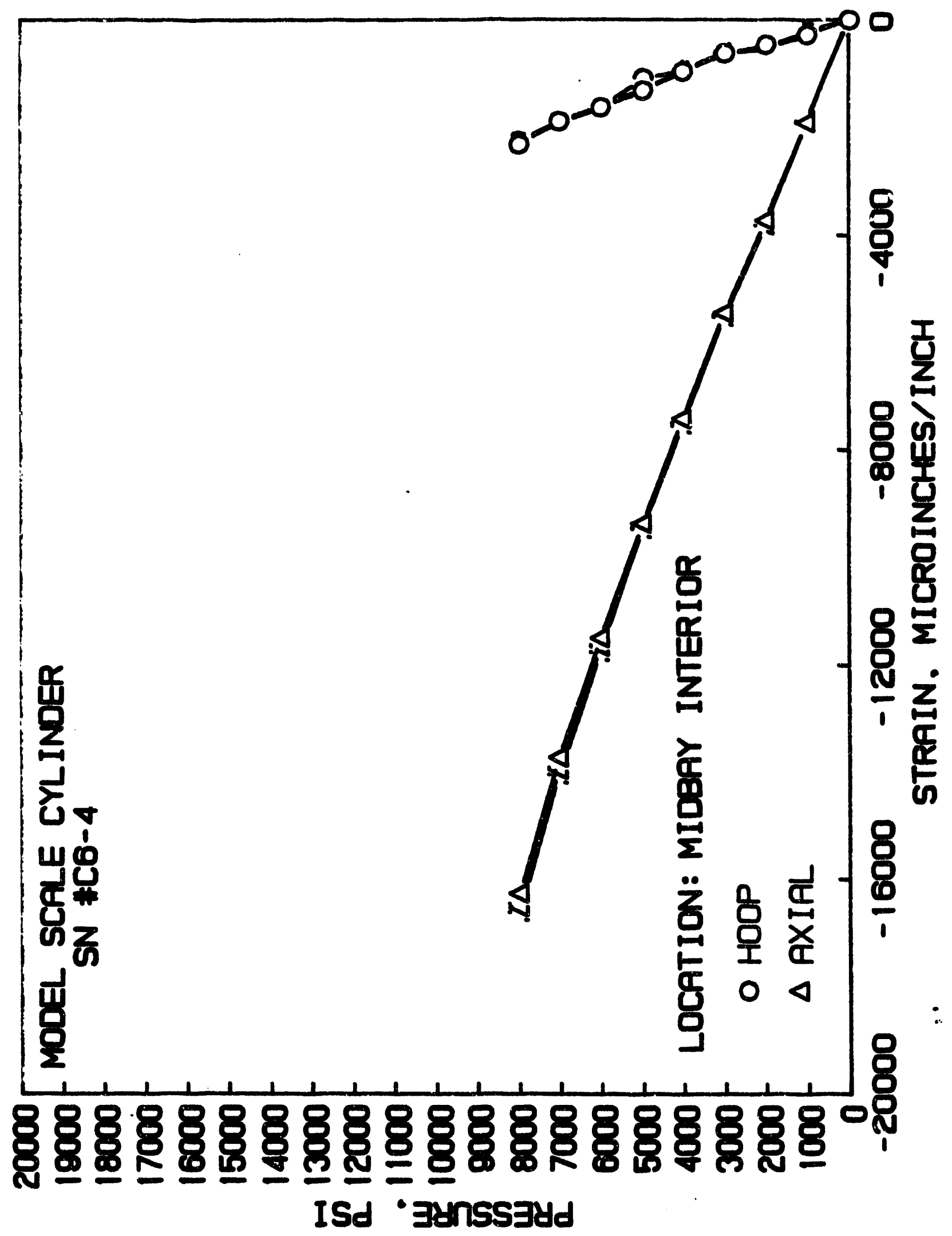




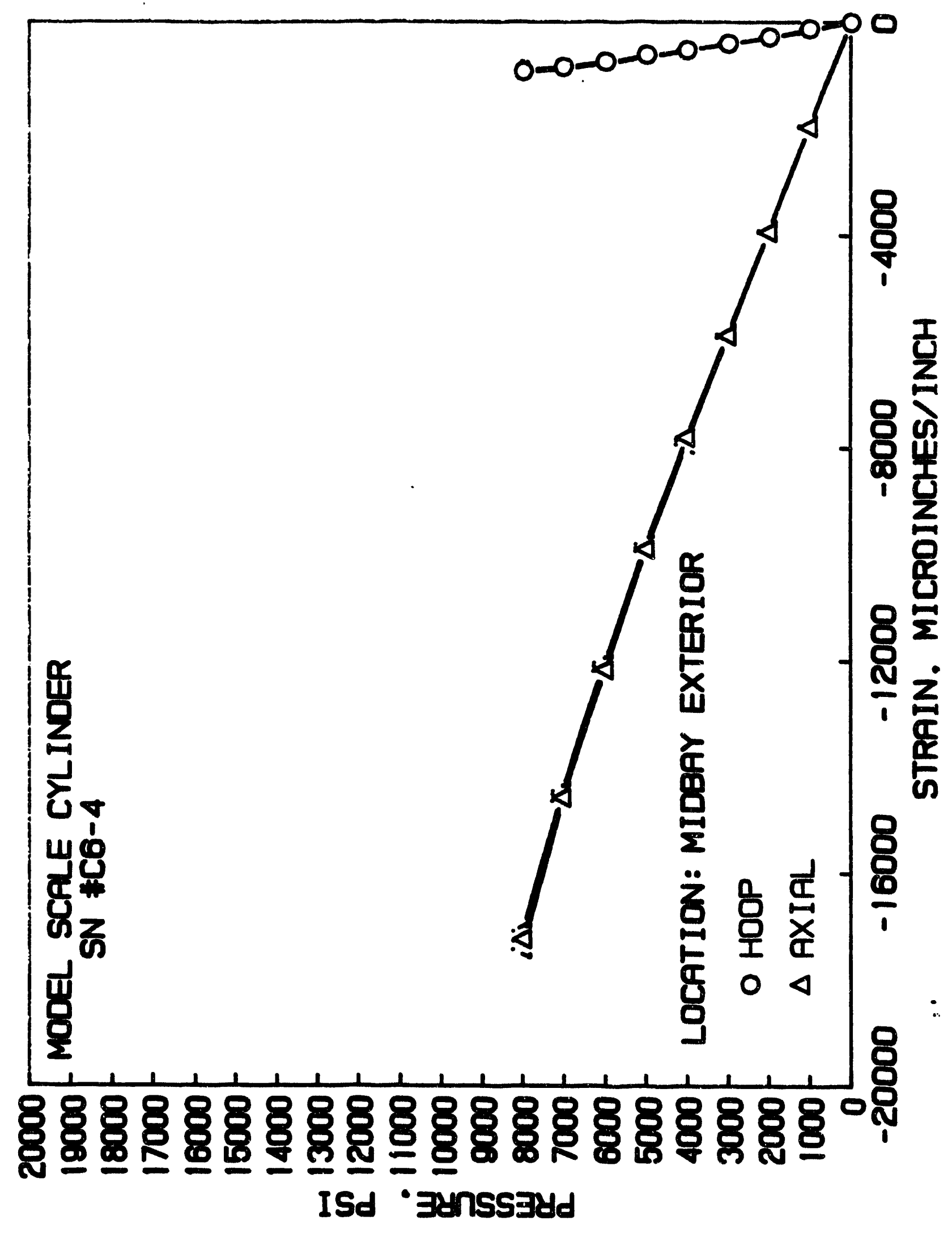




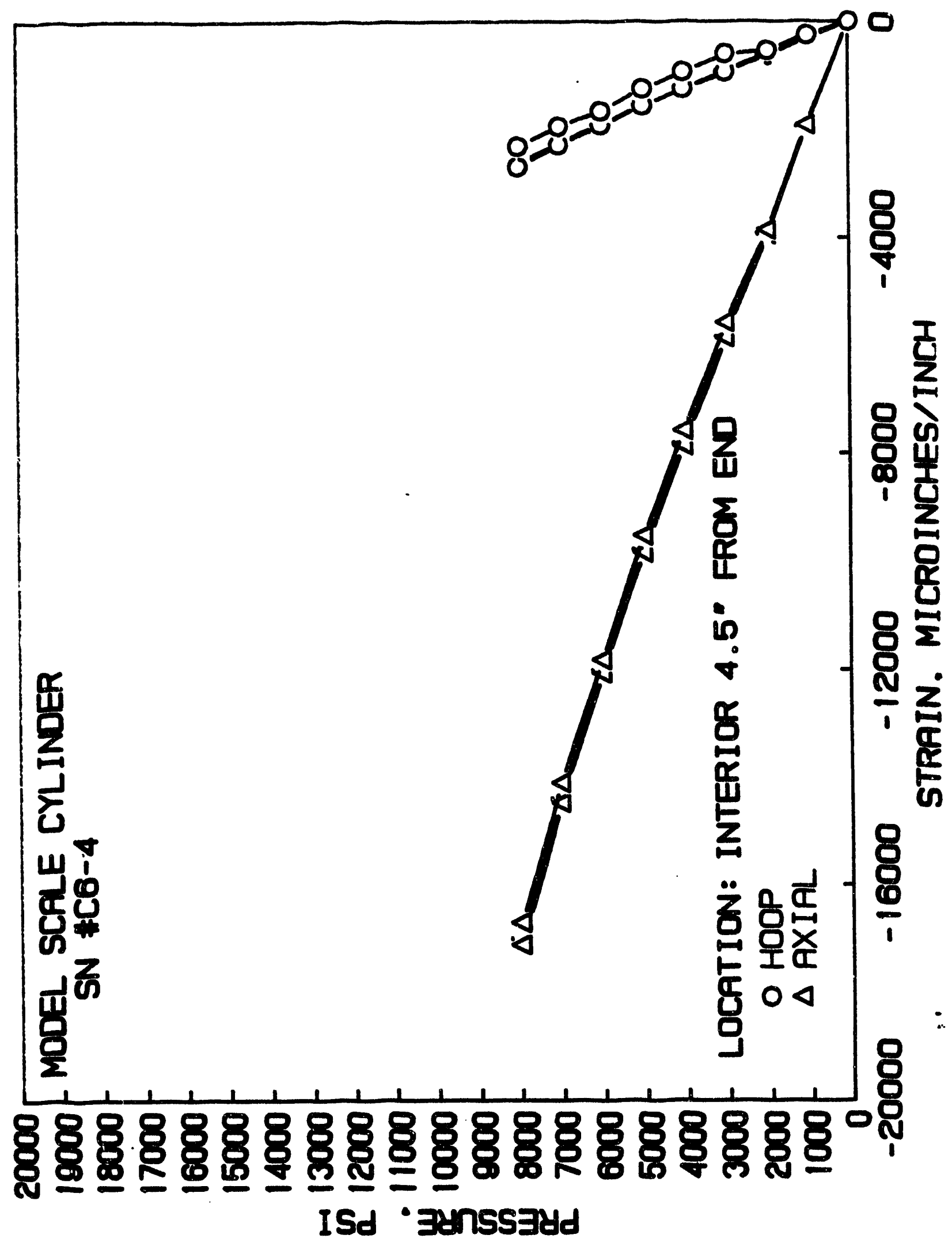




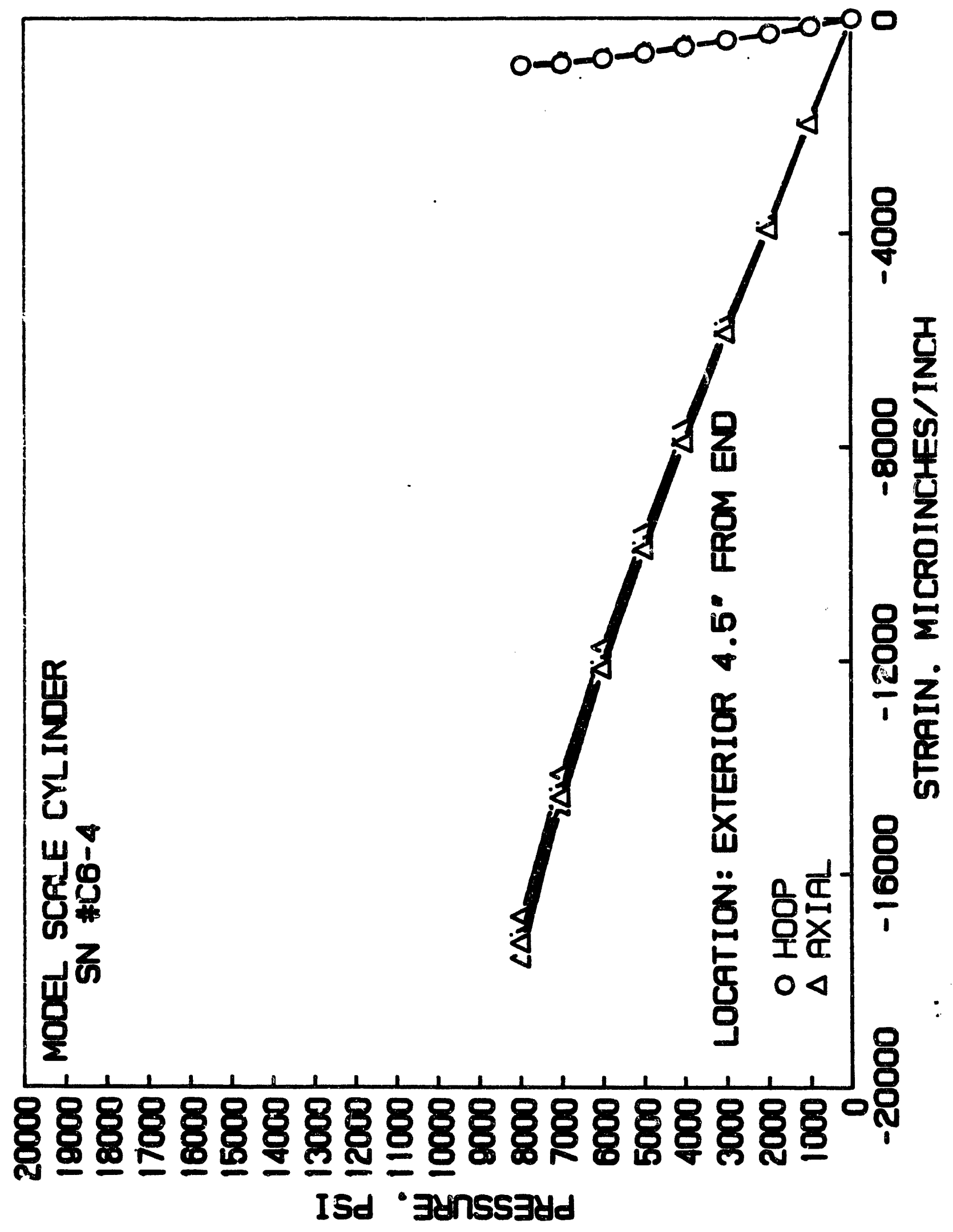




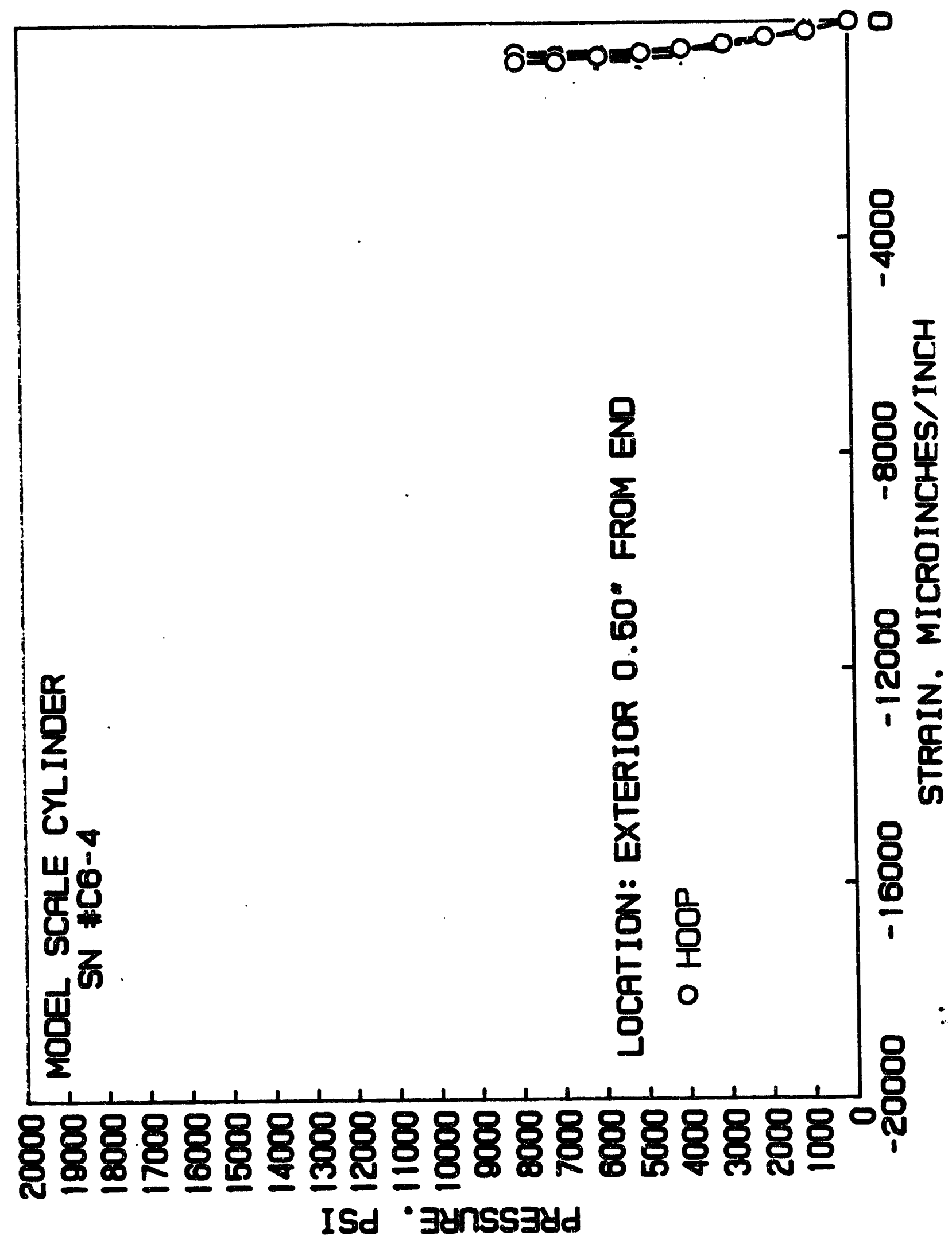




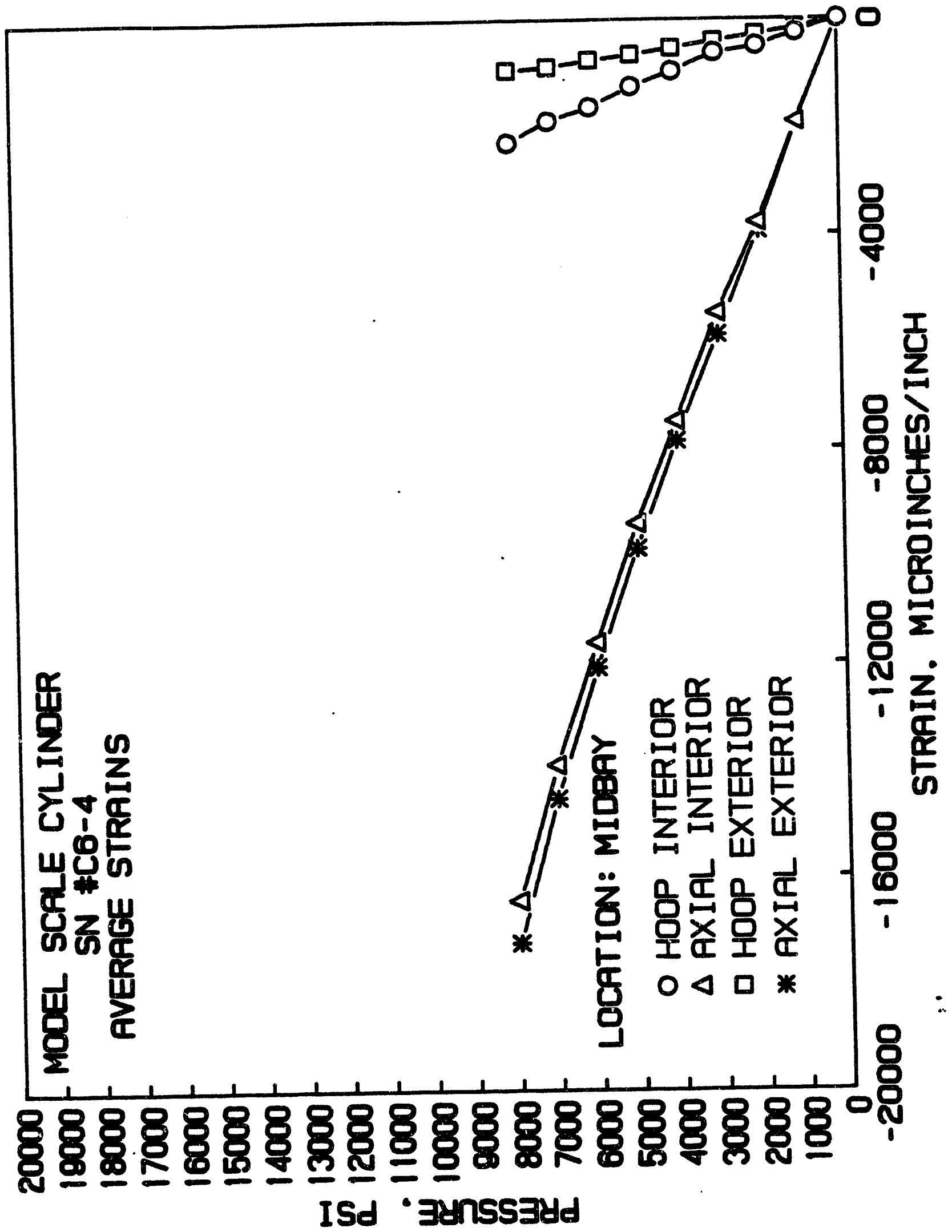




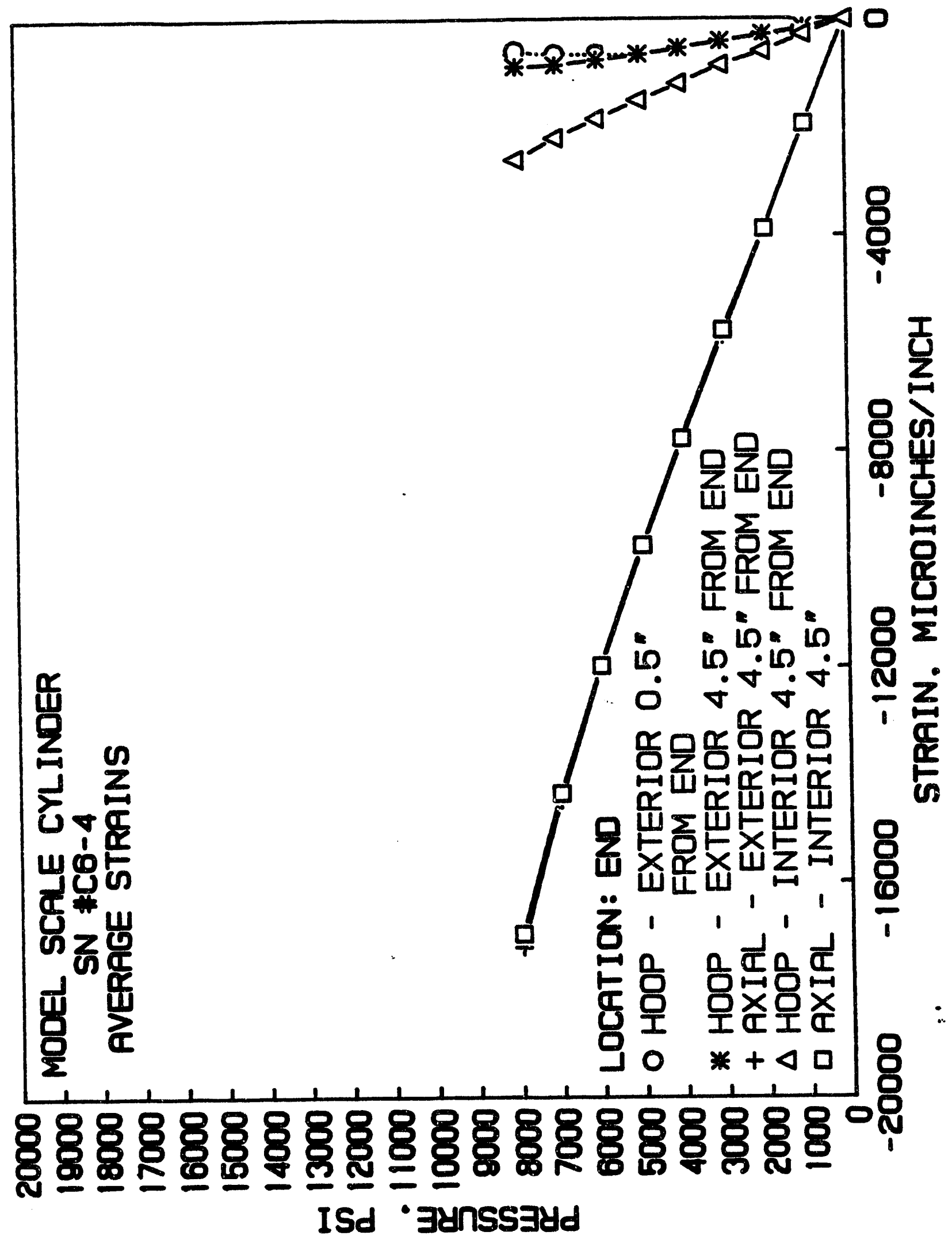




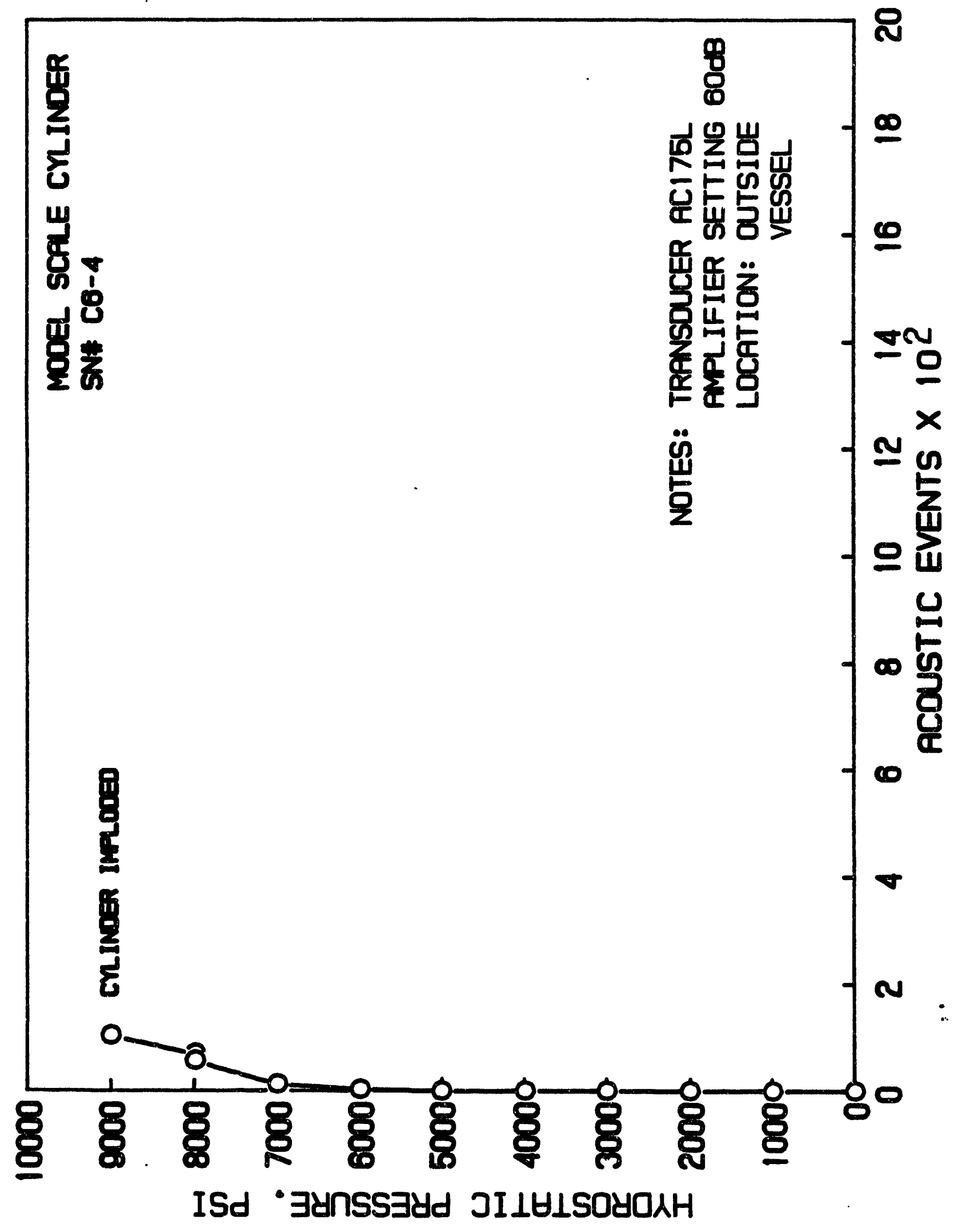




\section{REFERENCES}

1. H. J. Garala, Structural Evaluation of Externally Pressurized, 4-Inch Diameter, Graphite Composite Cylinders, NDW-DTNSRDC 4610/3 (Rev. 3-80), David Taylor Naval Ship Research and Development Center, Bethesda, MD 20094-5000, Aug. 1984.

2. H. J. Garala, Experimental Evaluation of Graphite-Epoxy Composite Cylinders Subjected to Hydrostatic Compression Loading, Society of Experimental Mechanics.

3. H. J. Garala, Structural Evaluation of 8-Inch Diameter Graphite-Epoxy Composite Cylinders Subjected to External Hydrostatic Compressive Loading, DTRC-89/016, Ship Structures and Protection Department, David Taylor Research Center, Bethesda, MD 20084-5000, Sep. 1989.

4. J. S. Mayes, Preliminary Consideration for Developing Designs of Composite, Ring-Stiffened Cylinders Under Hydro-Static Loading, DTRC-SSPD-91-172-41, Ship Structures and Protection Department, David Taylor Research Center, Bethesda, MD 20084-5000, Apr. 1991.

5. Z. Hashin, "Failure Criteria for Unidirectional Fiber Composites," I. Appl. Mech., Vol. 47, pp. 329-334, Jun. 1980.

6. H. W. Blake and J. M. Starbuck, Hydrostatic Pressure Testing of Graphite/Epoxy Cylinder C6-1, ORNL/ATD-63, Oak Ridge National Laboratory, Martin Marietta Energy Systems, Inc., Jul. 1992.

7. J. J. Kibler, CLASS - Composite Laminate Analysis Systems, MSC TIR 1801, Material Sciences Corporation, Blue Bell, PA 19422, 1986.

8. J. Goering, NDPROP - N Direction Composite Effective Property Program, MSC TIR 1506, Material Sciences Corporation, Blue Bell, PA 19422, Jul. 1984.

9. University of Delaware Engineering Research Center for Composites Manufacturing Science and Engineering, Users Manual for CYLAN - Cylinder Analysis, Technomic Publishing Co., Inc., Lancaster, PA 17604, Aug. 1987.

10. J. O. Hallquist, NIKE2D - A Vectorized, Implicit, Finite Deformation, Finite Element Code for Analyzing the Static and Dynamic Response of 2-D Solids, UCID-19677, Lawrence Livermore National Laboratory, Feb. 1983.

11. M. W. Hyer, "Hydrostatic Response of Thick Laminated Composite Cylinders," Jrl. Reinforced Plastics \& Composites, Vol. 7, pp. 255-262, Aug. 1988.

12. H. W. Blake, H. J. Grimsby, J. M. Starbuck, and D. E. Welch, Development of Performance Models for Thick Composites in Compression, ORNL/ATD-62, Oak Ridge National Laboratory, Martin Marietta Energy Systems, Inc., Nov. 1991.

13. V. Z. Vlasov, General Theory of Shells and Its Applications in Engineering, NASA Technical Translation, NASA TTF-99, 1964. 
14. S. A. Ambartsumyan, Theory of Anisotropic Shells, NASA Technical Translation, NASA TTF-118, 1964.

15. J. M. Whitney, "On the Use of Shell Theory for Determining Stresses in Composite Cylinders," J. Comp. Matl., Vol. 5, pp. 340-353, Jul. 1971.

16. J. O. Hallquist, MAZE - An Input Generator for DYNA2D and NIKE2D, UCID-19029, Rev. 2, Lawrence Livermore National Laboratory, Jun. 1983.

17. J. O. Hallquist, ORION - An Interactive Post-Processor for the Analysis Codes NIKE2D, DYNA2D, and TACO2D, UCID-19310, Rev. 1, Lawerence Livermore Laboratory, Jul. 1983.

18. H. W. Blake and J. M. Starbuck, "Shear Deflection Theory for Analysis of End Plugs for External Pressure Tests of Composite Cylinders", ASTM Symposium on Compression Response of Composite Structures, Nov. 16-17, 1992, Miami, Florida, (to be published).

19. S. B. Dong, K. S. Pister, and R. L. Taylor, "On the Theory of Laminated Anisotropic Shells and Plates," Jrl. Aero. Sci., pp. 969-975, Aug. 1962.

20. A. P. Christoforou and S. R. Swanson, "Analysis of Simply-Supported Orthotropic Cylindrical Shells Subject to Lateral Impact Loads," Jrl. Appl. Mech., Trans. of ASME, Vol. 57, pp. 376-382, Jun. 1990.

21. W. Flügge, Stresses in Shells, Springer-Verlag, New York, 1967.

22. S. W. Tsai and E. M. Wu, "A General Theory of Strength for Anisotropic Materials," J. Comp. Matl., Vol. 5, p. 58, 1971.

23. R. J. Miller, "End Plugs for External Pressure Tests of Composite Cylinders," ASTM STP 460, American Society for Testing and Materials, 1969.

24. J. M. Starbuck and H. W. Blake, "A Performance Model of Thick Composite Cylinders Subjected to External Hydrostatic Pressure", ASTM Symposium on Compression Response of Composite Structures, Nov. 16-17, 1992, Miami, Florida, (to be published). 


\section{ACKNOWLEDGEMENTS}

The authors with to thank Dr. Jerry Stachiw of Stachiw Associates for the assembly and testing of the cylinders. Special thanks are also extended to Dr. Joan Stachiw, Cynthia Cesena and Mark Cesena for their assistance in conducting the tests and for recording and compiling the data.

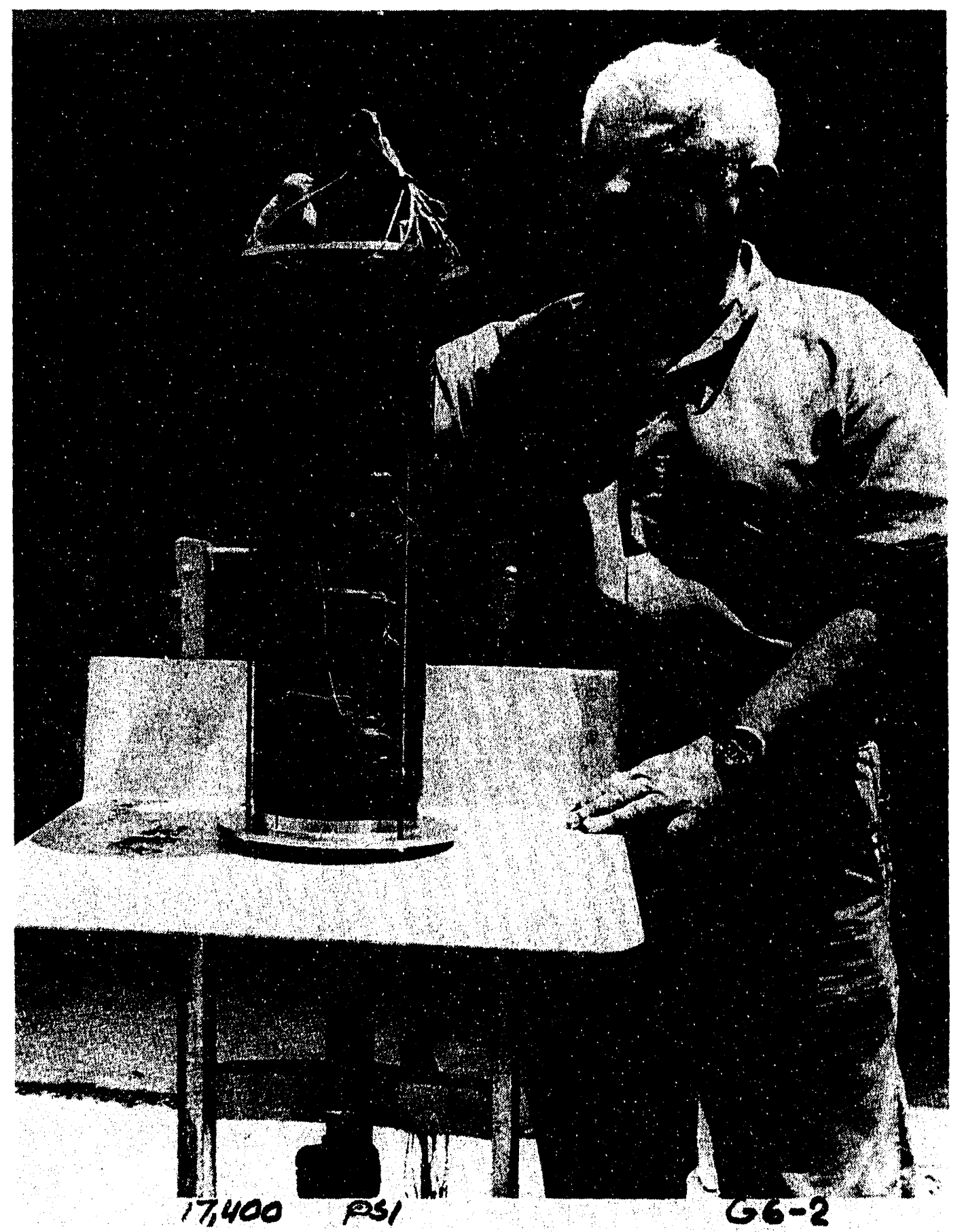




\section{DISTRIBUTION}

\section{Martin Marietta Energy Systems, Inc.}

B. R. Appleton

H. W. Blake (10)

R. G. Boeman

R. S. Carismith

J. L. Cook

J. M. Corum

B. J. Frame

W. Fulkerson

J. G. Hansen

D. R. Johnson

J. E. Jones Jr.

W. S. Key

W. R. Martin

W. C. McWhorter

R. O. Meyers

R. E. Norris

D. U. O'Kain

J. T. Shaffer

B. B. Smith

J. M. Starbuck

J. O. Stiegler

A. J. Szady

R. C. Ward

D. A. Waters

Y. J. Weitsman

D. E. Welch

G. E. Wrenn

R. E. Ziegler

A. Zucker

Manager, Laboratory Directed Research and Development

Laboratory Records - RC

Laboratory Records Department (2)

Central Research Library

Applied Technology Library

Department of Energy Field Office, Oak Ridge

Assistant Manager, Energy Research and Development 


\section{Extemal Distribution}

M. G. Abdallah, Hercules Advanced Materials and Systems Company, Mail Stop 2343L, P. O. Box 98, Magna, Utah 84044-0098

D. F. Adams, Mechanical Engineering Department, Composite Materials Research Group, University of Wyoming, P. O. Box 3295, Laramie, Wyoming 82071

A Alexander, Custom Analytical Engineering Systems, Inc., Star Route Box 4A, Flintstone, Maryland 21530

J. M. Augl, Code R-31, Naval Surface Warfare Center, White Oak Laboratory, 10901 New Hampshire Avenue, Silver Spring, Maryland 20903-5000

R. Badaliance, Code 6380, Mechanics of Materials Branch, Naval Research Laboratory, 4555 Overlook Avenue, Southwest, Washington, D.C. 20375-5000

D. L. Bonanni, Ship and Structures and Protection Department, Naval Surface Warfare Center, Carderock Division, Bethesda, Maryland 20084-5000

C. E. Browning, Structural Materials, WRDC/MLB, Wright Research Development Center, Wright-Patterson Air Force Base, Ohio 45433-6523

B. P. Burns, Mechanics and structures Branch, SLCBR-1B-M, U. S. Army Ballistic Research Laboratory, Aberdeen Proving Ground, Maryland 21005-5066

A. A. Caiazzo, Materials Sciences Corporation, Union Meeting Corporate Center, 930 Harvest Drive, Blue Bell, Pennsylvania 19422

E. T. Camponeschi, Code 2802, Composites Program Office, Naval Surface Warfare Center, Annapolis Facility, Annapolis, Maryland 21042-5067

J. R. Carlberg, Ship and Structures and Protection Department, Naval Surface Warfare Center, Carderock Division, Bethesda, Maryland 20084-5000

R. F. Charette, Ship and Structures and Protection Department, Naval Surface Warfare Center, Carderock Division, Bethesda, Maryland 20084-5000

R. O. Claus, Electrical Engineering Department, Fiber and Electro-Optics Research Center, Virginia Polytechnic Institute and State University, 648 Whittemore Hall, Blacksburg, Virginia 24061

S. J. DeTeresa, Lawrence Livermore National Laboratory, Mail Stop L-338, P.O. Box 808, 7000 East Avenue, Livermore, California 94550

D. J. Dorr, Advanced Structures and Materials, McDonnell Douglas Aircraft Company, D.390, Mail Code 1021310, P. O. Box 516, St. Louis, Missouri 63166-0516 
S. Earle, 5128 Department of Commerce, National Oceanic and Atmospheric Administration, 14th \& Constitution Ave, NW, Washington, DC 20230

W. W. Feng, Lawrence Livermore National Laboratory, 7000 East Avenue, Livermore, California 94550

D. Flaggs, Lockheed Missiles \& Space Company O/93-30 B/251, 3251 Hanover Street Palo Alto, California 94304

G. S. Friar, Advanced Technology Section, Research Branch, Benet Weapons Laboratory, Armament Research and Development Center, SMCAR-CCB - Watervliet Arsenal, Watervliet, New York 12189-4050

H. J. Garala, Code 1720.2, Naval Surface Warfare Center, Carderock Division, Bethesda, Maryland 20084-5000

J. W. Gillespie, Jr., Center for Composite Materials, University of Delaware, 201 CMSL, Newark, Delaware 19716

R. G. Gilliland, Engineering Materials and Processes, Aluminum Company of America, Alcoa Technical Center, Alcoa Center, Pennsylvania 15069

L. B. Greszczuk, McDonnell Douglas Space Systems Company, Mail Stop 13/3, 5301 Bolsa Avenue, Huntington Beach, California 92647

S. E. Groves, Lawrence Livermore National Laboratory, 1274 Sea Vista, Brentwood, California 94513

H. T. Hahn, The Pennsylvania State University, 227 Hammond Building, University Park, Pennsylvania 16802

B. M. Halpin, Jr., Composites Development Branch, SLCMT-MEC, U.S. Army Materials Technology Laboratory, Arsenal Street, Watertown, Massachusetts 02172-0001

A. L. Highsmith, The University of Alabama, Box 870280, Tuscaloosa, Alabama 35487-0280

M. W. Hyer, Engineering Science amd Mechanics Department, Virginia Polytechnic Institute and State University, 225 Norris Hall, Blacksburg, Virginia 24061

R. F. Jones, Code 1720, Submarine Structures Division, Naval Surface Warfare Center, Carderock Division, Bethesda, Maryland 20084-5000

J. J. Kelly, DARPA/UWO, Defense Advanced Research Projects Agency, 3701 North Fairfax Drive, Arlington, Virginia 22203-1714

R. Y. Kim, University of Dayton Research Institute, 300 College Park Avenue, Dayton, Ohio 45469-0168 
S. R. Kopf, E. I. du Pont de Nemours \& Company, Chestnut Run Plaza, P. O. Box 80702, Wilmington, Delaware 19880-0702

G. Lee, Hitco, Inc., „MS15C, 13722 Harvard Place, Gardenia, California 90249

G. F. Leon, Electric Boat Division/General Dynamics, Mail Stop D442, 75 Eastern Point Road, Groton, Connecticut 06340

J. S. Mayes, Ship and Structures and Protection Department, Naval Surface Warfare Center, Carderock Division, Bethesda, Maryland 20084-5000

J. D. McColskey, National Institute for Standards and Technology, 325 Broadway, Boulder, Colorado $\mathbf{8 0 3 0 3}$

T. Morton, Code 2802, Composites Program Office, Naval Surface Warfare Center, Annapolis Facility, Annapolis, Maryland 21402-5067

R. J. Nuismer, Hercules Composite Structures, Mail Stop X11K4, P.O. Box 98, Magna, Utah 84044-0098

G. P. O'Hara, Applied Math and Mechanics Section, Research Branch, Benet Weapons Laboratory, Armament Research and Development Center, SMCAR-CCB - Watervliet Arsenal, Watervliet, New York 12189-4050

W. Phyillaier, Code 1720.2, Naval Surface Warfare Center, Carderock Division, Bethesda, Maryland 20084-5000

D. A. Pecknold, University of Illinois, Department of Civil Engineering, 205 North Mathews Avenue, Urbana, Illinois 61801

V. Peros, Martin Marietta Aero \& Naval Systems, Mail Stop 700, 103 Chesapeake Park Plaza, Baltimore, Maryland 21220

Y. D. S. Rajapakse, Code 1132-SM, Office of Naval Research, 800 North Quincy Street, Arlington, Virginia, 22217-5000

E. A. Rasmussen, Code 1720.4 Ship and Structures and Protection Department, Naval Surface Warfare Center, Carderock Division, Bethesda, Maryland 20084-5000

D. B. Rogers, School of Engineering and Technology, Tennessee State University, 3500 John A. Merritt Boulevard, Nashville, Tennessee 37209

R. Rockwell, Code 1720, Submarine Structures Division, Naval Surface Warfare Center, Carderock Division, Bethesda, Maryland 20084-5000

B. W. Rosen, Materials Sciences Corporation, Union Meeting Corporate Center, 930 Harvest Drive, Blue Bell, Pennsylvania 19422 
A. J. Roy, University of Dayton Research Institute, 300 College Park Avenue, Dayton, Ohio 45469-0001

B. E. Sandman, Code 8215, Design and Structures, Naval Undersea Warfare Center, Division Newport, Newport, Rhode Island 02841

G. N. Skaper, L. J. Broutman and Associates, 3424 South State Street, Chicago, Illinois 60616

F. J. Spicola, Code 8215, Design and Structures, Naval Undersea Warfare Center, Division Newport, Newport, Rhode Island 02841

J. D. Stachiw, Code 9402, Naval Ocean Systems Center, 273 Catalina Boulevard, San Diego, California 92152-5000

J. L. Stachiw, Stachiw Associates, P.O. Box 2343, El Cajon, California 92021 (2)

M. S. Stahl, College of Business Adminstration, The University of Tennessee, Knoxville, 8 Humanities Building, Knoxville, Tennessee 37996-0100

S. Starrett, Mechanics Division, Southern Research Institute, 2000 Ninth Avenue, South, P.O. Box 55305, Birmingham, Alabama 35205

K. B. Su, Engineering Technology Laboratory, E. I. du Pont de Nemours \& Company, 80304 Experimental Station, Wilmington, Delaware 19880-0304

R. F. Swan, Code 92RL, Advanced Submarine Research and Development, Naval Sea Systems Command, Department of the Navy, Washington, D. C. 20362-5101

S. R. Swanson, Department of Mechanical and Industrial Engineering, University of Utah, 3209 MEB, Salt Lake City, Utah 84112

S. W. Tsai, Department of Aeronautics and Astronautics, Durand Building, Stanford University, Stanford, California 94305

S. S. Wang, National Center for Composite Materials Research, University of Illinois, 216 Talbot Laboratory, 104 South Wright Street, Urbana, Illinois 61801

J. M. Whitney, Department of Graduate Materials Engineering, University of Dayton, 300 College Park, Dayton, Ohio 45469

I. Wolick, Code 6383, Naval Research Laboratory, Washington, D. C. 20375-5000

E. M. Wu, Code AAWU, Department of Aeronautics, Naval Postgraduate School, Monterey, California 93943

Office of Scientific and Technical Information (2), P.O. Box 62, Oak Ridge, Tennessee 37831 

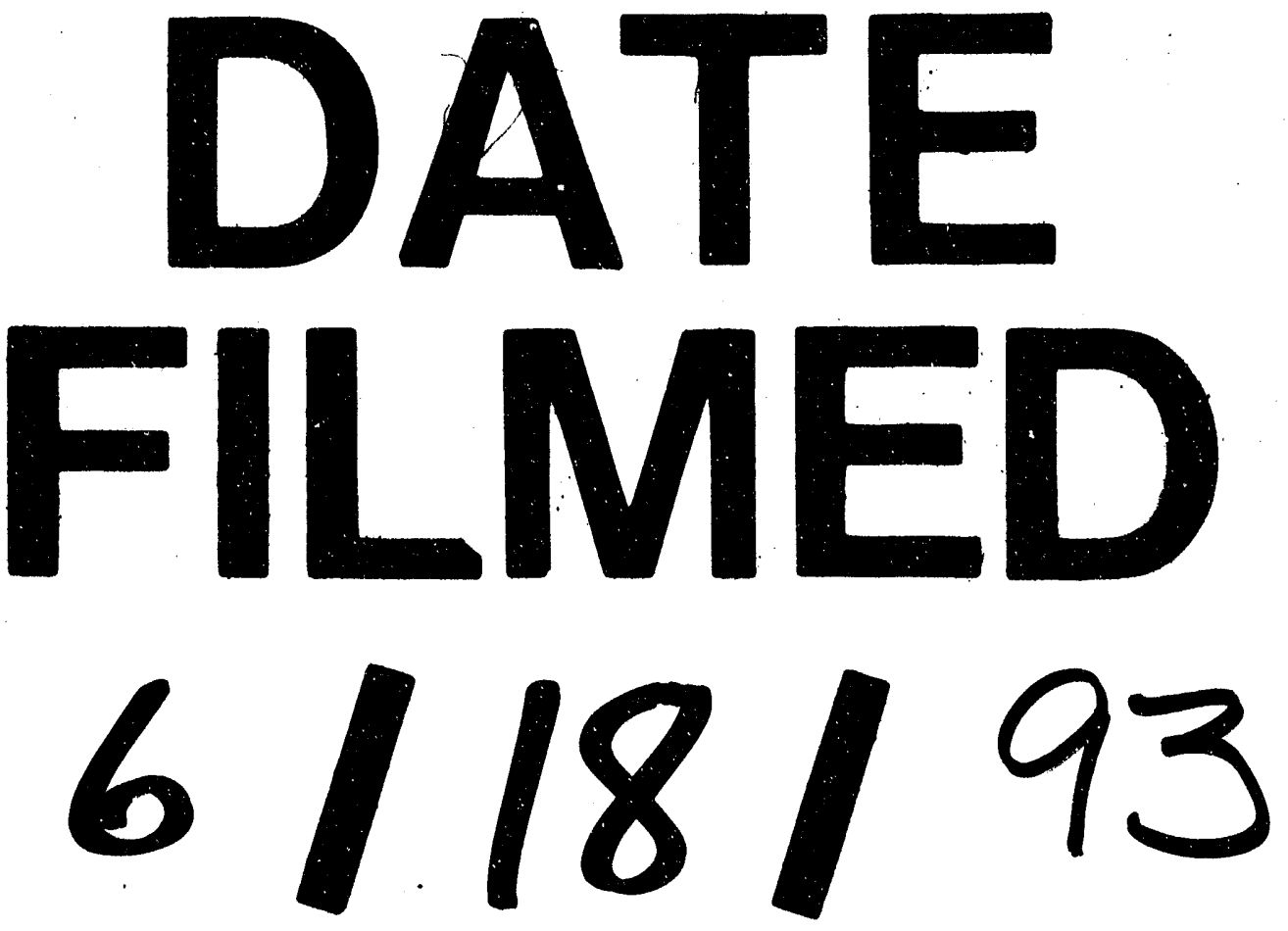